\title{
ARCHITECTURE, AFFECT AND ARCHITECTURAL PRACTICE
}

BY

AKARI KIDD (NAKAI)

A thesis

submitted to the Victoria University of Wellington

in fulfilment of the requirements for the degree of

Doctor of Philosophy

Victoria University of Wellington 


\section{Abstract:}

This thesis builds on and contributes to work in theories of affect that has risen within diverse fields, including geography, cultural studies, media studies and feminist writings, challenging the nature of textual and representational-based research. Although numerous studies have examined how affect emerges in- and through- the occupation of architectural spaces, little analytical attention has been paid to the creative process of design and the role that affect plays in the many contingencies and uncertainties that arise in the process. In this context, the question that this thesis explores is what architectural and theoretical relations can be drawn out when architectural practices are viewed through the lens of affect. Such inquiry is critical to allow practices of architecture to be seen not through defined patterns or contained agenda's but rather through intensities and forces between bodies (both human and non-human); it is to discover practice as sites of potential - and in doing so to address the usefulness of affect to be applied to more grounded empirical fields. In order to explore the above question, the study is based on a qualitative research methodology, including interviewing; writing of observational notes; visiting the architectural offices as well as the projects, where possible/appropriate; and collection of key documents, architectural drawings, and images relating to the design project discussed. This thesis begins with a review of current critical thinking of affect. Its focus is upon how these renderings present particular links between affect, body and space. Further, the thesis considers a range of ideas from architectural scholars and geographers attempting to identify connections between architecture, affect and architectural practice, through notions of affective mediation, tinkering, and stuttering. The thesis then moves forward to present an in-depth case study of three architectural practices, RUR Architecture PC, Kerstin Thompson Architects and Shigeru Ban Architects, with specific architectural projects, in order to evaluate how affect is a significant element in the design process for emergent practices of architecture. Ultimately, this thesis argues how architectural practice may extend theories of affect, particularly broadening Sara Ahmed's notion of 'sticky affects' within the context of architecture, through sticky images, sticky processes and sticky objects, respectively to each case study. Importantly, the thesis engages with the often mundane but highly creative aspect of design processes, not so much in terms of the results, or impact, of affect in the final architectural space, but in terms of how design processes consist of stuttering's where affect can bring bodies together through affective stickiness. The thesis offers an alternative and extended model for the study of how affect plays itself out in the dynamic relationships between different bodies, happenings and relations in practices of architecture. 
ii.

Preface:

This Ph.D. thesis contains the result of research undertaken at the School of Architecture of the

Victoria University of Wellington, New Zealand. However, this thesis also represents a

culmination of learning that has taken place from the start of my architectural studies at The

Cooper Union in New York from 2001-2006, continuing on to working as an architectural

designer in the architectural practice of Kengo Kuma and Associates in Japan from 2006-2008,

and finally, moving to New Zealand to pursue further architectural studies in 2009.

The thesis has its origin in my personal struggle with the gap I experienced between architecture in school (theory-orientated) and architecture in practice. As a result of my studies at The Cooper Union School of Architecture, I was heavily impacted by Modernists such as Le Corbusier and those associated with the Bauhaus movement- including but not limited to Mies van der Rohe's work, and the interactions that occurred between architecture and music, architecture and art, and most strongly, architecture and theory.

Upon graduating from the Cooper Union in 2006, I began working as an architectural designer under architect Kengo Kuma in Japan. This allowed me to experience the real life context in which architecture was practiced, but also raised the question of the role of theory in current practices of architecture. This generated an interest in the affective inter-relationships between architectural theory and architectural practice. This thesis seeks to propose how theory is indeed crucial to architectural practices by examining instances in actual and current practice where we may reconsider the role of theory, specifically affect theory, in architecture. 
Acknowledgements:

I would have never reached the point of finishing my dissertation without the help and support of others. I am grateful for the Victoria University of Wellington Faculty of Graduate Research for awarding me with the Ph.D. Scholarship as well as the Ph.D. Submission Scholarship, providing me with the financial assistance to undergo my research.

These four years have been a challenging but equally rewarding journey, with surprises and 'stuttering's'. Fortunately, I was not alone on this road, but accompanied by an always willing supervisor, Dr. Jan Smitheram, who helped and motivated me. I express my deep gratitude for the inspiring collaboration, and for providing stimulating discussions to further improve this research. For all this, I would like to kindly thank her. I also thank my second and third supervisors, Simon Twose and Dr. Joanna Merwood-Salisbury for their invaluable remarks and advice. I am grateful for the architects as well as others involved in the architectural projects discussed in this thesis that volunteered their time and gave insightful comments for this research. I wish to mention architects Jesse Reiser, Kerstin Thompson, and Shigeru Ban. Looking further back, special thanks must go to Dr. Anthony Vidler, Prof. Lebbeus Woods, Prof. Diane Lewis, amongst others in the faculty of The Cooper Union's School of Architecture, for introducing me to the joy of architecture, its potentials, criticalities, and affects.

Lastly, but most importantly, throughout these years, my best encourager was my husband, Alan. Without his love and support this work would never have been completed. I also thank Taieri Israel, our son, who was born at the beginning of this research, and encouraged me to keep moving on, with his contagious smiles and infectious giggles. I dedicate this thesis to both Alan and Taieri.

Wellington, New Zealand, 2015 
iv.

Table of Contents:
i.
Abstract
ii.
Preface
iii. Acknowledgements
iv. Table of Contents
v. List of Figures

Chapters

1. Introduction and Methodology

1.1 Introduction 1

1.2 Identifying Key Issues 2

1.3 Researching Affect through Practices of Architecture 4

$\begin{array}{lll}1.4 & \text { Overview of Thesis } & 14\end{array}$

2. Literature Review: Contemporary Affect

2.1 Introduction 19

2.2 Historical Lineage and General Approaches to Affect 20

2.3 Abstracting Affect 29

2.4 Localizing Affect: Towards Emotional Affects 41

2.5 Concluding Discussion 51

3. Theory: Architecture, Affect and Architectural Practice

3.1 Introduction 53

3.2 Perspectives from Architecture: Affective Mediations 55

3.3 Perspectives from Geography: Affective Tinkering's 64

$\begin{array}{lll}3.4 & \text { Concluding Discussion } & 75\end{array}$

4. Theory: Affect, Architectural Practice and Time

$\begin{array}{ll}4.1 \text { Introduction } & 79\end{array}$

4.2 Background on Affect, Architectural Practice and Time 80

4.3 Affect, Architectural Practice, Extended Present: Stilled Stutters 86

4.4 Affect, Architectural Practice, Future: Quickened Stutters 89

4.5 Concluding Discussion: Affective Oscillations 92 
5. Case Study 1 - RUR Architecture PC

$\begin{array}{lll}5.1 & \text { Introduction } & 95\end{array}$

5.2 Towards Sticky Images: Intersections between Architecture, Image, Affect 96

5.3 Case Study and Methodology 102

5.4 Affective Charge of Sticky Images 105

$\begin{array}{ll}5.5 \text { Concluding Discussion } & 124\end{array}$

6. Case Study 2 - Kerstin Thompson Architects

$\begin{array}{lll}6.1 & \text { Introduction } & 127\end{array}$

6.2 Towards Sticky Processes: Intersections between Architecture, Process, 129 Affect

6.3 Case Study and Methodology 134

6.4 Affective Interplay between Sticky Processes 139

6.5 Concluding Discussion 150

7. Case Study 3 - Shigeru Ban Architects

7.1 Introduction 155

7.2 Towards Sticky Objects: Intersections between Affect and Matter 156

7.3 Case Study and Methodology 163

7.4 Affective Restlessness of Sticky Objects 168

$\begin{array}{ll}7.5 \text { Concluding Discussion } & 180\end{array}$

8. $\quad$ Final Considerations

8.1 Introduction 185

$\begin{array}{ll}8.2 \text { Overview of Thesis } & 186\end{array}$

8.3 The Thesis in Context: Making a Contribution 190

8.4 Critical Reflections and Suggestions for Further Research 197

8.5 Drawing Affective Conclusions 200

vi. References 203 
List of Figures:

Fig.1 RUR Architecture PC, Interior Visualization of Kaobsiung Port Terminal, 2013, digital render. (C) Image and courtesy of RUR Architecture PC.

Fig.2 RUR Architecture PC, Exterior Visualization of Kaobsiung Port Terminal, 2013, digital render. (C) Image and courtesy of RUR Architecture PC.

Fig.3 RUR Architecture PC, Exterior Visualization of Kaobsiung Port Terminal, 2013, digital render. (C) Image and courtesy of RUR Architecture PC.

Fig.4 Andrew Wyeth, Christina's World, 1948, oil painting, The Museum of Modern Art, New York, (purchased 1949). Illustration from Thomas Hoving, Two Worlds of Andrew Wyeth: A Conversation with Andrew Wyeth (Boston: Houghton Mifflin Company, 1978), 118-119.

Fig.5 RUR Architecture PC, Exterior Visualization of Kaobsiung Port Terminal, 2013, digital render. C Image and courtesy of RUR Architecture PC.

Fig.6 Kerstin Thompson, Crates, 2013, sketch drawing. (C) Image and courtesy of Kerstin Thompson Architects.

Fig. 7 RémyZaugg, Scattered Rooms, 1986, drawing, in The Art Museum of My Dreams, or A Place for the Work and the Human Being, trans. Liz Libbrecht, (Berlin: Sternberg Press, 2013): 48. (C) Image and courtesy of Mai 36 Galerie, Zurich.

Fig. 8 Kerstin Thompson, Light and Views, 2013, sketch drawing. (C) Image and courtesy of Kerstin Thompson Architects.

Fig. 9 Rémy Zaugg, The Walls, 1986, drawing, in The Art Museum of My Dreams, or A Place for the Work and the Human Being, trans. Liz Libbrecht, (Berlin: Sternberg Press, 2013): 27. (C) Image and courtesy of Mai 36 Galerie, Zurich.

Fig. 10 Kerstin Thompson, Corners, vistas, itineraries, 2013, sketch drawing. (C) Image and courtesy of Kerstin Thompson Architects.

Fig. 11 Rémy Zaugg, Gallery for Baron Thyssen, 1986, drawing, in The Art Museum of My Dreams, or A Place for the Work and the Human Being, trans. Liz Libbrecht, (Berlin: Sternberg Press, 2013): 58. (C) Image and courtesy of Mai 36 Galerie, Zurich. 
Fig. 12 Kerstin Thompson, Parallels, 2013, sketch drawing. (C) Image and courtesy of Kerstin Thompson Architects.

Fig. 13 Kerstin Thompson, Final Plan of MUMA, 2013, drawing. (C) Image and courtesy of Kerstin Thompson Architects.

Fig. 14 Kerstin Thompson Architects, Interior view of MUMA, 2013, photograph. (C) Image and courtesy of Kerstin Thompson Architects.

Fig. 15 Kerstin Thompson Architects, Interior view of MUMA, 2013, photograph. (C) Image and courtesy of Kerstin Thompson Architects.

Fig. 16 Shigeru Ban, Christchurch Transitional Cathedral Concept Drawing, 2011, sketch drawing. (C) Image and courtesy of Shigeru Ban Architects.

Fig. 17 Shigeru Ban, Christchurch Transitional Cathedral - Local Materials, 2011, drawing. (C) Image and courtesy of Shigeru Ban Architects.

Fig. 18 Cardboard Paper Tube Manufacturing Company, Recycled Paper Strips, 2013, photograph.

Fig. 19 Cardboard Paper Tube Manufacturing Company, Quail Stand, 2013, photograph.

Fig. 20 Cardboard Paper Tube Manufacturing Company, Gline Bath, 2013, photograph.

Fig. 21 Cardboard Paper Tube Manufacturing Company, Core Winding Machine, 2013, photograph.

Fig. 22 Damage to Cardboard Paper Tubes, 2014, photograph.

Fig. 23 Detail of Damage to Cardboard Paper Tubes, 2014, photograph.

Fig. 24 Shigeru Ban Architects, Cardboard Tubes for Fundraising, 2012, photograph. Courtesyof Anglican Taonga News, $<$ http://www.anglicantaonga.org.nz/News/CommonLife/Cardboard-tubes-in-funding-drive>, accessed 12 Aug. 2013. 
Introduction and Methodology:

\subsection{INTRODUCTION}

The concept of affect is attracting attention in recent social and cultural scholarship. This thesis is a critical exploration of the implications and usefulness of affect theory in architectural discourse. Specifically, this thesis seeks to explore the ways in which affect works through- and in- practices of architecture and its design processes. The question that confronts this thesis at the beginning is therefore: What is affect, and how does it relate to architecture and its practice?

The term affect in its various forms - affectus, affectio, l'affect, affect - has a rich place in the history of philosophy, from Baruch Spinoza, Friedrich Nietzsche to Gilles Deleuze and Félix Guattari; it combines the active senses of drive, will and desire, and at times involves the more passive sense of passion. ${ }^{1}$ Deleuze and Guattari, however, tell us that "[a]ffect is not a personal feeling, nor is it a characteristic; it is the effectuation of a power of the pack that throws the self into upheaval and makes it reel." In the Spinozist and Deleuzian-Guattarian sense, affects engage the body through forms of capacities and processes or becomings. Here, the body is not exclusively the human body, but in alignment with Deleuze, it "can be anything: it can be an animal, a body of sounds, a mind or an idea; it can be a linguistic corpus, a social body, a collectivity." ${ }^{\prime 3}$ Nietzsche concurs; bodies (subjects) are a multiplicity, sites of perpetual transformation rather than a single definite entity. ${ }^{4}$ Affecting and affected bodies are hence bodies-without-order (unstructured), always in the process of becoming other, becoming more. In this sense, the concept of affect challenges textual and representational-based research, and offers, as geographer Hayden Lorimer points out, exciting new ways to understanding "our selfevidently more-than-human, more-than-textual, multisensual worlds." ${ }^{5}$ As such, through the lens of affect, we are able to explore the everyday embodied practices and the flows of actions that encompass them. Particularly, this thesis seeks to find out how affect occurs through the activities, actions and operations that constitute architectural practices. The research highlights

\footnotetext{
${ }^{1}$ Baruch Spinoza, The Ethics and Selected Letters, edited by Seymour Feldman and translated by Samuel Shirley (Indianapolis: Hackett Publishing Company, 1982). Friedrich W. Nietzsche, The Will to Power: A New Translation, translated by Walter Kaufmann and R.J. Hollingdale (New York: Vintage, 1968). Gilles Deleuze and Felix Guattari, A Thousand Plateaus, translated by Brian Massumi (Minneapolis: University of Minnesota Press, 1987). This definition of affect is taken from the work by Christoph Cox, Nietzsche: Naturalism and Interpretation (Berkeley: University of California Press, 1999$), 127$.

2 Deleuze and Guattari, A Thousand Plateaus, 240.

3 Gilles Deleuze, Spinoza: Practical Philosophy, translated by Robert Hurley (San Francisco: City Lights Books, 1988$), 127$.

${ }^{4}$ Friedrich W. Nietzsche, On the Genealogy of Morals, translated by Walter Kaufmann and R.J. Hollingdale (New York: Vintage, 1967).

${ }^{5}$ Hayden Lorimer, "Cultural Geography: The Busyness of Being 'More Than Representational,” Progress in Human Geography 29, no.1 (2005): 83.
} 
how affect operates in architectural practices with particular focus on design process, and in return explores how practices of architecture can add to theoretical understandings of affect. Such exploration aims to develop the potential to extend the use of the theory of affect into more practical and grounded practices.

This first section has served as a brief introduction to this thesis. The second section below identifies key issues around affect and the potential place of architecture and architectural practice in- and through- affect. This section also discusses the aims of the study. Then, in the third section, the chapter introduces and expands on the research methodology underpinning this thesis' study. This methodology section discusses data collection and analysis methods as well as explaining the stages involved in the study. Furthermore, it remarks on the limitations as well as the expectations embedded in this research. The chapter concludes in the fourth section by providing an overview of the thesis.

\subsection{IDENTIFYING KEY ISSUES}

Contemporary body theory is being rewritten by notions of affect. Recently, the attention given within human geography, the social sciences and humanities on the emotional subject through to work on affect, shows that there is now an emergent area questioning the barren objectified body. ${ }^{6}$ This turn towards the affective has allowed extended discussions about culture, subjectivity, identity and bodies and has proposed a shift in current theoretical writings to the affective dynamisms immanent in bodily matter. Furthermore, the rise of affect theory attempts to disrupt the constructed dualisms of subject/object, mind/body, and material/immaterial. Thinking through affect, the material, the immaterial, the objective, the subjective, and the mind and body are all joined (co-constituted) through contingency and spatiality; the body moves through connections and intensities within a space of, in Nigel Thrift's words, 'continual encounters. ${ }^{7}$ As discussions on these affective encounters and definitions of the term 'affect' are numerous, this thesis will use the definition first suggested by Baruch Spinoza, who saw it as a capacity of the body to act - and be acted upon. ${ }^{8}$ In this context, our bodies and our

\footnotetext{
${ }^{6}$ This is expanded further in Chapter 2. See for example on works from human geography: Nigel Thrift, Non-Representational Theory: Space, Politics, Affect (London and New York: Routledge, 2007); Derek McCormack, "Engineering Affective Atmospheres on the Moving Geographies of the 1897 Andrée Expedition," Cultural Geographies 15 (2008): 413-430; Erin Manning, "Always More than One: The Collectivity of a Life," Body \& Society 16, no.1 (2010): 117-128. See also, works from social sciences and humanities: Brian Massumi, Parables of the Virtual: Movement, Affect, Sensation (Durham: Duke University Press, 2002); Mark B.N. Hansen, "Affect as Medium, or the 'Digital-Facial-Image," Journal of Visual Culture 2, no.2 (2003): 205-208; Teresa Brennan, The Transmission of Affect. New York: Cornell University Press, 2004) and Steven Pile, "Emotions and Affect in Recent Human Geography," Transactions of the Institute of British Geographers 35, no.1 (2010): 5-20.

${ }^{7}$ Nigel Thrift, "The Still Point: Resistance, Embodiment and Dance," in Geographies of Resistance, edited by Steven Pile and Michael Keith (London: Routledge, 1997), 133.

${ }^{8}$ Though we may never determine the extent of what our bodies can do (body's capacity) affectively, as this lies outside out control, we can examine how our potential to affect is diminished or enhanced, and observe what occurs to our bodies during this
} 
environment are not contained or stable, but always affecting and affected by each other, generating new forms of material, embodied experiences.

In contrast to the transient indeterminable nature of affect -as the unexpected, and the multiplicity of the unstructured bodies it produces, architecture's purpose has often implied a sense of permanence, order, stability and protection, tolerating only a human order that is unemotive, bounded and predictable, ignoring the vulnerable and contingent. ${ }^{9}$ Such notion also extends to the practice of architecture, as Jeremy Till writes, "from the beginning ... the identification of architecture [has been] an act of imposing order, of taking the unruly and making it coherent." ${ }^{\prime 10}$ The practice of architecture thus still identifies with Vitruvius' notion of bringing beauty through pure form, cleanliness and order. In order to uphold these qualities, the operations conducted by architectural practices are largely dictated by what Stan Allen describes as the "rules set down elsewhere." Participants (architects, engineers, builders) involved in a buildings becoming are seen to be subjected to "normalizing control," focused on functions rather than everyday human needs, desires, demands, and affects. ${ }^{12}$ Countering such descriptions, this thesis seeks to turn to affect to challenge the often embedded nature of thinking architecture - as an autonomous discipline, as a self-defined contained independent practice and, as a structured practice that produce static buildings. Thinking through the ways in which affective factors are generated from and generated by architectural practices, this research aims to question the often assumed bounded and fixed nature of practice and calls forth the potential for a flexible practice that engages with both the real and the possible. ${ }^{13}$

This research will argue, instead, for the incorporation of affect as a significant element in the design process for emergent practices of architecture. It does this by asking the following research question: What architectural and theoretical relations can be drawn out when architectural practices are viewed through the lens of affect? This thesis makes evident how practices of architecture and the

process of affecting and being affected. Spinoza clarifies that "[the human body's] power of activity is increased or diminished" Spinoza, The Ethics and Selected Letters, 104 / E. III, post. See also, Ian Buchanan, "The Problem of the Body in Deleuze and Guattari, or, What Can a Body Do?” Body and Society 3, no.3 (1997): 76.

${ }_{9}^{9}$ Jeremy Till, Architecture Depends (Cambridge, Massachusetts: MIT Press, 2009), 34. That is, the self-referential field of architecture that perceives the world not "open for transformation, but as a static abstraction, there only to receive mute form" Till, Architecture Depends, 14.

10 Till, Architecture Depends, 28. See also, Iain Borden, Skateboarding, Space and the City: Architecture and the Body (Oxford: Berg, 2001); Jonathan Hill, Architecture: The Subject is Matter (London: Routledge, 2001); Jonathan Hill, Immaterial Architecture (Abingdon: Routledge, 2006); Rob Imrie and Emma Street, "Regulating Design: The Practices of Architecture, Governance and Control," Urban Studies 46(12) (2009): 2507-2518.

${ }^{11}$ Stan Allen, Practice: Arcbitecture Technique and Representation, $2^{\text {nd }}$ Edition (Abingdon and New York: Routledge, 2009), xii.

12 Till, Architecture Depends, 42.

${ }^{13}$ It is necessary to acknowledge here how 'the virtual and the actual' is another couplet normally associated in relation to 'the real and the possible' and importantly, one which is often discussed around affect. According to Nicole Shukin, Deleuze and Guattari, for instance, claim how through affect, the body is seen through its "virtuality rather than its actuality," which projects lines (of flight) outward, allowing for planes of affect to emerge. Nicole Shukin, "Deleuze and Feminism: Involuntary Regulators and Affective Inhibitors," in Deleuze and Feminism, edited by Ian Buchanan and Claire Colebrook (Edinburgh: Edinburgh University Press, 2000), 150. In this sense, affect plays a critical role in perceiving the body outside its borders, not as form but as unformed virtualities. It is the position of the researcher that through affect, our bodies interpenetrates space and unites with other bodies through virtual relations, that is, through their potentialities (capacity to affect and be affected). 
design processes they go through produce multiple affective registers and responses. Through the theory of affect, the practice of architecture may begin to be defined by its movements and potentials. ${ }^{14}$ What follows identifies a possible gap in affect research and how this thesis will bridge this gap through both theoretical and empirical enquiries of architectural practices.

\section{Problem Statement and Aims of the Thesis}

Although the theory of affect in cultural as well as feminist studies, but also human geography has been extensively studied in the past few decades, the affect of practice, specifically, the practice of architecture has remained relatively unexplored. Of course, architectural geographers, such as Peter Adey and Peter Kraft have looked at affect (as intensity) that are produced in architectural spaces, however, there is less attention to affects that arise in the process of design. ${ }^{15}$ That is, to date, few investigations have been undertaken to examine the correlation between architecture, affect and architectural practices. What is missing is the notion that the practice of architecture, with its activities, actions and operations and which is embodied in buildings is also embodied in affecting and affected bodies. In this thesis, the possibility to explore architectural practice and its design process, focusing in particular on the patterns of operations that belong to architecture, through the lens of affect is presented and discussed in detail through both theoretical and empirical studies. The latter includes in-depth studies of the design processes undertaken by the architectural practices of RUR Architecture (Jesse Reiser and Nanako Umemoto), Kerstin Thompson Architects and Shigeru Ban Architects. In this way, this thesis offers a way to take affect into real-world situations and particularly attends to the potential and usefulness of affect to be applied to the field of architectural practice by drawing both architectural and theoretical relations between architecture, affect and architectural practice together. The following section concentrates on the methodology of this research.

\subsection{RESEARCHING AFFECT THROUGH PRACTICES OF ARCHITECTURE}

In light of the aims highlighted above and in the context of the current affect discourse; this section discusses the research methodology and the specific approach the study takes to investigate the research question. It also attends to issues arising as part of the research, including the verification method, ethical considerations, as well as delimitations of the study are provided.

\footnotetext{
14 Allen, Practice: Architecture Technique and Representation, xiii.

15 See for example Peter Kraftl and Peter Adey, "Architecture/Affect/Inhabitation: Geographies of Being-in Buildings," Annals of the Association of American Geographers 98, no.1 (2008): 213-231.
} 
This thesis is aligned with the work of Alan Latham and Derek McCormack, who also reflect on attending to the affective qualities of images. In their text, 'Thinking with Images in Non-Representational Cities: Vignettes from Berlin, ${ }^{16}$ traditional visual methods are extended to account for more sensory and what they term "affective intensities" embodied in images, that are sensed or "felt in bodies." ${ }^{17}$ Such perspectives on the capacity of images (both moving and still) to be charged with non-representational forces, including that of affect, allows for new ways of documenting, analysing and engaging with visual materialities. As addressed below, this thesis also explores the potential of images to gain insight into sensory/affective dimensions of the architectural design process, beyond that which is communicated in words. What follows seeks to outline how this thesis contributes to such current non-representational moves of experimenting with different forms of researching. Particularly, this thesis experiments with researching instances that occur in everyday architectural practices through the lens of affect, employing indepth interviews and visual documentations, including diagrams, architectural drawings, and images.

\subsubsection{Qualitative Research using Case study strategy}

The main research method employed follows a qualitative research methodology. A qualitative approach is chosen as the thesis examines and seeks to understand affect within the everyday context of architectural practices, as this is an area of study that is little known. ${ }^{18}$ Moreover, qualitative method is designed to gain insight into under-studied dimensions (and by extension, concepts such as affect) through people within specific on-going contexts where according to Michael Quinn Patton; the researcher is the primary data collection instrument. ${ }^{19}$ To this end, this thesis follows four features of a qualitative research defined by David Wang and Linda Groat. ${ }^{20}$ These four consist of, an emphasis on first, a natural setting, second, interpretation and meaning, third, how respondents themselves understand the phenomenon in questions, and finally, the use of multiple sources. ${ }^{21}$ This thesis considers these specifically in the following way: first, by engaging with the particular setting of architectural practices, second, interpreting the data gathered through the lens of affect, third, focussing on how architects themselves understand the phenomenon in question by conducting in-depth interviews, and lastly, the study uses various

\footnotetext{
16 Alan Latham and Derek McCormack, “Thinking with Images in Non-Representational Cities: Vignettes from Berlin'," Area 41 (2009): 252-262.

17 Latham and McCormack, "Thinking with Images in Non-Representational Cities," 253.

18 As Yvonna S. Lincoln and Egon G. Guba explain, qualitative research involves uncertain dimensions and relies on the

"mutually shaping influences and value patterns that may be encountered" in interactions between researcher and participant(s).

Yvonna S. Lincoln and Egon G. Guba, Naturalistic Inquiry (Beverly Hills: Sage, 1985), 40.

${ }_{19}$ Michael Quinn Patton, Qualitative Evaluation and Research Methods, 3rd Edition (Thousand Oaks: Sage Publications, 2001$), 14$.

${ }^{20}$ David Wang and Linda Groat, Architectural Research Methods (New York: John Wiley and Sons, 2002).

21 Wang and Groat, Architectural Research Methods, 167-177.
} 
data, including diverse forms of visual data, in addition to the interview transcripts. The latter component of employing multiple sources of data is a specific characteristic of qualitative research with a case study strategy. This is expanded on below.

\section{Case Study Strategy}

The qualitative research undertaken uses the case study approach which is defined by Robert K. Yin as "an empirical inquiry that investigates a contemporary phenomenon within its real-life context; when the boundaries between phenomenon and context are not clearly evident; and in which multiple sources of evidence are used." ${ }^{, 2}$ In this sense, the case study approach is employed for explorations that go in detail for on-going continuing events, such as architectural design processes.

In this thesis, a case study strategy is used to gain in-depth but also diverse understanding of how and when affect arouse in particular architectural processes, and what might this offer for research on affect. This specific approach is particularly appropriate for this thesis because it offers an in-depth analysis of architectural practices, settings and processes, providing different perceptions through each case study of how affect is indeed part of every unique design process. The selected cases are thus "opportunities to study the phenomen[on]"23, or in this case, the concept of affect. Moreover, and to reiterate a point made above, the case study strategy consists of gathering multiple sources of data, providing for what Sharan B. Merriam refers to as a "thick description." 24 Accordingly, the present study seeks to disrupt the boundary between theoretical concept and context, affect and architectural practices, through an analysis of multiple sources of data collected through interviews, note-taking, observational data, and gathering of visual material. This 'thick description' provides the researcher ways to analyse affect in the often changing and indeterminate flows of architectural design processes.

\subsubsection{Data Collection and Recording Procedure}

The research data collection undertaken can be divided roughly into two phases. ${ }^{25}$ The first phase involved semi-structured interviews; the second phase consisted of gathering visual material including sketches, architectural drawings and images based on projects discussed in the interviews. The following discusses these phases in turn.

\footnotetext{
${ }^{22}$ Robert K. Yin, Case Study Research: Design and Methods (3rd ed.) (Thousand Oaks, CA: Sage Publications, 2003).

${ }^{23}$ Robert E. Stake, "Qualitative Case studies," in Handbook of Qualitative Research, 3 ${ }^{\text {rd }}$ Edition, edited by Norman K. Denzin \& Yvonna S. Lincoln (Thousand Oaks, CA: Sage Publications, 2008), 129.

24 Sharan B. Merriam, Qualitative Research and Case Study Applications in Education (San Francisco: Jossey-Bass, 1998 ), 29.

25 Described by Wang and Groat as a "research design [that] involves combining two or more strategies in a sequence of distinct phases" Wang and Groat, Architectural Research Methods, 362.
} 
The first phase consisted of in-depth semi-structured interviews with three contemporary architects to understand how they practice architecture. More specifically, the discussions explored how they approach and engage with specific design process from what Robert Bogdan and Sari Knopp Biklen specify as "their own frame of reference."26 In this sense, the qualitative interviewing process allows the interviewees to explain, in their own words, details of their design practice, offering an in-depth account (compared to, for example, questionnaire surveys) of how they place meaning on different situations that may arise through each unique design process. ${ }^{27}$ Additional in-depth interviews were also conducted, where possible, with local parties involved in the design process. In this thesis, the specific architects and their corresponding practices selected as the case studies included Shigeru Ban and his practice, Shigeru Ban Architects, Jesse Reiser and Nanako Umemoto, and their practice RUR Architecture PC, and Kerstin Thompson, and her practice, Kerstin Thompson Architects. The researcher selected these case study practices based on their extensive range of projects that have generated 'affective atmospheres', hence, they are "purposefully select[ed]" cases. The case studies were selected intentionally where the practices are similar in size and have work portfolios that are comparable, with projects ranging from domestic to commercial and public buildings. However, the three practices also presented differences, such as in the principal architect's gender, cultural backgrounds, geographical location[s] of their practices, and perhaps most importantly, diverse design approaches. The latter difference strengthened the research by providing opportunities to explore the presence of affect across a wide range of scenarios that occur in the design of spaces.

Interviewees were contacted by email in the first instance, requesting the possibility of an interview. From the outset, all three interviewees agreed to the interview and understood that it would be informal, taking place at a time and location suitable to them. The interviews were conducted in the architect's practice or their appointed location and lasted approximately one hour in length. They were undertaken between January 2013 and August 2014 and occurred in three separate geographical locations: Wellington, New Zealand, New York, USA and Melbourne, Australia. The discussions were composed of a small number of open-ended questions relating to a list of key themes/issues prepared in advance. Furthermore, no specific architectural project was chosen prior to the interview, due to the large breadth of built works designed by each architect. The primary intention of using this strategy was to obtain the perspective of each architect on the design activities and operations of their practice and to allow them to use

\footnotetext{
${ }^{26}$ Robert Bogdan and Sari Knopp Biklen, Qualitative Research in Education: An Introduction to Theory and Methods, 3rd Edition (Boston: Allyn \& Bacon, 1998), 3.

27 It is important to note here that while affect is the theoretical framework of this thesis, the theory of affect does not constrain or drive the data collection stage. Instead, the theory is used to analyse the gathered data, and therefore, affect is extended and built up by the factors and multiple responses that emerge from the respondents' answer.
} 
examples of their own work as they see appropriate. Despite the informal and friendly nature of the interviews, it should be further pointed out that the insights and information produced by each architect were, to some degree, teased out by the researcher. This means that the researcher made particular interruptions if necessary to bring back the discussion to reflect the thesis question, for example, deliberately asking whether they consider 'atmosphere' in their design process. The discussions themselves consisted of three interrelated components that characterise the practice of architecture, albeit in the most general sense: design activity (i.e. designing of space), design action (i.e. drawing, modelling), and practice operation (i.e. design process and managing profession).

The conversations were audio-recorded with two of the three interviews with the principal architects video-recorded, to record the movement of the body posture and motion when conducting the interview. ${ }^{28}$ The researcher also gathered observational notes recording the portrait of each architect as well as description of the interview setting. ${ }^{29}$ The researcher's notes focused primarily on the affects that arose through the interview interactions, or the lack thereof. As such, observational data is important as affect may arise and be grasped through external actions that cannot be expressed in words.

The second phase involved the collection of supporting visual documents, such as drawings, architectural plans and photographic images of specific design features from projects discussed in the interview. ${ }^{30}$ This gathering of visual material was undertaken post-discussion (Phase 1). ${ }^{31}$ Here, the researcher acknowledges the "need to supplement the familiar repertoire of humanist methods that rely on gathering talk and text with experimental practices that amplify other sensory, bodily and affective registers." ${ }^{32}$ As a general guide, the multiple data acquired during this stage of the research, (including the interviews, observation notes, visual documents) were analysed through the framework of affect. This is discussed in detail in the following subsections.

\footnotetext{
28 Steiner Kvale, Interviews: An Introduction to Qualitative Research Interviewing (Thousand Oaks, CA: Sage Publications, 1996). ${ }^{29}$ Creswell, Research Design: Qualitative, Quantitative, and Mixed Methods Approach, 189. Patton further explains, "the data from observations consists of detailed descriptions of people's activities, behaviors, actions, and the full range of interpersonal interactions and organizational processes that are part of observable human experience" Michael Quinn Patton, Qualitative Evaluation and Research Methods, 2nd Edition (Thousand Oaks: Sage Publications, 1990), 10.

${ }^{30}$ Gillian Rose, Visual Methodologies (London and Thousand Oaks: Sage Publications, 2007), 255.

31 Visual documents are, according to Lincoln and Guba, as rich source of information which allow the researcher to observe and analyse the specific image or drawing in-depth in conjunction with (and reflecting on-) the interview data. Lincoln and Guba, Naturalistic Inquiry (Beverly Hills: Sage, 1985).

32 Sarah Whatmore, "Materialist Returns: Practicing Cultural Geography In and For a More-Than-Human World," Cultural geographies 13 (2006): 606-607.
} 


\subsubsection{Data Analysis}

The analysis of the data for this research is broadly divided into two stages: the first stage involved the analysis of transcripts generated from the interviews. The second stage involved the analysis of visual documentation collected for specific projects discussed in the interviews through existing visual methodologies modified to relate to the topic of affect. It must be noted that as a qualitative research, the data analysis and data collection occurred as an iterative process, whereby there was no specific line drawn between data collections stage and analysis phase.

Stage One: Data Analysis of Interview

The analysis of the interviews in this research made use of thematic analysis in combination of meaning condensation and meaning interpretation. ${ }^{33}$ The analysis drew directly on the theoretical concept of affect, which allowed the researcher to select and interpret specific parts of the interviewees' words. ${ }^{34}$ Firstly, a provisional reading was undertaken after each interview had been transcribed where the researcher read for clarification, but also made notes and marked relevant sections. The noted sections where then analysed in more detail - commenting on what the interviewees said and the tone they said it with. These relevant points were then collated to analyse how these specifically related to each other, but also to other interview transcripts generated as part of the same case study. The meaning of the highlighted parts were analysed in relation to the research question: What architectural and theoretical relations can be drawn out when architectural practices are viewed through the lens of affect? The first stage of analysis thus examined the architects' attitudes and perceptions regarding their architectural practices through the framework of affect.

\section{Stage Two: $\quad$ Data Analysis of Visual Documentation}

As part of the research, the second stage involved the analysis of visual material of specific buildings discussed in the interviews and gathered by the researcher. Due to the time-frame of the research, the number of selected projects was kept to one single architectural project. The

\footnotetext{
${ }^{33}$ For clarification, Nigel King and Christine Horrocks suggest a basic system of thematic analysis as a 'straightforward' method consisting of descriptive coding, interpretive coding and defining of overarching themes. Nigel King and Christine Horrocks, Interviews in Qualitative Research (Thousand Oaks: Sage Publications, 2010), 149-150. King and Horrocks themselves use the term "straightforward" to describing the thematic analysis. King and Horrocks, Interviews in Qualitative Research, 173. Steiner Kvale illustrates the latter two methods in the following manner: "Meaning condensation entails an abridgement of the meaning expressed by the interviewees into shorter formulations. Long statements are compressed into briefer statements in which the main sense of what is being said is rephrased into few words" Kvale, Interviews: An Introduction to Qualitative Research Interviewing, 192. Meanings interpretation analysis involves the researcher to go "beyond what is being directly said to work out structures and relations of meaning not immediately apparent in a text. This requires a certain distance from what is said, which is achieved by a methodical or theoretical stance, recontextualizing what is said in a specific conceptual context. Kvale, Interviews: An Introduction to Qualitative Research Interviewing, 201.

34 Some of the points described below incorporate steps described by Nigel King and Christine Horrocks as illustrated in Figure

9.1. King and Horrocks, Interviews in Qualitative Research (Thousand Oaks, CA: Sage Publications, 2010).
} 
examination of the architectural drawings and images were qualitative in nature and were analysed separately by project -by asking the question: how does the image evoke affect? ${ }^{35}$ More specifically, following Gillian Rose's position, existing visual methodologies were developed to relate to the topic of affect. ${ }^{36}$ The method of analysing the collected media (including but not limited to sketches, drawings, and still-images) was conducted through a modified form of "compositional interpretation" ${ }^{37}$ which Rose describes as consisting of the following components: content analysis, colour, spatial organization, light and expressive content. ${ }^{38}$ For this research, the visual material gathered in Phase 2 was assessed by observing both design and environmental factors in a qualitative manner. Specifically, the following affective dimensions of the images were critically examined:

1 Objects and Materials: examine the image as a composition of objects/figures/bodies. This involves compositional interpretation as defined by Rose, to "look very carefully at every element of an image and their interelations." ${ }^{39}$ Moreover, this method allows us to analyse the "visual impact of images." 40

2 Light/texture/colour: examine light, texture and colour intensity/movement as a visual property that has potential to "stress [and highlight] certain elements of an image." 41 How is light manipulated to generate affect?

3 Direction/rhythm: assess how do the materialities incorporate poetics of rhythm, direction, through variations of density/pressure/direction

\section{Ratio/Proportion of Images}

\section{Expressive content ${ }^{42}$}

While these assessment criteria are discussed further in the appropriate case study chapters, it is important to note how the expressive content of a still image or a drawing has capacity to "evoke affective characteristics." ${ }^{\prime 3}$ This requires the researcher to assess the "image's possible effects on the spectator." ${ }^{\prime 4}$ This latter point was critical in assessing the images gathered for RUR Architecture PC’s Kaohsiung Port Terminal project.

\footnotetext{
35 Rose, Visual Methodologies, 242.

${ }^{36}$ Rose, Visual Methodologies.

${ }^{37}$ Rose, Visual Methodologies, 57.

38 Rose, Visual Methodologies, 40-49.

${ }^{39}$ Rose, Visual Methodologies, 157.

${ }^{40}$ Rose, Visual Methodologies, 57.

${ }^{41}$ Rose, Visual Methodologies, 48.

${ }^{42}$ Rose, Visual Methodologies, 49.

${ }^{43}$ Rose, Visual Methodologies, 49.

${ }^{44}$ Rose, Visual Methodologies, 57.
} 


\subsubsection{Trustworthiness of the Research}

There are a number of issues in doing qualitative research particularly in terms of the trustworthiness or accuracy of the analysis. This thesis follows the suggestion made by Yin who addresses three criteria specific for case study based research to increase reliability and construct validity. These are, first, the use of multiple sources of evidence, second, the creation of a case study database and lastly, the maintaining of a chain of evidence. ${ }^{45}$ Two of these criteria were considered as well as a third criterion of dependability. ${ }^{46}$

\section{Multiple Sources of Data}

As discussed above, data was collected through multiple sources that include interviews, observations, and gathered supporting documents (drawings, architectural plans and images of buildings). The combination of text, drawings, and still-images collected in this data gathering stage was interdependent in nature. That is, the collected visual materials are "intended as a parallel source of understanding" with the gathered words where the primary effect of the images will be "to affirm the veracity of [the] text" ${ }^{47}$ and hence to actively confirm the account of each architect. The validity of the process is verified by using such multiple data-collecting methods which accumulates rich data that is both detailed and varied. ${ }^{48}$

\section{Chain of Evidence}

Validity of the study was further increased by maintaining a chain of evidence, as outlined by Yin, ${ }^{49}$ where the link and process between the research question, the interview protocol, the image-documenting, and the evidence gathered through visual material and the conclusions of the study are able to be followed clearly. What is also important to note here is the flexibility of a qualitative methodology allows the cross-checking of information gathered through each data collection stage. For instance, responses from the architects gathered in the interview can be explored in connection with the images collected of the design projects described in these interviews. In this way, the internal validity of the information is gained by developing connections between data. The analysis in this thesis has attempted to show a deep and rich

\footnotetext{
45 Robert K. Yin, Case Study Research: Design and Methods, 4th Edition (Thousand Oaks, CA: Sage Publications, 2009$), 114$.

46 As identified by Clive Seale, “Quality in Qualitative Research," Qualitative Inquiry 5, no.4 (1999): 465-478.

${ }^{47}$ Rose, Visual Methodologies, 247.

48 Robert K. Yin, Case Study Research, Design and Methods, 3rd Edition (Newbury Park: Sage Publications, 2003). See also, Robert C. Bogdan \& Sari Knopp Biklen, Qualitative Research for Education, 3rd Edition (Boston: Allyn and Bacon, 1998), cited by Jerry W. Willis, Foundations of Qualitative Research (Thousand Oaks, CA: Sage Publications, 2007), 220.

${ }^{49}$ Yin, Case Study Research: Design and Methods, $4^{\text {th }}$ Edition, 123.
} 
exploration of each case study practice, rather than aiming to use the findings towards a proposition of generalizability.

\section{Dependability}

Finally, examining for dependability requires that the data of the research is both elaborate and deep in content. ${ }^{50}$ In response to this, this thesis has described the study's data collection stages and analysis in detail (in the above sections of this chapter). The findings have been connected with the collected data and explained in the case study chapters. Finally, parts of this research has been presented to academics and researchers in conferences and through published journals both instances of which dependability was attained by "peer auditing procedures." ${ }^{51}$ What follows addresses ethical issues that arose in undertaking this research.

\subsubsection{Ethical Considerations}

As a qualitative research, the researcher has attempted to gain in-depth understanding of architectural design processes, which in turn required an intimate engagement with the selected interviewees. These interactions, while not causing any harm or risk to the participants, do raise some ethical issues that should be addressed in this introductory chapter.

Firstly, the researcher has ensured that necessary steps were taken to follow ethical research standards, including the submission of an Ethics Approval application to be reviewed and obtaining permission by the university's Human Ethics Committee. The researcher also developed an informed consent which informed each participant of the nature and purpose of the study, the data collection method, and the extent of the use of the data in academic conferences, but also academic publications. The informed consent form was sent to each interviewee to sign prior to conducting the interviews.

Secondly, in attempting to assure confidentiality for the participants in the interviews, the researcher made clear through both the informed consent as well as other correspondence in the form of emails and phone calls that their participation was only for academic research purpose and if requested, anonymity will be ensured. Within the research process, only one participant asked for their anonymity, and this has been respected by adhering to describing this participant as the representative of a manufacturing company.

\footnotetext{
50 Seale, "Quality in Qualitative Research," 468.

${ }^{51}$ Seale, "Quality in Qualitative Research," 468.
} 


\subsubsection{Delimitations}

While the researcher attempted to ensure the rigor of the investigation and to maximize validity, being a qualitative research, the study of this thesis raises some issues that need to be addressed at the beginning in this introduction as well as in the conclusion chapter.

\section{Scope of Case Study Practices}

The study relied on a purposive sample of three case study architectural practices - while the three case studies has been primarily chosen to reflect three distinct practices from different geographical locations (Japan, Australia, America), it is clear that issues relating to practice is highly dependent on the location of the project site. For instance, RUR Architecture PC (Reiser and Umemoto) project of Kaohsiung Port Terminal is in Taiwan, while Shigeru Ban's project of the cathedral is in Christchurch, New Zealand. The nature of the process as well is often influenced by the local bodies, and while for Shigeru Ban's case study, the researcher attempted to gather in-depth knowledge through interviewing various bodies involved in the project in Christchurch, this was not possible in the case of RUR Architecture PC. The researcher acknowledges the disparity of data gathered in terms of quantity, but argues that the quality of analysis attended for each case study has remained the same. For instance, while Kerstin Thompson Architect's case study involved data gathered and analysed from interviews with the architect and the curator, these two voices provided insightful views of the intense engagement that occur in a design for a museum. In this sense, the in-depth information gathered from the two voices was equal to the quality of data gathered in Shigeru Ban Architect's case study, where four interviews were conducted.

In addition to these delimitations, the researcher recognizes that the case studies selected, in terms of the scale of the architectural practices, encompass what is often categorized as 'boutique' architectural firms. This selection may risk a comparatively narrow scope. The limited variance of architectural practices also extends to the chosen architectural projects, as the three projects discussed in the case studies are particularly orientated to projects for the public, as opposed to more domestic scale projects. Considering these delimitations, it is not possible to determine the extent to which the obtained results may represent all architectural practices and their design process - that is, some aspects of the interviewees' voices and explained processes may not be comparable with other design practices that are larger or smaller in number - and operate at different scales. However, these delimitations also uncover ways, as it will be pointed out in the Discussion and Conclusion chapter of this thesis, in which affect can be further explored through other types of architectural practices. 
This section has considered the methodology undertaken for this thesis' research. The research was qualitative in nature with a focus on case study approach. The data was collected primarily through in-depth semi-structured interviews with additional notes taken both through observation and reflection. This was complemented with visual documentation of specific architectural projects collected after the conversations with the architects. Affect was the framework of analysis for the data gathered.

\subsection{OVERVIEW OF THESIS}

As outlined in this introductory chapter, this thesis is situated within but also builds on and contributes to work in theories of affect that has risen within diverse fields, including geography, cultural studies, media studies and feminist writings. Although affect, particularly in geographical studies, such as by Peter Adey and Peter Kraftl, have examined how affect emerges and is intensified in built environments, there is a limited understanding on how the affective discourse may be undertaken to examine the creative design process itself and the role that affect plays within the process. This thesis addresses this issue by looking in-depth at three case study design processes - and argues how the incorporation of affect is a significant element in the design of spaces for emergent practices of architecture. But also, and more importantly, how architectural practice may extend theories of affect. The following outlines the chapters involved in this thesis.

Specifically, following this introductory chapter (Chapter 1), Chapter 2 offers a critical survey of the contemporary contributions to the study of affect from across disciplines, with a focus on geographers and cultural theorists. This chapter lays the groundwork for the empirical studies herein by reviewing and critiquing the relevant literatures. Signalling the importance of the Spinoza-Nietzsche-Guattarian-Deleuzian historical lineage of affect, it reviews two distinct contemporary interpretations of affect: first, it reflects on the works of theorist Brian Massumi, ${ }^{52}$ human geographers Derek McCormack and Nigel Thrift, and second, it investigates feminist writers, Deborah Thien, Clare Hemmings, and Sara Ahmed. ${ }^{53}$ While the chapter will review their works in depth, in the most general sense, the first group understands affect as abstract and autonomous - but also has potential to extend into our everyday spaces of homes and urban

\footnotetext{
52 Massumi, Parables of the Virtual (Durham: Duke University Press, 2002).

${ }^{53}$ The particular texts that will be explored in Chapter 2 are: Deborah Thien, "After or Beyond Feeling? A Consideration of Affect and Emotion in Geography," Area 37 (2005): 450-4. Clare Hemmings, "Invoking Affect: Cultural Theory and The Ontological Turn," Cultural Studies 19, no.5 (2005): 548-567. Also works by Sara Ahmed, including: Sara Ahmed, The Cultural Politics of Emotion (Edinburgh: Edinburgh University Press, 2004); Sara Ahmed, “Affective Economies," Social Text 79 22, no.2 (2004): 117-139; Sara Ahmed. "Collective Feelings or: The Impressions Left by Others," Theory, Culture and Society 2, no.2 (2004): 25-42; Sara Ahmed, "Multiculturalism and the Promise of Happiness," New Formations 63, no.1 (2007): 121-137; Sara Ahmed, "Happy Objects," in The Affect Theory Reader, edited by Melissa Gregg and Gregory J. Seigworth, 29-51 (Durham and London: Duke University Press, 2010).
} 
contexts. The second group represents critical voices towards the recent turn to affect through feminist writings who propose a different tradition of affect, one of localized affect, proposing affect as context-specific and situated. ${ }^{54}$ Particularly, works by Ahmed suggest affect as something which attaches to things, generating sticky relationships between bodies. In her words, affect is "what sticks, or what sustains or preserves the connection between ideas, values, and objects." 55 Ahmed's position forms a strong platform for this thesis, but she is not writing about a design situation. This thesis seeks to extend Ahmed's work to propose how affect as a sticky component arise through real architectural design processes. Ahmed's work is further expanded in each of the Case Study chapters (Chapter 5, 6, and 7).

Against this theoretical framework of affect and the scepticism behind it, Chapter $\mathbf{3}$ and Chapter 4 investigates the way in which architectural practices are involved in generating affects, and in parallel, how affects are affecting these practices. Specifically, Chapter $\mathbf{3}$ attempts to draw stronger links in the works by architectural scholars and geographers - between architecture, affect and architectural practices. It explores this through two orientations: the first considers the range of debates and ideas on practice from the angle of architectural scholars. Here, it is suggested that they are approaching practice and architects as mediating affective relations (through participatory practice) as well as mediating affective dispersion (through entrepreneurial risk-taking practice). The second orientation addresses recent developments in geography that suggest grounds for reconsidering practice as a condition that is susceptible, receptive and exposed, attending to practices of affective tinkering both of space, and of matter. Importantly, while much architectural writing does not attend to aspects outside of designing and construction, geographers are looking further beyond, including architectural practices that occur postoccupancy. Looking at the small tinkering activities, and placing importance on this, is critical to see how affects may be extended to address issues of post-occupancy in architecture. Although most of the authors discussed in this chapter do not explicitly use the language of affect, it is arguably attractive to both architectural and geographical discourses on practice, precisely because it delivers currents of openness and fluidity into practice.

Drawing from the geographer's perspectives, Chapter 4 considers the practice of architecture through various temporal relations. Particularly, it explores two forms of temporalities: firstly, stilled stutters, and secondly, quickened stutters. It is at the turning points of these interplays where affects are triggered. The focus on these stutters attends to the moments of pause (or inaction) that practices of architecture and the design process they partake in often,

\footnotetext{
${ }^{54}$ See for example, Hemmings, "Invoking Affect," 548-567; Thien, "After or Beyond Feeling?” 450-454. See also, Ahmed, The Cultural Politics of Emotion; Ahmed, "Multiculturalism and the Promise of Happiness," 121-137; Ahmed, "Happy Objects," 29-51. 55 Ahmed, "Happy Objects," 29.
} 
if not always, come upon. It is in these stilled or waiting times that affects emerge, sticking ideas and bodies together. Of course, the design process does not remain in its stillness, and thereby, the chapter moves on to attend to quickened stutters which allows jumps in the process whereby affects leap forward and project the process forward rapidly. As a way of concluding this chapter, a discussion is put forward regarding the relation between the stilled and quickened stutters. It suggests that they are indeed never separate but rather are in affective oscillation - and moreover through these processes of holding together, we are able to see how these different temporalities come to have real effects in the practice of architecture. This chapter thereby acts as a bridge between theoretical attachments of affect and practice in regards to both architects and geographers, and the more grounded and practical attachments that will be drawn out in the subsequent three case study architectural practices (Chapter 5, 6, 7).

Chapters 5, 6, and 7 place emphases on empirical case studies in order to further draw connections between architecture, affect and architectural practice. These chapters examine three key contemporary practices of architecture each with a specific architectural project they are involved in: RUR Architecture PC and the Kaohsiung Port Terminal, Kerstin Thompson Architects and their Monash University Museum of Art, and finally, Shigeru Ban Architects and the recently completed Christchurch Transitional Cardboard Cathedral. As detailed above in the Methodology section of this chapter, each case study, discussed in turn in separate chapters, is based on a qualitative research methodology, and involves in-depth interviews with the architects as well as analysis of visual documentation in the form of drawings, architectural plans and images for the specific projects discussed in the interviews.

Importantly, and to reiterate a point made above, the case study chapters extend Ahmed's account of 'sticky affects' and explore this characteristic of affect within design processes. The data gathered followed by a critical analysis addresses three particular themes: sticky-images, sticky-processes and sticky-objects, respectively to each chapter. The outcome is a study of the extent to which affect is accounted for in architectural practices through its different activities, actions and operations which accompany a design process. Finally, the case study chapters argue that affect (as a theory applicable to practice) is crucial as a means of thinking through architecture and in turn this offers the possibility of shifting how we interpret and think affect theory. In concluding this thesis, Chapter $\mathbf{8}$ seeks to illustrate the specific contributions of the thesis as a whole to current affect theory and reflects on its strengths and weaknesses in the context of its areas of contribution.

Finally, it is expected that the research will disrupt the common assumption of architectural practice as bounded by constraints and fundamentally concerned with making 
architecture that is stable and definite. Instead, attending to and thinking through affect allows practices to become flexible operations, or in Stan Allen's words - "defined by its movements and trajectories." 56 These practices in turn serve as research platforms for manipulating and exploring affective registers/responses through the design and production of buildings. Importantly, the notion of affect highlights the dynamic nature of relationships between different human bodies partaking in the design process, but also objects, and images and offers an extended model for the study of how affect plays itself out in different happenings and relations, a model which holds much promise for future investigation.

56 Allen, Practice: Architecture Technique and Representation, xiii. 


\section{Thinking through Contemporary Affect}

\section{1 INTRODUCTION}

The topic of affect has been studied in various branches of social sciences, thus there exists a large number of different theoretical approaches. Recently, there has been an increase in the range of understanding and interest in affect not only in human geography, but in critical theory as well as feminist studies. Given the multiplicity of perspectives, it is not possible within the framework of this thesis to undertake a survey of all the interpretations of affect. Instead, this chapter aims to build a contemporary understanding of affect through a review of relevant literature, focusing on a non-representational mode of thinking affect. This turn towards affect has allowed extended discussions about culture, subjectivity, identity and bodies and has proposed a shift within critical theory from particularly three areas - studies of a singular selfcontained body, emphasis on representation and, textual discourse - towards explorations of affective processes that occur through-and in- bodies, both human and non-human, including spaces and our built environment. ${ }^{1}$ In Hayden Lorimer's words, affect and the more general field of non-representational geography, aims to understand "our self-evidently more-than-human, more-than-textual, multisensual worlds." " Hence, through the lens of affect, our focus turns towards practices and their flows of action.

This chapter is divided into five sections. After this Introduction (2.1), the subsequent section (2.2) provides, albeit briefly, the historical lineage of Spinoza-Nietzsche-Deleuzian and Guattarian (hereafter referred to as D\&G) strain of affect. This historical thread is important to this thesis as it anticipates contemporary views of affect and sets the ground-work for the remaining sections of this chapter on contemporary affect discourse. This section (2.2) also reviews general approaches to affect, and discusses how contemporary notions of affect has been engaged by, and interweaved across several disciplines. After this background on affect, this chapter turns its focus in works on affect that pay particular attention to affect-body-space relations, and pursues the following two areas of investigation: firstly (2.3), it addresses scholars associated with the 'affect' group (as termed by Deborah Thien), specifically Massumi,

\footnotetext{
1 Another interesting reading on affect is by John Protevi in terms of linking Affect and Politics. See, John Protevi, Political Affect: Connecting the Social and the Somatic (Minneapolis: University of Minnesota Press, 2009); See also papers in the collection edited by Melissa Gregg and Gregory J. Seigworth, eds., The Affect Theory Reader (Durham and London: Duke University Press, 2010).

2 Hayden Lorimer, "Cultural Geography: The Busyness of Being 'More Than Representational," Progress in Human Geography 29, no.1 (2005): 83.
} 
McCormack, and Thrift. ${ }^{3}$ All three theorists, to various degrees, suggest affect as which "follow[s] different logics and... different orders" ${ }^{\prime 4}$ from the structured, personal emotion, where the latter is something that can be put into words, such as 'I feel happy', while affect is described as autonomous because it occurs before we are able to name how we feel; it precedes emotion. Importantly, for the purpose of this thesis, the review attempts to tease out the spatial connotations of affect through their works. Secondly, suggesting an alternative account of affect, the following section (2.4) investigates critical voices towards the recent turn to affect through feminist writers Deborah Thien, Clare Hemmings and Sara Ahmed. ${ }^{5}$ It must be noted that while Thien and Hemmings' work are reactionary texts to the former 'affect' group's approach to affect, Ahmed's work is significant to this thesis in that she moves on from critiquing the 'affect' group to suggesting ways of expanding affect theory by attending to emotional affects. And more significantly, she illustrates the ways in which affects move locally between bodies - highlighting further the spatial relevance of affect. Finally, and by way of conclusion, the last section (2.5) discusses the importance of attending to this different tradition of affect focused on the localization of affect. Such perspective offers an alternative possibility of understanding the correlation between affect-bodies-space, where affect is seen as the medium through which bod$\mathrm{y} /$-ies relate(s) to the materiality of its environment.

\subsection{AFFECT SCHOLARSHIP}

\subsubsection{Spinoza-Nietzsche-D\&G's Historical Lineage of Affect ${ }^{6}$}

The Spinozian-Nietzschean and D\&G lineage of affect is presented as a forerunner to many contemporary affect theorists. ${ }^{7}$ Particularly, Spinoza's affective doctrine, as Brian Massumi points

\footnotetext{
3 Thrift, "Intensities of Feeling," 67.

${ }^{4}$ Massumi, Parables for the Virtual, 27.

5 Ahmed, “Affective Economies," 117-139; Ahmed, “Collective Feelings or: The Impressions Left by Other,” 25-42; Ahmed, The Cultural Politics of Emotion (Edinburgh: Edinburgh University Press, 2004); Ahmed, "Multiculturalism and the Promise of Happiness," 121-137; Ahmed, "Happy Objects," 29-51.

${ }^{6}$ The review will examine three contributions that compose this affective lineage: firstly Baruch Spinoza and his work on 'The Ethics,' secondly, Friedrich Nietzsche and his book The Will to Power, and thirdly, Gilles Deleuze in conjunction with Feliz Guattari and their work $A$ Thousand Plateaus. While these three texts are not necessarily the only historical texts of an affect scholarship, they do highlight some common threads that have impacted contemporary voices. Indeed there are more scholars of affect. For instance, see Silvan Tomkin's and Henri Bergson's work. Particularly, see Henri Bergson, Matter and Memory (New York: Zone Books, 1991).

${ }^{7}$ It must be noted here how Spinoza and D\&G's work is often cited by contemporary affect theorists. Nietzsche, however, is less relied on. Yet, Nietzsche has been referenced by William Connolly, but also by Deleuze, Brian Massumi and most recently, Sara Ahmed to consider affects such as pain. See for instance Ahmed's work which draws on Nietzche's understanding of the "retrospective causality of affect." Ahmed illustrates this through pain experienced by the nail: "I can just apprehend the nail and I will experience a pain affect, given that the association between the object and the affect has been given. The object becomes a feeling-cause" Sara Ahmed, The Promise of Happiness (Durham, N.C.: Duke University Press, 2010), 28. Also, Massumi, in an interview with Mary Zourzani, takes on Nietzsche's stance to explore how 'good' is not the opposite of 'evil' but rather different intensities or charge of affect. Brian Massumi, "Navigating Movements (interview)," in Hope: New Philosophies for Change, edited by Mary Zourzani, 210-242 (New York: Routledge, 2002).
} 
out, is the most powerful work that has spoken most clearly and persuasively to $20^{\text {th }}$ century contemporary writings of affect. Massumi writes, "on the irreducibly bodily and automatic nature of affect... it is the name of Baruch Spinoza that stands out." Spinoza shows that affects are the varied and transferable capacities to affect and be affected, filling everyday life with a continual motion of relations and events. 'In order to achieve a full understanding of Spinoza's doctrine on affect, two key terms, 'affectio' and 'affectus,' need remarking upon. By 'affectio' (translated to 'affection' in English), we are looking at a body, or bodies, and refers to an active state that is a condition of the affected body, implying the presence of an affecting body. It is a mixture of two or more bodies - one body acting on another, the latter receiving the impression or trace of the former. By 'affectus' (translated as 'affect' in English) Spinoza means the passage from one state to another. Now, a passage connotes a temporal occurrence that is always necessary fleeting and experienced in lived duration. 'Affectio' therefore suggests a state of body/bodies: a condition of exteriority involving bodies being affected and affecting, while 'affectus' is a "transitive state through which bodies pass, they meander through and between bodies, resting like 'foreign objects', or excessive impersonal forces, awaiting transformation into the thought-imbued emotions of subjective experience." ${ }^{10}$ Affectus then, roams outward (external) but also inward (internal), always within (enveloped by) 'affectio.' In this thesis, the two terms are used interchanging; however, the particular focus will be on the second term 'affectus'. This expression is used not only in a critical sense, but also to mean that which can sculpt and shape both the body and its environment/space. ${ }^{11}$

Following Spinoza, Nietzsche concurs that we do not control affect and that we are not aware of it working in the same way as personal feelings. ${ }^{12}$ Instead, as described by Christopher

\footnotetext{
${ }^{8}$ Massumi, Parables of the Virtual, 28.

${ }_{9}^{9}$ Baruch Spinoza, The Ethics and Selected Letters, translated by Samuel Shirley (Indianapolis: Hackett Publishing Company, 1982). Note: All quotations from the Ethics will be from The Ethics and Selected Letters, ed. S. Feldman and trans. S. Shirley (Indianapolis, IN: Hackett Publishing Company, 1982 [1977]). In citing passages from The Ethics, this thesis refers to part (E), proposition (prop.), definition (def.), note or proof.

${ }^{10}$ Caroline Williams, "Affective Processes without a Subject: Rethinking the Relation between Subjectivity and Affect with Spinoza," Subjectivity 3, no.3 (2010): 251.

${ }^{11}$ Spinoza, The Ethics and Selected Letters. Furthermore, Spinoza claims two important theories regarding the encounter/contact of bodies. First, he writes that the degree to which the individual body may undergo modification is "proportional to the extent of the surface areas along which [the bodies] are in close contact" Spinoza, The Ethics and Selected Letters, 74 / E. II, axiom 3. This contact (impact between two bodies) appears in the form of a pressure which impresses against the skin/surface of the body and leaves a trace. Caroline Williams, "Thinking the Political in the Wake Of Spinoza: Power, Affect and Imagination in The Ethics," Contemporary Political Theory 6 (2007): 355. See also Spinoza, The Ethics and Selected Letters, 104, where he writes, "The human body can retain impressions or traces of objects." Correspondingly, when two or more bodies press together and retain their impressed/pressed bodies, they compose one united body. Second, Spinoza describes various structural characteristics of surfaces, distinguishing them through hardness, softness, and fluid state. Our human body has many parts of these diverse features, some are fluid, some hard, and others soft. For Spinoza, the body is not a mass enclosed by a fixed envelop. Rather, we are looking at a consistently transforming boundary which hardens or softens only to a certain depth, depending on the affect. The surface receives impressions from another body's surface, transmitting affect to the interior. This surface also reacts, receiving impulses from inside of the body. Affect, once inside, can extrude back into the environment, via the skin. The surface area of the body is the first space of affect. Spinoza, The Ethics and Selected Letters, 74 / E. II, axiom 3.

12 Nietzsche, Beyond Good and Evil: Prelude to a Philosophy of the Future.
} 
Cox, Nietzschean affects "are a pulling or pushing in one direction or another," 13 explaining that some affects generate perceptual projections that impress upon us while others retrieve into the periphery, shaping the experience of the environment. ${ }^{14}$ Nietzsche's affects, then, have a specific direction and expression where "each one has its perspective that it would like to compel all the other drives (affects) to accept as a norm." ${ }^{\prime 15}$ For example, I enter a room looking for a specific person. I look around and the faces of people leap out at you - they impress themselves. The room itself, the furniture, are all peripheral. Here, my body enters its environment with a particular force that has a specific direction. This prompts my body to act differently according to the objects encountered (the body is prompted by objects/bodies toward a particular affect). As the skin registers the traces of the event, it tenses as it receives and retains the impressions, modifying the shapes and contours of the body. The Nietzchean perspective presents affect as structuring the body's experience of its environment as well as modifying and distorting the features of the surrounding environment/condition through impressions, projections and recessions. Thus, it is argued here that Nietzschean affects must always be understood in relation to the outside, particularly the space of our bodies. Such a view of the interrelated nature of the body-affect-space relation helps to set the framework for the more recent articulations of affect investigated in Section 2 of this chapter.

Finally, Deleuze and Guattari theorize affect as that which follows "lines of flight" and conceptualize it as a force that follows unpredictable directions outside bounded territories. ${ }^{16}$ Moreover, they redefine bodies not by what they are but by what they are capable of doing affectively. Thus for Deleuze and Guattari, affect exceeds the terrain of the subject, while emotion belongs to it. ${ }^{17}$ Further, Deleuze and Guattari emphasize the emergence of a space that is intense with affect through notions of mappings and connections in the 'zone of indetermination ${ }^{18}$. To place our bodies in this 'zone of indetermination' is to be in the interface of sensations. For example, listening to a live music concert, the energy of the musicians feed into space and project towards the listeners (audience) - where the audience can 'feel' the musician's energy/affect and vice-versa - the crowd's energy is projected out, traverses through space towards the musicians. Here, borders of identity break down - and we enter a zone of

\footnotetext{
13 Christopher Cox, “The 'Subject' of Nietzsche's Perspectivism," Journal of the History of Philosophy 35 , no.2 (1997): 283.

14 Nietzsche, Beyond Good and Evil, 19. Also, for further reference, see Paul Harrison, "Making Sense: Embodiment and the Sensibilities of the Everyday," Environment and Planning D: Society and Space 18, no. 4 (2000): 502.

15 Nietzsche, The Will to Power, 326.

16 Gilles Deleuze and Félix Guattari, A Thousand Plateaus: Capitalism and Schizophrenia, translated by Brian Massumi (Minneapolis: University of Minnesota Press, 1987).

17 Deleuze and Guattari, A Thousand Plateaus.

18 Deleuze and Guattari, A Thousand Plateaus. See also Deleuze and Guattari, What is Philosophy?, 173.
} 
uncertainties. ${ }^{19} \mathrm{D} \& \mathrm{G}$ 's affect space is a field of forces in movement which consists of all possible directions, tendencies and affects: an open space in which all possible systems and states can occur. This force-field, borrowing Shukin's terms, is space seen through its virtuality rather than its actuality. ${ }^{20}$ It is a space of potential where the Deleuzian-Guattarian body "can actualize something that has not previously been." 21 Thinking space through D\&G propose a shift to conceive space as a process of becoming rather than an already defined, determined entity, the former having extensive implications for architecture.

Important to the thesis, this Spinozian-Nietzschean and D\&G affect lineage, develops two points: firstly, about the multiplicitous and uncertainty of affect, and secondly, about the emergence of a space that is intense with affect. In this context, what is emphasized is an understanding of affect as always having a spatial extension (that is, interrelated with space). Here, space is discussed as a dynamic process rather than a container for the static body, and asks the question, what does (can) space do when seen through the lens of affect? The argument here is that investigating the do-ing of space has far-reaching implications for architecture. This lineage continues to influence affect theory in terms of taking seriously affective matters within and through our body/-ies and the spaces we inhabit/encounter, considering how these spatial experiences open up different ways of engaging with our environment. Such a view of the interrelated nature of the body-affect-space relation helps to set the framework for the more recent articulations of affect investigated at length in the subsequent section (Section 3) of this chapter. ${ }^{22}$ Prior to this, what follows gives an overview of the different ways affect has engaged in contemporary discourse.

\section{General Approaches to Affect}

First, it is useful to outline the main approaches of affect that has been explored by geographer Nigel Thrift, as it illustrates the diverse ways affect has been interpreted. More importantly, Thrift's work highlights how most contemporary theorists follow the Spinozian-Nietzschean and D\&G's strain of affect explored in the previous subsection (2.2.1). Thrift explains 'affect' to be

\footnotetext{
19 Another example, in the experience of listening to music which can arouse affect in listeners, Ian Buchanan asserts that "music... sets in motion a particular listener" Ian Buchanan, "Deleuze and Pop Music," American Humanities Review (August 1997), accessed March 30, 2012, http://www.australianhumanitiesreview.org/archive/Issue-August-1997/buchanan.html The trigger of affect is expressed through your body as an exclamation, or even through an easing or tensing of the muscles. Listening to a random selection of songs, a particular song is played that produces vibrations (either of pleasure or sadness) through your body. Here you enter into a zone of becoming or 'indetermination' where you form relations with other external forces outside your own.

${ }^{20}$ Nicole Shukin, "Deleuze and Feminism: Involuntary Regulators and Affective Inhibitors," in Deleuze and Feminism, edited by Ian Buchanan and Claire Colebrook (Edinburgh: Edinburgh University Press, 2000), 144-155.

21 Andrew Ballantyne, Deleuze and Guattari for Architects (London and New York: Routledge, 2007$), 8$.

22 Indeed there are more scholars of affect. For instance, see Silvan Tomkin's and Henri Bergson's work. Particularly, see Henri Bergson, Matter and Memory (New York: Zone Books, 1991).
} 
characterized through four main areas of research: first, "different kind of intelligence" 23 constituted by embodied knowledge; second interrelational response [as opposed to drive]; third, capacity for interaction; and fourth, involuntary form of communication through physiological change. ${ }^{24}$ More specifically, by embodied knowledge, he refers to affect "as a set of embodied practices that produce visible conduct as an outer lining." ${ }^{25}$ That is, affect as a mode of expression. The second translation places affect in opposition to the Freudian psychoanalytic framework of drive. ${ }^{26}$ Led by Silvan Tomkins, this approach suggests a distinction between drives which are inherently triggered mainly out of biological functions, such as hunger and that of affect, which unlike drive is 'adaptable' and is thus able to move between and through various bodies - human and non-human. ${ }^{27}$ Furthermore, the third translation of affect is understood as "the property of the active outcome of an encounter" where by 'property' Thrift means the capacity of the body and mind to act. ${ }^{28}$ Such account of affect is indebted to Spinoza who is interested in what he calls the 'affections of the body', where "the body's power of activity is increased or diminished, assisted or checked." ${ }^{29}$ Here, affect as movement or passage between bodily states is at focus. ${ }^{30}$ Lastly, in the fourth approach Thrift identifies affect as stemming from a neo-Darwinian approach where affect is most visible as it involves facial expressions, and other autonomic bodily responses (i.e. respiration, tone of voice, posture of body) to communicate affect involuntarily. ${ }^{31}$ It is important to note that each of these four approaches of affect involves the body as a necessary component. As these four approaches to interpreting 'affect' reflects the diverse lines of research, this chapter does not attempt to involve the full range of contemporary affect literature nor search for the correct definition of 'affect'. Instead it will focus on what ties most directly to a 'non-representational' theory, as presented by Thrift, ${ }^{32}$ and has evident connections to Spinoza's stance of affect as "the capacity to affect and be affected." 33

Following Thrift's work, and second, the following subsection explores the less acknowledged contemporary works of affect. While some of these works are indeed identified by Thrift, for the purpose of this thesis, it is relevant to discuss the more recent and present engagements with affect theory that is applied to a variety of different fields; primarily, these are

\footnotetext{
23 Nigel Thrift, "Intensities of Feeling: Towards a Spatial Politics of Affect," Geografiska Annaler B 86, no.1 (2004): 60.

24 Thrift, "Intensities of Feeling," 60-64.

25 Thrift, "Intensities of Feeling," 60.

26 Thrift, "Intensities of Feeling," 61.

27 Thrift, Non-representational Theory, 221.

28 Thrift, "Intensities of Feeling," 62.

29 Baruch Spinoza, The Ethics and Selected Letters, translated by Samuel Shirley (Indianapolis: Hackett, 1982$), 104$.

30 Thrift, Non-representational Theory, 225.

31 See Thrift, "Intensities of Feeling," 64. See also Thrift, Non-representational Theory, 223-224.

32 Thrift, Non-representational Theory, (London and New York: Routledge, 2007).

33 Ruth Leys, "The Turn to Affect: A Critique," Critical Inquiry 37, no.3 (2011): 442, notes 22.
} 
works that have come about after Thrift's, "Intensities of Feeling: Towards a Spatial Politics of Affect," was published in 2004.

\subsubsection{Contemporary Approaches to Affect}

While this thesis focusses on a non-representational angle of affect scholarship, prior to looking at this in-depth in Section 3 of this chapter, it is important to acknowledge some of the other, and perhaps less identified (but more contemporary) approaches to affect. Extending Thrift's comprehensive analysis of the main approaches of thinking through affect, the contemporary engagement of affect explored hereafter emphasizes in particular the potential usefulness and accessibility of affect theory to investigate the often fleeting experiences, actions, and movements of everyday situations.

For instance, in phenomenological approaches, as discussed by Paul Russell, affect is grounded in perception, and with it, subjective, sensory experience. ${ }^{34}$ As such, affect shapes what consciousness sees, but also what bodies can do. Ethical arguments presuppose an understanding of affect too, affects that are context-specific, influenced by cultural and social formations, and thereby are moulded responses. Specifically, such angle of affect is found in psychological and psychoanalytical frameworks. This includes Silvan Tomkins' inspired works by Eve Kosofsky Sedgwick and Elspeth Probyn as well as literature by Sianne Ngai. ${ }^{35}$ These works, albeit each presenting a slightly different set of concerns, provide a distinctly negative aspect of affect through 'raw emotions' or in Ngai's terms "Ugly Feelings." For instance, these include embodied experiences of shame, disgust, but also envy and paranoia in everyday life. The significance of these works rests in their ability to explore affective issues that may indeed be 'ugly' when exposed, but equally highlights the importance of- and strong link between- our cultural, contextspecific values and affects.

Of course, within feminist and queer writings, there are those attending to more promising and positive affects. Sara Ahmed and Kathleen Woodward, for example, are bringing in aspects of compassion, hope and promises that are embedded in situated and localized contexts. ${ }^{36}$ Likewise, in the field of anthropology, specifically Kathleen Stewart and her work on

\footnotetext{
34 Russell, Paul L., "The Phenomenology of Affect," Smith College Studies in Social Work 76, no.1/2 (2006): 67.

35 Eve Kosofsky Sedgwick, "Shame in the Cybernetic Fold: Reading Silvan Tomkins," in Touching Feeling: Affect, Pedagogy, Performativity, edited by Eve Kosofsky Sedgwick and Adam Rank (Durham and London: Duke University Press, 2003); Elspeth Probyn, "Doing Shame," in Blush: Faces of Shame (Minneapolis: University of Minnesota Press, 2005).For discussions on affects such as disgust and envy - see Sianne Ngai, Ugly Feelings (Cambridge: Harvard University Press, 2005). Specifically, her chapters on "Afterword: On Disgust" and "Envy."

36 Sara Ahmed, The Promise of Happiness (Durham: Duke University Press, 2010). See also Kathleen Woodward, "Liberal Compassion, Compassionate Conservatism," in Statistical Panic: Cultural Politics and Poetics of Emotions (Durham: Duke University Press, 2009). It is important to note that both Ahmed and Woodward also have written on negative affects. See for example, Sara Ahmed, "Shame before Others," in The Cultural Politics of Emotion (New York: Routledge, 2004); Sara Ahmed, "The Affective
} 
Ordinary Affects, ${ }^{37}$ the most ordinary things in everyday life are unpacked through affect. Situated alongside Stewart's text, is another prominent scholar and work: Lauren Berlant and her book, Cruel Optimist. ${ }^{38}$ While this thesis cannot provide a comprehensive review of Berlant's theoretical concepts, her contribution to affect scholarship must be acknowledged as she demonstrates how objects may be embodied with affects that promise happiness or possibilities for desires to come true. In this proposition, we are attached to things in 'optimistic' ways. ${ }^{39}$ However, Berlant cautions that some attachments can be 'cruel' and compromise, or in her own words, become "an obstacle to your flourishing" ${ }^{\prime 40}$. In the most general sense, these feminist and queer perspectives turn to affect as a way of attuning to everyday ordinariness, conditioning and conditioned by the present. $^{41}$

Another approach to affect is taken recently in media studies, most prominently by Mark Hansen. ${ }^{42}$ In his work 'Affect as Medium, or the 'Digital-Facial-Image,' he explores artists such as Kirsten Geisler and her virtual exhibition which consists of digitally composed face-images, as well as interactive artwork by Luc Corchesne, again made of images of computer-based people but allows the participant to engage in conversation with the digital image. According to Hansen, these works begin to alter and extend our understanding of the human-computer/digital interface. Hansen further proposes that through these digital close-ups of sad faces, happy faces, emotionally-detached faces, we (as viewer-participant) are affected and our bodies experience this affective intensity. This latter embodied experience is referred to as the 'virtualization of the body ${ }^{43}$ - the capacity of our bodies to be shaped by new affects. Affect then, becomes, in Hansen's words, as “medium to engage with the digital processes of contemporary image production." 44

Finally, another notable engagement that is made in contemporary discourse is the link between affect and materiality. Recently, as noted by Tim Ingold, a turn to new materiality has

Politics of Fear," in The Cultural Politics of Emotion (New York: Routledge, 2004). Kathleen Woodward, "Containing Anger, Advocating Anger: Freud and Feminism," in Statistical Panic: Cultural Politics and Poetics of Emotions (Durham: Duke University Press, 2009).

${ }^{37}$ Kathleen Stewart, Ordinary Affects (Durham: Duke University Press, 2007).

${ }^{38}$ Lauren Berlant, Cruel Optimism (Durham: Duke University Press, 2011).

${ }^{39}$ Berlant, Cruel Optimism, 24.

${ }^{40}$ Berlant, Cruel Optimism, 1.

${ }^{41}$ Also, for other feminist studies, see Deborah Thien, "After or Beyond Feeling? A Consideration of Affect and Emotion in Geography," Area 37 (2005): 450-454; See also Lisa Blackman, "Embodying Affect: Voice-hearing, Telepathy, Suggestion and Modelling the Non-conscious," Body \& Society 16, no.1 (2010): 163-192. From a critical point, Jenny Edbauer Rice, referencing Brian Massumi's point describes how these understandings may conflate emotion and affect, imparting to the latter a "content that is shaped through specific cultural, social, and political contexts" Jenny Edbauer Rice, "The New "New": Making a Case for Critical Affect Studies," Quarterly Journal of Speech 94, no. 2 (2006): 201. See also, Brian Massumi, Parables of the Virtual: Movement, Affect, Sensation (Durham: Duke University Press, 2002).

${ }_{42}$ Mark B.N. Hansen, "Affect as Medium, or the 'Digital-Facial-Image," Journal of Visual Culture 2, no.2 (2003): 205-228.

${ }^{43}$ Hansen, "Affect as Medium, or the 'Digital-Facial-Image," 217.

${ }^{44}$ Hansen, "Affect as Medium, or the 'Digital-Facial-Image," 212. 
aimed to redirect "our attention from the materiality of objects to the properties of materials." 45 Critical in this perspective are the expressive properties of materials - that is, as Karen Barad explains, matter's relational, interactive and affective capacities. ${ }^{46}$ This exploration of the affect of matter (material affect) and effect of affect (affective materiality) is made possible by a raft of discourse centred on "materiality in-process", including contemporary feminist and cultural theory scholars Manuel DeLanda, Barad and Diana Coole and Samantha Frost. ${ }^{47}$ This thinking on new materialism is particularly interesting for architectural discourse as it undoes the common-sense conceptions of matter as passive substance, favouring instead a conception of matter as actively engendering and always in-process. In this sense, affective formations invites the possibility that space itself may be recognised as bodies of matter sustained according to variable states of rest and transition, beginning to address what Alan Latham and Derek McCormack term as spaces of "affective materiality". ${ }^{8}$

One area of scholarship that has taken affect as a mediating force in spatial and built environments is the field of geography. They specifically assume affect, as described by Jenny Edbauer Rice, as something that "does not necessarily have a narrative, and neither is it crafted through cultural contexts. ${ }^{~}{ }^{49}$ Within this group, Nigel Thrift comes to the forefront, and is discussed in-depth in this chapter, particularly in the way he develops the affect-body-space relation. Of course, there are also other significant contributions from geographical scholarship. For instance Steve Pile, Ben Anderson and Paul Harrison, along with an often cited writer Eric Shouse are worth mentioning here. ${ }^{50}$ Specifically, these works offer an extension, or alternative way of understanding Thrift's concept of affect, which is presented somewhat abstractly. In comparison to the strict separation of affect from emotion and feeling, Pile, Anderson and Harrison and Shouse, in separate texts illustrate how affect is but one of three modes of expression - first, there is affect, autonomous and pre-personal, then, feelings, which are autonomic bodily responses expressed through a blush or tension exerted from a body or a space,

\footnotetext{
45 Tim Ingold, “Materials Against Materiality,” Archaeological Dialogues 14, no.1 (2007): 12.

${ }^{46}$ Karen Barad, "Posthumanist Performativity: Towards an Understanding of How Matter Comes to Matter," Signs: Journal of Women in Culture and Society 28, no.3 (2003): 822.

${ }^{47}$ Manuel DeLanda, "Material Complexity," in Digital Tectonics, edited by Neil Leach, David Turnbull and Chris Williams, 70-77 (London: Wiley-Academy, 2004); Karen Barad, "Re(con)figuring Space, Time and Matter," in Feminist Locations: Global and Localm Theory and Practice, edited by Marianne DeKoven, 75-109 (New Brunswick: Rutgers University Press, 2001); Barad, "Posthumanist Performativity: Towards an Understanding of How Matter Comes to Matter," 801-831. See also, Diana Coole and Samantha Frost, "Introducing the New Materialism," in New Materialisms: Ontology, Agency and Politics, edited by Diana Coole and Samantha Frost, 1-43 (Durham and London: Duke University Press, 2010).

48 Alan Latham and Derek McCormack. "Moving Cities: Rethinking the Materialities of Human Geographies," Progress in Human Geography 28, no.6 (2004): 706.

${ }^{49}$ Rice, "The New "New": Making a Case for Critical Affect Studies," 201.

${ }^{50}$ Ben Anderson and Paul Harrison, "Questioning Affect and Emotion," Area 38 (2006): 333-335; Steve Pile, "Emotions and affect in recent human geography," Transactions of the Institute of British Geographers 35, no.1 (2010): 5-20. See also, Eric Shouse, "Feeling, Emotion, Affect," M/C Journal 8, no.6 (2005), accessed May 15, 2011, http://journal.media-culture.org.au/0512/03shouse.php.
} 
third, there is the more cognitive and narrative emotion. ${ }^{51}$ It must be clarified that this illustration does not strictly order these three - rather, in Anderson's own words, the "three modalities slide into one another to disrupt the neat analytic distinction. Diverse feedforward feedback loops take place..."52 In this perspective, feelings, emotions and affects connect in slippery ways. This position on affect is also taken up widely by scholars who are particularly following Thrift's nonrepresentational theory (hereafter referred to as NRT) ${ }^{53}$ and affect work. For instance, geographer John Wylie and Mitch Rose engage with practices of landscape - or in their own words, 'animating landscape. ${ }^{54}$ Individually, Wylie has attended to bodily actions such as walking that occur within our body's sensuous engagement with the surrounding environment. ${ }^{55}$ With a similar agenda, Hayden Lorimer engages with topics of human and non-human animal relations mapped out in local landforms, whereby the connection between humans-animals (such as reindeers)- and their movement's impact/shape local environments ${ }^{56}$; and also noteworthy is Derek McCormack's work which discusses affect within dance and therapeutic exercises. ${ }^{57}$ This latter work by McCormack is articulated further in this chapter as an example of how geographers are taking the affect theory into more practical and everyday situations.

As a general note, and to reiterate, what can be highlighted in the above contemporary positions on affect is how most follow and often cite the Spinoza-Nietzsche-D\&G's historical thread. The next section aims to consider the significance of the emergent attention given to affect as a means to shift towards a non-representational mode of thinking the relation between bodies and space, and thereby useful for architectural discourse.

\footnotetext{
${ }^{51}$ Margaret Wetherell describes Anderson's work explicitly in this way. See, Margaret Wethrell, Affect and Emotion: A New Social Science Understanding (London: Sage, 2012).

52 Ben Anderson, "Becoming and Being Hopeful: Towards a Theory of Affect," Environment and Planning D: Society and Space 24 (2006): 737. Cited by Wetherell, Affect and Emotion, 66.

${ }^{53}$ As explained thoroughly by geographer Hannah Macpherson, "NRT is a term coined by British geographer Nigel Thrift (1996). He attaches this term to a set of philosophical work which places an emphasis on how space and time emerge through embodied practice." Macpherson further notes the lineage through which Thrift brings about his NRT: "Thrift draws on the post-structural work of writers such as Wittgenstein, Foucault, Deleuze and Haraway; the actor network theories of Latour, Law and Serres and on a range of writing on practice from the likes of Benjamin, De Certeau, Heidegger and Merleau-Ponty to outline and expand upon an agenda for non-representational ways of thinking and research" Hannah Macpherson, "Non-Representational Approaches to Body-Landscape Relations,” Geography Compass 4, no.1 (2010): 2.

${ }^{54}$ Mitch Roseand John Wylie, “Animating Landscape,” Environment and Planning D: Society and Space 24, no.4 (2006): 475-479.

${ }^{55}$ John Wylie, "A Single Day's Walking: Narrating Self and Landscape on the South West Coast Path," Transactions of the Institute of British Geographers 30 (2005): 234-237.

${ }^{56}$ Hayden Lorimer, "Herding Memories of Humans and Animals," Environment and Planning D: Society and Space 24, no.4 (2006): 497-518. Lorimer's text is further articulated and expanded by Hannah Macpherson. See Macpherson, "Non-Representational Approaches to Body-Landscape Relations," 8-9.

${ }^{57}$ Derek McCormack, "An Event of Geographical Ethics in Spaces of Affect," Transactions of the Institute of British Geographers 28 , no.4 (2003): 488-507; Derek McCormack, "A Paper with an Interest in Rhythm," Geoforum 33, no.4 (2002): 469-485. See also Derek McCormack, "Molecular Affects in Human Geographies," Environment and Planning A 39, no.2 (2007): 359-377.
} 


\subsection{ABSTRACTING AFFECT}

Surveying the current literature on affect and evaluating the ample modes of thinking through affect, the following review provides a brief analysis of affect frameworks introduced by Massumi, McCormack and Thrift. Associated with these perspectives is the emergence of nonrepresentational theory (hereafter referred to as NRT) which claims that affect is an important part of spatial experience. As reflected briefly in the introduction of this chapter, there are other scholars, such as geographer Ben Anderson, who is often associated with this particular approach to affect. While unable to elaborate here, it is important to acknowledge Anderson's work on affective atmosphere's (which expands on Mikel Dufrenne and Gernot Böhme's positions) as a contribution to a spatial understanding of affect. ${ }^{58}$ Anderson's concept of 'affective atmosphere' offers an understanding of affective forces that emerge from interactions between bodies, including non-human entities, impacting the 'feel' or atmosphere of the space (room, street, city) that surrounds the specific engagement. ${ }^{59}$ To further expand on Anderson's work would necessarily involve tracing the concept of atmosphere back to other philosophical lineages (distinct from affect) and by doing so, perhaps complicating terms between affect and atmosphere. Hence, this section aims to discuss and tease out spatial connotations of affect through the works of Massumi, McCormack and Thrift. It must be noted at the start that the works employed in the review do not add up or aim to cover everything that these authors have written as contributions to the affect scholarship. Rather, what the section attempts to do is evaluate some particular ways these scholars engage with and situate theories of affect within spatial environments which in turn offer ways to extend affect into architectural contexts. This angle of affect allows us to sensitize research to affect's capacity in shaping and being shaped across- different bodies, including our own environments and spaces we inhabit.

Importantly, following the philosophies of Spinoza, Nietzsche and D\&G, scholars of the 'affective turn,' as identified by Patricia Ticineto Clough and Jean Halley, ${ }^{60}$ draw a distinction between affect and emotion where emotion is something that can be enunciated - for instance, statements like "I feel sad," "I feel happy" - while affect is understood as autonomous because it occurs before we are able to name. In short, affect precedes emotion and therefore maintains a degree of autonomy from the subject. This framing of affect as autonomous provides a variety of

\footnotetext{
${ }^{58}$ Specifically, see Ben Anderson, “Affective Atmospheres," Emotion, Space and Society 2 (2009), 77-81. It is also worth noting that in Anderson's most recent work, 'Encountering Affect,' he proposes affect as that which is simultaneously encountered as an object-target, a bodily capacity and a collective condition. Ben Anderson, Encountering Affect: Capacities, Apparatuses, Conditions (Farnham, Surrey and Burlington, VY: Ashgate Publishing Limited, 2014), 18.

59 Anderson, "Affective Atmospheres," 78.

${ }^{60}$ Patricia Ticineto Clough and Jean Halley (eds), The Affective Turn: Theorising the Social (Durham: Duke University Press, 2007).
} 
ways of conceptualising the pre-conscious, pre-intentional, pre-verbal processes that occur between bodies.

The difference between affect and emotion is critical in understanding the works by Massumi, McCormack and Thrift - where affect is generated as a product of relations between bodies, are not entirely personal and subjective, or socially constructed. The following reviews the strength of these works in their attempt to take the obscure language of affect and discuss this by linking it with practical experiments and events but also with our everyday spaces. Such enquiry extends our way of thinking affect as a medium through which the body relates to the materiality of its environment, and also, how the environment acts back on us.

\subsubsection{Brian Massumi: Affect-Body-Space}

Following the Spinozian-Nietzschean and D\&G lineage, affect for Massumi is about the changing capacity of the body as it engages with the world (body as a process, rather than a substance or essence). In his book, Parables for the Virtual: Movement, Affect, Sensation, Massumi articulates how the body carries a constantly increasing or decreasing potential or capacity for movement and change, and because of this shifting power to affect and be affected, the "body does not coincide with itself. It coincides with its own transition; its own variation." ${ }^{91}$ As a consequence, this constant change means the body has an odd affective relationship to itself.

What is critical to understand from Massumi's perspective is indeed the necessity of the body in any affect discourse. As Patricia MacCormack explains, Massumi "describe[s] the body as a consistently experienced within the constellations of movement, affect, sensation and time." In this sense, to delve into the affective discourse is to invest in exploring the body in relation and always fluctuating through affect. Such position is further developed by Massumi in his observation of Hertha Sturm's research on the three versions of a short German film (a wordless version, an emotional version with narration of the man's emotional states, and a factually narrated version). ${ }^{63}$ While this thesis cannot provide an in-depth account of Sturm's research, what is useful for the discussion is how Massumi explores the surface of the body through this affective experiment. He observes how the wordless version drew out the strongest physiological response in terms of skin conductivity, while the factual had the greatest affect on their breathing

\footnotetext{
61 Massumi, Parables for the Virtual, 5.

62 Patricia MacCormack, "Parabolic Philosophies: Analogue and Affect," Theory, Culture \& Society 21, no.6 (2004): 186.

63 Using Hertha Sturm's research, Massumi challenges what we may perceive as 'pleasure': He asks, why is the saddest, most

disturbing version of the film, the silent images of a man building a snowman, taking it to the mountains, bidding it goodbye, and leaving it to melt, experienced by its viewers as the most pleasurable. Massumi sees pleasure as the multiplying, amplification, and intensifying of energies. He proposes that the saddest is the most pleasurable, because it is the most intense. Massumi, Parables for the Virtual, 24.
} 
and heart rate: the heart-brain processed information effectively, but the skin remained unresponsive.

Reading these seemingly contradictory responses to the three versions of the snowman story Massumi argues that the intensity level, which registers on the skin, "is outside expectation and adaptation ... [i]t is narratively delocalized, spreading over the generalized body surface like a lateral backwash from the function-meaning interloops that travel the vertical path between head and heart." ${ }^{14}$ The body, here, has a grammar of its own that cannot be fully captured in words because it "doesn't just absorb pulses or discrete simulations, it infolds context." moment, hundreds of stimuli impact and encroach upon our bodies' surfaces and they respond by infolding them and registering them as intensity: affect is this intensity. According to Massumi, by resonating with the intensity (affect) of the contexts and events it infolds, the body attempts to ensure that it is prepared to respond appropriately to a given circumstance or particular event. This is the body's readiness to act. ${ }^{66}$ Affect is seen as the changing capacity of the body as it engages with things in its proximity - here, the body carries an increasing or decreasing potential to act towards/for what will happen in the near future. ${ }^{67}$ Such study could be extended to address how our bodies may instantly jolt between deciding to cross the road, may shiver before we enter a room, our face flush of embarrassment before a public performance. We could extend this further into architectural contexts, whereby the design process and the bodies involved are not always driven by rational, logical actions, but rather react to often surprising and unexpected occurrence with acts of sub-conscious hunches, that is, intuitive acts. In this sense, architectural practice holds the capacity to face and anticipate changes in the program or budget of the project; always ready to act if and when unexpected demands arise. Affect is this force that seem to play out before our reflective minds and thoughts comes in, triggering embodied responses before the mind decides to act.

By thinking of the body in affective terms as a surface of intensities- (surface of incipient action and expression) - whose regions become folded - infolded and unfolded - allows us to understand the body/skin as a receptacle for affective experiences. In this sense, affect is taken as the medium through which the body relates to the materiality of itself, other bodies in its proximity, and its environment. ${ }^{68}$ What follows seeks to bring Massumi's account of affect from being what happens in-between surfaces of bodies, to how this impacts and generates affective

\footnotetext{
64 Massumi, Parables for the Virtual, 25.

65 Massumi, Parables for the Virtual, 30.

66 Massumi, Parables for the Virtual, 30.

67 See also, Thrift, "Intensities of Feeling," 67.

68 Massumi, Parables for the Virtual, 59.
} 
spaces. Massumi's work provides us with an understanding of how affect is indeed, in our everyday architectural spaces.

\section{Home as Affect-Space}

Massumi shifts our view of domestic dwelling from a space awaiting occupancy (that is, static), to an understanding of domestic space in relation to 'attractors', which he describes as 'catalytic part-subject, and the sensate part-objects.' In Massumi's analysis, a potential attractor could be a lounge space; this attractor-space can hold a potential powerful catalytic part-subject, the television. The television as a part-subject has potential to array various domestic bodies around it - that is, draw bodies towards it (as an attractor) which potentializes or at times can depontentialize the event-space of the lounge, in this case, its affect of watchability. Depending on the television's entertainment potential (affect), the domestic bodies, or part-objects become arrayed by the part-subject of the television - either drawn to it, or repulsed by it. ${ }^{69}$ In this context, home-space is potentialized through affective (media) transmission becoming an event-space. ${ }^{70}$ Analysing the affective conditions during Superbowl Sunday within the home-space, Massumi writes:

The sociohistorical home place converts into an event space. The television suddenly stands out from the background of the furnishings, imposing itself as a catalytic partsubject, arraying domestic bodies around itself according to the differential potentials generally attaching to their gender type. For a moment, everything is up in the air--and around the TV set, and between the living room and the kitchen. ${ }^{71}$

This account allows us to decipher what occurs in this event-space. First, it is important to acknowledge the television as an affective conductor. The body or bodies close to the television can stir them to do things, to speak things that are unfamiliar. Or as Massumi describes, "[i]n proximity to the TV, words and gestures take on unaccustomed intensity." Massumi clarifies, "what the mass media transmits is not fundamentally image-content but eventpotential." ${ }^{, 73}$ What this suggests is how the television acts as a mediator of affect, a transmitter of possibility of the event of the Superbowl Sunday, in this instance, into the home-space. Third, Massumi's observation and analysis is not a theory of spectatorship identification, but of affective

\footnotetext{
${ }^{69}$ Brian Massumi, "The Political Economy of Belonging and the Logic of Relation," in Anybody, edited by Cynthia Davidson (Cambridge: MIT Press, 1997), 182. See also Massumi, Parables for the Virtual, 80.

${ }^{70}$ Massumi, Parables for the Virtual, 81. Massumi describes: "What is pertinent about an event-space is not its boundedness, but what elements it lets pass, according to what criteria, at what rate, and to what effect" Massumi, Parables for the Virtual, 85.

71 Massumi, Parables for the Virtual, 80-81.

72 Massumi, Parables for the Virtual, 81.

${ }^{73}$ Massumi, Parables for the Virtual, 269, footnote 5.
} 
intensification: the entangled engagement of technology, bodies, matter, movements, and energetic transfers between the bodies in the space. Therefore, and fourthly, it could be argued that the focus here is asking, what are the affective conditions necessary for the event-space to unfold? The television, for one, becomes an agent that affects the space and bodies around it. Indeed, in Massumi's own words, "anything could happen" from the television. The television in this sense becomes a matter with force that determines who moves where and how and when.

Massumi's position on affect offers ways to consider the complex set of processes and events that are tied to our everyday practices and mundane activities. He attempts to draw a link between the abstract concept of affect and concrete real-life practices. The following investigates the work of geographer Derek McCormack who attends to specific events triggered on bodies through events, and how this is sensed. At the heart of McCormack's event-specific account of affect is this interest in the ways in which affective event or 'moments' - brings about the possibility of things emerging surprisingly (rather than being predetermined). The passing between and relations between things is where affect is produced.

\subsubsection{Derek McCormack - Affect as Touch and Rhythm}

What is perhaps unique to McCormack's work is his own immediate immersion in the affective practices and experiences - his work provides an investigation of affect empirically and in this sense, gives us a personal encounter, in a literal sense, of/with affect. The following focuses on just two of a myriad of events of affect explored by McCormack. The first focuses on the therapeutic event of touch, and the second on the dance event. As it will be argued, both events are interested in affect as movement and materiality. The two studies of interest are distinct in that one is a relatively controlled therapeutic experimentation and another a less constrained dance experience. However, while reflecting the NRT movement, both events also move us away from thinking affect through body/brain activity (as in Massumi's case). McCormack's empirical studies attend to the more "processual immediacy of events like a smile, a movement, a gesture, the playful use of an apparently useless object, the movement of the body when talking about movements, or the touch of a hand given over to the response of another." ${ }^{, 75}$ Tracing affect that is pre-intentional and non-subjective yet immediate (close to the body), McCormack's position

\footnotetext{
${ }^{74}$ Massumi, Parables for the Virtual, 81.

75 McCormack, “An Event of Geographical Ethics,” 494-495.
} 
emphasizes how affect acts as a 'bridge' through and between the affective events that unfold in space. $^{76}$

\section{Affective Event of Touch}

Examining the potential array of relations between bodies McCormack immerses himself into the practice of Dance Movement Therapy. ${ }^{77}$ This therapeutic event consists of nonverbal exercises, where indeed, what is sensed is privileged over what is known. As McCormack describes, placed in pairs, one person is assigned the role of the guide, while the other is blind. The guide takes the hand of his partner and leads him through a space, applying pressure on his partner's hands to change directions when confronted with another body - or object. He further observes:

As the movement continues, the surface of contact between hands becomes the most important place in the room, becoming a moving surface of orientation. And guiding becomes more than the mind of one person guiding and giving instructions to another. Rather, what moves and guides is now that surface of orientation, that inbetweenness of touching. ${ }^{78}$

Throughout this session, roles are changed, random objects are introduced in the room, some are removed, the blind encounter the "shape, touch and texture of material" and while lost in this encounter, another hand (guide) takes over - "a hand without a name, a hand with a different style." ${ }^{, 79}$ Thus we have a range of movements, objects, and the bridge that connects them, or in McCormack's words, the "moving surface[s] of orientation," which come together to make up the affective space. ${ }^{80}$ The position of each object/body determines the affective relation as well as the potential of relations.

Another observation is made: as the visual sense is blocked, there is only, as McCormack describes, the "sensing of changing directions", the guided-body is never aware of a concrete change in direction. There are 'promptings,' that provide "anticipations of what might be happening" - but never actual happenings. This anticipation of motion is at times accompanied by subtle tactile hints of change in direction, while other times interrupted by material surfaces (objects/props). McCormack writes regarding these latter lifeless objects becoming 'therapeutic

\footnotetext{
76 McCormack's full quote reads: "the importance of affect is not necessarily its personal or interpersonal quality but its transversal quality, the way in which it operates as a catalytically eventful bridge between a multiplicity of movements and relations" McCormack, "An Event of Geographical Ethics," 496.

${ }_{77}$ Margaret Wetherell, in analysing McCormack's work describes DMT (Dance Movement Therapy) as a "practice that uses dance and movement as a way of encouraging direct emotional expression, creating a new medium for the display of unconscious dynamics, and encouraging therapeutic insight and transformation through reflections on what emerges" Margaret Wetherell, "Affect and Discourse - What's the Problem? From Affect as Excess to Affective/Discursive Practice," Subjectivity 6, no.4 (2013): 356.

78 McCormack, "An Event of Geographical Ethics," 487.

79 McCormack, “An Event of Geographical Ethics," 498.

80 McCormack, “An Event of Geographical Ethics," 487.
} 
props' that have the power to transform (and holding a 'catalytic role'): “They catalyze transversal affective relations that open up fields of the virtual in the actuality of sensible movement. And their force in this regard comes from the fact that most of them are so indeterminate." ${ }^{\prime 1}$ This illustrates how affect as energy has the potential to be discharged through objects, making it possible to read space/environment as affective. What is more, the changeable nature of affect, and our sense of it, intensifies our experiences and our positionalities to them. The DMT session thus flows through both moving-surfaces and static-surfaces of orientation. Such body communication, that is, transfer of affect between bodies, specifically through touch, can produce feelings of affection, joy, but also insecurity and inhibition. Furthermore, the surface effects of the movement of affect through and across bodies, object, and spaces introduce affective registers that exceed representation. Affect in this sense is a force that arises out of and through exchange - which allows participants to become sensitized to and shape affect space.

\section{The Rhythmic Space of Affect}

McCormack introduces a temporal and spatial dimension to affect through his notions of 'affective rhythms' ${ }^{82}$ Through another observation of dance, this time, through Cajun dance, he interlaces affect with notion rhythms - affectivity moves through bodies rhythmically (as opposed to through a process of representation). ${ }^{83}$ Rhythm suggests the notion of time and prompts us to ask: how does affect travel spatio-temporally? According to McCormack, affect is characterized as rhythmic, and in this sense composed of sounds, gestures, words, as these affects move, the composition of bodies within the space gather in rhythmic relation, or more specifically, affective rhythms. For instance, in thinking through the metronome as a body, it senses diverse and discordant rhythms. McCormack illustrates his position further:

[T] hink about an occasion when you have entered a dance venue of any kind....

Regardless of what kind of dancing might have been taking place, the affective quality of the space in which bodies move is never only something personal - it is a product of a complex mix between music, light, sound, bodies, gesture... what is clear is that this affective intensity is felt - you can feel it in your gut. ${ }^{84}$

The rhythmic movement between these bodies, which circulate around, allows McCormack to characterize affective space as transversal and relational; in other words, the space of affect is of anticipation and expectancy, but also of involvement, cooperation and collaboration. It could be

\footnotetext{
81 McCormack, “An Event of Geographical Ethics,” 498.

82 McCormack, "A Paper with an Interest in Rhythm," 469-485.

83 Derek McCormack, “Geographies for Moving Bodies: Thinking, Dancing, Space,” Geography Compass 2, no.6 (2008): 1828.

84 McCormack, “Geographies for Moving Bodies,"1827-1828.
} 
suggested here that for McCormack, space is redefined through a sense of spacing, where spacing suggests a process or an event of "distributed atmosphere of expectancy." 85 Another point worth mentioning is how bodies can be caught and situated within the affective event-space - through flowing intensities, responses and sensations This perspective posits that there is no singular body, rather a series of potential bodies that are multiple and emergent. Affect here describes sensation characterized by intensities and energies that can be discharged through objects and spaces in the form of affective rhythms making it possible to read many other things, such as space and the environment as affective. ${ }^{86}$

So far, both Massumi and McCormack present a positive angle to the potentiality of affect. The next section turns the focus on an account of affect as being able to be engineered. This is explored through the work of Thrift, who is interested in how affect is capable of being planned out and prefigured in the spaces and environments to control our bodies. For this to occur, affective engineering must consider the vulnerable body and the binding affective force that brings bodies together in the urban space. The following discusses these two points in turn.

\subsubsection{Nigel Thrift: Affect as Belonging to the World and to Each Other}

The importance of Thrift's work in human geography - including his contributions to recent discussions around the cultural $\operatorname{turn}^{87}$ and affective $\operatorname{turn}^{88}$ - is extensively cited and embraced by scholars across different disciplines. While it is impossible to do full justice to all of Thrift's works, three key engagements can be identified that are critical to this thesis. The first of these concerns writings by Thrift that enliven geography through "engagement with the emergent" ${ }^{89}$. The second and equally important interest draws from Thrift's own Non-representational theory, specifically in terms of its application in everyday bodily practice and performance. ${ }^{90}$ The third issue concerns affective politics; the potentially controlling force of affect which, in Thrift's

\footnotetext{
${ }^{85}$ McCormack, "Engineering Affective Atmospheres," 417-418.

86 One critical point warrants brief mention here. Recently, Margaret Wetherell has provided a critical assessment of McCormack's work, noting on the heavily textual narrative through which McCormack describes his affective experience - as that which is somewhat contradictory to NRT's position on affect. McCormack's work is indeed entangled with communicating affect (as opposed to NRT's stance whereby affect is unable to put into words) - a place where NRT is supposedly attempting to counter. Wetherell, "Affect and Discourse - What's the Problem?” 358.

${ }^{87}$ Nigel Thrift, "Introduction: Dead or Alive," in Cultural Turns/Geographical Turns, edited by Ian Cook, David Crouch, Simon Naylor, and James R. Ryan (Edinburgh: Prentice Hall, 2000), 2. Emphasis original.

88 See for example, Thrift, Non-representational Theory: Space, Politics, Affect, 2008.

${ }^{89}$ See for example, Nigel Thrift and John-David Dewsbury, "Dead Geographies - And How to Make Them Live Again," Environment and Planning D: Society and Space 18, no.4 (2000): 411-432.

${ }^{90}$ See for example, Nigel Thrift, "The Still Point: Expressive Embodiment and Dance," in Geographies of Resistance, edited by Steve Pile, and Michael Keith, 124-151 (London: Routledge, 1997). See also, Nigel Thrift, "Intensities of Feeling: Towards a Spatial Politics of Affect," Geografiska Annaler B 86, no.1 (2004): 57-78. Nigel Thrift, "Movement-Space: The Changing Domain of Thinking Resulting from the Development of New Kinds of Spatial Awareness," Economy and Society 33, no. 4(2004): $582-604$.
} 
words, "dictate bodily movement." however, the following looks at the connections drawn by Thrift, between body, affect, and space, specifically, through the vulnerable body, the engineering of affect and the urban city. ${ }^{92}$

To begin, Thrift is concerned with the assumption made by the emergent literature of the body. In his book Non-Representational Theory, Thrift gives a cautionary note: "[T] oo often, it is simply assumed that bodies are bodies-in-action, able to exhibit a kind of continuous intentionality able to be constantly enrolled into activity." ${ }^{\prime 93}$ Rather, he suggests that bodies experience fatigue, exhaustion and even at times, reluctance to engage. ${ }^{94}$ Bodies are hence, at times, exhaustive and disengaging. This lack of the consideration for the vulnerability is highlighted as a problem, as Thrift claims that as our bodies make mistakes, we trip, we fall - the experience of embodiment must include notions of vulnerability, passivity, suffering. ${ }^{95}$ But what is interesting is how this position also brings about the potential of affect as a force that can control our bodies to act or react in certain ways. Or as Thrift claims, “... people have little or no control over their bodies or environments but are under the control of an affective force." 96 Indeed, for Thrift, affect is a collective of autonomic force and response that control the movement of bodies. ${ }^{97}$

Furthermore, according to Thrift, this vulnerability of the body (caused by the affective force of anxiety, obsession and compulsion) is often shielded by other objects, whereby the latter extends our body's circumference and has potential to move us in certain ways. ${ }^{98}$ He extends the notion of affective force beyond the human body to objects (non-human bodies) even to say that objects also possess "affective force that is active... [that is] both moved and moving." "99 Thrift therefore blurs the boundary between body (as human) and thing (object body) claiming that objects are not passive or inanimate. ${ }^{100}$ Thrift's position of the body is defined by interactions between bodies (both human and non-human) whereby affect criss-crosses between the bodies,

\footnotetext{
91 According to Thrift, "affect is a semiconscious phenomenon, consisting of a series of automatisms... which dictate bodily movement" Thrift, Non-representational Theory, 239.

${ }^{92}$ In terms of the connection drawn between affect and the urban city, some other notable writers must be acknowledged. For instance, the work by Dovey et al. looks at urban 'intensities,' particularly in Melbourne. While the authors do not directly use the term 'affect,' their research engages with the "sense,' 'feel', 'atmosphere”, or (affective) intensities of everyday place (urban) experiences, challenging the assumption that a 'character' of a city is solely determined by physical forms. Kim Dovey, Ian Woodcock and Stephen Wood, "A Test of Character: Regulating Place-identity in Inner-city Melbourne," Urban Studies 46, no.12 (2009): 2595-2615. See also, Michael Buser, "Thinking through Non-representation and Affective Atmospheres in Planning Theory and Practice," Planning Theory 13, no.3 (2014): 227-243.

93 Thrift, Non-representational Theory, 242.

94 Thrift, Non-representational Theory, 242.

95 Thrift, Non-representational Theory, 238.

96 Thrift, Non-representational Theory, 240.

97 Thrift, Non-representational Theory, 239.

98 Thrift, Non-representational Theory, 239. And also, "[objects] add to what and how the body can experience" Thrift, Nonrepresentational Theory, 239.

99 Thrift, Non-representational Theory, 292.

100 Nigel Thrift, "Understanding the Material Practices of Glamour," in The Affect Theory Reader, edited by Melissa Gregg and Gregory J. Seigworth (Durham \& London: Duke University Press, 2010), 302.
} 
giving a sense of aliveness and transfer of expectancy (engineered affect). This engineering of affect draws bodies together; affect acts as a corporeal sense of this communicative act, generating what Thrift calls "affective bonds." ${ }^{\text {"101 }}$ For example, Thrift suggests affect is generated in the intimate gatherings of collective bodies (both human and non-human) that the urban space offers. Without being aware of each other, the bodies involved in what he calls, "light-touch, partially-engaged, partially disengaged"102 small-gatherings increasingly bond together through affect, the latter acting as a kind of glue between bodies. ${ }^{103}$ Using Canadian philosopher Charles Taylor's work, Thrift argues that the urban society consists of bodies that do not know each other, but as they rub shoulders, they are "affecting each other."104 One such 'light-touch' gathering space is the morning rush where other bodies become obstacles to your own body in movement towards a specific place. Thrift quotes Taylor's work to explain this occurrence:

... large numbers of people rub shoulders, unknown to each other, without dealings with each other, and yet affecting each other... each individual or small group acts on their own, but with the awareness that their display says something to others, will be responded to by them, will help build a common mood or tone that will color everyone's actions. ${ }^{105}$

In this sense, each individual body's action is influenced by the display of affect of others, generating a sense of belonging together to the situation (of the morning commute). What this passage also clarifies is the potential of strangers - bodies that do not know each other to gather and define the mood of the environment they share. Hence, the commuting bodies are clearly caught up, albeit unconsciously, in affective practice. These bodies, which gather through intensive encounters: 'rubbing of shoulders' in the morning rush, or in crowded festival streets, or at a stadium sports game- become hybrid combinations, 'glued' together through what Thrift describes as a "binding affective force." 106 Through this perspective, urban events can be understood as affectively engineered, where the prefigured affect is not necessarily immediately identifiably, but is nevertheless forceful.

Importantly, Thrift's work demonstrates affective practice as both situated and engineered, encompassing people, objects, spaces and the built environment (a multiplicity of

\footnotetext{
101 Nigel Thrift, "But Malice Aforethought: Cities and the Natural History of Hatred," Transactions of the Institute of British Geographers 30, no.2 (2005): 145.

102 Thrift, "But Malice Aforethought,"138.

103 Thrift, "But Malice Aforethought," 146.

${ }^{104}$ Charles Taylor, Modern Social Imaginaries (Durham: Duke University Press, 2004), 168. Quoted by Thrift, in Thrift, "But Malice Aforethought," 146.

105 Taylor, Modern Social Imaginaries, 168. Quoted by Thrift, in Thrift, "But Malice Aforethought," 146.

106 Thrift, "But Malice Aforethought," 146.
} 
relations), communally working towards building a 'kind' city. ${ }^{107}$ What follows seeks to develop Thrift's position of the affect as 'engineered,' through a further spatial focus, as he likens affect as something moving and running through a city like pipes and cables.

\section{Through 'Pipes and Cables'}

Thrift presents a case of affect in transit using an engineering oriented metaphor: "a network of pipes and cables." ${ }^{108}$ In this sense, he illustrates the intermediary space of affect through the notion of channelling. As Thrift describes:

... affect is more and more likely to be actively engineered with the result that it is becoming something more akin to the networks of pipes and cables that are of such importance in providing the basic mechanics and root textures of urban life ... a set of constantly performing relays and junctions that are laying down all manner of new emotional histories and geographies. ${ }^{109}$

This observation points to ways in thinking through the motion of affect as a complex system of mechanically bridged connections. This channelling of communication through 'pipes and cables' contributes to an understanding of affect as interlinked, intersubjective and always connected. However, what is inconsistent between this metaphor and affect is that while affect, in accordance to Thrift's non-representational theory and Massumi's conception of affect as autonomous - is unstructured and unformed, the picture of 'pipes and cables' and to some extent the notion of 'engineering' are both structured and knowable, that is, something systematically organized. What is more, rather than the uncontained, inexpressible nature of affect, 'pipes and cables' contains affect within confined, ordered, labelled spaces. Moreover, Steve Pile explains how through this specific metaphor, affect is "[cast] as something that can be piped or cabled, rewired, rerouted, re-networked in conscious and intentional ways," ${ }^{\prime 110}$ where affect's network of forces and intensities cannot spread wide across but is rather limited within the structured and controlled system of 'pipes and cables.' Additionally, this metaphor “presumes that affect are immutable in transit" ${ }^{\prime 11}$ - which is at odds with Thrift's own theory of affect, where affect is

\footnotetext{
107 Indeed, we must be cautious that Thrift's work focusses primarily on 'Western' cities (as opposed to cities in the South), as Thrift himself distinguishes this difference. See for instance, Thrift, "But Malice Aforethought," 138. Furthermore, the engineering of affect has been explored by Peter Adey most closely, in terms of linking affect to Foucauldian concepts of discipline and power. In the architecture of airports, for instance, Adey argues how "seemingly personal realms of affect... are part of the process of controlling and regulating people in airport space." Similarly, Thrift describes how cities -especially Western cities- are increasingly engineered by an entertainment-military complex which seeks to control our movement and emotions. 108 Thrift, "Intensities of Feeling," 58.

109 Thrift, "Intensities of Feeling," 58.

110 Steve Pile, "Emotions and Affect in Recent Human Geography," Transactions of the Institute of British Geographers 35, no.1 (2010): 12.

111 Pile, "Emotions and Affect in Recent Human Geography," 18.
} 
taken as indeterminate and as constantly transforming. ${ }^{112}$ Nevertheless, we can associate closely with a picture of 'pipes and cables' and thus perhaps this perception of affect travel - a channelling composed of wires and cylindrical tubes controlled by programmed networks permits us to ground the abstract theory of affect within the practical world that we live in. Even so, by pipes we envision water current, and by cables we conceive of electricity - so we may question, is affect as constant as water flow, and as stable as electricity?

Notably, Thrift's pipes and cables metaphor of how affect moves and flows underlines the intersections between physical and affective mending. Urban spaces operates everyday through a 'hum' of physical mending activities (or in Thrift's words, "repair and maintenance" that necessitate the pipes and cables). For example, within our everyday, waste water transported through sewer 'pipes,' is carried through a network of underground pipes towards treatment plants. In more abrupt events, such as in earthquakes or severe storms, repair of broken power lines is immediate to bring back electricity (at least in the Western cities). In turn, these mending activities operate as a kind of 'glue' where the 'hum' of pipes and cables, quicken affective recovery, such as of 'broken hearts. ${ }^{113}$ The pipes and cables movement of affect can arouse hope. Here, in affect's systematic movement of pipes and cables, Thrift provides a more flexible organization of pipes and cables that is not hard or contained, but rather open to affective flows. This makes the concept of affect particularly tuned towards practices that are often assumed to be fixed and stable (and by extension - unaffected), for instance, architectural practice, but at close investigation is composed of fluid movements of bodies (human and non-human) that generate affective relations.

\subsubsection{In Reflection}

There is a kind of consistency amongst the writers explored in this section, albeit from different angles. Massumi approaches affect through neuroscience (the automatic and involuntary forms of unintentional communication within the body and mind), McCormack through immediate events of touch and dance, while Thrift presents in a more cautionary tone the power and engineered form of affect that operates as a binding force in urban space. In a general sense, within these frameworks affect is presented as a somewhat unstructured force or intensity (what is sensed) rather than as something that exists as a directly graspable object. In this sense, following

\footnotetext{
112 Despite these critiques, McCormack supports the metaphoric picture of pipes and cables, as he responds to Deborah Thien's criticism against Thrift's ontology of 'pipes and cables' as being "masculinist, technocratic and distancing" Thien, "After or Beyond Feeling?" 452. As McCormack writes in his text 'For the Love of Pipes and Cables': "I remain... irredeemably attached to pipes and cables... [m]y inclination is to think more of the performative and moving force of lines, diagrams and, where possible, pipes and cables, because I take these things to be of rather than separate from the world" Derek McCormack , "For the Love of Pipes and Cables: A Response to Deborah Thien," Area 38, no.3 (2006): 332.

113 Thrift, "But Malice Aforethought," 135-136.
} 
Massumi, affect remains outside awareness and points towards the multiplicity and movement that characterize materiality or corporeality. ${ }^{114}$ Massumi, McCormack and Thrift's work is important to this thesis as they address the issues of affect's potential, to change and transform, through bodies relations to others as well as its environment. Of course, the complexity of the body and space from the lens of affect is only attended here in a relatively limited manner. However, through this particular review of affect, it has become possible to talk about moods and affects of spaces, both domestic and urban -and in turn, provides a way of understanding our built environment not simply as contained, but rather emergent, in terms of a wide range of affective relations.

Critically, there is also something of an over-generalisation of bodies and in the acceptance of the autonomy and multiplicity of relations (body mediated by processes and practices) something is missed; affect's abstract nature arouses discomfort, as it seems only too eager to bypass the particulars, such as the gendered body. What is missing is the question of affect involving more localized, emotional affects. In the process of exploring the 'transhuman' and unstructured qualities of affect, the theory of affect introduced in this section risks cutting emotions off from the everyday ordinary experiences of being and having a body. The following section seeks to extend and address the issues discussed here by considering how feminist scholars reconfigure and reinvent the concept of affect.

\subsection{LOCALIZING AFFECT: TOWARDS EMOTIONAL AFFECT}

In terms of feminist geography's general uptake of the concept of affect, the space of distinction between affect as 'transhuman' and emotion as 'personal' has become a key point of application for critical discourse. For example, Iris Marion Young suggests that "woman have an inhibited intentionality' in part because they do not get behind their bodies since women see their bodies as 'objects' as well as 'capacities." "115 From a similar angle Liz Bondi adds, "feminist geographers have drawn attention to, and sought to destabilise, associations that link masculinity to rationality, mind and objectivity, while femininity is linked to emotionality, body and subjectivity." 116 This rather feminist standpoint has emerged to tackle the inaccessibility of affect - and does so through a more personalized, everyday life lens. Acknowledging the composite nature of social life, they argue affect over-universalizes and generalizes as well as risks ignoring the particularity of scenes and relations, and also, bodies.

\footnotetext{
114 Massumi, Parables of the Virtual, 260.

115 Iris M. Young, On Female Body Experience: "Throwing Like a Girl” and other Essays (New York: Oxford University Press, 2005 ), 35. ${ }^{116} \mathrm{Liz}$ Bondi, "Making Connections and Thinking through Emotions: Between Geography and Psychotherapy," Transactions of the Institute of British Geographers 20, no.4 (2005): 436.
} 
This section seeks to extend and add to the works reviewed in section 3.2, by considering how feminist scholars are re-configuring and reinventing the concept of affect. Critical of the 'transhuman' theoretical framework of affect which studies affect as being outside the human subject, this section looks at three key feminist theorists, Deborah Thien, Clare Hemmings and Sara Ahmed, who have taken a stance against the geography of affect that resists critical interpretation. The first part reviews both Thien and Hemmings work, focussing solely on their reactionary positions to what they refer to as a 'masculinized' approach to affect. For this reason, these reviews are short in length in comparison to the works discussed in the above section (2.3). At the heart of the critical discourse presented here, these feminist perspectives question the latter Spinozian lineage for its inattentiveness to the actual, everyday affect, and attempt to ground affect in a more concrete, material reality. ${ }^{117}$ The second part explores Ahmed's work which while also suggesting scepticism of claims for the autonomy of affect also begins to offer more concrete ways to challenge affect theory, making a case for emotional affects. Lastly, the third part seeks to further the spatial connotation of affect by reviewing Ahmed's analogy of our bodies and our environment as being 'sticky' and full of affective value. This position offers a way to see the human body (but also non-human bodies) not as a singular subject but rather as series of potential subjectivities that are multiple and emergent, impacting and impacted by the space and objects around it.

\subsubsection{Reactionary Positions - Feminist Critical Engagement}

\section{Thien: Personal View of Affect}

Calling for an attention towards the discursive and emotive body Thien rises to claim that the 'masculinized' tradition of affect "discourages an engagement with everyday emotional subjectivities, falling into a familiar pattern of distancing emotion from 'reasonable' scholarship..." ${ }^{118}$ Charging the 'affective' group as having passed over the human subject, she writes that as a consequence of this move 'after and beyond humanity"119 is the formation of a politics which is 'masculinist, technocratic and distancing' and insensitive to the emotional landscape of daily life. ${ }^{120}$ What is more, Thien argues that the 'transhuman' work on affect reinstitutes the binary distinction between "masculinist reason and feminized emotion." 121 Hence, the recent 'affective turn' is in danger of facing the classic mind-body problem - and furthermore,

\footnotetext{
117 See for example: Stacey Alaimo and Susan Hekman, "Introduction: Emerging Models of Materiality in Feminist Theory," in Material Feminisms, edited by Stacey Alaimo and Susan Hekman, 1-19 (Bloomington: Indiana University Press, 2008).

118 Thien, "After or Beyond Feeling?" 450.

119 Thien, "After or Beyond Feeling?" 450.

120 Thien, "After or Beyond Feeling?" 452.

121 Thien, "After or Beyond Feeling?" 452.
} 
that of the masculine-feminist delineation. Liz Bondi concurs, as she claims the setback of the more-than-human nature of affect is that it risks becoming detached from ordinary, everyday emotion and in her words, "resists relinquishing the position of the rational knower surveying its subject(s) from a distance." 122 These views highlight the concern of affect to once again project a concept so far away from the 'other' bodies, including but not limited to feminine, queer and disabled bodies.

Proposing an affective geography that "dissolves... public/private boundaries," 223 Thien suggests a more sensitive, feminized and personal view of affect - one that is accessible, and allows critical interpretation, which in her point of view, has a more promising agenda than the current model of affect. Instead of seeking to separate her 'feminist personal' vision from the 'transhuman' vision on affect, she advocates for an integration of emotional geographies within the current affect discourse, giving attention to feminist studies on relational spaces. ${ }^{124}$ What is clear, then, is Thien's proposition of affect-emotion as joint, relational activity in which they intertwine together. Analysing the varying definitions of 'affect' from psychoanalysis to more recent social theory, in particular affect as "impulse, mode of organization, instrumentality,", 125 Thien suggests that within such framework "affect is the flow of emotion... the motion of emotion.." ${ }^{126}$ Hence, both emotion and affect are relational and tied crucially together. Affect propels emotion: the force of affect is largely that which emotion is made of. From this position, the assumption of the autonomy of affect where a strong distinction is drawn between affect and emotion is questioned.

\section{Hemmings: Why this Affect?}

Noting the tension between the universalized/abstract and the local/inward engagements of affect, Hemmings offers a critically aware overview of the Deleuzian/Massumian (and by extension, their followers) as well as Silvan Tomkins/Eve Sedgwick's 'beyond-human' theory of affect by posing the important question, why is this tradition of affect celebrated? In "Invoking Affect: Cultural Theory and the Ontological Turn," Hemmings challenges the assumptions which seem to support the leading affect theory writer, Massumi. This passage is worth quoting at length:

\footnotetext{
122 Bondi, "Making Connections and Thinking through Emotions," 438.

123 Thien, "After or Beyond Feeling?" 452.

124 Thien, "After or Beyond Feeling?" 452.

125 Thien, "After or Beyond Feeling?" 451.

126 Thien, "After or Beyond Feeling?" 451.
} 
While many will concur with Massumi's scepticism of quantitative research in its inability to attend to the particular, we are left with a riddle-like description of affect as something scientists can detect the loss of (in the anomaly), social scientists and cultural critics cannot interpret, but philosophers can imagine. ... How then can we engage affect in light of the critical projects we are engaged in, or are we to abandon the social sciences entirely? In fact ... Massumi ... [is] advocating a new academic attitude rather than a new method, an attitude or faith in something other than the social and cultural, a faith in the wonders that might emerge if we were not so attached to pragmatic negativity. ${ }^{127}$

For Hemmings, the 'affective turn' involves, at best, "a new attitude" within the academic realm; at worst, a vague, inaccessible contemplation of the incapacity of human cognition to grasp the transcendent. ${ }^{128}$ Looking closer at her text, Hemmings explains two kinds of affects: the bad affect relating to epistemology and 'pessimism of social determinism' (the hypothesis that social interactions and constructs alone determine individual behaviour vs. freedom from social constraint), and the good affect, relating to ontology and the "optimism of affective freedom."129 She claims that Massumi dismisses or ignores the negative/bad affect and by only pursuing the good affect, he presents a rather skewed/biased and partial argument. Furthermore Hemmings contends that the "ultimate' role of "good affect that undoes the bad" is that of a persuasive tool for theorists to have a "more productive frame of mind" and convince cultural theorist to the value of the ontological. ${ }^{130}$ What this means is that 'good affect' is used as a rhetorical tool to influence recent critical discourse towards thinking through affect to inquire into the nature of being itself, rather than focusing on the origin and limits of human knowledge. ${ }^{131}$

In addition, Hemmings asks her readers to question the recent affective celebration and suggests us to consider the potential of feminist work which is characterized by epistemological framework that "attends to the emotional investments." 132 Accordingly, the feminist standpoint never separates or opposes epistemology/signification and ontology. She highlights that Massumi's theory of affect as 'autonomous' is a "theory written from the margins... outside the reach of critical interpretation" and thus, can be misreading. ${ }^{133}$ With a cautionary tone, she seems to say, take the ontological drive of affect theory, and the autonomy of affect, simply as an experiment and no more.

\footnotetext{
127 Hemmings, "Invoking Affect," 563.

128 Moreover, according to Blackman, Hemmings foregrounds this recent interest in affect as one which "promises to emancipate the subject from social constraint, and thus to sideline theories and theorists who might wish to explore affect, as an enduring mechanism of social reproduction" Lisa Blackman, "Embodying Affect: Voice-hearing, Telepathy, Suggestion and Modelling the Non-conscious,” Body \& Society 16, no.1 (2010): 189.

${ }^{129}$ Hemmings, "Invoking Affect," 551.

130 Hemmings, "Invoking Affect," 551-559.

131 As Blackman further clarifies: "[t]hus 'good affect' is that which is taken to 'undo' whereas 'bad affect' is that which sticks, fixes and prevents movement and change" Blackman, "Embodying Affect," 189.

132 Hemmings, "Invoking Affect," 557.

133 Hemmings, "Invoking Affect," 558-562.
} 
As a response to Hemmings' call above, and echoing Thien's position, the following part presents Ahmed's writings, which make a compelling case to challenge an idea of affect that isolates emotion to an individual. Ahmed's writings present a case for the potential relationality and intimate connection of affect and emotion; they are not autonomous but rather intertwined in various ways. Accordingly, we are collective subjects caught in intersubjective relations that are affect-ridden but also, emotion-ridden.

\subsubsection{Ahmed: $\quad$ Emotions are Not Private either}

Recent research by Ahmed in spatial orientation has put into question D\&G and Massumi's theory of affect and emotion as having opposing and irreconcilable properties. She challenges their stance of emotion that describes it as, and to reiterate on Massumi's words, a "subjective content (that can be attributed to an already-constituted subject), personal, conscious and qualified." ${ }^{134}$ This theoretical discourse by Ahmed on emotion, affect, bodies, and objects is crucial in engaging with questions of materiality and the spacing of emotional affects. She begins by stating: "I do not assume there is something called affect (or for that matter emotion), that stands apart or has autonomy; as if it corresponds to an object in the world.... Instead, I would begin with the messiness of the experiential, the unfolding of bodies into worlds and the drama of contingency, how we are touched by what comes near." ${ }^{\prime 35}$ This account presents a critique of Massumi and to some extent, McCormack's work, who argue that affect is always unpredictable and 'transhuman' while emotion is situational and is inherently personal.

Indeed for Ahmed, emotion is not a personal property, rather, it is 'a feeling of bodily change, ${ }^{, 136}$ suggesting that emotions "do not involve processes of thought, attribution or evaluation: we feel fear... because our heart is racing, our skin is sweating." ${ }^{\prime 137}$ Attending to this dimension affords not only a strong sense of human subjectivity but also that emotions involve the materialization of bodies. ${ }^{138}$ From this point of view, emotion pertains to a similar order as affect - where it does not reside in subjects or objects, cannot be fully realized in language, and is rather an experience of 'bodily change' - an interpersonal and intersubjective process. ${ }^{139}$

Criticizing a model of emotion that is based on the "presumption of interiority" and that "assume[s] the objectivity of the very distinction of inside and outside," 140 Ahmed comments on

\footnotetext{
134 Massumi, Parables of the Virtual, 28.

135 Ahmed, "Happy Objects," 30.

136 Ahmed, The Cultural Politics of Emotion, 5.

137 Ahmed, The Cultural Politics of Emotion, 5.

138 Ahmed, The Cultural Politics of Emotion, 1.

139 Thien, "After or Beyond Feeling?" 453.

140 Ahmed, The Cultural Politics of Emotion, 8-9.
} 
a two-part model: first, where emotions are understood to either move "inside out" towards objects and others, and second, conversely, "outside in" where "emotions are assumed to come from without and move inward." ${ }^{141}$ In the first model emotion is sensed as a property that can be owned, "I have feelings, and they are mine"142 which when expressed outward, becomes the property of another. The second model thinks of emotion as a force that penetrates inwards from without - in such case, emotion is something "We" or the "collective" have. ${ }^{143}$ Countering these models, Ahmed argues, “emotions are not 'in' either the individual or the social, but produce the surfaces and boundaries that allow the individual and the social to be delineated as if they are objects." 144 The use of the terms 'surfaces' and 'boundaries' is of no coincidence here: as we reflect on thinking through affect as a 'sensation of the periphery', we can equally think through emotions as a sensation of the surface - that which allows us to be aware of the surface of our bodies. ${ }^{145}$

Turning to happiness, Ahmed challenges the assumption that happiness is a state of emotion or an inner feeling. She claims that "happiness... does not reside in subjects or objects but is an effect of what gets passed around" "146 and asks: "Does bad feeling enter the room when somebody expresses anger about things, or could anger be the moment when the bad feelings that saturate objects get brought to the surface in a certain way?" ${ }^{247}$ Equally, we can say that 'happiness' or good feeling emerge onto the surface of an object or body, which causes a 'happy moment,' but it is not until this feeling is passed around, impresses upon other surfaces, that we may call it affect. That is, "the surfaces of bodies 'surface' as an effect of the impression left by others." ${ }^{148}$ For Ahmed, (emotional-) affects are thus ‘bodies-in-relation' where bodies are "something touching, which is touched"149 impressing and impressed by affect. Giving attention to the potentialities and materialities of bodies, through her position of emotion as not being 'in'

\footnotetext{
141 Ahmed, The Cultural Politics of Emotion, 10.

142 Ahmed, The Cultural Politics of Emotion, 8.

143 Sara Ahmed, "Collective Feelings or: The impressions Left by Others," Theory, Culture \&o Society 2, no.2 (2004): 28.

144 Ahmed, The Cultural Politics of Emotion, 6-8.

145 Ahmed, "Collective Feelings or: The impressions Left by Others," 24. Thinking through negative emotional affects - Ahmed writes on pain: "The affectivity of pain is crucial to the forming of the body as both a material and lived entity" Ahmed, The Cultural Politics of Emotion, 24. She explains that "it is through the flow of sensations and feelings that become conscious as pain and pleasure that different surfaces are established" Ahmed, The Cultural Politics of Emotion, 24. When pain flows between an object to a body, or between bodies, and is sensed in the body, surface emerges. Without affect then, our bodies remain unbounded/without a surface. In support of this argument, Ahmed looks at an everyday setting: “...say I stub my toe on the table. The impression of the table is one of negation; it leaves its trace on the surface of my skin and I respond with the appropriate 'ouch' and move away, swearing. It is through such painful encounters between this body and other objects, including other bodies, that 'surfaces' are felt as 'being there' in the first place” Ahmed, "Collective Feelings or: The impressions Left by Others," 29.

146 Ahmed, "Multiculturalism and the Promise of Happiness," 126.

147 Ahmed, "Multiculturalism and the Promise of Happiness," 128.

148 Ahmed, The Cultural Politics of Emotion.

${ }^{149}$ Husserl, vol.2: 155, quoted in Sara Ahmed, “Orientations Matter," in New Materialisms: Ontology, Agency, Politics, edited by Diana Coole and Samantha Frost (Durham \& London: Duke University Press, 2010), 245.
} 
us, ${ }^{150}$ Ahmed illustrates the two-way relationship that exists between affect and emotion, feeding back and forth, calling forth a discourse towards emotional affects. What follows continues to review Ahmed's work but turns to texts which offer a more spatial focus to affect.

\subsubsection{Through 'Stickiness' and 'Orientation'}

Ahmed presents a case against an understanding of affective travel through 'pipes and cables', as discussed earlier in this chapter. She also challenges other metaphoric descriptions of affect movement, such as by Anna Gibbs and Teresa Brennan, who liken affect to a virus that is contagious and also able to be transmitted like radio waves, respectively. ${ }^{151}$ While the engineering metaphor of 'pipes and cables' as a structured bridging network within the space-in-between allows us to penetrate the inaccessible and inexpressible notion of affect, grounding affect in the practical realms, the conception of radio waves and viruses, both invisible to the eye are related more to the unstructured, indeterminate flow of affect. In both cases, however, we are still to question, following Pile, "[w]hat is the quality of reception?" and press on to ask, how do we pick up affect? How far or intimate do our bodies/objects have to be and how far does affect reach from one body to another, across a room? ?152 $^{152}$

This brings us to Ahmed's work, who is critical of thinking affect as moving through contagion and transmitted like radio waves which she argues "tends to underestimate the extent to which affects are contingent (involving the hap of a happening): to be affected by another does not mean that an affect simply passes or 'leaps' from one body to another. The affect becomes an object only given the contingency of how we are affected." ${ }^{\prime 153}$ In this sense, affect is dependent on our contact with bodies and other affects, but also, her position implies that our bodies and spaces that we inhabit are never neutral. ${ }^{154}$ We always carry a certain affective dimension when encountering another affective body or object - or enter a room saturated with affect. ${ }^{155}$ This mutual feedback engagement between our bodies and spaces in our proximity is important in understanding Ahmed's use of affect. The following reviews Ahmed's position, highlighting particularly her notion of affect's stickiness and its impact on our orientation towards things. The account given here will be further extended in detail through each of the case study chapters (Chapter 5, 6, 7) of this thesis.

\footnotetext{
150 Ahmed, The Cultural Politics of Emotion, 17.

151 Anna Gibbs, "Contagious Feelings: Pauline Hanson and the Epidemiology of Affect," Australian Humanities Review 24 (2001), accessed 15 July 2011, http:/ /www.australianhumanitiesreview.org/archive/Issue-December-2001/gibbs.html. See also, Teresa Brennan, The Transmission of Affect (New York: Cornell University Press, 2004).

152 Pile, "Emotions and Affect in Recent Human Geography," 16.

153 Ahmed, "Multiculturalism and the Promise of Happiness," 125.

154 Ahmed, "Multiculturalism and the Promise of Happiness," 125.

155 Ahmed, "Multiculturalism and the Promise of Happiness," 126.
} 
Ahmed questions how does affect as a medium acts to bring the already affect-ridden body in relation to other bodies within a given space. She explains this through her concept of stickiness. Specifically, in 'Happy Objects,' Ahmed describes affect as "what sticks, or what sustains or preserves the connections between ideas, values, and objects." 156 This sticky character of affect maintains connections between bodies (both human and non-human) which in turn generate common orientations toward things (objects). What this means is that things accumulate characteristics and tendencies over time. ${ }^{157}$ Accordingly, when an object laden with 'happy' affect is passed around or is circulated between bodies, it is not the happy feeling that passes, but is rather an orientation toward that object (as something that brings happiness) that is shared. ${ }^{158}$ What this clarifies is that some affects are already attributed to certain objects such that these objects become sticky - filled with affective value.

Ahmed provides us with a spatial illustration of affect: ${ }^{159}$ "So we may walk into the room and 'feel the atmosphere', but what we may feel depends on the angle of our arrival. Or we might say that the atmosphere is already angled; it is always felt from a specific point. The pedagogic encounter is full of angles." ${ }^{\prime 160}$ This account illustrates how the motion and circulation of affect is never determinate but rather dependent on various factors - what kind of stickiness/tendencies our bodies carry, what kind of affective value the objects have, how intense is the affect -laden space which our bodies and objects inhabit? This drawing toward or angle towards an object/body/space is something personal and biographical because every person has a distinct set of previous sensation from which to draw - a unique affect-ridden body. Indeed, each body perceives situations but also objects, and experiences them, as Ahmed writes, "in a certain way." "This is where Ahmed puts an emphasis on the fact that our relation to our own environment, that is, spaces in our proximity, is derived from our position and angle in the world.

Furthermore, Ahmed articulates how the bodies' turning toward motion to objects or bodies around them brings about a question of orientation. Looking further at the space of affect, Ahmed discusses how orientation affects the way we inhabit space. ${ }^{162}$ In one of her most recent

\footnotetext{
156 Ahmed, "Happy Objects,” 29-30.

157 Ahmed, "Collective Feelings or: The impressions Left by Others," 40. Correspondingly, in her work The Cultural Politics of Emotion, Ahmed notes that "signs become sticky through repetitive use" and likens this to the relation between our bodies and objects/space, where the degree of stickiness is dependent on "histories of contact that have already impressed upon the surface of the object" Ahmed, The Cultural Politics of Emotion, 90-91.

158 Ahmed, "Happy Objects," 37.

159 In response to Brennan who reflects: “...if I feel anxiety when I enter the room, then that will influence what I perceive or receive by way of an 'impression" Brennan, The Transmission of Affect, 6. Ahmed writes: "Anxiety is sticky: rather like Velcro, it tends to pick up whatever comes near. Or we could say that anxiety gives us a certain kind of angle on what comes near.... If bodies do not arrive in neutral, if we are always in some way or another moody, then what we will receive as an impression will depend on our affective situation" Ahmed, "Multiculturalism and the Promise of Happiness," 125.

160 Ahmed, "Multiculturalism and the Promise of Happiness," 125.

161 Ahmed, Queer Phenomenology. Orientations: Objects, Others (Durham: Duke University Press, 2006$), 27$.

162 "Orientations involve directions towards objects that affect what we do, and how we inhabit space. We move toward and away from objects depending on how we are moved by them” Ahmed, Queer Phenomenology, 28.
} 
texts, 'Orientations Matter,' Ahmed illustrates this by drawing on Husserl's writer and desk metaphor: 'Spaces (too) are orientated in the sense that certain bodies are 'in place' in this or that place. The study might be oriented around the writer, who is then 'in place' in the study. To say spaces are oriented around certain bodies is to show how some bodies will be more 'in place' that others." 163

Interestingly, it is not only our bodies (human) that arrive to a space with specific angle/positions, spaces also come angled with certain stickiness. In other words, spaces are shaped by the bodies that tend to inhabit them given their tendencies. And yet, it is not always decided which bodies inhabit which spaces, even when spaces extend the form of some bodies and not others. ${ }^{164}$ Ahmed describes how we perceive our state of being in relation to the proximity between body and objects through action. Sitting at a writing table, with a pen in hand, we are engaged in a specific act, such as 'writing'. This action/intentionality shapes our perception and how we orientate ourselves toward the desk. That is, the act of writing creates a sticky orientation toward the writing table and other surrounding objects. ${ }^{165}$

For Ahmed, the space of affect is sticky as it operates as the 'contact zone of impressions' and orientations. ${ }^{166}$ This sticky motion of affect involves a process of attribution where affects are assigned to objects, making them sticky. The affect-laden bodies/objects are passed around and as they come in contact with our own bodies (full of affective value), they impress upon us, stick on us and our bodies impress (stick) upon them, producing further sticky relationships. It must be clarified that the sticky movement of affect does not refer specifically to design situations. Yet, this thesis argues that Ahmed's sticky metaphor, can be extended to consider how affect, in its various and not always agreeable movements, provides ways to look into the contingencies, movements and processes of architecture and its practice. Of course, in architectural discourse, we are not discussing how bodies (both human and non-human) including spaces, stick, in the literal sense. Rather, through the metaphor of sticky affects, we may begin to discuss how design ideas and attitudes, for example, may attach to other designs; how affects aroused by an object, may begin to attach to bodies coming close to its proximity. Such 'sticky' possibilities are discussed further in each of the case study chapters (Chapter 5, 6 and 7).

\footnotetext{
163 Ahmed, “Orientations Matter," 235.

164 Ahmed, "Orientations Matter," 252.

165 Ahmed, “Orientations Matter,” 234-257.

166 Ahmed, "Collective Feelings or: The impressions Left by Others," 30.
} 


\subsubsection{In Reflection}

This section has drawn attention to the increasing call for integrating emotional geographies within the affective discourse. First, it reviewed reactionary texts by Thien's and Hemming's critiquing the 'masculinist' theory of affect and highlighting how the recent celebration of the Deleuzian-Massumian affect theory should be approached with caution, respectively. Second, through the work of Ahmed, it investigated the perhaps misleading conceptualization of affect and emotion as having opposing and irreconcilable properties. ${ }^{167}$ The feminist arguments reviewed here bring forward the question: Is affect emotion? And more pressingly, is there a place for emotional affect? In fact, our emotional responses are in large part driven by affect: affect propels emotion. Feminist scholars have since in various ways raised objections against claims on affect as autonomous, most prominently, Ruth Leys and the critical exchange that has happened between her text 'The Turn to Affect' and scholars such as Adam Frank and Elizabeth A. Wilson as well as Charles Altieri, but also works by Lisa Blackman. ${ }^{168}$ Like other recent critics, both Leys and Blackman, albeit from different angles, emphasize the risk that an all too far driven non-representational approach to affect may end up too generalized and abstract for empirical studies. The important task is not to avoid personal, situated and localized emotional affects, but to learn to integrate them within the current affective discourse.

Importantly, and third, the section attended to Ahmed's sticky metaphor of affect. Exploring the stickiness of affect through and between bodies and their environment, the metaphor of 'stickiness' - allows us to perceive more dynamic, intersubjective and multiple experiences of affect that can no longer be referenced by- or to- the singular body. Finally, Ahmed's work contributes to the understanding of how affects move and how they accrue value and intensity, and most importantly to this thesis, accumulate stickiness, through circulation, exchange, and movement. This is important as a sticky spatial connotation of affect looks beyond the privileging of affect's autonomy, fostering instead attendance on affect's materiality and generative potential.

\footnotetext{
167 Indeed, Ahmed criticizes discourse of emotion that is based on the "presumption of interiority" and suggests rather provocatively that "emotions are not simply something 'I' or 'We' have" Ahmed, The Cultural Politics of Emotion, 24. 168 See for example, Ruth Leys, "The Turn to Affect," Critical Inquiry 37 (Spring 2011): 434-472. For the critical response to Leys text, see Adam Frank and Elizabeth A. Wilson, "Critical Response I: Like Minded," Critical Inquiry 38 (Summer 2012): 870-877. Also see, Charles Artieri, "Critical Response II: Affect, Intentionality, and Cognition: A Response to Ruth Leys," Critical Inquiry 38 (Summer 2012): 878-881. For a response to the above two texts by Leys, see Ruth Leys, "Critical Response III: Facts and Moods: Reply to My Critics," Critical Inquiry 38 (Summer 2012). See also Lisa Blackman, "Embodying Affect: Voice-hearing, Telepathy, Suggestion and Modelling the Non-conscious," Body \& Society 16, no.1 (2010: 163-192. Also, Lisa Blackman, "Habit and Affect: Revitalizing a Forgotten History," Body \& Society 19, no. $2 / 3$ (2013): 186-216.
} 


\subsection{CONCLUDING DISCUSSION}

Concentrating primarily on the intersubjective and relational qualities of affect, the aim of this chapter has been to explore how and why affect play an important role in determining the relationship between our bodies, our environment, and others, and the affective experience that we encounter as affect dissolves into our everyday. Section 2.3 outlined the recent attention to affect-body-space relation. Thinking through affect's abstractivity and potentiality it introduced texts by Massumi, McCormack and Thrift. This section noted that one limitation of this existing literature is the 'philosophical' lens through which this affective discourse is presented, which risks being inaccessible and distancing from the ordinary emotive subject. Section 2.4 examined critical responses to the affective-turn looking through a more emotionally-attuned, personalized, and feminized lens of Thien, Hemmings and Ahmed. At the heart of the range of critical voices presented here, there is a commitment for reinstituting and re-valuing emotional geographies with the possibility of placing emotion within the same order as affect. Indeed, this call for a sensibility towards emotion rather than diminishing it as what Thrift calls, 'touchy-feely' or as what McCormack refers to as a 'limiting concept ${ }^{\text {"169- }}$ - may be a way forward in contributing to the construction of an emphatically human affective geography.

What has been highlighted here is that affective researchers are far more decided and united on where to draw the line between affect and emotion, while emotional researchers question if (indeed) a line can or should be drawn. While there may be differences between affect and emotion, we cannot ignore that they are also intimately connected: affect is the motion of emotion, ${ }^{170}$ affect propels emotion, and therefore, affect is in large part what emotion is made of. Emotions, like the affects they are derived from, are carriers of intensity. A necessary subject to advance the existing affective studies is not a focus on their distinctions but rather on the possibilities that an emotion-ridden affect (emotional affect) may offer.

What is more, the main question that arises, and is perhaps of interest to this thesis, is the methodological consequences of the positions introduced through Massumi, McCormack and Thrift. Similarly, Steve Pile has recently written: "Like emotions, affects matter - but they cannot be grasped, made known or represented. This would appear to leave affectual geography with a problem: it's archetypal 'object of study' - affect - cannot, by its own account, be shown or understood." ${ }^{171}$ Such account is critical as affect's autonomy and abstract nature may impede any

\footnotetext{
169 McCormack, "An Event of Geographical Ethics in Spaces of Affect," 488-507.

170 Thien, "After or Beyond Feeling?" 451.

171 Pile, "Emotions and Affect in Recent Human Geography," 9. Also cited in Margaret Wetherell, "Affect and Discourse -

What's the Problem? From Affect as Excess to Affective/Discursive Practice," Subjectivity 6, no.4 (2013): 357.
} 
form of affect orientated research; if affect is indeed ungraspable, non-communicable and nonrepresentational - any affect research would be problematic. For the purpose of this thesis then, it is important to address how we are able to address this problem. Section 2.4 has attempted to do so through the works by feminist writers, who are bringing back the particular and situated affects through a call for emotional affects. When affect is applied to empirical studies (such as the studies taken up by this thesis) - it becomes necessary to not assume a radical cut between emotion and affect, representation and non-representation.

Accordingly, it is the position of this thesis that albeit being mindful of the distinctions of emotion and affect celebrated by the affective group, and the bringing together of these terms by feminist writers, the focus is perhaps to go beyond these tensions and begin to attend to the way in which affect may move and in its movement begin to solidify aspects of itself that can be grasped in a spatial context, rather than lost. In other words, the spatial connotations of affect are important as we need to be able to talk about the very particular nature of affect, the different way that is moves and draws as well as repels bodies, objects, and spaces. This would allow us to engage with affect in useful ways- through both situated and relational processes.

In view of the above position, Ahmed's affective stickiness is crucial in terms of understanding affective practices, particularly the practice of architecture. Architectural practice is full of intimate affective moment's involving heated discussions over a particular structural details, unexpected stops at certain stages of the design causing disappointment and confusion; issues with finance leading to delay in delivery activating irritation; handing-over the project to the client, which (in most cases) triggers a sense of joy. These specific affective moments often attach to images, objects, ideas, and/or processes (becoming affectively charged themselves). The affectobjects are then passed around and circulated between the different bodies that partake in the design process, taking on different intensities as they meet with others (bodies both human and nonhuman) in both supportive and at times unexpected and surprising ways. With the possibility of extending the affect-body-space relations introduced in this chapter - particularly Ahmed's sticky metaphor - to be investigated within the uncertain and at times conflictual movements and processes of architecture and its practice, the next chapter (Chapter 3) seeks to investigate the way in which practices of architecture are practicing affects, and in parallel, how affects are affecting these practices. It asks: What architectural and theoretical relations can be drawn out when architectural practices are viewed through the lens of affect? In order to answer this, the theoretical concepts of affect explored in this chapter (Chapter 2) will be extended to analyse theories of architectural practice. 
Theory: Architecture, Affect and Architectural Practice

\subsection{INTRODUCTION}

The emphasis of affect has produced a number of debates. The previous chapter (Chapter 2) addressed and explored these recent debates of affect in three different ways. First, through the framework of Massumi, McCormack and Thrift, it discussed an emphasis on affect as a somewhat nebulous and indefinable force as opposed to something that exists as a directly graspable object. In this sense, affect remains outside our awareness. ${ }^{1}$ Second, suggesting an alternative account, the discussion turned to feminist writers who propose to look at affect as more localized and contextualized. Finally, and third, against the background of a contemporary turn to affect and the counter-interpretations of it, chapter 2 illustrated how affect moves - the works engaged have a concern in particular with metaphors used in illustrating the flow of affect within, between and among bodies, human and non-human, as well as objects and spaces. Attending to affect's movement allows inquiry into the real and practical situations of everyday practices. Particularly, this present chapter (Chapter 3) seeks to investigate the way in which practices of architecture are practicing affects, and in parallel, how affects are affecting these practices. It is about asking: What architectural and theoretical relations can be drawn out when architectural practices are viewed through the lens of affect? In order to answer this, the theoretical concepts of 'affect' explored in chapter 3 will be extended to analyse theories of architectural practice.

Perspectives on architectural practice are taken up in diverse contexts and from different angles. Therefore, this chapter does not aim to sum up all possible connections that can be drawn out between affect and practice. Instead, it explores two specific orientations, and is organized in two main sections. The first (3.2) considers the range of debates and ideas on practice from the angle of architectural scholars. ${ }^{2}$ Central to this is the particular attention to the patterns of routines, actions, orientations that, as Dana Cuff suggests, architects 'just do. ${ }^{3}$ Here, two approaches of practicing are addressed: one focussed on mediating affective relations (through participatory practice), the other focussed on mediating affective dispersions (through risk-taking entrepreneurial practice). Rather than opposing these two forms of practice, however, the aim

\footnotetext{
1 This is in reference to works reviewed in Chapter 2, which includes: Massumi, Parables of the Virtual: Movement, Affect, Sensation (Durham: Duke University Press, 2002); McCormack, “An Event of Geographical Ethics in Spaces of Affect,” 488-507;' and Thrift, "Intensities of Feeling," $57-78$.

2 See, for example: Robert Gutman, Architectural Practice: A Critical View (Princeton: Princeton Architectural Press, 1988); Cuff, Architecture: The Story of Practice (Cambridge, Mass: MIT Press, 1991); Stan Allen, Practice Architecture, Technique and Representation (London: Routledge, 2000); Michael Speaks, “Design Intelligence and the New Economy," Architectural Record 190, no.1 (2002): 72-76; Jeremy Till, Architecture Depends (Cambridge: MIT Press, 2009).

${ }^{3}$ Cuff, Architecture: The Story of Practice, 1991.
} 
here is to show how affect is already evident in their research, albeit not named directly as such. These connections lie in the kinds of power, precisely, affective powers, triggered through hopes, desires and fear, drawing bodies together, to form stronger attachments with the design process. While architectural scholars are providing insight into ways affect and practice might be able to flow together, there is nevertheless shortcoming in these accounts - where the focus is on production-orientated activities, and thereby, result oriented. This is where geographers are broadening the marginality of architectural practice, questioning what the excess of practice (the consequence of-) is. ${ }^{4}$ Therefore, the second section (3.3) addresses what remains unconsidered by architectural scholars. Recent developments in geography suggest grounds for reconsidering practice as a condition that is susceptible, receptive and exposed, attending to practices of affective 'tinkering." The term 'tinkering' is useful for this thesis as it attends to miniscule or small acts that often go unnoticed, but are nevertheless powerful as it often relates to actions that are intimate and thereby affective. Here, two of such informal processes are explored: affective tinkering of space (through re-occupation and re-design), and affective tinkering of matter (through repair). Architectural practice viewed via geographers attends to loose processes, that is, tinkering-orientated activities, that generate and are generated by affects.

The purpose of this chapter, then, is threefold. The first is to draw out, through various interpretations by architectural scholars, how the practice of architecture may be seen to mediate affective relations and dispersions. The second focusses on social geographers, who shift in emphasis from practice not only as design-process and production (what is done), but also as small tinkering activities that at times undo what is already made, or care for spaces that may be prone to neglect. Most significantly, this chapter looks at architectural scholars and geographers who come close to linking architecture, affect and architectural practice, but not directly link all three. To clarify, these scholars do not directly link the particular instances of practice as affectrelated; however, this thesis proposes how the language of affect, is arguably, attractive to architectural scholars' and geographers' discourse on practice, precisely because it delivers currents of openness and fluidity into practice. Finally, this chapter makes suggestions over what the concept of affect is useful for in practices of architecture, and how practices of architecture may offer ways to extend current theories of affect.

\footnotetext{
${ }^{4}$ See, for example: Tim Cresswell, "Landscape and the Obliteration of Practice," in Handbook of Cultural Geography, edited by Kay Anderson, Mona Domosh, Steve Pile, and Nigel Thrift, 269-281 (London: SAGE, 2003); Isabel Stengers, "Introductory Notes on an Ecology of Practices,"Cultural Studies Review 1, no.1 (2005): 183-196; Jane M. Jacobs, "A Geography of Big Things." Cultural geographies, 13, no.1 (2006): 1-27; Kirsten Simonsen, "Practice, Spatiality and Embodied Emotions: An Outline of a Geography of Practice." Human Affairs 17 (2007): 168-181; Jane M. Jacobs and Peter Merriman, "Practising Architectures," Social and Cultural Geography 12, no.3 (2011): 211-222.

5 The term 'tinkering' is used by Thrift and Graham where they explore the practices of maintenance and repair in the urban space - to develop a notion of how urban spaces are continually being 'tinkered' through such practices that often go unnoticed. This thesis seeks to use this word as well, but it does so to highlight the activities that often go unnoticed or are in the background in more domestic spaces.
} 


\subsection{PERSPECTIVES FROM ARCHITECTURE: AFECTIVE MEDIATIONS}

\subsubsection{Historical Background}

The rich and diverse body of work exploring the practice of architecture have, historically, tended to explore its deeply sociological and culturally orientated aspects. ${ }^{6}$ Stemming back to Judith Blau, and a little later by Robert Gutman who further enriches the concept of practice as influenced by construction industry as well as media and culture industries, ${ }^{7}$ the practice of architecture is inevitably embedded in, and borrowing Dana Cuff's words, a "social process" ; and as market and economy-driven ${ }^{9}$. These earlier works on practice have come from a macro-perspective, ${ }^{10}$ tending to focus on the surface/exterior of practice and the variety of ways this is influenced by its environment and society. There are also important contributions by architects and designers, as well as each of the respective fields' scholars that analyse practice, ${ }^{11}$ and specifically design methods more locally from a micro-perspective. For instance, Lionel March focusses on architectural problem-solving through synthesis; ${ }^{12}$ while Donald Schön attends to practice as 'reflective' influenced by “design thinking” (motivations, attitudes). ${ }^{13}$ These explorations are often

${ }^{6}$ See for example: Spiro Kostof, ed.,The Architect: Chapters in the History of the Profession (New York: Oxford University Press, 1977); Judith Blau, Architects and Firms (Cambridge and London: MIT Press, 1984); Robert Gutman, Architectural Practice: A Critical View (New York: Princeton Architectural Press, 1988); Robert Gutman, “Emerging Problems of Practice," Journal of Architectural Education 45 (1992): 198-202; Dana Cuff, Architecture: The story of practice (Cambridge, MA/London: MIT Press, 1991); Bill Hubbarb, A Theory for Practice: Architecture in Three Discourses (Cambridge and London: MIT Press, 1995).

${ }^{7}$ Gutman, Architectural Practice: A Critical View, 1988.

${ }^{8}$ Cuff outlines how architects can "lay claim to the entire design process" as she addresses four necessary features that the practice of architecture need to engage with, these are: 1) the collective in practice, 2) design as making sense of situation, 3) connection between art and business, 4) architect as specialist (vs. generalist). Cuff, Architecture: The Story of Practice, 248-262. ${ }^{9}$ Gutman, Architectural Practice: A Critical View, and Hubbarb, A Theory for Practice: Architecture in Three Discourses. Hubbarb challenges architects to perform the service of architecture unconstrained by the "provision of form." Rather, he suggests seeing practice "not burdened by but consisting of the client meetings, the public hearing, the publicity, ceremonies, music, lights... everything... that is required in order for the anticipated experience to occur" Hubbarb, A Theory for Practice: Architecture in Three Discourses, 164.

${ }^{10}$ This orientation of practice of architecture as part of a larger field/society - has been taken up in recent scholarship (see for example, Thomas Fisher, In the Scheme of Things: Alternative Thinking on the Practice of Architecture (Minneapolis: University of Minnesota Press, 2000); Tom Spector, The Ethical Architect: The Dilemma of Contemporary Practice (New York: Princeton Architectural Press, 2001); Nicholas Ray: Nicholas Ray, ed., Architecture and its Ethical Dilemmas (London and New York: Taylor and Francis, 2005).

${ }^{11}$ See for example, Lionel March, "The Logic of Design and the question of value," in The Architecture of Form, edited by Lionel March (Cambridge, 1976); Donald Schön, The Reflective Practitioner: How Professional Think in Action (London: Temple Smith, 1983); Peter Rowe, Design Thinking (Cambridge: MIT Press, 1987); Chris Jones, Design Methods, 2nd Edition (New York: Van Nostrand Reinhold, 1992); Stephen A. Brown, Communication in the Design Process (London and New York: Spon Press, 2001); Mike Press and Rachel Cooper, The Design Experience: The Role of Design and Designers in the Twenty-First Century (Aldershot, Hands, England; Burlington, VT: Ashgate, 2003); Simon Urwin, Analysing Architecture, 2nd Edition (London and New York: Routledge, 2003); Klaus Krippendorff, The Semantic Turn: A New Foundation for Design (Boca Raton, London and New York: Taylor and Francis, 2006); Tim Brown and Barry Katz, Change By Design: How Design Thinking Transforms Organizations and Inspires Innovation (New York: Harper Business, 2009); Nigel Cross, Design Thinking (Oxford and New York: Berg, 2011).

12 March, "The Logic of Design," cited in Cross, Design Thinking. As opposed to practices such as science that use analysis to solve problems.

${ }^{13}$ Schön's work is based on 'reflection-in-action' where doing and thinking are complementary. In The Reflective Practitioner, he explains that "competent practitioners usually know more than they can say. They exhibit a kind of knowing in practice, most of which is tacit.... Indeed, practitioners themselves often reveal a capacity for reflection on their intuitive knowing in the midst of action and sometimes use this capacity to cope with the unique, uncertain, and conflicted situations of practice" Schön, The Reflective Practitioner, 8-9, cited by Visser 2010. 
inner-focussed, concerned with what Schumacher claims as "inferred and implicit"14 aspects of practice. In this sense, the practice of architecture is seen at a more local- and internal-scale, inevitably focussing on itself and distinguishing itself as the "unit of analysis." 15 Such early formulations depict architectural practice as, according to Jones, carefully managed and contained, where the architect is at the centre and works towards attaining authenticity. ${ }^{16}$

This section seeks to take an alternative and more contemporary approach by focusing on discussions by architectural scholars that attend to practice as consisting of "contingently assembled durations, velocities, intensities." ${ }^{\prime 17}$ Specifically, this section aligns with architectural writers who tend to question the assumption that architecture is a 'static [and contained] construct' and instead evaluate practices in their messiness, ${ }^{18}$ as Stan Allen puts it, which bring about arguments toward practice as transformative action, ${ }^{19}$ desiring drive, ${ }^{20}$ adaptive intelligence, ${ }^{21}$ and arena of innovation ${ }^{22}$, to name a few perspectives. ${ }^{23}$ Most recently, a collection of essays in The SAGE Handbook of Architectural Theory address practice through an outwardfocused approach. It is beyond the scope of this thesis to provide a thorough account of these diverse contributions, however, albeit in the broadest sense, these works are important in that they expose and tease out preoccupations within practices that drive and move the activities, operations and design processes between different bodies. This thesis seeks to tease out from these contemporary works, by architectural scholars, specific orientations that offer grounds to evaluate and connect architectural practices to recent work on affect.

Importantly, there are two contemporary interests of practice that are interrelated - and are key to rendering affect visible: the attention given to participatory practices and the increasing interest in risk-taking or entrepreneurial practices. To expand further, first, from an operational stance, scholars highlight the 'relational' aspects of architectural practice, looking at different bodies that 'rub up' against each other. What follows attends to two orientations: Jeremy Till's discussion of 'negotiations of hope' and Doina Petrescu's participatory practice driven by desiring bodies. Importantly, this thesis narrows down the focus on these two authors as they attune to

\footnotetext{
${ }^{14}$ Patrik Schumacher, The Autopoiesis of Architecture: The New Agenda for Architecture (West Sussex: John Wiley and Sons, 2012$), 259$. 15 Andrew D. Brown, Martin Kornberger, Stewart Clegg and Chris Carter, “'Invisible Walls' and 'Silent Hierarchies': A Case Study of Power Relations in an Architecture Firm," Human Relations 63, no.4 (2010): 526.

16 Jones, Design Methods.

17 Jacobs and Merriman, "Practicing Architecture," 218.

18 Allen, Practice Architecture, Technique and Representation (London: Routledge, 2000).

19 Jeremy Till, Architecture Depends (Cambridge: MIT Press, 2009).

${ }^{20}$ Doina Petrescu, "Losing Control, Keeping Desire," in Architecture and Participation, edited by Jones Blundell, Doina Petrescu, and Jeremy Till, 43-64 (London and New York: Spon Press, 2005).

21 Michael Speaks, "Design Intelligence and the New Economy," Architectural Record 190, no.1 (Jan 2002): 72-76. See also, Michael Speaks, "Intelligence After Theory," Perspecta 38 (2006):103-106.

22 Peggy Deamer, "Practicing Practice."

23 Others references include Paul-Alan Johnson, The Theory of Architecture: Concepts, Themes, \& Practices (New York: Van Nostrand Reinhold, 1994); Scott Marble, "Imagining Risk," in Building (in) the Future: Recasting Labor in Architecture, edited by Peggy Deamer and Phillip G. Bernstein (Princeton: Princeton Architectural Press, 2010).
} 
find hopes and desires, even in the most banal activities, such as storytelling. Following Till and Petrescu's positions, it is possible to suggest architectural practices as mediating affective relations. Second, beyond the localized, context-specific operations which are described above, contemporary architectural practices are also seen as mediating affective dispersions. It is suggested here, that the affective dispersion of risk (affects of fear) works to preserve the community of bodies (human and non-human) partaking in the design process. While this topic has been recently explored through various authors, this thesis focusses on the work of Scott Marble as he suggests how fear associated with risk in practice can be contributing positive force in the design process. ${ }^{24}$ In identifying these two orientations by architectural scholars, the aim here is not to argue for one of these models of practice as being superior to another, but to weave these together as intersecting orientations of 'practicing' architecture. Central to these particular discussions is the notion that practicing is an encounter between and amongst several things. To consider practice like this acknowledges connections, disruptions, multiple routes and permutations. Affect may provide a ground on and through which we can develop a grasp of how practices cope, manage, explore and negotiate different forces - in its lively architectural processes. ${ }^{25}$

\subsubsection{Mediating Affective Relations}

How does architectural practice mediate affective relations through different bodies that rub up against each other? While there are a number of scholars attending to different relations, this section limits its enquiry to focus on the work of Jeremy Till and Doina Petrescu. Both Till and Petrescu's work, albeit approached from different angles, contributes to an understanding of architectural practice which embraces difference through mediating hopes and desires, respectively. Their focus is on the potential of practice to be adaptive, innovative and orientated towards negotiation and collective connectedness via everyday practices. ${ }^{26}$ It should be clarified

\footnotetext{
${ }^{24}$ It must be noted here how these works on entrepreneurial architectural practices are still in its emergence and hence, the researcher seeks to avoid generalizing these new movements to one particular orientation. For example, there are other works engaged in contemporary practices, notably the current discourse on 'network practices' by scholars including, but not limited to Peggy Deamer and Phillip Bernstein, as well as Anthony Burke and Therese Tierney. See the collection of essays in Anthony Burke and Therese Tierney, eds. Network Practices: New Strategies in Architecture and Design (New York: Princeton Architectural Press, 2007).

${ }^{25}$ While it cannot be expanded here, Pia Ednie-Brown's work is worth noting as she discusses the ways in which architectural production operates in 'affective' and 'processual' dimensions. Ednie-Brown draws attention to how design processes (albeit the examples she uses are experimental/artistic projects) must engage and become sensitive with forces of affects in the "process of formation." She suggests how this focus on process (form as duration) links to the "materiality of affect." The concern of this thesis, however, goes beyond design experimentations, to address the ways in which affect is present within existing architectural practices and design processes. Pia Ednie-Brown, "Falling into the Surface (toward a materiality of affect)," International Journal of Screendance 2 (2012): 99-106.

${ }^{26}$ From a different, more humanitarian perspective, scholars and activists are calling practices to be more 'pro-active' as well as 're-active' - working towards a 'public-interest' practice. This orientation of practice of architecture as part of a larger field/society - is focussed on "community design" and primarily is a practice of architecture that responds to humanitarian and
} 
here that the concern (of this thesis) - is not to define what is 'hope' or 'desire,' or to map the relation between these different kinds of affects. Rather, what follows seeks to examine how hopes and desires, that arouse through the practice of architecture and design processes, pull or move us towards something - in the very articulation (verbal or physical) of what it is that is hoped or desired for. To reiterate, affects such as hope and desire - emerging from participatory practice, produce a kind of power, precisely, an affective one of drawing bodies together to form stronger attachments.

\section{Mediating Hope through Storytelling}

First, Till attends to the process of "transformative participation" where the object-oriented aspect of architectural practice is replaced by what he terms, 'negotiations of hope.' Here, hope is affective matter, opportunistic and accepting difference. Capturing the significance of hope in participatory practices, Till follows architectural scholar John Forester to elaborate a process through which we can approach the everyday, mundane architectural operations, specifically, that of talking - as rich and complex sites of, what is suggested here as, affective connectedness. Till counters the commonly associated notion of a resolution-driven, service-orientated view of architectural practice by introducing his concept of the 'negotiation of hope'. This notion of hope pertains to the opportunities or the 'acceptance of difference ${ }^{27}$ that come about in the practice of opening up the design process to the input and control of others. Specifically, the 'negotiation' consists of, in the most practical sense, a process of "sense-making" -a practice that engages together different parties - architects and users - to 'make best sense' of the design together. ${ }^{28}$ This engagement interjects an exterior force through user input. The user's voice can "actively transform the knowledge of the architect", that is, the architect no-longer making all decisions based on his or her expertise.

Following Forester, Till proposes 'sense-making' as the "matter of altering, respecting, acknowledging, and shaping people's lived worlds. ${ }^{29}$ Such account exemplifies a form of affective relation, encouraging participants to engage with the design process through positive reenforcement which inevitably leads to the process of negotiating multiple opinions and hopes. In a more practical sense, these negotiable scenarios are mediated by, in Till's words, 'ordinary

environmental concerns. See for example, Thomas Fisher, Architectural Design and Ethics - Tools for Survival (Oxford: Architectural Press, 2008).

27 Jeremy Till, "The Negotiation of Hope," in Architecture and Participation, edited by Jones Blundell, Doina Petrescu, and Jeremy Till (London and New York: Spon Press, 2005), 40.

28 Till, "The Negotiation of Hope," 40.

${ }^{29}$ John Forester, "Designing: Making Sense Together in Practical Conversations," Journal of Architectural Education 38, no.3 (1985):

14-20, cited in Till, "The Negotiation of Hope," 36. 
conversation' - or more specifically, storytelling. ${ }^{30}$ Opposed to other forms of architectural communications, mainly conventional architectural drawings, storytelling not only offers immediate engagement, but also, embodies affective power to arouse response. For instance, it is worthwhile to offer Till's example here: "The authoritative positivist explanation of the expert ('You should have your front door here because it is closes to the road') is replaced by the suggestive and imaginative storyline of the potential dweller ('we ran through the back door, steaming bodies into air dense with chip fat $)^{\prime} .{ }^{31}$ Of course, this example may be seen to propose an exaggerated scenario that, to some degree, requires bodies to imagine a fleeting feeling that is highly unreal and dream-like. However, negotiating through such illustrative (and spatially provocative) stories, involves (and allows for) an imaginary encounter with a not-yet realized architecture, activated through motion (running body) and familiar smells. The familiarity and immediacy of storytelling stimulates affective responses that can indeed offer hope towards a particular design agreement and intimacy. As further explored in Chapter 5 through the case study analysis of RUR Architecture PC, the image/image-making is another form of affective site in practices of architecture that can equally be charged with affect and arouse a sense of stickiness towards the design. Of course, as affective sites, the outcome of negotiation may contain "unintended consequences" attending to the contingency of practice. ${ }^{32}$

Following Till's analysis then, it is possible to suggest a kind of attraction and repulsion between bodies taking part in the participatory conversations. But more importantly, through the exhaustive negotiation of differing embodied stories, the practice of architecture is seen here as generator of hope - for example, hope for a new house; for a better life and future; for economic stability; for a change in quality of life - and in so doing, practice acts as mediator of affective relations.

\section{Mediating Desires through Active Engagement}

This links with Petrescu's work, who through her own 'live projects,' highlights participatory design as driven by desires. While practice of 'negotiation of hope' promotes adaptation through engagement of different voices - and thus as an outcome, produce a unified design (through unity of interest), Petrescu (reflecting on her own practice) attends to the co-evolution of design driven by desires, coproduced through the continual participation of her users. ${ }^{33}$ She depicts practice as producing "zones of articulation of intensities, flows and desires" ${ }^{34}$ where different

\footnotetext{
30 Till, "The Negotiation of Hope," 37.

31 Till, "The Negotiation of Hope," 38. Emphasis added.

32 Till, "The Negotiation of Hope."

33 Petrescu, "Losing Control, Keeping Desire," 54.

34 Petrescu, "Losing Control, Keeping Desire," 51.
} 
creative habits/expertise, creative rhythms of work - transverse and are moved by desires. ${ }^{35}$ Important to this thesis, is how desire is illustrated as a 'microscopic' force that can be both collective and individual. This force is, in Petrescu's words, "an agent of change, always 'revolutionary." 36

In her design-in-action practice, desire plays the role of producing creative differences into the activities, operations, design processes and inhabitations. While it must be noted how Petrescu's work draws on theorists such as Deleuze and Guattari to describe such things as the role of desire in practice, it is nevertheless of interest to this thesis as she applies and tests these theoretical positions into real practice. In this sense, Petrescu provides an intellectual engagement with practice, while also embracing the reality of the built environment. The work of ECO-box exemplifies a 'live project' whereby such forces of desire continually alter the architectural design and usages. Actively involving planners, users, as well as objects, such as "recycled pallets",37 design ideas and decisions are both prompted by - and made by- a conglomeration of different desires - or to borrow Petrescu's own words, the "assembl[age] [of] collective economy of desire." ${ }^{38}$ Such an account of practice may appear somewhat withdrawn from the realities of architectural practice ${ }^{39}$ - yet, the ECO-Box practice, albeit experimental, provides grounding to the potential of design, that removes total control of the architect where the architect is but one (and equal in position) of many participating bodies (becoming 'architect-resident' or 'architectuser $^{{ }^{40}}$ ), and allows exercising power to local bodies. The practice of SBA analysed thoroughly in Chapter 8 of this thesis, is another case-in-point. Specifically, the design process for the cardboard paper tubes for Christchurch's Transitional Cathedral is driven by multiple desires from different bodies, notably changing the design of the tube from one that is structural to one that is purely aesthetic. In this context, desires (as affects) become "stimulator of diffused creativity and imaginary production." ${ }^{41}$ Of course, there are more examples of participatory practices, but what is significant about ECO-box project is the focus of complete and live integration. Here, the role of the practice of architecture is, once again, the mediator of the design process $^{42}$ - the architect not only listens or converses (as in Till's example) with the users, but empowers them to imagine, design, build and inhabit the space, giving desire priority over control.

\footnotetext{
35 Petrescu, "Losing Control, Keeping Desire," 49.

36 Petrescu, "Losing Control, Keeping Desire," 46.

37 There recycled pallets which are part of the ECO-BOX practice/project, form "mobile furniture module - [that] act as urban catalysts in the area - [and] generate temporary agencies and form progressive networks of actors." Petrescu, "Losing Control, Keeping Desire," 59.

38 Petrescu, "Losing Control, Keeping Desire," 44.

39 The researcher also questions whether such a model of practice is orientated more towards art practices, instead of practices of architecture.

40 Petrescu, "Losing Control, Keeping Desire," 55.

41 Petrescu, "Losing Control, Keeping Desire," 60.

42 Petrescu, "Losing Control, Keeping Desire," 56.
} 


\section{In Reflection}

The interest in participatory practices, as discussed above, expands our understanding of what the practice of architecture does to allow for inputs by present and future users (as well as other bodies, consultants, construction experts, etc.). Opening practice to these diverse voices, stories, and inhabitations, triggered by- and through- hopes and desires, heightens the degree of creativity to accommodate for difference within a practice's operations. Above all, it is to form bonds connections and permutations through proximity. From a critical angle, these scenarios of participatory practice only seem to tell us part of the story of contemporary practices. To clarify, for both Till and Petrescu, 'participation' still implies a practice that is situated in a particular context, where often, the actions are acted through tendencies that each participant holds. Such perspective also focusses on the production of an object (or objects) - though produced through negotiations and conversations involving multiple bodies - it is nevertheless a model of practice that works towards a specific project, of specific scale and location, where the end is defined as a stage of 'handing off' to the client-(albeit, this may be temporary - such as the case of Eco-box project). ${ }^{43}$ Finally, although driven by conversations and design-in-action that are both openended processes, participatory practices are often formalized and under some form of control, that is, an organized involvement. Yet - and this thesis suggests, even in the organized, structured set-up, there is space for affect to work. While both Till and Petrescu do not use the specific language of 'affect' in their explorations, we see how the regularized forms of participation can indeed attend to and provoke affect - as any participation involves bodies with tendencies to act in a certain way, generating affective intimacies. The following part continues to explore the practice of architecture through architectural scholars, but particularly, it explores architectural practice as more than problem-solving service. Instead, and following Michael Speaks who calls forth practices to orient towards the "unexpected" ${ }^{\text {,4 }}$ - or what he names the 'entrepreneurial' capacity of practice, the discussion seeks to tease out affect within risk-taking ('entrepreneurial') architectural practices, opening practice to "intangible things - ideas, information, and relationships" ${ }^{45}$ to seep in, such as affects of "fear and uncertainty." 46 Here, the

\footnotetext{
${ }^{43}$ Michael Speaks, referencing Gregg Pasquarelli from SHoP, is critical of this form of practice. Speaks directly quotes Pasquarelli and his approach to a new form of architectural practice: "[w]e looked around and none of the existing models of practice were of interest to us. Design had pushed itself into a thinner and thinner, horizontal part of the industry, and we were looking for a more vertical integration of the process, in which design was not just handed-off but was part of an entire approach" Michael Speaks, "Design Intelligence and the New Economy," Architectural Record 190, no. 1 (2002): 74.

${ }^{44}$ Speaks, "Intelligence after Theory," 105.

45 Speaks, "Design Intelligence and the New Economy," 72.

${ }^{46}$ Speaks, "Design Intelligence and the New Economy," 76
} 
discussion evaluates, albeit briefly, the work by Scott Marble who draws attention to the practice of architecture are mediating affective dispersions.

\subsubsection{Mediating Affective Dispersions}

Literature on the practice of architecture and its design process specifically rests upon explorations of strategies and methods towards the avoidance and reduction of risk, which decrease the chance for any change or alteration. ${ }^{47}$ Scholars such as Stephen A. Brown, as well as Karen A. Franck and Teresa von Sommaruga Howard, address how risk and variability is prevented even at the initial stage, where, for instance, clients choose familiar people as their "choice of an architect"; architects adopt strategies such as "repetitive use of same consultants,"48 or re-using previous designs - that is, again, sticking to the familiar. These may tend to be a boring sequence of sameness - however, involving familiarity does not necessarily ensure a riskfree project. ${ }^{49}$

To provide a more specific account of this affective dispersion, what follows will draw on Scott Marble's work on 'Imagining Risk.' Here, risk is enlivened (positively) as an affective force that pursues architectural uniqueness through "non determined" operations. Of course, the common notion is that indeed, risk must be avoided. ${ }^{51}$ An increase in risk increases probability of loss, whether that is of a loss in quality of design, time, or project finance, to name but some. But as Marble points out, risk also holds potential (affirmative) capacity and challenges the predominant notion of affects such as fear linked with risk - as something negative to be overcome. Instead Marble wants to think risk in terms of "a resilience- where innovation occurs ... interpreting and imagining alternative outcomes." ${ }^{2}$ Following Marble it is important to emphasize that as risk is dispersed through the different bodies, it can act as an affective force of attraction and retraction; it can trigger desires to risk suggesting diverse and inventive design, or work against innovation through fear, where the digital takes over, offering certainty but nevertheless predictable design.

Drawing from Marble, the dispersion of risk then could be interpreted to take two forms: first, it exposes (increasing possibility of loss, and thereby fear), and second, it capacitates

\footnotetext{
47 See for example Stephen A. Brown, Communication in the Design Process (London and New York: Spon Press, 2001); Karen A. Franck and Teresa von Sommaruga Howard, Design Through Dialogue: A Guide for Architects and Clients (West Sussex: John Wiley \& Sons, 2010).

48 Brown, Communication in the Design Process, 84.

49 Throughout the process of design, issues of budget are "nearly always a source of anxiety.... The client worries whether there will be enough money to complete the project; the architect worries about realizing the client's dreams while holding responsibility for managing the budget. It is always a sensitive process" Franck and Howard, Design Through Dialogue, 68.

50 Marble, "Imagining Risk," 41.

51 Marble, "Imagining Risk," 41.

52 Marble, "Imagining Risk," 43.
} 
(increases variability of design through imagining). Here risk is taken to be a real force distributed through each contributing assemblage of bodies, human and non-human/things. . Through the dispersion of risk (as force), then, fear and 'imagining' powers moves in many ways: affectively, imaginatively, and collectively. All these movements require the practice of architecture to mediate and regulate the distribution of affects.

\section{In Reflection}

Working through- and in-, risk-taking practices is a turn to practice that valorises flows rather than stasis. This section, albeit briefly, has picked up affective moments of fear that seep in these flows of practice. Beyond the localized, context-specific operations which are described in 3.2.2, contemporary architectural practices are also seen as mediating affective dispersions. That is, the practice of architecture is redefined as a potential site of complex assemblage of bodies, where we may recognize these assemblages as the sharing of affects. It is through these different arrangements of architectural bodies connected through dispersed affects that a community of diverse bodies is able to be preserved. And once again, we are able to attend to the openness of contemporary practices of architecture. By examining affective distributions of- and in- practice, we may see how affects play critical roles in the practice and the making of architecture.

The architectural perspective has offered sites to explore affect in practices - where there is nevertheless a limit to the extent where affect may interact with practice. What if practices of architecture engaged with wider issues that look at how buildings animate and are animated by bodies in the post-construction stage, such as processes of repair and maintenance? Such issues are explored in the following section (3.3) through recent works by geographers through two tinkering-oriented activities - first, tinkering with, and in-space in the post-occupancy stage (through re-design), and second, tinkering with- and through-matter (through re-pair and maintenance). Both these practices trigger and are triggered by affects - which increase, and at times, diminish a body's (occupant, repairer, as well as objects such as trash) power to act and form relations. By examining these practices of affective tinkering, we may see how these backstage activities play critical roles in expanding the practice of architecture, and equally, how such practices may have an effect on theories of affect. 


\subsection{PERSPECTIVES FROM GEOGRAPHY: AFFECTIVE TINKERING'S}

\subsubsection{Geographical Perspective of Architectural Practice: A Background}

The previous section explored propositions by architectural scholars on their practice, noting orientations towards a practice of architecture that is open to 'other' bodies, beyond the architect. As such, it was suggested that architects in practice mediate affective relations and dispersion. While architectural perspectives look at how practices produce 'things' - buildings, systems, formations - through affects, such as hope, desire, and fear, this section turns to the field of geography which engages in how practices re-produce ${ }^{53}$ through informal processes of affective 'tinkering. ${ }^{54}$ It should be clarified that the authors introduced here have not used the term of affect specifically in their works, however, and importantly, there are obvious links to theories of affect (discussed in Chapter 2) where the process of occupying as design reveals an ongoing constitution of affect. Beyond the hand-off/-over stage by the architect, these tinkering activities occur post-construction, and attends to the excess of- (of what is beyond) practice of architecture through a range of bodies - both human and non-human - that come together in re-producing but also, caring for architectural space. This section therefore asks how one might begin to attend and draw out affect - theoretically and practically - through the informal practices of tinkering.

While this thesis engages with tinkering-oriented activities in architectural practices, it is nonetheless important to acknowledge, albeit briefly, the field of geography's preoccupation with informal practices. This is done particularly through an approach, well-articulated by Loretta Lees in her essay, 'Critical geography of architecture,' that calls geographers to engage with built environments more intimately, by evaluating how everyday people animate architectural spaces through occupation. ${ }^{55}$ Connected to this, and as a response to Lees call, there is attention given to "building events," such as by Lloyd Jenkins and Jane M. Jacobs. ${ }^{56}$ Considering building through a

\footnotetext{
${ }^{53}$ It seeks to respond to the call to "rethink... the assumption that once space is built they are simply consumed by residents [and users]" Mark Llewellyn, "Polyvocalism and the public: 'doing' a critical historical geography of architecture," Area 35, no.3 (2003): 269.

${ }^{54}$ The word 'tinkering' - by Graham and Thrift is identified within what they call 'vernacular tinkering' - in contemporary consumption practices. Stephen Graham and Nigel Thrift, "Out of Order: Understanding Repair and Maintenance," Theory, Culture \& Society 24, no.3 (2007): 1-25.

55 Loretta Lees, "Towards a Critical Geography of Architecture: The Case of an Ersatz Colosseum," Cultural Geographies 8, no.1 (2001): 52-86. Specifically, this call has been taken up by Krafl and Adey, "Architecture/Affect/Inhabitation," 213-231. See also the collections of essays in Cultural Turns/Geographical Turns: Perspectives on Cultural Geography, edited by Ian Cook, David Crouch, Simon Naylor, James Ryan (London, Prentice-Hall, 2000). Also, works included in Jonathan Hill, ed., Occupying Arcbitecture, (London, Routledge, 1998).

${ }^{56}$ Lloyd Jenkins, "11, Rue De Conservatoire and the Permeability of Buildings," Space and Culture 5, no.3 (2002): 222-36; Jane M. Jacobs, "A geography of big things," Cultural Geographies 13, no.1 (2006): 1-27.
} 
process of becoming, both Jenkins and Jacobs rethink the practice of architecture as coconstituted through shifting and fluctuating experiences of ourselves and our built environment. ${ }^{57}$

This thesis aligns with these works, but draws on particular architectural geographers, namely, Ayuna Datta, Alex Vasudevan, Tim Edensor and Ignaz Strebel. What is unique to these scholars is an attunement to the smallest, mundane, often neglected and underplayed activities that occur in- and through- buildings. Specifically, the discussion focuses on two tinkeringoriented activities in the post-occupancy stage: first, tinkering with, and in-space (through works by Datta and Vasudaven), and second, tinkering with- and through-matter (through works by Edensor and Strebel). An important aspect of these activities is its involvement of- and close connection between- different bodies (for example, occupants, repairers, architectural materials, as well as objects such as trash). As the discussion in this section suggests, the exposure of the practice of architecture allows an understanding of not only practice's interdependency and vulnerability - but also, and more important, to issues of affective needs, commitments and care (i.e. care for matter), which are the driving forces of tinkering-orientated activates.

To clarify further, this section uses the word 'tinkering' to suggest a kind of loose act between loosely connected bodies, objects, things - trying things out in a playful way, but also, it can suggest an act to improve or repair something, thus having a purpose. In this thesis, tinkering is discussed through the often invisible-, categorized at times as, and borrowing Tim Ingold and Elizabeth Hallam's words, "neglected” and "mundane"58 - or what Christopher Henke calls, 'backstage ${ }^{59}$-practices. The aim is to bring these invisible acts of architectural practice to the forefront, not only as an informal process of interactions, in general, but also to draw out intimacies, or borrowing John Wylie words (following Paul Harrison) "affective bonding" ${ }^{60}$ that are generated by - and through- commitments to- and caring for- architectural spaces.

\footnotetext{
${ }^{57}$ For other examples that address this call for a 'critical geography of architecture' see: Tim Cresswell, "Landscape and the Obliteration of Practice," in Handbook of Cultural Geography, edited by Kay Anderson, Mona Domosh, Steve Pile, and Nigel Thrift, 269-81 (London: Sage, 2003); Paul Harrison, "Making Sense: Embodiment and the Sensibilities of the Everyday," Environment and Planning D: Society and Space 18 (2000): 575-95; John Wylie, "Landscape, Absence and the Geographies of Love," Transactions of the Institute of British Geographers 34, no.3 (2009): 275-289.

${ }^{58}$ Tim Ingold and Elizabeth Hallam, "Creativity and Cultural Improvisation: An Introduction," in Creativity and Cultural Improvisation, edited by Elizabeth Hallam and Tim Ingold, 1-24 (Berg, 2007).

${ }^{59}$ Christopher Henke, “The Mechanics of Workplace Order: Toward a Sociology of Repair,” Berkeley Journal of Sociology 43 (2000): 55-81; cited by Graham Thrift, "Out of order," 8 .

${ }^{60}$ Wylie, "Landscape, Absence and the Geographies of Love," 284. See also Paul Harrison, “The Space Between Us: Opening Remarks on the Concept of Dwelling," Environment and Planning D: Society and Space 25, no.4 (2007): 625-47.
} 


\subsubsection{Tinkering In- And With- Space: Towards Architectural Practices of Need and Spatial Commitment}

Geographers such as Ayona Datta and Alex Vasudevan, are noting the possibility in extending the practice of architecture to include notions of what the built form offers. ${ }^{61}$ Of course, other authors have addressed this issue, with major contributions by Mark Llellewyn and AbdouMaliq Simone. Overlapping these works is the priority given to, as Vasudevan writes, 'creative reappropriation ${ }^{62}$ where, architectural spaces are tinkered with - that is, occupied and 'reproduced' by individuals living there in accordance to their everyday lives. In this sense, a built form provides chances of producing new and "endless possibilities of remaking." highlights two aspects of such remaking of space, namely, first, the tinkering of dwelling in a widow-colony driven by needs, and second, tinkering of architectural space by squatters driven by a sense of commitment. These examples are situations amongst many others, but they are unique ones - as Datta and Vasudevan offer an account of socially differentiated bodies (widows and squatters), encouraging and encouraged by- an active participation in the re-making of modes of dwelling, reformulating new ideas of domesticity. More important, by attending to the everyday, unfixed and unformed tinkering in- and with- space-, we are able to trace how architectural spaces that have been deliberately designed via forms of separation and segregation evolve to become spaces that generate, albeit subtly, positive affective attachment.

\section{Re-Appropriating Dwellings}

First, Ayuna Datta's reflections on a low-income widow housing in Delhi and its tinkeringactivities by the new users, shed light on how architectural spaces, dwellings, to be specific, are produced and reproduced through different forms of needs. ${ }^{64}$ According to Datta, too often, lowincome housing is designed with the presumption of who the users are - forcing preconfigured

\footnotetext{
61 Alex Vasudevan, "Dramaturgies of Dissent: The Spatial Politics of Squatting in Berlin, 1968-," Social \& Cultural Geography 12, no.3 (2011): 293; Ayona Datta, “Architecture of Low-Income Widow Housing: 'Spatial Opportunities' in Madipur, West Delhi," Cultural Geographies 15 (2008): 231-253. From a similar perspective, Mark Llewellyn (2003) considers the ways in which space is 'reproduced' by the "bodily traces of the building's occupants." Through 'polyvocal' narratives on architectural space, Llewellyn calls for a balanced consideration (and value) of bodily traces of building's occupants and original design/planning asserting that "everyday life has a productive capacity." The practice of architecture hence involves "active engagement." Llewellyn, "Polyvocalism and the Public: 'Doing' a Critical Historical Geography of Architecture," 264-270. See also, AbdouMaliq Simone (2005) "Urban Circulation and the Everyday Politics of African Urban Youth: The Case of Douala Cameroon," International Journal of Urban and Regional Research 29 (September 2005): 516-532.

62 Vasudevan, "Dramaturgies of Dissent," 293.

63 AdbouMaliq Simone, For the City yet to Come: Changing African Life in Four Cities (Durham, NC: Duke University Press, 2004), 9; cited by Vasudevan, "Dramaturgies of Dissent," 293.

64 Ayona Datta, “Architecture of Low-Income Widow Housing: 'Spatial Opportunities' in Madipur, West Delhi," Cultural Geographies 15 (2008): 231-253.
} 
spaces through predetermined livelihoods which are often disconnected to the needs of future users. That is, albeit made for habitation, it is not fit for habitation.

Particularly, Datta illustrates how a series of 'spatial opportunities' built into the widow colony are manipulated and seized upon by the new inhabitants (who were not satisfied with the given spatial configuration) - through activities that both creates and responds to shifting needs. Here, needs are a driving force in the tinkering processes, which includes, for example "inserting shuttered windows, grilles, and steel doors" - to respond to a need for privacy ${ }^{65}$; and introducing "concrete floor slabs and solid wooden doors with steel grills" guaranteeing security - a need for solidity. Another tinkering is replacing the previous porous flooring with "solid flooring so that the insects don't come through" of the dwelling space. Through this latter account, we get a sense that in addition to the various needs, to design for privacy and security of domestic space, the interruptions of 'other' bodies generates a need that effectively prompts the inhabitants to tinker with the architecture, making space habitable. ${ }^{67}$ Further, these activities concern not only the tinkering with architectural materialities, but also, the capacity to transgress the pre-determined spatial configurations of domestic life. It involves the re-appropriation of space through creative practices.

Datta illustrates particular cases whereby a dweller turns her front room to a grocery store (as she needs to keep occupied); another uses her balcony as a tuition space (need to make money), while another converts a public courtyard to a social gathering space (need to expand her social life beyond the confines of her home). These cases demonstrate how informal processes of tinkering architectures (in terms of introducing new programs) are driven by- social and economic needs and can be seen as 'politicized practices.' As Datta explains, the process of redesign ('tinkering') in the widow-colony constitutes a force of power that is "translated by the users as they [seek] to remake themselves and their spaces." ${ }^{68}$ This power is affective in that it transforms individual bodies and spaces but also, expands to affect social and collective ways of living. In this context, bodies can be seen to attach to these spaces -as they invest themselves, both materially and emotionally, to them. Here, it is important to note that as a 'colony,' that is, a community of houses, what each inhabitant does to her space outwardly effects those around her (neighbours), even though the one imposing the alteration may be indifferent to the other residents, perhaps even undoing the domestic space of another. For example, the resident who extended her dwelling to the public courtyard space - influences her relationship to her

\footnotetext{
${ }^{65}$ Datta, "Architecture of Low-Income Widow Housing," 242.

${ }^{66}$ Datta, "Architecture of Low-Income Widow Housing," 246.

${ }^{67}$ Considering Graham and Thrift's comment- these practice of redesign "produc[es] gradual but distinctive changes in their layout, skin and appearance" Graham and Thrift, "Out of Order," 8.

68 Datta, "Architecture of Low-Income Widow Housing," 250.
} 
surroundings - which in turn provides ways of reaching out to 'others'. Individual residents circulate their needs amongst each other and draw bodies towards each other. In this very tinkering process - households and livelihoods - are reproduced in new forms of dwelling, socializing and working. Arguably, the widow-colony, built through localized tinkering of space, achieves a sort of social domesticity, connecting individual residents together. Here, affect could be said to inscribe the tinkering operations of re-design as bodies are driven by needs - need for more rooms to accommodate family, need for an extension to amplify social space. And what's more, it is a reminder for the practice of architecture that there are always unpredictable needs by occupants that continues to animate and alter architectural space beyond the hand-over stage by the architect.

\section{Squatting / Convivial Living}

Second, the work of Alex Vasudevan adds to Datta's ideas by exploring 'squatting' as a spatial practice - or more accurately, an experimental 'performance' on, and of- architecture. $\mathrm{He}$ explains the squatting practice through K77 (Kastanienallee 77) described as "a formal squat and now communal housing project" in Berlin. ${ }^{69}$ The discussion which follows does not provide the specific background of this project, but rather, attends to how the convivial living arrangements in K77 is conducted through a double process of social activity and, in Vasudevan's account, "queering the idea of home." ${ }^{70}$ It is thereby both a practical as well as symbolic act. An important aspect of squatter's tinkering-orientated activities is how they operate as a form of disturbance to architecture, but equally, can also move positively through a sense of commitment to the space.

Driven by adaptive improvisation of existing and found building materials, squatting in K77 provides a collective experience of being with others in 'occupied' space- fostering new modes of living together, but also, how to agree together. As recounted by a previous occupant: "Every two years, the inhabitants sort out who wants to live where and in which constellation, so that the usage and interpretation of available spaces is constantly renewed...."71 This renewal of domestic space occurs through informal tinkering activities where architectural elements "wallboards... wall partitions ... light openings ... room connections ... [and] breaks" - are continuously altered, removed, added on, and at times, broken - through negotiations between

\footnotetext{
${ }^{69}$ Vasudevan, "Dramaturgies of Dissent: the Spatial Politics of Squatting in Berlin, 1968-," 294. This is further described by Mathias Heyden (original occupant) as "architecture of self and co-determination [that] questions the right to the design and use of space” Hayden n.d., cited in Vasudevan, "Dramaturgies of Dissent," 297.

${ }^{70}$ Colin McFarlane and Alex Vasudevan, "Informal Infrastructures," in The Routledge Handbook of Motilities, edited by Peter Adey, David Bissell, Kevin Hannam, Peter Merriman and Mimi Sheller (London and New York: Routledge, 2014$), 267$.

71 Mathias Heyden, "Evolving Participatory Design: A Report from Berlin, Reaching Beyond,” Field Journal 2 (2008): 35-36; cited in Vasudevan, "Dramaturgies of Dissent," 298.
} 
bodies. In this way and others, the play of pulling and pushing space concerns not only the material changes, but also, as Vasudevan explains, the capacity to produce "geographies of attachment, dwelling and expression. ${ }^{, 72}$ Thus squatting is a process of attachment, that is a commitment to space, expressed through ambitious acts on space - even at times, shaking architectures, both physically and symbolically. But also, and equally important, acts by space, where the kind of grasp the space has on the squatter - is not necessary positive. Here, the power of affect lies in the capacity of space to be played with through informal tinkering - as one former occupant reflects - "we made theatre."73

As such, Vasudevan is putting forward a performative understanding to informal squatting. What could be suggested is how the playing with space (in creative ways), adds an open-ended account of practice of architecture. That is, practicing involves tinkering activities of freedom to alter architectural space. This freedom is able to, if we are to follow Vasudevan, produce "affective ... geographies" "74; pulling bodies (i.e. squatters) apart in "emotional breakdown" or bringing bodies together through a sense of convivial happiness. ${ }^{75}$ Such opposing forces illustrate the challenge of negotiating multiplicities; the circulation of different spatial gestures and intentions - which demands, to put it simply, bodies to get on together. Tinkering with space, then, involves overcoming (letting-go of) one's individual desire -for the sake of the collective. We can see how squatting, as but one example of a tinkering-orientated activity operates in a double-affective experience, at once unsettling and yet attractive (for the happiness it may provide).

To reiterate, tinkering in- and of- space disturbs normalized ways of domesticity, ${ }^{76}$ but it also evokes bodies, such as ours, to dedicate our time and body to a shared cause, no matter how much opposition there is, or work is required. Of course, some of these alterations evolve naturally through the inhabitant's experience of dwelling, but what Vasudevan's account differs from Datta's, which could be seen as activities of DIY - is the issue of ownership. Squatters have no ownership of the property they are occupying and 'redesigning' and thereby their acts are seen as intruding and encroaching on dwelling spaces. In this sense, the act of tinkering with space carries affective charge and forces us to think new, what Vasudevan (following Ingold) terms, 'dwelling perspectives ${ }^{977}$ that are themselves dependent upon the unpredictable evolution of

\footnotetext{
72 Vasudevan, "Dramaturgies of Dissent," 284-85.

73 Vasudevan, "Dramaturgies of Dissent," 296.

74 Vasudevan, "Dramaturgies of Dissent," 284-85.

75 Vasudevan, "Dramaturgies of Dissent," 296.

76 McFarlane and Vasudevan, "Informal Infrastructures," 267.

77 Tim Ingold, Perceptions of the Environment, Essays on Livelihood, Dwelling, and Skill (London and New York: Routledge, 2000).
} 
spaces. ${ }^{78}$ This leads to an account of architectural practicing that emphasizes social exchange and moving bodies involved in shaking architecture after-production.

\section{In Reflection}

While the thesis does not wish to force some sort of consistency across the two examples discussed above (widow-colony and squatting) it is interesting that the theme of reformulating domesticity through affective tinkering emerge as a common theme. But also, and possibly more importantly, the exposure of such practices of tinkering space also addresses practice's interdependency and vulnerability. Indeed, new users and squatters shake architecture. ${ }^{79}$ But simultaneously, architecture, specifically its interior, can trigger - intensify/amplify - people's needs and commitments to the space. In this sense, the practice of architecture is perhaps more complex than the process of conception, design, and construction where there is tendency to treat "buildings as neutral entities." ${ }^{80}$ Instead, geographers are calling towards a practice of architecture that explores wider issues that look at how buildings animate and are animated by bodies.

Indeed, it should be noted here that there are works by architects as well as architectural scholars that are equally engaged in- and highlight architecture as vulnerable and weak, and similarly explore the dynamic dimensions of architectural practice. ${ }^{81}$ There is also a contemporary focus by architects engaging in post-occupancy discourse, primarily exploring the effect of 'green buildings' for occupancy satisfaction as well as user performance. ${ }^{82}$ In this context, the current nature of discussions around post-occupancy evaluations diverges between social geographers

\footnotetext{
78 Vasudevan, “Dramaturgies of Dissent,” 297.

79 The term 'shake' or more precisely, 'shaking architecture' is used by Mark Wigley in his work, The Architecture of Deconstruction: Derrida's Haunt. As he writes "architecture is always trembling, that its very stability is but an effect of the repression of the uncontrollable movements in its foundation, the movements that found it" Mark Wigley, The Architecture of Deconstruction: Derrida's Haunt (London: MIT Press, 1995), 55.

${ }^{80}$ Lloyd Jenkins, "Geography and Architecture: 11, Rue du Conservatoire and the Permeability of Buildings," Space and Culture 5, no. 3 (2002): 234.

81 See for example architect and architectural scholar Mark Wigley's work, The Architecture of Deconstruction, but also more recent works by Stan Allen and Peggy Deamer. Additionally, Dutch architect Lars Spuybroek, in his work "The Architecture of Variation" presents practice not as a contained entity but as operating systems. In this context, Spuybroek explores outward focussed and dispersed forms of architectural practices. One particular 'turn' is perhaps worth mentioning - that of variable practices or as Lars Spuybroek describes it, practice's that are "mov[ing] design away from the production of single objects to the wider scope of a possible range of objects" Lars Spuybroek, "Foreword: Research \& Design," in Research \& Design: The Architecture of V ariation, edited by Lars Spuybroek (London: Thames and Hudson, 2009), 7. Here, each object is a system, and each system is a "set of variables." Spuybroek, "Foreword: Research \& Design,” 7. The term 'variability' together with 'architecture' is used by Spuybroek and the collection of essays within his book Architecture of Variation. According to Ali Rahim "such variable practices operate across different scales and contexts: from the molecular scale of materials to that of the human body; from the dimensions of a building to those of a city" Ali Rahim, "Uniformity and Variability in Architectural Practice," in Research \& Design: The Architecture of Variation, edited by Lars Spuybroek (London: Thames and Hudson, 2009), 41. As scale-less formations, it holds capacity of combining with and interacting with other systems. This offers an alternative way of practicing architecture - where form is the assemblage of variables and such assemblage is capable of linking individual systems to form larger assemblages. It is a process of "discovering relationships and techniques that are not yet known" Rahim, "Uniformity and Variability," 42. Such works shift the orientation of practices of architecture towards generating systems, as opposed to a form (building).

${ }^{82}$ See for example, Brian W. Edwards and Emanuele Naboni, Green Buildings Pay: Design, Productivity and Ecology, Third Edition (Abingdon: Routledge, 2013).
} 
and architects. Importantly, the focus on geographers is useful for this thesis as they illustrate actual practicing architectures that occur after construction and post-occupancy. These practicing activities, albeit small tinkering actions that may go unnoticed, are also, to use Thrift's words, "part of the hum of everyday life," $" 33$ and by extension, everyday practicing architectures.

On a critical note - studies focussing on the 're-productive capacity' (through tinkering space/redesign) remains to some degree human-centred. It is what people, like us, actively do to architectural spaces. But what of other-bodies? Or what Jacobs and Merriman address as nonhuman, material, immaterial, discursive, "intensities and flows of architectural assemblages." 84 The next part seeks to address this stronger through the material and immaterial assemblages the hold buildings together - which aids in continuing the practice of architecture beyond the handover stage.

\subsubsection{Tinkering With- And Through- Matter ${ }^{85}$ : Towards Architectural Practices of Care}

The second part focuses on processes of tinkering with- and through-matter - which reflects another recurrent feature within the recent scholarship of geography - focussing on practices of 'maintenance and repair.' While authors like Graham and Thrift, as well as works by Ingold and Hallam, and Christopher Henke contribute to these processes, they are, albeit generally, explored within a more urban context. ${ }^{86}$ This thesis draws on geographers who take up the task of articulating more minor forms of repair - involving local actors. Specifically, Edensor and Strebel explore practices of repair and maintenance by tracing the force of wear of material matter (stony-matter), and the force of tear of building matter, respectively. Both processes attend to bodies and objects as connections needing to be maintained and cared for - where care have capacity to reshape and cultivate new affective relations. In this sense, care is both affective value and practice. These tinkering practices of care - offers hope for rethinking in more fruitful ways

\footnotetext{
83 Thrift, Non-Representational Theory, 93. To clarify, Thrift uses the word 'hum' in the context of urban city conditions. His full quote reads: "Small bits of hardware and software are now part of the hum of everyday life, working away silently on their calculations in all manner of unexpected locations."

${ }^{84}$ Jacobs and Merriman, "Practicing Architecture," 218.

85 This part responds to the call by Latham and McCormack that there is a "need to pay a lot more attention to the work of maintenance and repair," practices that indeed works towards the sustaining of architecture. Alan Latham and Derek P. McCormack, "Globalizations big and small: note on urban studies or Network Theory, and geographical scale," in Urban Assemblages: How Actor-Network Theory Changes Urban Studies (New York: Routledge, 2010), 65.

86 See for example the collection of essays edited in Jacobs and Merriman, "Practicing Architecture," 212. Also, see for example, Graham and Thrift, "Out of Order: Understanding Repair and Maintenance," 1-25; Monica Degen, Gillian Rose and Begum Basdas, "Bodies and Everyday Practices in Designed Urban Environments," Science Studies: An Interdisciplinary Journal for Science and Technology Studies 23, no.2 (2010): 60-76; Ignaz Strebel, “The Living Building: Towards a Geography of Maintenance Work,” Social and Cultural Geography 12, no.3 (2011): 241. Other studies of repair and maintenance are explored in, for example: Christopher R. Henke, "The Mechanics of Workplace Order: Toward a Sociology of Repair," Berkeley Journal of Sociology 43 (2000): 55-81; Susan Leigh-Star, "The Ethnography of Infrastructure," American Behavioural Scientist 43, no.3 (1999): 377-91.
} 
how practices of architecture could encompass how we take care of architectural space and things (in better ways).

\section{Caring for Stone-Matter}

First, Edensor traces 'stony-matter,' particularly the sand-stones used for St. Ann's church in Manchester, as a micro-geography that requires tinkering processes of repair and maintenance. ${ }^{87}$ The force of wear on stone is described by Edensor as the effects of non-human agencies "biofilms salt, weather, air quality, agencies of birds, bats rodents, insects, moss, [and] fungus" that generate eventual decay. ${ }^{88}$ These effects make clear how the process of wearing away is not an isolated act- but rather involves multiple unseen bodies - and can be, as Edensor describes, "accidental, contingent, and situational." ${ }^{\circ 9}$ Here, the materiality of stone is affected by external/foreign forces, and its impact, communicated through the progressive deterioration of stone-matter, calls for a response. Thus, to combat these forces, a process of care is needed through practices of cleansing, consisting of "brushing, rubbing, washing, steaming...” but also, albeit through more recent technologies, practices of 'sandblasting. ${ }^{90}$ Following Edensor, this latter tinkering process, however, is seen to threaten the destruction of the sand-stone's surface, as sandblasting produces “indentations and a blunting of detail.” Therefore, cleansing St.Ann's stones demands a more "careful hand-rubbing" process. ${ }^{91}$ In this sense, the practice of care is, literally, being-in-touch with the materiality of stone. This pays attention to the connections and interaction of objects - putting agency into matter (stony-matter). What is more, the acts of tinkering matter translate into positive or negative traces on the stone itself - leaving impressions on its surface.

Moreover, the re-pair of 'stony-matter' generates connections that go beyond material matters. Caring through tinkering draws together local bodies of suppliers, stone quarries, technical expertise, transporters and labourers. This generates supply chains where often these connections are "intermittent, volatile and variable" 92 but are nevertheless held together through a feeling of concern/interest for the matter (of stone). ${ }^{93}$ For tinkering to occur, then, requires making connections - with the 'right' caring bodies - (stone-supplying sites), that is prioritizing

\footnotetext{
${ }^{87}$ Tim Edensor, “Entangles Agencies, Material Networks and Repair in a Building Assemblage: The Mutable Stone of St. Ann's Church, Manchester," Transactions of the Institute of British Geographers 36, no.2 (2011): 242-243.

88 Edensor, "Entangles Agencies," 249.

${ }^{89}$ Edensor, "Entangles Agencies," 243.

90 Edensor, "Entangles Agencies," 246-248.

${ }^{91}$ Edensor, "Entangles Agencies," 247.

92 Edensor, "Entangles Agencies," 244.

${ }^{93}$ As Edensor, following Bruce Braun puts it: "[t] hese stone supply networks through which places and materialities are entangled vary in their stability, involving 'tangled webs of different length, density and duration"' Bruce Braun, "Environmental Issues, Global Natures in the Space of Assemblages," Progress in Human Geography 30 (2006): 644. Cited in Edensor, "Entangles Agencies," 245.
} 
relations that have a caring approach to matter. ${ }^{94}$ In this context, the necessary successive repairs of St. Ann's stones depend on the supply chain, which evolve. ${ }^{95}$ With the passing of time, new connections of local bodies emerge. This variability of stone-supply networks - directly affect the more aesthetic values of the stone (which also require care). Edensor accounts, "the variegated building [of St Ann's] stands out from its monochrome neighbours, and this multi-coloured appearance has only increased because subsequent repairs have involved a still greater diversity of supplementary stone. ${ }^{, 96}$ What this passage makes clear is how St. Ann's 'stony-matter' is now a kind of patchwork - or "a mosaic of various sandstones" - with stones that have come from various locations (quarries) of supply. ${ }^{97}$ Different stones from different quarries converge upon one-another, forging varying and new capacities to fend off the non-human bodies that attack them. This also addresses how tinkering practices of care for the stone consists of not only cleansing but also preserving its aesthetic and affective value, through what Edensor terms, "cosmetic maintenance." "The latter involves a careful consideration of 'colour matching' describing how people may feel or experience these stones, is dependent on how it 'looks'. In this sense, exploring the continual careful upkeep and care of stone-matter - opens architectural practice "to valorize the 'sensate'; that which is felt, experienced, senses."'99 Affective care (of matter) evolves through different configurations of objects, technologies and bodies - where these come together and are involved in fending off everyday wear of matter (such as stone). ${ }^{100}$ Here, the discussion moves from stone-matter to the matter of buildings.

\section{Caring for Buildings}

The practice of architecture is further entangled by interventions of "maintenance workers" human/mobile bodies - manoeuvring through 'other' architectural assemblages. Ignaz Strebel explores important ways in which all buildings hold together as the materialized assemblages we call architecture. Specifically, he analyses "what people do with objects, tools and technologies"101

\footnotetext{
${ }^{94}$ Kirsten Simonsen writes that these actors/agents are recognized as "friendly and/or strange," where at times, the 'strange' thing (body) is 'affectively marked' as 'different', causing "merging's, clashes and interferences" between different bodies - where there are outcomes of "multiple becomings" of affective resonances. Kirsten Simonsen, "Practice, Spatiality and Embodied Emotions: An Outline of a Geography of Practice," Human Affairs 17 (2007): 168-181.

${ }^{95}$ Edensor further explains: "Moreover, material elements from elsewhere are affected by agencies that circulate around the situated assemblage to which they have been imported" Edensor, "Entangles Agencies," 249.

${ }^{96}$ Edensor, "Entangles Agencies," 245.

${ }^{97}$ In this context, the "ongoing (re)constitution of buildings can depend upon making connections with stone-supplying sites... [where] things are thus brought into new and often unpredictable relations with different agencies, many of which may come from outside an assemblage or network to catalyse a material emergence" Edensor, "Entangles Agencies," 249.

${ }^{98}$ Edensor, "Entangled Agencies,"248.

${ }^{99}$ Harrison, "Making Sense: Embodiment and the Sensibilities of the Everyday," 498.

${ }^{100}$ It is worth noting here that Edensor himself uses the term 'affect' - or more correctly, 'affected' - however, this is more in the context of the stone as having the property and capacity to affect and be affected by other matters, rather than in the context of caring practices - for the stone.

101 Strebel, "The Living Building," 249.
} 
during a block-check at Red Road's high rise building. According to Strebel, the activity of 'block-check' is by nature "systematic," 102 but is also largely dependent on the worker's "ability to assemble, localise and distinguish particular parts of a building in the repetitive environment of ... architectural form." ${ }^{\prime 103}$ In this sense, it orientates towards more informal activities rather than as automated, regularized course of actions. ${ }^{104}$ The practice of block-check, then, consists of a multitude of small tinkering's: "Walk[ing] through doors, around corners, down the stairs, ${ }^{, 105}$ climbing over, passing by or ignoring certain objects. The worker navigating the building can never be sure what he/she will encounter - continually facing disruptive forces through locked doors, blockages, leakages, and slips, to name but some examples.

Importantly, the negotiating relationship between different objects - such as "bulky things ... graffiti on walls, broken cupboards and doors ... traces of ... incidents" and even, small amounts of rubbish, are often the cause of frustration. ${ }^{106}$ As Strebel describes, "the successive scenes of interruptions, troubles and disturbances ... derange and disrupt the routine walk" of the practice. ${ }^{107}$ Frustration here is formed (and transformed and negotiated) through the intertwining of the 'body' of the worker, the moving materiality, and the object (localized and fixed materiality- pushing bodies' away but also prompting them to act, or stop acting. Frustration can diminish a body's capacity to act - even distancing the worker from the object. The frustrations articulated, however, have a particular quality - a sense of care: a small pool of water on the floor, for example, may halt the routine walk - as the worker must assess the problem (symptom) and subsequently find the cause (localization of its origin) - in this case, an “ill-fitting window." 108 This assembling/linking process of 'symptom' to 'cause' -at times halts the practice of block-check momentarily and changes the worker's pace. ${ }^{109}$

We can see here the connection between building objects (material-matter) that the worker encounters, and the practice of assemblage (by working-bodies) as being unstable, indeterminate and often, unexpected. Here, a sense of care is forged from the very instability of the building's compositions - 'block-check' and its ways of tinkering with- and through- objects provide a site for affective connectedness - and commitment to the building. From this perspective, to be involved in buildings encompasses more than dwelling or working in it (passively); it is also to actively take care of it.

\footnotetext{
102 Strebel, "The Living Building," 243.

103 Strebel, "The Living Building," 256.

104 Strebel, "The Living Building," 253.

105 Strebel, "The Living Building," 253.

106 Strebel, "The Living Building," 258.

107 Strebel, "The Living Building," 259.

108 Strebel, "The Living Building," 258.

109 Strebel, "The Living Building," 256.
} 


\section{In Reflection}

The understanding both Edensor and Strebel offer is one which concerns the potential of the body to act on-, with- and through- matter (stone-matter and built-matter) in terms of practices of care. Here, we find an explicit attempt to replace a treatment of the building as finished form with a caring understanding that building's (and the matter's that compose it) indeed need ongoing maintenance and repair. Matter and buildings are understood through the potential combination it can enter into with other bodies, and the affects it can produce -through necessary tinkering activities. Geographers, such as Edensor and Strebel, explore how small things that can happen while caring (i.e. tripping over objects, falling over, making mistakes) can open the practice of architecture to account for loose systems in the post-occupancy stage that are "prone to error and neglect and breakage and failure." ${ }^{\prime 10}$ This calls architectural practices not only to adequately assess bodies' (human and non-human) actions towards buildings, matters and objects - but also to evaluate how building's after construction may, in Strebel's words, 'gain momentum, ${ }^{111}$ (be affected) and thus act back (affect) on us. What this thesis wants to take from these accounts is how the act of tinkering matters, walking through and around "material assemblages," driven by a sense of affective care is an embodied architecture practice, where human and material elements negotiate (by affecting and being affected) towards the on-going emergence of architecture. ${ }^{112}$ Importantly, this thesis takes these discussions and extends them into exploring the design process of architectural projects.

\subsection{CONCLUDING DISCUSSION}

This chapter has explored how architectural and theoretical relations can be drawn out when architectural practices, specifically, practices as explored in theoretical discourse, are viewed through the lens of affect. It brought together current investigations of the practice of architecture, particularly from the discipline of architecture and geography. The first section (3.2) explored perspectives offered by architectural scholars by attending to how architects mediate affective relations that rub up against each other and how they mediate affective dispersions. By teasing out affect in these works, both these aspects provide a ground on- and through- which practices develop more porosity and openness, but also works to preserve communities of bodies.

\footnotetext{
110 Graham and Thrift, "Out of Order," 5.

111 Strebel, "The Living Building," 259.

112 Edensor, "Entangled Agencies," 240.
} 
Of course, there appears to be a gap between these two specific orientations given by architectural scholars - that is, a gap between the localized/integrative and globalized/dispersed focussed architectural practices, the former concentrated on affects commingled, the latter, dispersed. However, in exploring recent architectural discourse on its practice, the primary aim for this section has been to question the often assumed notion of a contained, 'static' practice of architecture. By removing this hold of autonomy, the above discussions have introduced orientations towards practice that explore how everyday patterns of operations, processes, engagements - are involved in the intensification of affect. In this sense, the language of affect, while not used directly by the authors presented in this section, is arguably, attractive to architectural scholars and discourse on practice, precisely because it delivers currents of openness and fluidity into practice - but also, equally, affirms the value of practice (and practitioners) through its role of mediation - thereby retaining some form of power and value of autonomy.

The second section of this chapter (3.3) examined several orientations and perspectives of architectural practice offered by geographers. These trajectories looked at the various 'practicing' of architectures, where they expose the build environment as continually reconstructed, reoccupied, repaired and cared for, through tinkering-oriented activities. Particularly, section 3.3 explored acts of 1) tinkering in- and with- space, and 2) tinkering of material matter. The discussions focussed on small but specific examples of such tinkering activities - all grounded in specific locations and contexts. Specifically, the above ideas have at least three implications.

The first one is that architectural practice involves often small, boring and mundane activities that take place after-production stage. Paying attention to such small stories and events, or what Kraftl and Adey describe as "the nitty-gritty, material, localized details" however, is crucial in two ways. First, these small tinkering activities can actively charge material environments with affect (through needs, commitments, caring), but also, and second, such explorations bring to address the vulnerability of practices of architecture. As such, we should not underestimate the backstage, messy tinkering's that occur in day-to-day lives of buildings - as they can alter our own and the building's rhythms of life.

Second, these ideas imply that geographers are projecting practices to open outwards and beyond- to account for buildings as always becoming. This sort of openness of what goes on in buildings allows architectural practices to be thought anew in terms of embracing freedom: freedom to tinker in- and with- space, to tinker with and through- matter. The examples discussed in this section hopes to show how buildings can become sites of practicing architecture itself - where needs, commitments and cares can move in affective ways. Following from this,

\footnotetext{
113 Kraftl and Adey, “Architecture/Affect/Inhabitation,” 228.
} 
and drawing from geographers, the next chapter (chapter 4) extends such analysis of small moves, small alterations, and small caring activities, to address the small stuttering temporalities of architectural practice. As it is important to focus on the mundane activities, this thesis suggests that is it also important to explore the gap in-between these larger events and activities through different temporal relations (present and future) when looking at architecture, affect, and architectural practice. Importantly, while the small tinkering acts discussed in this chapter are largely orientated towards actions that occur in the occupation phase (that is, after design is completed), it is proposed, through the case studies in this thesis, how different tinkering activities also occur in the design process itself - and is thereby of interest to the current study of architectural practices.

Third, the geographers' perspective relocates our understanding of practice from an architectural perspective focussed on the role of the architect - as a mediator of relations and dispersions (of processes that occur before and up until -production), to an understanding of how architecture is continually and communally being made - and cared for. Through 'practicing' - rather than 'practice' - accounts by geographers amplify 'other' bodies (human and nonhuman) that come together through ordinary everyday tinkering activities. This is extended in this thesis to relate to design practice and process. It is in the discontinuities, thresholds and limits of these sticky relations where we may draw out affects - in different forms and intensities.

The next chapter looks at the practice of architecture through various temporal relations. Indeed, time of architecture has been explored by architects and architectural theorists. However, the chapter draws specifically on geographers who are attending to time of architectural practice. Particularly, it draws out two forms of temporalities: firstly, stilled stutters, and secondly, quickened stutters. It is at the turning points of these interplays where affects are triggered. These two affective plays do not attempt to cover all that goes on in practicing architecture's. Rather, Chapter 4 attends to views that might enable us to see how architectural bodies, things, activities and processes, hold together in affective temporal oscillations - and how these come to have real effects in the practice of architecture. Chapter 4 thereby acts as a bridge between theoretical attachments of affect and practice in regards to both the architects and geographers and the more grounded and practical attachments that will be drawn out in the subsequent three case study architectural practices (Chapter 5, 6, 7). 


\section{4.}

\section{Theory: Affect, Architectural Practice and Time}

\subsection{INTRODUCTION}

The previous chapter (Chapter 3) explored architectural scholars as well as geographers, respectively, who have come close to linking architecture, affect and architectural practice - but not linking all three. Exposing the everyday forces/capacities by which the building as process is continually being constructed, it attended to notions of practice as mediating relations and dispersions, and engaged in different forms of affective tinkering, namely tinkering in- and withspace, and tinkering with-and through- matter. The chapter aimed to draw out and connect together different instances within the arguments to make the links of architecture, affect and architectural practice, clearer. In this sense, while the language of affect was not always used directly by the authors, the chapter made suggestions of the usefulness of thinking through affect, precisely as the research makes people aware of what already exists to challenge how we define architecture by attending to currents of openness and fluidity of practices.

Chapter 4 aims to explore these links further, by bringing in temporal characteristics of affect - in terms of affective oscillations between forms and intensities of stutters. Discussions on time of architecture have been extensive in architectural discourse, with contributions from architectural writers, most notably architectural historian Sigfried Giedion. ${ }^{1}$ Moreover, recent writings address time of architectural practice, explored by architects and writers such as Jeremy Till. ${ }^{2}$ These works develop an argument of time and architecture that helps provide grounding from which to propose an account for time of affect in architectural practice. In this chapter, the intention is less to create a thorough outline of affect's temporality than to suggest a few proximities between architecture, affect and architectural practice through some temporal relations to which geographers are alluding to. As discussed in Chapter 3.3, geographers such as Datta, Vasudevan, Edensor and Strebel are looking at extending the present to a series of small acts. Such appreciations of the small tinkering activities that occur in practicing of architecture are indeed instrumental in attending to the various affective states that often go unnoticed, particularly through a sense of spatial commitment and care. However, and this chapter suggests, architectural practice has much to do with the active moments as it does with the inactive temporalities. It is the movement between these two temporalities (activity and inactivity) - not as opposition, but in interplay - where there is a kind of stuttering - an inability to settle on one

\footnotetext{
${ }^{1}$ Sigfried Giedion, Space, Time and Architecture: The Growth of a New Tradition (Cambridge: Harvard University Press, 1952). ${ }^{2}$ Jeremy Till, Architecture Depends (Cambridge, MIT Press, 2009).
} 
side or the other. In this sense, this chapter proposes to shift our thinking of the connection between architecture, affect and architectural practice to consider time, and asks, what can stuttering temporalities (times of stillness and quickening) tell us about the relation and link between affect and architectural practice?

In particular, this chapter proceeds in five sections. Following this introduction, section 4.2 reviews the connection between time and architecture as well as practice and time offered by historical accounts. Importantly, this chapter takes these discourses further, by looking at the time of architectural practices, through the notion of stuttering. This section will conclude by offering a brief exploration of the term 'stutter' as it will be used throughout the chapter, with reference to Deleuze's work on 'stuttering' that has been taken up by architectural writing and other allied disciplines. With this background, section 4.3 discusses stilled stutters that slows the present in practices of architecture; a present characterized by a looming/pending sense of "not yet become." ${ }^{3}$ And in 4.4, it explores quickened stutters which accelerate the move towards the future; a future characterized through a mode of the beyond (its not-yetness). If we are to follow Ahmed, these latter two sections (4.3 and 4.4) seek to discover what occurs in the "now to the not yet" of practices. In concluding (4.5), the chapter considers how the practice of architecture operates in the affective oscillation between the stilled and quickened stutters. Indeed, when looking at architecture, affect and architectural practice, different temporal relations emerge that can serve to drive us toward movement (expansion in affectability), or conversely, suspend us (sustained state of affective relation), and even overwhelm us (burst of affective acceleration). The position of this chapter, and this thesis, is an urge not to separate these two forms of stutters but to see how they pull together through affect's stickiness. Finally, this chapter provides a framework in which the case studies of this thesis will be analysed. Looking at the time of practice through the different and yet interlinked temporal and affective relations (past, extended present and future) offers a way to navigate how affect seeps through the stutters and inherently unstable moments in practices of architecture.

\subsection{ARCHITECTURE, ARCHITECTURAL PRACTICE and TIME}

This section seeks to review notable works in architectural discourse, but also practice theory, in order to establish an understanding of the temporality of architecture (architecture and time), and subsequently, the temporality of practice (practice and time). The purpose of this review is to

\footnotetext{
3 The term 'not yet become' is used by Ben Anderson (who cites Ernst Bloch 1986) in describing the temporality of boredom. See Ben Anderson, "Time-stilled Space-slowed: How Boredom Matter," Geoforum 35 (2004): 739-754. Also, see Ernst Bloch, The Principle of Hope (vols. 2-3), translated by Neville Plaice, Stephen Plaice and Paul Knight (Blackwell: Oxford, 1986).

${ }^{4}$ Sara Ahmed, "This Other and Other Others," Economy and Society 31, no.4 (2002): 562.
} 
provide a background from which to extend the inquiry, particularly for this chapter, to account for time of affect in architectural practice. This section concludes with an explanation of the term 'stuttering' that will be used to illustrate the different temporalities of architectural practice.

\subsubsection{Background on Architecture and Time}

Discussions of time in architecture have had substantive accounts in architectural discourse.

While this thesis does not have the space to elaborate in detail what these works involve, it is worth reviewing some key texts that are still influential in contemporary discussions of architecture. ${ }^{5}$ Architectural historian Sigfried Giedion, for example, identified in his work Space, Time and Architecture how approaches to understanding time and space in the past (specifically, in analysing Baroque architecture) tend to be characterized both as stable - time was continuous and space was stable and confined by its physical boundaries - and a closed system. ${ }^{6}$ Significantly, time and space were considered independent of each other. Critical of such position, Giedion's work suggests a new articulation of the temporality of space, where time and space are entangled together through motion. This concern with what Giedion terms "space-time" (referring to Hermann Minkowski $)^{7}$ became one of fragmentation of any stability of time and space structures, towards upholding an open and a freer connection between time and architecture/space.

Particularly interested in the entanglement of architecture and the arts in early 20th Century, Giedion reflects on Cubism as a movement which brought about a "new conception of space lead[ing] to a self-conscious enlargement of the ways of perceiving space." ${ }^{8}$ For example, the work by artist Marcel Duchamp, integrates aspects of space and time specifically by capturing motion of the body. With a critical tone towards Giedion's position, Ignasi de Solà-Morales describes a contemporary time through what he refers as "a diffracted explosion in which there is no unique and single time ... instead various times." In this context, "Weak Architecture," as he titles his essay, has a temporality whereby time "does not present itself as a system but as an aleatory instant that, responding above all to chance, is produced in an unforeseeable place and moment." ${ }^{\prime 10}$ It is clear from de Solà-Morales' statement that weak architecture prioritizes the fluidity of time-space in real experiences and events.

\footnotetext{
${ }^{5}$ While it cannot be expanded here, Italo Calvino's Invisible Cities proposes an imaginative time-frame to envision architectural spaces, more precisely, cities - and is an influential text in architectural discourse. See Italo Calvino, Invisible Cities, translated by William Weaver (New York and London: Harcourt Brace Jovanovich, 1974).

6 Giedion, Space, Time and Architecture: The Growth of a New Tradition, 1952.

${ }^{7}$ Minkowksi (1908) writes: "Henceforth, space alone or time alone is doomed to fade into a mere shadow: only a kind of union of both will preserve their existence". Quoted in Giedion, Space, Time and Architecture, 376.

${ }^{8}$ Giedion, Space, Time and Architecture, 368.

9 Ignasi de Solà-Morales, "Weak Architecture," in Architecture Theory Since 1968, edited by Michael K. Hays. 616-623 (Cambridge: MIT Press, 2002), 621.

10 Solà-Morales, "Weak Architecture," 622.
} 
A number of scholars have also drawn attention to contemporary time and its effect on architecture. For instance, Peter Zellner in his work Hybrid Space: New Forms in Digital Architecture reflects on the influence of advancement in digital technology, as he writes, "[ $[\mathrm{t}]$ he globalized liquid 'soft architectures' of digital media flow over, under and through the local, concrete and 'hard architectures' of our contemporary cities, creating an intermediate, 'floating' environment, an interface between public and private, collective and subjective, provincial and planetary." this sense, there is blurring of architectural spaces that used to be distinct physical qualities, and moreover, the emergence of timelessness of architecture. This attends to what Paul Virilio argues as uncertainty of physical environments, or as he quotes Nikolai Gogol in his text The Third Interval: "Without even leaving, we are already no longer there." ${ }^{12}$ Virilio further argues his concern with the speed of contemporary bodies and cities, where "instantaneous transmission" and intensive time, that is, "real-time of immediacy and ubiquity" overpowers/deprives 'real space' of architecture. ${ }^{13}$

More recently, Jeremy Till in his book Architecture Depends describes the time of architecture through more grounded and practical terms. According to Till, 'thick' temporality, as he proposes, is to think through architecture as "situated in" time. That is, time is always part of the "life of the buildings, bringing with it the forces of entropy, use, and change." 14 Important to Till's argument is how entropy, in contrast to the other two forces (use and change) is due to uncertain and unexpected weathering conditions, and is therefore outside the architect's control. Nevertheless, Till proposes that in fact, the force of entropy can be engaged with. As in artist Robert Smithson's case and his Spiral Jetty, his collaborative stance with entropy has offered continuity of the jetty's existence - as it disappears and appears again over time. Till brings this into architectural context, where "[e]ntropic time is seen not as an affront, but as a partner in a process of design." ${ }^{\prime 15}$ Such position begins to consider time in practices of architecture. This insight into the temporality of practice is expanded on below.

\subsubsection{Background on Practice and Time}

The idea of practice as connected with temporality is hardly a new one. Pierre Bourdieu, for instance, argues in his text The Logic of Practice how "[p]ractice unfolds in time ... [i]ts temporal structure, that is, its rhythm, its tempo, and above all its directionality, is constitutive of its

\footnotetext{
11 Peter Zellner, Hybrid Space: New Forms in Digital Architecture (London: Thames \& Hudson, 1999), 9.

12 Paul Virilio, "The Third Interval," in Open Sky, 9-21 (New York: Verso, 1997), 9.

13 Virilio, "The Third Interval," 13-20.

14 Till, Architecture Depends, 104.

15 Till, Architecture Depends, 106.
} 
meaning." ${ }^{16}$ While this thesis does not attend to Bourdieu's perspective in length, for the purpose of this chapter, it is important to note the action of practice, for Bourdieu, extends and flows in time, characterized through a sense of direction; practice then, moves forward towards what is yet to come, and is future-orientated. ${ }^{17}$ Of course, other works, namely Michel De Certeau's The Practice of Everyday Life also stresses a related point as he illustrates the movement of practice through 'trajectories', which in his words imply a "temporal movement through space."18 More recently, Kerstin Simonsen exploring geographies of practice looks at practice not as "isolated, intentional acts, but rather as continuous flows of conduct." ${ }^{\text {19 }}$ These forward orientated perspectives of the temporality of practice suggest the actions of practice are in a forward rush, where time continually presses forward.

More specific to the practice of architecture, and referring again to Till's work, he breaks down the design process into different stages - such as 'drawing time' - illustrating architectural production through "communicative stages." ${ }^{20}$ In this sense, Till's discussion sees practice as an "open framework that can accommodate the multiple action of time." Indeed, the process of architecture is contingent and fluctuating through contributing forces by architects, clients, manufacturers, builders, but also the users. ${ }^{21}$ Similarly, Stan Allen suggests that the temporality of architectural practice relies on the various bodies that are at work, whose interplay and connections cohere together to produce effects. These bodies-in-action are often driven by an agenda decided in advance. According to Allen, these unfolding's of architectural practice events "work to effect transformations of reality at a distance ... [and] simultaneously inhabits both ... imagination and realization." 22 Through this account, it could be argued that the movement and temporality of practice attends to the now (present) but also the future (the distance). The practice of architecture and its design process is dedicated to the promises of that which might become. It is therefore extensive, in that it stretches out the situated and related bodies, senses and things in the present towards the future.

\footnotetext{
16 Pierre Bourdieu, The Logic of Practice, translated by Richard Nice (Stanford, Stanford University Press, 1990$), 81$.

${ }^{17}$ Lisa Adkins gives an extensive critical review of Bourdieu's approach to time and practice. Lisa Adkins, "Practice as

Temporalization: Bourdieu and Economic Crisis," in The Legacy of Pierre Bourdieu: Critical Essays, edited by Simon Susen and Bryan S. Turner, 347-366 (London: Anthem Press, 2011).

18 Michel de Certeau, The Practice of Everyday Life (University of California Press: Berkeley, 1984), 35.

${ }^{19}$ Kerstin Simonsen, "Practice, Spatiality and Embodied Emotions: An Outline of a Geography of Practice," Human Affairs 17

(2007): 170 .

20 Till, Architecture Depends, 113.

21 Till, Architecture Depends, 116.

22 Allen, Practice Architecture, Technique and Representation, 3-7.
} 


\subsubsection{Time of Architectural Practices through Affect}

So, how might affect be inputted in these discussions? Putting a lens of affect over the temporality of practice - is to bring notions of intensity into the picture. How might affect intensify (or equally diminish) practice's temporality? To briefly review, affect, according to Deleuze, is the "product of actions between bodies (animate and inanimate) ... [where] [a]n action causes a response - a movement, transition, or transformations - and this response takes many forms: perhaps an inspiration, or an instance of action." ${ }^{23}$ So affect is in movement between bodies - where bodies, according to Erin Manning, "not only seek out but create the [potentiality of] relations." ${ }^{24}$ Intensifying temporality implies intensifying the movement of affect in-between two bodies/relations, ${ }^{25}$ but also between different temporalities -where the intensification of stimulating affairs take places - unravelling "ambiguities of desires, provoking and maintaining individual differences ... which at the same time demand practices of indifference. ${ }^{, 26}$ As suggested above, in the context of the practice of architecture, these intensified relations comprise the in-between's of expectation and realisation; intension and production; original needs (brief) and altered needs. ${ }^{27}$ Affect thus navigates between and through practice's temporality - where affect 'happens' not as/in a separate dimension - but as inherent in the process of practice.

In this sense, thinking through affect, the time of practice is not wholly anticipatory. It is the position of this thesis that affect is a productive way of exploring the time of practice because it allows an emphasis on the in-between times of practices, precisely where the future can only be partially known. Indeed, this thesis suggests that linking affect and architectural practice through time, requires looking at the moments of "indeterminacy, undecidability and ambivalence" 28 of practice - that is, the stilled times, or stilled stutters of practice. Because processes of design take time and projects frequently stretch out beyond the original schedule. Before proceeding to the next section, it is important to clarify on the term "stuttering" as it is used throughout the chapter in considering the time of architectural practice.

\footnotetext{
${ }^{23}$ Felicity Colman, "Affective Terrorism," in Deleuzian Encounters: Studies in Contemporary Social Issues, edited by Anna HickeyMoody and Peta Malins (Houndmills: Palgrave Macmillan, 2007), 124.

${ }^{24}$ Erin Manning, "Sensing Beyond Security," in Deleuzian Encounters: Studies in Contemporary Social Issues, edited by Anna HickeyMoody and Peta Malins (Houndmills: Palgrave Macmillan, 2007), 118.

25 Ben Anderson, "Becoming and Being Hopeful: Towards a Theory of Affect," Environment and Planning D: Society and Space 24, no.5 (2006): 737.

${ }^{26}$ Michael Schillmeier, "Assembling Money and the Senses," in Urban Assemblages: How Actor-Network Theory Changes Urban Studies, edited by Ignacio Farías and Thomas Bender (London and New York: Routledge, 2010), 234.

27 Stephen A. Brown, Communication in the Design Process (London and New York: Spon Press, 2001), 87.

28 John Shotter, The Cultural Politics of Everyday Life: Social Constructionism, Rhetoric and Knowing of the Third Kind (Buckingham: Open University Press, 1993), 52. Cited in Till, "The Negotiation of Hope," in Architecture and Participation, edited by Jones Blundell, Doina Petrescu, and Jeremy Till (London and New York: Spon Press, 2005), 37.
} 


\subsubsection{Time of Architectural Practices: On Stuttering}

The term stutter carries two resonances that need explanation. First, stuttering suggests a series of breaks within a whole motion. In this sense, there is a sense of process, where the series of bits and pieces are held together under the present that is extended through; borrowing Ben Anderson's words "stilled-slowed time" ${ }^{29}$ (sustained stuttering). Second, and at the same time, the idea of stutter also incorporates abrupt suspensions (suspensions of affect intensity) and suggests a temporal motion that hurries on towards the future. In this sense, stuttering is a form of temporal mediation: it takes place as a temporal relation of proximity between present and future - its temporality is not about the immediate, but about the conditions in-between. Importantly, and this thesis suggests, the stutters (as temporal intervals) are not empty; they are filled by affective content.

It is critical here to acknowledge Deleuze's essay titled "He Stuttered," to the stuttering of the writer as a perfomative activity, "making the language ... stutter" through "an affective intensity". ${ }^{31}$ In Deleuze's terminology, stuttering is the dislocated relations between words by the writer, rather that the speaker, whereby the language can "roll from right to left ... toss from back to front". ${ }^{32}$ Moreover, according to Deleuze, stutter occurs when a language system “overstrains itself"- and furthermore, this strained language system "suffers a pressure that delivers it to silence." ${ }^{33}$ In other words, through the inarticulate stutter, the language system becomes affective and intensive (rather than function and extensive).

What can Deleuze's stuttering of language tell us about the time of practice? The concept of the stutter is significant to the argument made in this chapter, specifically in how it highlights how involuntary and disjunctive repetition of actions (in the case of language, sounds and silences in speech) can trigger affects, in the forms of embarrassment, discomfort, forestalling progress. But also, as Deleuze tells us, when turning to the space between (the time-gap of stutters), we may consider the disequilibrium of stuttering as an "affirmative disjunction". ${ }^{44}$ This affirmative approach turns stuttering into a "[c]reative stuttering ... [where] language grow[s] from the middle, like grass; it is what makes language a rhizome instead of a tree, what puts language in perpetual disequilibrium.. ${ }^{, 35}$ Following this 'growing from the middle' illustration, this chapter begins with the position that indeed, practices are bound to stutter as it grapples with

\footnotetext{
${ }^{29}$ Ben Anderson, "Time-Stilled Space-Slowed: How Boredom Matters," Geoforum 35 (2004): 749.

30 Gilles Deleuze, "He Stuttered," in Gilles Deleuze and the Theater of Philosophy, edited by Constantin V. Boundas and Dorothea Olkowski (New York and London: Routledge, 1994).

31 Deleuze, "He Stuttered," 23.

32 Deleuze, "He Stuttered," 26.

33 Deleuze, "He Stuttered," 28.

34 Deleuze, "He Stuttered," 26.

35 Deleuze, "He Stuttered," 27.
} 
inherently unstable bodies that partake in design processes. The practice of architecture is, as a system, albeit an open-system, overstrained and pressured, and thus, begins to stutter creatively and affirmatively through affective temporalities.

\subsection{AFFECT, ARCHITECTURAL PRACTICE, EXTENDED PRESENT}

As evident in the different active 'happenings' that occur as part of practicing architecture, discussed through the perspective of geographers in Chapter 3.3 (i.e. re-designing, reoccupation/re-appropriation, active caring) - the present of practice involves active bodies/assemblages that are here seen as collections of dynamic temporalities (degrees of power). These accounts are, albeit generally, concerned with how actions are continually occurring (bodies are always moving), going from one event to another, where time flows in a linear manner. As Paul Harrison critically notes, this is an attention to the "busyness ... [of] bodies which are doing things, which are in some essential sense bodies-in-action. ${ }^{36}$ However, what about the inactivity's, or times of stillness, that occur in practices of architecture? What of the withdrawals from action, the times of waiting? While not underplaying the significance and positive nature of the contributions addressed in Chapter 3.3, the following discussion draws on geographers who are calling attention to the potential of more passive, susceptible practices. This thesis refers to these practices as 'affective stuttering' temporalities of the present.

\section{Stilled Stutters: Sustaining Affects in the Present}

Recent scholars from the field of geography are attending to these 'stutters,' most notably Ben Anderson, Paul Harrison and David Bissell. ${ }^{37} \mathrm{~A}$ full discussion of this scholarship lies beyond the scope of this thesis, but what should be pointed out is how their works stress a different temporality from the temporality in which bodies are always 'doing,' - practicing daily tasks (for example, Anderson discusses times of boredom, while Harrison notes on temporality of sleeping). More specifically, they set out to challenge the notion of 'inactive' practices (i.e. sitting, waiting) as something which is negative, and undesirable. ${ }^{38}$ The following focusses on the work by Bissell which provides suggestive ways of rethinking temporal relations in practices of architecture. $^{39}$

\footnotetext{
36 Paul Harrison, "In the Absence of Practice," Environment and Planning D: Society and Space 27, no.6 (2009): 989.

37 David Bissell, “Animating Suspension: Waiting for Mobilities,” Mobilities 2, no.2 (2007): 277-298.

38 Bissell, "Animating Suspension," 283.

39 Where it involves temporal processes of what Ben Anderson term "stilling and slowing" that sustains practices in the present. Anderson, "Time-Stilled Space-Slowed," 743.
} 
Bissell argues that geographers have failed to appreciate the necessary stillness before any action. In a recent article on 'Comfortable bodies: Sedentary affects,' he draws attention to the practice of sitting and waiting (in a chair). While Bissell's exploration is focussed on practices of travel - the examples he provides is most helpful to this thesis as they can be applied to architectural practices. That is, waiting is something practices of architecture often involve waiting for the client's feedback, waiting for the contractor's agreement, waiting for a designed object to be manufactured or transported. ${ }^{40}$ But also, as the accounts by the architects interviewed in this thesis makes evident, design work is, borrowing Bissell's description of office work, "frequently undertaken whilst travelling over long-distance, in cars, trains, and planes." These stilled moments within a design process suggest a prolonged length of time, or duration an exaggerated/extended present. While these quiet times may be seen as uninteresting, boring and even, purposeless, Bissell argues that through stillness - or stilled time (stuttering), although the 'sitting' body (or waiting) is inactive, "the body may not cease to be moved, affectually." What this proposes is that even when bodies are still - or there are stilled stutters - these moments are not merely, as Schweizer puts it, "empty intervals between instants" but rather, contains the possibility of arousing affects, shifting or pressing on bodies. In the practice of architecture, what Bissell describes as the period of "lying-in-wait-for" ${ }^{43}$ (temporality of stillness) could be seen as the temporal in-between stutter occurring between moments of focussed and productive designing (sitting at desk); staying put waiting for the structural engineer's report; waiting in anticipation for approval of final plans for tendering process. Of course, these events of inactivity - often disrupt (or in Bissell's words, "becomes out of sync with-" ${ }^{, 4}$ ) the expected speed of the design process. Anyone who has been involved in some aspect of the practice of architecture knows that these stilled stutters (long thresholds and discontinuities) can stir certain affects of frustration, anxiety and impatience that can indeed linger on. ${ }^{45}$ Particularly, Bissell notes

\footnotetext{
40 One of the most common moments in practices of architecture -is the times of stillness that precede any action. Before and inbetween decisive acts, stillness appears. Stillness in this sense, "denotes apprehending and anticipating spaces and events in ways that sees the body enveloped within the movement of the environment around it; bobbing along intensities that course their way through it; positioned towards pasts and futures that make themselves felt, and becoming capable of intense forms of experience and thought" Peter Adey, "Holding Still: The Private Life of an Air-Raid," M/C Journal: A Journal of Media and Culture 12, no.1 (2009), accessed September 10, 2014, http://journal.media-culture.org.au/index.php/mcjournal/article/viewArticle/112.

41 David Bissell, "Comfortable Bodies: Sedentary Affects," Environment and Planning A 40, no.7 (2008): 1702.

42 Bissell, "Comfortable Bodies: Sedentary Affects," 1699.

43 Bissell, "Animating Suspension," 282. Or what Kraftl and Adey address as the "affectual slowing down of movement/intensity" Kraftl and Adey, "Architecture/Affect/Inhabitation," 225.

${ }_{44}$ David Bissell, "Passenger Mobilities: Affective Atmospheres and the Sociality of Public Transport," Environment and Planning D: Society and Space 28, no.2 (2010): 275.

45 In these instances/happenings - the bodies "do not consciously choose to feel in a particular way." Instead, "anxiety flaring up in the delayed" move through the bodies semiconsciously, "and in doing so, modify their capacity to affect and be affected" Bissell, "Passenger Mobilities," 276.
} 
(following Schweiser), how impatience, is an inability to bring together ('reconcile') the present and the future. ${ }^{46}$ Hence, stilled stutters sustain bodies' in-between these two temporalities.

However, rather than focussing on the 'inabilities' that stilled stutters may highlight perhaps we can put these periods of waiting into more affirmative terms. It is suggested here how holding still, heightens our sense to-/of- affects, but also, increases our awareness of the present - the suspended now. In this sense, acts of waiting slows time down, extending the present - but more importantly, it is in these stutters where, as Tim Cresswell notes, we can "pay attention to moments when the movements of ideas gets stuck, is made still, or is forced to wait for receptive audiences." ${ }^{47}$ Franck and Howard further emphasize how an act of slowing down "gives relationships a sticky quality." ${ }^{38}$ Both these accounts alert us to not only the waiting game as a temporality of the present (a form of stutter in the otherwise 'active' processes of practice) - that is productive, in terms of generating affects (in Peter Adey's words, "channel the possibilities of affect" ${ }^{49}$ ) - but is also about a sense of "connectedness" $" 50$ between different ideas, but also different groups of bodies, both human (i.e. architects, users, engineers, contractors, manufacturers) and non-human (i.e. technology, politics, designed objects). In other words, thinking through stilled times in practice is partly about locating the affective encounters and attachments between bodies and ideas moving toward each other. What is more, the act of waiting in practices of architecture connects the present (yet-ness) and the future (not-yet-ness) by doing so, it creates a zone of proximity or affectability between different temporalities.

So, how to move on from the stillness and waiting periods of practices? What triggers the move from "now to the not yet" ${ }^{\text {" }}$ within practice? The following section addresses a different, yet interconnected form of temporality in practices of architecture. While in stilled stutters (through waiting) - we linger in the present, letting time pass and ideas stick through affect we are also, spontaneously aroused, through quickened stutters that stirs sudden affects, pushing us to the future; a future characterized through a mode of the beyond (its not-yetness).

\footnotetext{
46 Harold Schweizer, “On Waiting," University of Toronto Quarterly 74, no.3 (2005): 781; cited by Bissell, "Animating Suspension," 290.

47 Tim Cresswell, “Mobilities II: Still," Progress in Human Geography 36, no.5 (2012): 651.

48 Franck and Howard, Design Through Dialogue, 84.

49 Peter Adey, "Airports, Mobility and the Calculative Architecture of Affective Control," Geoforum 39 (2008): 441.

50 Bissell, "Animating Suspension," 291.

51 Ahmed, "This Other and Other Others," 562.
} 


\subsection{AFFECT, ARCHITECTURAL PRACTICE, FUTURE}

Reflecting briefly back on the previous part, Peter Adey claims how the end of stillness is "usually marked by a reactionary 'flinch,' 'start' or 'jump." 52 Following this, the discussion below suggests how access to the future is through quickened stutters - whereby abrupt and sudden 'jumps' allow for something new to happen within the practice of architecture. Hence, we move here from stilled intervals to, and borrowing Seigworth and Gregg's words, the "in-between or blooming intervals." 53 This part continues to draw from geographers, particularly works that are addressing affect more directly, such as Peter Kraftl and Peter Adey, David Conradson and Alan Latham, and also seeks to interweave these geographer's perspectives with affect theorists. ${ }^{54} \mathrm{It}$ is worth noting how these works are making the link between architecture and affect through the occupation of space, rather than the design of space.

\section{Quickened Stutters: Intensifying Affects towards Future}

The practice of architecture and its temporality is often snatched and rushed by sudden design changes, altered needs, unexpected stop in construction, to name but few stutters. While these occurrences may be short-lived, most cannot be anticipated in advance. For instance, and following Kraftl and Adey, while fear can be anticipated, things like "anger, enjoyment, sadness, distress" appear through tensions ${ }^{55}$ - and only appear when a certain situation happens as an instance of action. Kraftl and Adey clarify further (following Thrift) how these actions "are not geared to any narrow instrumental aim or need and can be focused on many kinds of objects."56 In the context of the practice of architecture, these intensified moments of tension, can indeed arouse uncomfortableness and unease as it disturbs and scrambles a design processes' anticipated schedules and organized sequence of activities. Broadly, this could be an abrupt shift in needs and change of needs. Or, more specifically, for instance, design meetings often involve architects "frustrated by what they perceive as opposition, grow defensive and try to persuade, reducing opportunities for open conversation or shared enquiry" ${ }^{\text {"57 }}$; clients on the other hand "often feel

\footnotetext{
52 Peter Adey, "Holding Still: The Private Life of an Air-Raid," 2009. Bissell also notes that "within every period of stasis, of stilling, is contained the potential to be otherwise, the possibility of rupture" Bissell, "Animating Suspension," 292.

53 Gregory J. Seigworth and Melissa Gregg, 'An Inventory of Shimmers,' in The Affect Theory Reader, edited by Melissa Gregg and Gregory J, Seigworth, (Durham: Duke University Press, 2010), 10.

54 See for example, Ben Anderson, "Becoming and Being Hopeful: Towards a Theory of Affect," Environment and Planning D: Society and Space 24 no.5 (2006): 733-752; Kraftl and Adey, "Architecture/Affect/Inhabitation," $213-231$.

55 Kraftl and Adey, "Architecture/Affect/Inhabitation," 215.

56 Thrift, "Intensities of Feeling," 57-78; cited by Kraftl and Adey, "Architecture/Affect/Inhabitation," 215.

${ }^{57}$ Franck and Howard, Design Through Dialogue, 102.
} 
they are not heard or respected" ${ }^{\prime 58}$ and are thus equally accumulating a sense of frustration. Other stutters include times when the architect sees his/her design intentionally altered and responds with outrage; the designer sees the client's satisfaction with the design, and his/her body reacts with a surge of joy. ${ }^{59}$ These sudden and quickened stutters of practice rouse bodies -pulling and pushing them out-of-joint, towards what Anderson (following Widdler) describes as "disjoined singularities" ${ }^{\circ 0}$ but also drawing them together. The practice of architecture, then, operates in these temporal irregularities and fragmentations. Disorder (abrupt stutters) in practice can also be an outcome of conflicts arising from a more 'vague' collective of bodies - for instance, in the case study of Shigeru Ban Architects that will be introduced in Chapter 7, economic and political forces attaches to the mundane object of paper tubes. But more importantly, these tensions and conflicts allow bodies to deviate from familiar habits and routinized practices, disrupting and escaping stability of familiar cycles of events and structured time. This unfamiliarity and fragmented temporality, allow affect to seep in. It is through these partial connections and disconnections - that come about quickened stutters that may, according to Franck and Howard, "open a path to something new, something that meets the client's needs in unexpected ways." Such account projects the practice towards the future positively and with a promise of something better.

This is an account of practice's temporality that emphasizes the 'interval' or in-between stutters as potential, and moreover, as holding capacity to angle the project in diverse directions. It could be towards rage, or towards happiness. ${ }^{62}$ In this perspective, it is important to note that these affects such as "rage, shame, melancholy, elation" ${ }^{63}$ are not a 'threat' or distraction from the normalized design process - but, as Till puts it, an 'opportunity ${ }^{64}$ to move towards the future, for change and innovation. In this sense, the practice of architecture is in part, enacted through the interferences and interruptions (quickened stutters) of different affects that erupt out of dis/partial- connections between bodies, each with a different degree of affective capacity. As Albrecht-Crane and Slack put it, "affective thresholds ... enter into composition with other

\footnotetext{
58 Franck and Howard, Design Through Dialogue, 62.

59 As a note, these reflections on the practice of architecture as often involving abrupt changes comes from the researcher's own experience working at architectural firms.

${ }^{60}$ Nathan Widder, "What's Lacking in the Lack: A Comment on the Virtual," Angelaki: Journal of the Theoretical Humanities 5, no. 3 (2000): 127; cited in Ben Anderson, "Becoming and Being Hopeful," 739.

61 Franck and Howard, Design Through Dialogue, 124.

62 If we are to follow Ahmed again, "[h] appiness is directed towards certain objects, which function as a means to what is not yet present" Ahmed, "Multiculturalism and the Promise of Happiness," 125.

${ }^{63}$ David Conradson and Deirdre McKay, "Translocal Subjectivities: Mobility, Connection, Emotion," Mobilities 2, no.2 (2007): 170 .

64 Till, “The Negotiation of Hope," 41.
} 
bodies' affective thresholds, thus ... setting in motion something new." ${ }^{65}$ We are then looking at how quickened stutters in the form of conflicts/tensions, (such as unexpected problems of site, design change, shortfall of budget, contradictory requirements, but also "imprecisions of ... human behaviour" ${ }^{\prime 60}$ ) move architectural practices forward rapidly, often radically and affectively altering the temporality of practices. Taking up these points, the present is not only extensive and stretched out (as discussed in 4.2.2), but is in intensive movement - inclined forward toward future temporalities.

\section{In Reflection: Considering the Past}

While the picture of the time of practice as both extended present and promising future is fundamental to practices of architecture and its operations, the question that arises is - what of the past? Affect, according to recent works, and as reviewed in Chapter 2 of this thesis, is that which has no past; no personal memory or past situations attached to it, and thereby is, in Thrift's words, "a gut feeling" "67. Indeed, it is precisely against the idea of bodily responses moulded by past forces that affect is developed. In this sense, while the past is problematic for affect, it is not the position of this thesis to ignore the past. Rather, this thesis puts forward a notion of embodied memories, that is, what is learnt from the past. As Elizabeth Grosz puts it, for instance, following Bergson: "The past lives in time. The past could never exist if it did not coexist with the present of which it is the past, and thus with every present." ${ }^{, 68}$ In this sense, the past always exists, whether we are removed from it physically and are outside its temporality, it is nevertheless contained in present time. Similarly, Ahmed, reflecting on temporalities of feminism, "ties the 'not yet' with a past that is living in the present." "' These accounts project a constant movement or entertaining between past, present and future temporalities. However, Rebecca Coleman cautions us to not assume this movement as linear, for "the past is not lying latent... but is to be re-experience through its intensity" - reminding us how in the act of remembering, we "jump or leap" into a past moments. ${ }^{70}$ We therefore do not experience a continuation, but abrupt moments that we leap into.

Particular to architectural practices, and as the architects in the case studies of this thesis mention, what is learnt from past designs is fed continuously into new designs. For instance, as

\footnotetext{
${ }^{65}$ Christa Albrecht-Crane and Jennifer Daryl Slack, "Toward a Pedagogy of Affect," in Deleurian Encounters: Studies in Contemporary Social Issues, edited by Anna Hickey-Moody and Peta Malins (Houndmills, Hampshire and New York: Palgrave Macmillan, 2007), 105.

66 Lars Lerup, cited in Till, Architecture Depends, 107.

67 Nigel Thrift, Knowing Capitalism (London: Sage, 2005), 1; cited in Rebecca Coleman, Transforming Images: Screens, Affect, Futures

(London and New York: Routledge, 2013), 13.

68 Elizabeth Grosz, Architecture from the Outside: Essays on Virtual and Real Space (Cambridge: The MIT Press, 2001$), 142$.

69 Ahmed, "This Other and Other Others," 559.

${ }^{70}$ Rebecca Coleman, “'Things That Stay': Feminist Theory, Duration and the Future," Time and Society 17, no.1 (2008): 94.
} 
part of the design process, Kerstin Thompson and her practice looks back at successful precedents of works of architecture and subsequently learn from such projects, adapt certain aspects of it and bring it into their own project. Particularly, Thompson articulates this: "If we are doing a museum, we look at other museums, and try to understand how they did it, and what might be applicable, or different for us, in our situation, for our project." Such account illustrates how the past is already and always relevant to the present. Also, Jesse Reiser, from RUR Architecture PC, describes the form of Kaohsiung Port Terminal as similar to their other projects:

Those formal traits [of Kaohsiung Port Terminal] actually came from other projects ... the first iteration of Taipei Pop actually is very similar. It's the inverse! I mean it works in an inverse way. Because one is outward looking, the other is inward focussing because it is a theatre. But they are actually connected, well there were connected interests about trying to deal with, a tower on the one hand, fusing a tower building with a more laterally developing building connected to a landscape. And it even pre-dates that, in other theatre designs, like from 20 years ago. ${ }^{71}$

Reiser's account acknowledges that indeed, in practice, you bring what you have done into different projects- because architectural practice is often driven by explorations and experimentations, be that of form or programmatic developments. ${ }^{72}$ In this sense, design processes are often triggered by past embodied memories and traces. Accordingly, if the present and future are intertwined through architectural activities, as this chapter has suggested, then the past also is a 'former present ${ }^{73}$ - and is thus an important temporality of architectural practices.

\subsection{CONCLUDING DISCUSSION: TOWARDS AFFECTIVE OSCILLATION}

The intention of this chapter has been to draw out affect through the different temporal dimensions encountered in practices of architecture. Rather than directing towards any one time (the present or the future) the discussion above has considered the in-between of these temporalities through stutters, both stilled ones and quickened ones. It is suggested that stuttering takes place as a temporal relation of proximity between present and future in practices of architecture.

Lastly, and as a concluding remark, this chapter seeks to address the relation of these two forms of stutters. It suggests that the temporal nature of architectural practice is necessarily

\footnotetext{
${ }^{71}$ Jesse Reiser, interview, (2014).

${ }^{72}$ Reiser further validates this process as a response to people who are "concerned about it": "Do Mies' buildings look all different? No. So then, there isn't really a problem” Reiser, interview, (2014).

${ }^{73}$ Grosz, Architecture from the Outside, 142.
} 
oscillating between stilled stutters and quickened stutters. The discussion has separated the two temporal relations to clarify the potential of each: stilled stutters generate an affective connectedness, while quickened stutters generate a sense of the new and better (affective possibilities). Of course, there will always be points of friction between these two intensities of stutters, but both act to connect across different temporalities (by holding together), between the "now to the not yet" these acts of stuttering as affective oscillations, we may begin to see how the most intense affective processes in practices of architecture are crowded together at the extremities of these two forms of stutters - and are made all the more intense through the contrast between the stilled and quickened temporalities.

To return to the question posed at the start of this chapter, what can stuttering temporalities (times of stillness and quickening) tell us about the relation and link between affect and architectural practice? - what follows offers a few considerations. While the stilled temporalities of the practice of architecture is essential in producing a heightened attunement (awareness) to affects, stillness also provides the possibility for quickened stutters that act to repel and push affects. ${ }^{75}$ Here, such affective forces generate instances of change that erupt out through the gaps and stutters of practice. ${ }^{76}$ These temporal in-between forces bring about practice's potential- an inclination for promising actions- where the stutters act as temporal means/opportunity for practices to 'flourish' or, borrowing Seigworth and Gregg's word, to 'bloom. ${ }^{, 77}$ To consider the temporal stutters of practice allows us to highlight practice's capacity to wait/stay still, as well as act/react to unforeseen happenings. In this sense, what is gained in accounts of practice's temporality through stilled and quickened stuttering is perhaps - the chance of action. ${ }^{78}$ Stuttering (in affective oscillation) may be the slow/stilled counterweight to bodies-in-action - or as Harrison puts it, an "interruption of the flowing of... durations." ${ }^{\text {,79 }}$ It is nevertheless a creative and affective intervention to architectural practices and its design processes.

\footnotetext{
74 Ahmed, "This Other and Other Others," 562.

75 The characterization of affect as push is referred to by Kraftl and Adey, who follow Nigel Thrift. Particularly, for Thrift, affect is "a sense of push in the world" Thrift, "Intensities of Feeling," 64. Cited in Kraftl and Adey, "Architecture/Affect/Inhabitation," 215.

76 Anna Hickey-Moody, "Intellectual Disability, Sensation and Thinking Through Affect," in Deleurian Encounters: Studies in Contemporary Social Issues, edited by Anna Hickey-Moody and Peta Malins (Houndmills: Palgrave Macmillan, 2007), 79.

77 Till, Architecture Depends, 133. Accordingly, it is through the stutter, brokenness and disorder that practice may effectively embrace difference - in other words, and borrowing Graham and Thrift's words, stuttering of practice are "born out of the everpresent presence of failure and malfunction and error - and the consequent opportunity to learn from them" - and furthermore to look at "breakdowns" as the means by which [practices] learn and learn to re-produce." Graham and Thrift, "Out of Order," 4-5. See also, Henry Petroski, Success through Failure: The Paradox of Design (Princeton: Princeton University Press, 2006).

${ }^{78}$ Following Harrison, it is "a movement of withdrawal from and separation between the existent and world, movements which are, at the same time, the very chance of every contact or involvement" Paul Harrison, "In the Absence of Practice," Environment and Planning D: Society and Space 27, no.6 (2009): 1003.

${ }^{79}$ Harrison, "In the Absence of Practice," 1003.
} 
Of course, these two forms of stutters in affective interplay do not attempt to cover all that goes on in practicing architecture's. Rather, Chapter 4 has attended to views that might enable us to see how architectural bodies, things, activities and processes, hold together in affective temporal oscillations - and how these come to have real effects in the practice of architecture. This chapter thereby acts as a bridge between theoretical attachments of affect and practice in regards to both the architects and geographers and the more grounded and practical attachments that will be drawn out in the subsequent three case study chapters (Chapter 5, 6, 7). Through the architectural practices of RUR Architecture PC, Kerstin Thompson Architects, and Shigeru Ban Architects, this thesis seeks to further explore the affective possibilities and different temporalities discussed in this current chapter through an empirical study of actual design projects and its particular design processes. Most important, for the purpose of this thesis, such study reflects more closely real-life (and everyday) connections between architecture, affect and architectural practice. 


\section{RUR Architecture PC: Sticky Images}

\subsection{INTRODUCTION}

The previous chapter (Chapter 4) explored temporalities in the practice of architecture, through two forms of stutters. The first considered stilled stutters, the second, quickened stutters. While the chapter remarked on these two temporalities separately, it also aimed to address that it is in the oscillation between the two stutters where we begin to witness the most intense affective moments and processes in practices of architecture. By way of conclusion, the chapter proposed how the discussed stuttering temporalities allow a heightened attunement and awareness of affects. For instance, it was suggested that we may see these instances in times of abrupt change of a project's programme or a client's demand, bringing an interruption to the design process. However, these stutters are, at the same time, opportunities for designs to positively flourish where the design process, within an extended present, expresses potential to promise something better for the future. Building on this latter theoretical study, the next three chapters turn to a much more grounded attempt to think about the relationship between affect and practice: through affective practices. Chapter 5 presents the first of three empirical investigations conducted for the analysis of architectural practices through the framework of affect. Specifically, this chapter seeks to evaluate how affect operates within practices of- and processes of- affective image-making. By doing so, this thesis aims to discover what the theorization of affect can add to discourse of practice, and subsequently, to extend the theory of affect to account for affective possibilities generating and operating through image-making practices.

The overall structure of this chapter is divided into five sections, including this introductory section (5.1). The subsequent sections are outlined as follows: Section 5.2 begins by laying out the platform of this chapter's research by considering affect as operating and arousing through- processes of image-making. Importantly, it draws attention to the work of cultural theorist Sara Ahmed who provides a critical engagement with affect. Of interest here is Ahmed's formulation of affect as a circulating process which involves two aspects: ${ }^{1}$ the first involves a production of stickiness; and the second aspect involves a process of (re)surfacing. This section explores how such notions of sticky affects, can extend to incorporate such things as sticky images- where the stickiness surfaces through the process of affective image-making. Section 5.3, illustrates the case study and methodology of this study, and is divided in two. First, it introduces

\footnotetext{
1 Ahmed, "Affective Economies," 120. As she notes, "[a]ffect does not reside in an object or sign, but is an affect of the circulation between objects and signs."
} 
the case study architectural practice of RUR Architecture PC and the analysed architectural project, Kaohsiung Port Terminal. As indicated above, the focus of this chapter is not on the project itself, but on the specific kind of images (visualizations) produced for the project and the relationship to their practice. Second, and specific to this chapter, existing visual methodologies are developed to allow an analysis of the affective content of images. In describing and evaluating the research material, Section 5.4 examines visualizations that RUR constructs for their Kaohsiung Port Terminal project; a series of exterior views and one interior view, the latter capturing, as Jesse Reiser describes, the "sweet spot" ${ }^{2}$ of the project. In these set of images, we find processes of affective charge that in part play upon art practice traditions. In discussing these image-making practices, this section is divided into three parts. The first evaluates RUR's play on artistic effect of the panorama to investigate their above mentioned interior image. The second considers a process of playing off atmospheric painterly means. Lastly, the third develops RUR's image-making as involving a play upon the art practice of iconography. As the argument developed indicates, RUR's image-making is invested in affective charge where the charge intensifies the surface of the images, thereby creating sticky images that both inform, and is informed by - the design process, driven by RUR's design ambitions.

The discussion section (5.5) considers the various theoretical and empirical aspects in order to critically consider the implications for the theory of affect, when applied to practice. Particularly, RUR's image-making practice is as much about a process of the charge of the image as about a process of generating new strategies to design from- or design to- for the production of architecture. At issue here is not a matter of image as representation that sticks to reality. Rather, as Latham and McCormack put it, the endeavour is "to make more of image,"3 where images (can) become sticky through affect. Reemphasizing the argument made in Chapter 4, the images in this chapter illustrate a slightly out of real-time, where the image surface connects the present (yet-ness) and the future (not-yet-ness) through affective stutters. Thinking through sticky-images this chapter concludes by considering some of the implications of extending the theory of affect to account for architectural practices invested in image-making.

\subsection{TOWARDS STICKY IMAGES}

Section 5.2 provides the context of this chapter by exploring architectural discourse that draws strong connections between architecture and image. This is followed by laying out the theoretical

\footnotetext{
2 Jesse Reiser, interview, (2014).

3 Latham and McCormack, "Thinking with Images," 252.
} 
platform of this chapter's research, considering affect as operating and arousing throughprocesses of image-making.

\subsubsection{Intersections between Architecture, Image (-making) and Affect}

Recent discourses in visual studies and cultural geography, as well as architectural and historical scholarship are re-working the relationship between architecture and its visualization. These discussions, notably by Iain Borden as well as Maria Antonella Pelizzari and Paulo Scrivano, shift away from interpreting architectural images (i.e. photography, moving-imagery, and lately, digital visualizations, or renderings) as purely documenting buildings (representational) ${ }^{4}$ towards a more "interdisciplinary approach" that considers things like the "context of production and media distribution of images." ${ }^{5}$ This concern allows us to recognize image-production as a vital part of architectural practices, where design processes necessarily involve, as Benjamin Buchloh notes, "an endless process of transforming the tectonic and spatial into the spectacular" through images. ${ }^{7}$ The potential role of the image within architecture is recognized historically by Walter Benjamin, as he observes: "one cannot say that they [images] re-produce architecture. They produce it in the first place." ${ }^{8}$ Similarly, Iain Borden, interpreting Charles Jencks' textualizing of images notes "the image is not object-centred... it reproduces not architecture but social meaning through a depiction of architecture." These considerations elevate the role images' play in architecture; not simply as re-productions or re-presentations of- architecture, rather, towards thinking images as capturing more of- and beyond the 'real' architecture. Specific to the process of production and construction of architectural images, Beatriz Colomina offers insight (through her analysis of Le Corbusier's image-practice) towards embracing (printed) media as "a new context of [architectural] production, existing parallel with the construction site." ${ }^{10}$ In this sense, architectural practice involves the careful construction of architecture "built as image," most

\footnotetext{
4 See Iain Borden, "Imaging Architecture: The Uses of Photography in the Practice of Architectural History," Journal of Architecture 12 (2007): 55-77.

5 Maria Antonella Pelizzari and Paulo Scrivano, "Intersection of Photography and Architecture-Introduction," Visual Resources 27, no.2: 109 .

${ }^{6}$ Benjamin Buchloh. Quoted in Pelizzari and Scrivano, "Intersection of Photography and Architecture-Introduction," 109.

${ }^{7}$ See also, Guy Debord, Society of the Spectacle (Detroit: Black and Red, [1967] 1983). Marshall McLuhan, The Medium is the Massage:

An Inventory of Effects (London: Penguin Books, 1967.) From a different angle, see also: Charles Jencks, The Language of Post-Modern Architecture (London: Academy Editions, 1977).

8 Walter Benjamin, The Work of Art in the Age of Its Technological Reproducibility And Other Writings on Media, ed. Michael W. Jennings, Brigid Doherty, and Thomas Y. Levin (London: Harvard University Press, 2008), 71. Also, reflecting on the desire held by the mass, Benjamin further comments: "Every day the urge grows stronger to get hold of an object at close range in an image..." Benjamin, The Work of Art, 23.

9 Borden, "Imaging Architecture," 71.

10 Beatriz Colomina, quoted in Pelizzari and Scrivano, "Intersection of Photography and Architecture-Introduction," 108. See also, Beatriz Colomina, Privacy and Publicity: Modern Architecture as Mass Media (Cambridge: MIT Press, 1994); Beatriz Colomina, "Architectureproduction," in This Is Not Architecture: Media Constructions, edited by Kester Rattenbury, 207-221(NewYork: Routledge, 2002).
} 
often by the architect. ${ }^{11}$ Concurring with Colomina, Kester Rattenbury argues how this new form of architectural construction (beyond representation of architecture) "establishes the paradigms of high-code architecture and affects how architects see the world and which things get described as architecture."12 Such arguments recognize architectural image-production (of the 'unbuilt') as having capacity/power to shape 'real' built environments, thereby confirming Kenneth Frampton's assertion of image as "agent of mediation." 13

Paralleling these views, there has been a critical reflection upon architecture as 'fully ensnared' within a contemporary condition described as an "ecstasy of communication." 14 This turn towards image focussed architecture has been observed largely through two interrelated streams. The first stream comments on the modern era of speed and instantaneity and aligns with works by Paul Virilio. ${ }^{15}$ Drawing on medium theorists such as Marshall McLuhan, Virilio analyses media innovation and its impact on modes of representation (images). Particularly, he argues the influence of new technologies as involving a process of "derealization and dematerializing of the object." ${ }^{16}$ Indeed, this view projects the effects of new visual mediums as contributing to the discontinuous and disembodied form of experience. Moreover, this turn towards new media forms (post-media in the digital age) has been identified by Lev Manovich through new digital imaging techniques, particularly through the concept of variation. ${ }^{17}$ This latter term, "variation," describes the constant fluctuating rematerialization of media (including images) - the idea that new media objects "can exist in different, potentially infinite versions." ${ }^{18}$ Whereas for Manovich, this "new media image is something the user actively goes into,", that is, the content of the work and the interface are separated, Mark B. N. Hansen explores the interpenetration and interchange of body and media. Evaluating the affective dynamics of images, Hansen draws on Bergson's notion of affectivity as "that part or aspect of the inside of our body which we mix with the

\footnotetext{
${ }^{11}$ Beatriz Colomina, "Media as Modern Architectures," in Thomas Demand, Serpentine Gallery (London: Serpentine Gallery; Munich: Mosel, 2006), 20.

12 Kester Rattenbury, "Introduction," in This Is Not Architecture: Media Constructions, edited by Kester Rattenbury, (New York: Routledge, 2002), xxiii. See also, Pierluigi Serraino, "Framing Icons: Two Girls, Two Audiences / The Photographing of Case Study House \#22," in This Is Not Architecture: Media Constructions, edited by Kester Rattenbury, (New York: Routledge, 2002), 127135.

${ }^{13}$ Kenneth Frampton, Commodification and Spectacle in Architecture: A Harvard Design Magazine Reader, ed. William S. Saunders (Minneapolis: University of Minnesota Press, 2005), 17.

14 Jean Baudrillard, referred to by Neal Leach in: Neal Leach, "Saturation of the Image," in The Anaesthetics of Architecture, edited by Neal Leach (Cambridge: The MIT Press, 1999), 1. See also Jean Baudrillard, “The Ecstasy of Communication,” trans. John Johston, The Anti-Aesthetic, ed. Hal Foster (Washington: Bay Press: 1983), 126-134. Baudrillard elevates the concept of the spectacle as a process of replacing reality with virtually - generating hyper-reality.

${ }_{15}$ Paul Virilio, The Lost Dimension, trans. Daniel Moshenberg (New York: Semiotext, 1991). See also Paul Virilio, "The Overexposed City," Architecture Theory Since 1968, ed. K. Michael Hays (Cambridge, MA: The MIT Press, 1998); Paul Virilio, The Original Accident (Cambridge: Polity Press, 2007).

16 Douglas Kellner, "Virilio, War and Technology," in Paul Virilio, from Modernism to Hypermodernism and Beyond, edited by John Armitage (London: Sage, 2000), 116

${ }^{17}$ Lev Manovich, What is New Media and Principles of New Media from the Language of New Media (Cambridge and London: MIT Press, 2002).

18 Manovich, What is New Media, 56.

${ }^{19}$ Lev Manovich, The Language of New Media (Cambridge: The MIT Press, 2001), retrieved from: http://www.manovich.net/LNM/Manovich.pdf, 167.
} 
image of external bodies. ${ }^{20}$ Hansen suggests visual technologies broaden the scope of human agency by extending the body's capacity for perceptually completing images. ${ }^{21}$

The second stream addresses the contemporary architectural condition through a tendency of spectacularity. In this context, Neil Leach is critical of architects' obsession with the image which has reduced "design ... to the superficial play of empty, seductive forms."22 Architectural practices, Leach argues, are engaged in this 'process of aestheticization' driven by the excess/surfeit of images, which has in turn reduced the image - empty of content. In agreement with Leach, authors such as $\mathrm{Hal}$ Foster address a turn of architectural practices from building toward prioritizing spectacle, that is, a shift towards "image-building." 23 Foster elaborates on Guy Debord's definition of spectacle, ${ }^{24}$ arguing through Frank Gehry's building, how spectacle is now "an image accumulated to such a degree that is becomes capital." 25 Foster's critique precisely addresses the implications when architecture becomes the image, or as Gevork Hartoonian puts is, when architecture becomes "the site of spectacle." 26 In divergent ways, the discourse of architecture and image is caught between spectacularity (art of display) and a need for creative response (to accommodation of use). Clearly, for Anthony Vidler and others, ${ }^{27}$ the practice of architecture cannot be completely disconnected from its inclination towards building for spectacularity. However, there is concern and debates over the extent to which spectacularity has imposed on practice.

These variations of critical analysis presented above, looks at issues spanning from architecture in images, imaging architecture to image in (focussed) architecture. What ties them together is their insistence for architectural practices to critically engage with image-making processes $^{28}$, as architecture is increasingly becoming defined and shaped through imagery. ${ }^{29}$

\footnotetext{
${ }^{20}$ Henri Bergson, quoted in Mark B. N. Hansen, New Philosophy for New Media (Cambridge and London: MIT, 2004), 100. Hansen also affirms how the image "can no longer be restricted to the level of surface appearance, but must be extended to encompass the entire process by which information is made perceivable through embodied experience." Hansen, New Philosophy for New Media, 10.

${ }^{21}$ Mark B. N. Hansen, Bodies in Code: Interfaces with Digital Media (New York and London: Routledge, 2006$), 3$.

22 Leach, The Anaesthetics of Architecture.

${ }^{23}$ Hal Foster, "Image Building," in Architecture Between Spectacle and Use, edited by Anthony Vidler ( New Haven: Yale University Press, 2008), 164.

${ }^{24}$ In The Society of the Spectacle (1967) Guy Debord defined spectacle as "capital accumulated to such a degree that it becomes an image."

${ }^{25} \mathrm{Hal}$ Foster, Design and Crime, and Other Diatribes (New York: Verso books, 2002), 41.

26 "Architecture today has become the site of spectacle, and its temporality is informed by a culture that is primarily image-laden." Hartoonian, Architecture and Spectacle, 3.

27 See the collection of essays edited by Anthony Vidler in, Anthony Vidler, Architecture Between Spectacle and Use (New Haven: Yale University Press, 2008). This includes, Mark Wigley, "Towards a History of Quantity," in Architecture between Spectacle and Use, ed. Anthony Vidler (New Haven: Yale University Press, 2008).

28 Architectural practices from Rem Koolhaas' OMA to BIG Architects are addressing the importance of architectural design processes and methods. See for example, the monograph by BIG Architects: Bjarke Ingels, Yes Is More: An Archicomic on Architectural Evolution (Koln: Taschen, 2009).

${ }^{29}$ Jacques Ranciére, for instance, thinks through images as operations. Jacques Rancière, The Future of the Image, trans. G. Elliott (London and New York: Verso, 2007), 3. Specifically, Rancière describes the images of Au hazard Balthazar as "not primarily manifestations of the properties of a certain technical medium, but operations: relations between a whole and parts; between a visibility and a power of signification and affect associated with it...." Rancière, The Future of the Image, 3.
} 
Recognizing the value of these studies, this chapter aims to extend the interrelation between architecture and its image, by considering affect, that is, the affective capacity of images, particularly through an affective image-making process. ${ }^{30}$ Significantly, this chapter asks two interrelated questions: first, what is an affective-image? And second, what is involved in the practice invested in affective image-making? This chapter explores these questions through a case study architectural practice of RUR Architecture PC (hereafter referred to as RUR), and their Kaohsiung Port Terminal project. A full discussion of the project lies beyond the scope of this dissertation, and hence, this chapter engages mainly with the images produced for the project prior to its construction. These images offer important sites of investigation into RUR's imagemaking practice. Particularly, the images allow analysis of the strategies and processes employed by RUR to charge their images with, borrowing Rebecca Coleman's words, "affective appeal”31 and thereby as sticky and active participants in the design process. What follows lays out the theoretical platform of this chapter's research by considering affect as operating and arousing through- processes of image-making.

\subsubsection{Ahmed: Sticking and Surfacing}

While contemporary notions of affect have been discussed in length in Chapter 2 of this thesis, this section highlights a few points of interest for the following case study analysis. Particularly, the theory of affect has often been articulated in terms of a movement in-process through different scholars. We see this in interpretations by Sylvan Tomkins, for instance, who affirms affect as activated through variations of "density of neural firing." 32 In this, affect is a process involving increase (amplification) or decrease of stimulus intensity, communicated outwardly by the affected body. According to Tomkins, this outward projection makes affect contagious, whereby the affected body and the observing body can experience the same parallel intensities. ${ }^{33}$ Reinforcing this view, Anna Gibbs describes affect's contagious process as "leap[ing] from one body to another, invoking tenderness, inciting shame, igniting rage, exciting fear." ${ }^{\text {34 }}$ Parallel to Tomkins and Gibbs formulations is Teresa Brennan's notion of "affective transmission," 35 which

\footnotetext{
30 This study thus aligns with recent geographical studies that consider the 'force of images,' that is, images as 'blocks of sensation with an affective intensity." Latham and McCormack, "Thinking with Images," 253.

31 Rebecca Coleman, Transforming Images: Screens, Affect, Futures (London and New York: Routledge, 2013$), 89$.

32 Silvan Tomkins, Affect, Imagery, Consciousness 4 vols, (New York: Springer, 1962-92). See also, Silvan Tomkins, Exploring Affect: The selected writings of Silvan S. Tomkins (Cambridge and New York: Cambridge University Press, 1995).

33 Anna Gibbs, "Contagious Feelings: Pauline Hanson and the Epidemiology of Affect," Australian Humanities Review 24 (2001).

${ }^{34}$ Gibbs, "Contagious Feelings," par. 1. See also, Anna Gibbs, "After Affect," in The Affect Theory Reader, edited by Gregory J. Seigworth and Melissa Gregg (Durham: Duke University Press, 2010).

35 Brennan identifies two types of transmission of affect, " $\mathrm{t}]$ here is transmission by which people become alike and transmission in which they take up opposing positions in relation to a common affective thread." Brennan, The Transmission of Affect, 9.
} 
addresses affect as a "process that is social in origin but biological and physical in effect." stresses affects as having an "energetic dimension ... [which is] why they can enhance or deplete" ${ }^{37}$ when they are transmitted. These views illustrate affect as a relational and transferable viral force that move freely and continuously between bodies. More recently, Sara Ahmed posits how affects are more than about flows of energy; they are also "about attachments or about what connects us to this or that." ${ }^{38}$ Whereas Tomkins, Brennan and Gibbs foregrounds affect as constituted through bodily processes of chemical transfer, Ahmed is more focussed on the "stickiness" between bodies highlighted through acts of orientations toward or away certain objects. $^{39}$

Ahmed's formulation of affect as a circulating process ${ }^{40}$, involves two key aspects: first, a production of stickiness, and second, a process of surfacing. ${ }^{41}$ Importantly, this section asks, what can the study of affects - particularly, sticky-affects, contribute to our understanding of architectural practice? Ahmed's position on affect as a process of sticking and surfacing is particularly useful for exploring practices of image-making, providing ways to address imagemaking as involving processes of intensification and charging. By exploring how notions of sticky affects can extend to incorporate such things as sticky images- we may be able to witness how stickiness surfaces through the process of affective image-making.

The sticky association of affect has been consistently emphasized by Ahmed. While the process of stickiness is significant to this chapter and is attended to through the case study analysis, this concept has been discussed in length in Chapter 2. Therefore, the following attends to another aspect of Ahmed's affect theory, that of the process of surfacing. This leads us to Ahmed's insight, which extends the first (sticking process), where the circulation of affects is explained as "an effect of surfacing, as an effect of the histories of contact between bodies." Given this, Ahmed refers to Judith Butler, where affect is expressed as involving a process of "materialization." ${ }^{43}$ Through her close analysis of the affectivity of pain, Ahmed suggests how pain [and other affects] is felt (impressed) on the surface of the body. ${ }^{44}$ Equally, affects such as disgust is "mediated by ideas that are already implicated in the very impressions we make of

\footnotetext{
36 Brennan, The Transmission of Affect, 3.

37 Brennan, The Transmission of Affect, 6.

38 Ahmed, The Cultural Politics of Emotion, 11

39 Ahmed, The Cultural Politics of Emotion, 18.

40 Sara Ahmed, "Affective Economies," 120. As she notes, "[a]ffect does not reside in an object or sign, but is an affect of the circulation between objects and signs."

41 Ahmed, The Cultural Politics of Emotion (New York: Routledge, 2004). See also, Ahmed, "Happy Objects," in The Affect Theory

Reader, ed. Gregory J. Seigworth and Melissa Gregg (Durham: Duke University Press, 2010).

42 Sara Ahmed, "The Performativity of Disgust," in Cultural Politics of Emotion (New York: Routledge, 2004): 90.

43 Judith Butler, quoted in Sara Ahmed, "Affective Economies," 121.

44 Ahmed, The Cultural Politics of Emotion, 27.
} 
others and the ways those impressions surface as bodies. ${ }^{\circ 5}$ In this sense, as a force that demarcates boundaries, affect participates in making impressions, shaping the "surfaces of individual and collective bodies." 46 These surfaces may indeed 'shiver' or 'recolour' (as Ahmed notes, specific to affect of fear). ${ }^{47}$ The focus is then, on the surface of impact/contact and on the mark of the impression. This chapter refers to this affective impression - as the charge of affect.

This section has provided a brief review of the theoretical context for this chapter, considering intersections drawn in architectural discourse between architecture, image and imagemaking. As the background has been previously discussed in Chapter 2, the section has teased out and fleshed out some of the characteristics of Ahmed's affective circulation. Focussing on the interactions between affect's sticking, surfacing and impressing processes, the following study evaluates the affective dynamics within images. Where the approach of this research departs from Ahmed's is in its proposition of extending notions of sticky affects to incorporate such things as sticky images. Specifically, the study explores how stickiness surfaces through the process of affective image-making. Importantly, Ahmed is not writing about a design situation. This chapter suggests that her concepts may be applied to the practice of architecture - where affective sticking and surfacing processes are an important part of design practices. The following section positions affect as a way of approaching images as more than just representational. Instead, it looks at images as affective mediations, that is, in terms of its surface intensity and stickiness- its affective charge. Thinking through sticky-images, images become a more complex site of exploration, and image-making, a more activating and at times, stuttering process.

\subsection{CASE STUDY AND METHODOLOGY}

As discussed in the Introduction Chapter of this thesis, in exploring the affective dynamics of images produced as part of the design process in practices, a qualitative research was carried out with a purposefully selected architectural practice. The study had two objectives: The first objective was to investigate the complex processes involved in a particular design project, and the understanding or interpretation of affect within these processes through architects design decisions and orientations. The second objective was to investigate the extent to which affect operates within the practice of image-making. In this sense, qualitative research allows for a better account for the complexity of design processes, revealing the multifaceted dimensions of affect within practicing architectures. In particular, the following research question was posed: What architectural and theoretical relations can be drawn out when architectural practices are viewed through the

45 Ahmed, The Cultural Politics of Emotion, 83.

46 Ahmed, The Cultural Politics of Emotion, 1.

47 Ahmed, The Cultural Politics of Emotion, 63. 
lens of affect? And a more focussed question asked: How does affective image-making operate within a research-led architectural practice? What follows is broadly divided in two. The first part introduces the case study architectural practice of RUR and their Kaohsiung Port Terminal project. The second part describes the methods of data collection and analysis particular to this chapter.

\subsubsection{Case Study 1: RUR Architecture PC}

The architectural practice of RUR is based in New York, USA and is led by principal architects Jesse Reiser and Nanako Umemoto. According to Reiser, their practice operates within a 'research-in-practice' where "[the] practice occupies a part of a larger architectural project ... in the way that the project transcends any particular project, and that the practice sort of fits into a wider set of interests, so that there are connections. ${ }^{, 48}$ In this context, RUR is concerned with the continuity across their architectural projects where unlike commercial practices driven by problem-solving and "doing buildings," RUR is motivated by "longer and wider on-going interests that the practice fits into." ${ }^{49}$ Hence, in Umemoto's words, the practice of architecture "shouldn't be just repeating work the builder is doing ... it should push things forward." 50 Here, 'practice' turns to 'practicing' - involving an advancing force - quickened affective stutters, leading to new discoveries. This illustrates how RUR's practice is interested in the 'process" ${ }^{51}$ rather than the 'end-product': "We see architectural design as a series of specific problem situations that, contrary to the discursive disciplines, cannot be argued away. The architectural design process allows openings and advances to occur before the problem's sheer recalcitrance shuts down developments. Thusly, design practice becomes agile enough to avoid getting stuck." 52

With such perspective, it is vital to understand RUR's interests, or practice 'ambitions,' which act as connective elements. Indeed, borrowing Ahmed's terms, RUR's projects are linked by the practice's sticky-interests and ambitions. Relevant to this research, three key ambitions are highlighted here. The first is RUR's desire to make connections across scales, that "the building design... be connected to larger scale systems of infrastructure, landscape design and urban planning. ${ }^{53}$ Another interest, and second, lies in going beyond designing for the abstract body

\footnotetext{
48 Jesse Reiser, interview, (2014).

49 Reiser, interview, (2014).

50 Nanako Umemoto, quoted in Andrew Benjamin, Jesse Reiser and Nanako Umemoto, "Jesse Reiser and Nanako Umemoto," BOMB 84 (2003): 69.

51 As Sanford Kwinter remarks in the introduction to RUR's book, Atlas of Novel Tectonics, asserting how "Reiser + Umemoto operate less like architects and much more like chemical engineers." 51 Sanford Kwinter, "The Judo of Cold Combustion," in Atlas of Novel Tectonics, Reiser + Umemoto (New York: Princeton Architectural Press, 2006), 13.

52 Jesse Reiser and Nanako Umemoto, Atlas of Novel Tectonics (New York: Princeton Architectural Press, 2006$), 21$.

53 Reiser, interview, (2014).
} 
towards engaging more with "the body's effect and affective spectrum." 54 Such engagement is possible due to, according to Reiser, the architect's ability to design for an intended ambiance. As he puts it, "the ambiance becomes a super important thing [in the design practice and process]. Because ... [it is] something an architect could control" through a "coordinated sort of development of the tectonics and lighting effects. ${ }^{, 55}$ This reflects RUR's position on the capacity of architectural practices to engage with temporal elements, "rendering [architecture] ambient." 56 Third, and most important to this chapter, is RUR's investment in image-making. This last point is elaborated further in the next section (5.4).

As such, RUR's 'repertoire of interests,' including developing connections between scales, engagement with the 'affective spectrum' of bodies which impact the ambiance of their design spaces, and their investment in image-making, are precisely how RUR operates through 'research-in-practice.' The following part outlines the data collection and analysis method that was conducted particular to this case study.

\subsubsection{Methodology}

The data collected for the research were primarily qualitative, and involved two stages, implemented in the period from October 2013 to December 2013. First, an in-depth semistructured interview was conducted with the principle of RUR, Jesse Reiser. The details of the interview data-gathering and analysis have been expanded in the introduction of this thesis (Chapter 1). ${ }^{57}$ Therefore, the following focuses on the second stage of research, which is of importance to this chapter. This second stage involved the collection of key visual documents relating to the design project discussed in the interview. In evaluating the visual documentation of the specific building project, a modified form of "compositional interpretation" Rather than applying solely traditional methodological qualities (measurable), the following analysis asked about the potential of strategies employed in art practices, to address the affective content. In this way, this study examined visual images as a site of investigation where affective charge occurs - where the material is assessed by observing both the extensive properties combined with the intensive properties ${ }^{59}$ of the image.

\footnotetext{
${ }^{54}$ Reiser and Umemoto, Atlas, 85.

${ }^{55}$ Reiser, interview, (2014).

56 Reiser and Umemoto, Atlas, 23.

${ }^{57}$ For an in-depth and detailed explanation of the data analysis of interview, please refer to Chapter 1, Methodology section.

${ }^{58}$ Rose, Visual Methodologies, 57. Rose describes this as consisting of the following components: content analysis, colour, spatial organization, light and expressive content.

59 Manuel DeLanda's concept of extensive and intensive space helps us to clarify the different qualities and dimensions of space (including image-space). DeLanda describes extensive space as "zones that extend in space up to a limit marked by a frontier. Whether we are talking about the frontiers of a country, a city, a neighbourhood or an ecosystem, in habiting these extensive
} 
Specifically, three criteria of evaluating images beyond its technical framing were explored. These involved assessing the images' through (1) artistic effect/painterly techniques (light, texture and colour palette) (2) spatial effect and scale (composition of objects) and (3) temporal effect/time variations (time and event). An in-depth account of the dimensions and characteristics of the images were discussed in the Methodology section of the Introductory Chapter of this thesis. Furthermore, the analysis of the visual material will also seek to examine the "image's possible effects on the spectator" ${ }^{60}$, considering the question: how does the image evoke affect ${ }^{61}$ Or more specifically, what are the particular qualities that make the image affectively charged, and thereby, sticky images? This chapter is then concerned with thinking about the making of 'affect images' through both the measurable (extensive) and intensive properties - all accounting for the charge of the image. It is through this manner that the researcher is able to attune to the affective content of images through the combination of these methods. In doing so, the evaluation extends Rose's criteria of analysis towards including such things as the 'affective' content.

In evaluating the research material, throughout the rest of this chapter, the discussion interweaves evidence both from interviews and the visual documentation, the latter focussing particularly on the visual renders made prior-to construction of the Kaohsiung Port Terminal project. The following section (5.4) of this chapter, examines visualizations that RUR construct's for this project; a sequence of exterior views and one interior view, the latter employing, as Reiser puts it, "the panorama effect." ${ }^{\prime 2}$ In these series of images, we find processes of affective charge that in part play upon art practice traditions. In discussing these image-making practices the following section argues RUR's image-making is heavily invested in affective charge where the charge intensifies the surface of the images, thereby creating sticky images.

\subsection{AFFECTIVE CHARGE OF STICKY IMAGES}

This section devotes itself to the affective exploration of image-making, asking specifically, how does affective image-making operate as a critical process of design? This question is examined through two particular visualizations and one series of external visualization that RUR construct's for their Kaohsiung Port Terminal project (prior to construction). In these series of images, we

\footnotetext{
spaces is part of what defines our social and biological identities" Manuel DeLanda, "Space: Extensive and Intensive, Actual and Virtual," in Deleuze and Space, edited by Ian Buchanan and Gregg Lambert (Toronto: University of Toronto Press, 2005), 80. In addition to extensive space, DeLanda talks about intensive space and "zones of intensity". These zones or spaces are bound in a different way, such as that of temperature, pressure, gravity or tension. DeLanda, "Space: Extensive and Intensive, Actual and Virtual," 80.

${ }^{60}$ Rose, Visual Methodologies, 57.

${ }^{61}$ Rose, Visual Methodologies, 242.

${ }^{62}$ Reiser, interview, (2014).
} 
find processes of affective charge that in part play upon art practice traditions - where such image-making process partakes in informing, as well as being informed by- the design process and the practice's design ambitions. Importantly, this section proposes to further the discussion presented in Chapter 3 and 4 of this thesis, through an exploration of affective tinkering's that occur in image-making processes.

In discussing RUR's image-making practices, this section is divided into three parts. The first evaluates RUR's play on artistic effect of the panorama, to investigate ways to generate their "sweet spot" of the project. The second considers a process of playing off atmospheric painterly means and the third develops RUR's play upon the art practice of iconography/iconology. In discussing these image-making practices this section argues RUR's image-making is heavily invested in affective charge where the charge intensifies the surface of the images, thereby creating sticky images. RUR's image-making practice is as much about a process of the charge of the image as about a process of generating new strategies to design from- or design to- for the production of architecture.

\section{Image-making Practice of RUR}

It is important to address here the significance of image-making for RUR. Specifically, as the practice of RUR is exclusively defined by competition work. Reiser describes how competitions become a 'real-life vehicle' providing opportunities to explore formal and organizational interests, within the constraints of the specific programmatic requirements. This is tied directly to the publication of their work, and thereby, to the practice's investment in image-making. Whether these projects are built or not, RUR asserts through the publishing of their work "there is a psychological fact to have been able to hang in" ${ }^{\prime 63}$ as they generate critical response. It is this "sense of interest for it which kept us (the practice), and keeps us going, even if we don't win." RUR's research-in-practice operates through the 'vehicle of competitions' - where the practice finds a chance to do and continue their research interests. ${ }^{65}$ To further emphasize RUR's investment in image-making - Reiser explains their selective approach to submitting to competitions: "We don't do the completely anonymous. We used to, but we can't afford it." Specifically, for their recent project of Kaohsiung Port Terminal, Reiser recalls the competition guideline "asked for past work as part of the submission." ${ }^{97}$ Such criterion places value on, as well as acknowledges the importance of, constructing architectural images that indeed are attractive

\footnotetext{
${ }^{63}$ Reiser, interview, (2014).

${ }^{64}$ Reiser, interview, (2014).

${ }^{65}$ Reiser, interview, (2014).

${ }^{66}$ Reiser, interview, (2014).

${ }^{67}$ Reiser, interview, (2014).
} 
and appealing, where following Coleman, the "image as potential" promises a better optimistic future for the given site. ${ }^{68}$ Furthermore, RUR's image-making exists as a critical process within their design production where the images produced prior to construction offer important sites of investigation into RUR's image making practice and how they carry out their design research. Particularly, the images for Kaohsiung Port Terminal allow analysis of the strategies and processes employed by RUR to affectively charge their image.

It is also necessary to note at the start that the images analysed here could be categorized as 'final' in that they are printed out and used in design meetings and presentations to discuss the developing design amongst involved bodies. However, these images are also partaking in the design process, as they are used as image-sites to discuss ideas, and as communicative tools to project RUR's design ambitions. Here, the images hold potential to impact the temporal aspect of the design process, where at times the project may stutter, in either stilled or quickened ways. In this sense, the images analysed here are, indeed, "involved in the production of feelings and experiences" ${ }^{\prime 69}$ - and therefore are analysed as active agents pulling bodies towards the design, but also as sites of investigation and experimentation. ${ }^{70}$ Interplaying between art practice techniques and RUR's design ambitions and desires for the Kaohsiung Port Terminal, image-making in an on-going but stuttering process, works in generating sticky relationships through the site of the image.

\subsubsection{Playing off Panorama Effect}

The first part of this section attends to RUR's investment in the affective charge of their images, focusing on one particular interior panorama image, depicting what RUR call the "sweet spot"71 of the project. In doing so, it provides an account of RUR's play off the art practice of panorama, where these panoramic strategies contribute to the production of an image charged with affect. This thesis cannot provide a comprehensive review of discourse on the panorama, therefore this part aims to focus on two particular, and to some degree, paradoxical -ways in which the panorama effect is understood within visualization practices. The first is the effect of total

\footnotetext{
68 Coleman, Transforming Images, 29.

${ }^{69}$ Coleman, Transforming Images, 18.

70 The mediation of architecture through image, whether of its final form through photography or in its speculative phase through rendering is often considered as an 'architectural strategy' to capture "a pure architecture," attracting the viewer to the architecture in its material form, as opposed to architecture experienced. D.Medina Lasansky, in her review of the "hyper-visual mediation" of Milstein Hall at Cornell University, questions the gap between the architectural image, decontextualized from context, and the multi-sensory non-visual aspects of architecture. See D. Medina Lasanksy, "Sensationalizing OMA's Milstein Hall at Cornell University," The Senses \& Society 9, no.1 (2014): 99-107. RUR's images for their Kaohsiung Port Terminal, in contrast, suggests means of interplaying these two conditions - the visual and the sensual/immediate- in their image-making; concerned with how their building looks, but also, how it offers places of sensual and affective interactivity.

71 Reiser, interview, (2014).
} 
immersion. Precisely, as in Oliver Grau's account, the panorama embodies a 'suggestive power' whereby its role in art practice is to create illusion of presence and participation in reality as 'being there' through immersive totality. ${ }^{72}$ The second is the effect of uncanny disorientation. ${ }^{73}$ There is, indeed, something strange about the aesthetics of the panorama. The lack of vanishing point and confusing sense of depth creates a disturbing or uncanny effect whereby as Baudrillard puts it - the impact is an "aesthetic hallucination of reality." "74 And as Grau further expands, "the spectator is subjected to a deception that is complete." ${ }^{, 75}$ Particular to RUR's image-making practice, the analysis that follows also examines the uncanny through the overload of whiteness/cleanliness - which in turn generates an overload of affect. Here, the image partakes in a process of affective mediation, drawing and repelling bodies. It is precisely this paradoxical combination of both immersion and repulsion (through uncanniness) that describe the panorama effect.

RUR's composed panorama - is also a construction that involves the oscillation of immersion and repulsion. What follows considers the specific interior image that play on the panorama effect as a vehicle through which RUR's design ambitions are potentially realized (fig.1). Importantly, the analysis of the playful oscillation of immersion and repulsion makes evident the connection between RUR's design process and image-making process, and is divided into two aspects. The first looks at the design process of architectural pushing and pulling, whereby the architect's accounts are translated in RUR's image-making, creating an immersive and intensive affective surface. The second examines the production of uncanniness through RUR's deliberate over-load of whiteness/cleanliness. Such image-making process saturates the eye and creates a sense of unease - generating a surface of over-affect- and moreover, as it will be argued here, resulting in repulsion. The oscillating process between immersion (through affective pull/push) and repulsion (through an overload of whiteness) speaks directly to RUR's practice that invests in designing and shaping ambiance - that is, a faux/false-immersive ambiance (through the panorama effect) - that is indeed 'sticky.' In this sense, RUR make sticky images -

\footnotetext{
72 Grau. "Immersion and Interaction," 292-313. This article can also be accessed at: http://www.medienkunstnetz.de/themes/overview_of_media_art/immersion/. In this light, the hyper-realistic and virtual realities of the early panorama present perception as an event -allowing not a visuality against the real, but as a potential that may be realised in different actualities. As Angela Miller suggests, the panorama effect immerses the viewer where one loses sensibility through its immersive spectacle. Angela Miller, "The Panorama, the Cinema, and the Emergence of the Spectacular," Wide Angle 18, no.2 (1996): 40. As spectacle, the art practice of panorama offers a simulacrum of reality. Guy Debord, Society of the Spectacle (Detroit: Black and Red, [1967] 1983).

73 In using the term 'uncanny' in this chapter, the work of Anthony Vidler must be acknowledged. In his book The Architectural Uncanny, Vidler draws a relationship of the uncanny to art, which is useful for this thesis. Particularly, he writes, "[a]rt is then uncanny because it veils reality, and also because it tricks. But it does not trick because of what is in itself; rather it possesses the power to deceive because of the projected desire of the observer." Anthony Vidler, The Architectural Uncanny: Essays in the Modern Unhomely (Cambridge and London: MIT Press, 1992), 35.

${ }^{74}$ Jean Baudrillard, "The Hyper-realism of Simulation," in Art in Theory 1900-2000, edited by Charles Harrison and Paul Wood (Oxford: Blackwell Publishing, 1993), 1019.

75 Grau, "Immersion and Interaction." 292-313.
} 
not 'sticky' - in that it sticks to reality, but on the contrary, to be false and deceptive, and still sticky through affect's attracting/ repelling forces. ${ }^{76}$

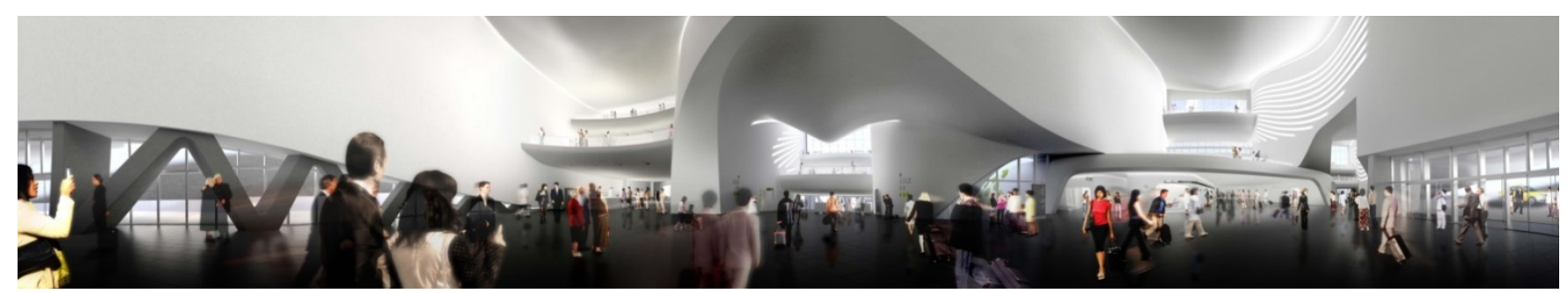

Fig. 1 RUR Architecture PC, Interior Visualization of Kaobsiung Port Terminal, 2013, digital render. ${ }^{77}$

\section{Immersion through Architectural Pull and Push}

First, what is important is the direct link made by Reiser himself between the interior visualization and the effects of the panorama. He notes: "This [image] is a kind of panoramic effect. I mean, this is flat, but you'd be rotating more .... Everything converges in this sweet spot." Such comment suggests the panorama's status beyond the still image - in other words, the scene, although not literally in motion, give the viewer possibility/suggestion of movement (through rotation), where the spectator is encompassed by the image - as if the action was happening along an immediate temporal and spatial continuity where, according to Reiser, "from that one spot ... you see everything." ${ }^{78}$ The convergence and compression of all 'things' at this particular spot accounts for RUR's play on the panoramic effect of immersion. However, this is further accentuated, and tinkered with, through the architectural pull and push occurring as part of the design process. Specifically, the design process involved in making this interior visualization is crucial in understanding how the image-making acts as a vehicle, or mediator and site to explore an affectively charged process. Reiser recounts on the ongoing tension between their practice and the 'logistics people' in developing the interior (depicted in the panorama image) of the port terminal:

\footnotetext{
${ }^{76}$ Moreover, while RUR's panorama is not literally "a circular pictorial representation," giving a 360-degree illusion of space, it is nevertheless a sticky image that provokes a sense of "being entrapped by the real." Oliver Grau, Virtual Art: From Illusion to Immersion (Cambridge/Mass.: MIT Press, 2013), 70.

${ }^{77}$ RUR Architecture PC, Interior Visualization of Kaobsinng Port Terminal, 2013, digital render, image (C) and courtesy of RUR Architecture PC.

${ }^{78}$ Reiser, interview, (2014).
} 
While we had very decided formal and organizational interests, there was always a really interesting friction [with the logistics team], a push back, well, you know, 'you can't get the conveyors to fit in this space' or 'how will cuing work in this non-regular space?' So that actually puts very good pressure on the project. You know, we are not, on the one hand just, systems managers, and making the most efficient terminal, let's say, from the point of view of baggage handling and cuing. But on the other hand, it puts a really good pressure on the project, its formal state. Because that does interest us. ${ }^{79}$

What is important is how such 'pressure,' as described by Reiser, influences the spatial design and is subsequently accentuated through the image-making process. The affective process of architectural pulling and pushing is crucial to point out here, where RUR's underestimation of the fire code requirements directly begins to modify the interior space, or more specifically, the "poché space" - which the project deals substantially with: "all the vertical movement, escalators, stairs and elevators, happen in these walls, in a thickened wall. So people will see the structure when they go inside the wall. It has a kind of Statue of Liberty impact." ${ }^{80}$ It is this thickened wall that is pulled and pushed through an affective stutter that occurs in the design process. As Reiser reflects:

What we weren't aware of were the fire codes. And there had to be a lot more space of refuge, more space around elevators and lobbies. Luckily, the poché idea was somewhat flexible. But those... parameters, all the requirements, to make the elevators and stairs work with the Taiwanese fire codes, which were much more stringent than here (US), meant that those spaces ruled. ${ }^{81}$

As things turn out, the most immediate effect is the expansion of the spaces in-between the architectural walls, that is, the poché spaces. According to Reiser,

[Architecturally] these spaces got wider. Overall, it didn't hurt anything. In a way, there was enough flexibility. But, you know, these were parameters that means - this wall started coming in - then there were issues of widths - to make sure all the flows would work properly, to get people to the gates and to the waiting areas. So there was a lot of pushing and pulling. ${ }^{82}$

This architectural push and pull, as a result of the 'good pressure' placed by the logistics people on the design process, is clearly depicted in RUR's image-making of the interior panorama. Here, the image-making seemingly acts as a device for RUR's practice to explore the compressingamplifying process of the poché spaces, as well as how these architectural tinkering's will alter,

\footnotetext{
${ }^{79}$ Reiser, interview, (2014).

80 Reiser, interview, (2014).

81 Reiser, interview, (2014)

82 Reiser, interview, (2014).
} 
enhance, or disturb the interior space. As such, the affectively charged design process generates affective charged images that in turn are feed back into the design development.

Importantly, the process involved in designing this interior has been enhanced through RUR's image making process, whereby the panorama effect of immersion has allowed for a continuous surface that appears to protrude forward, retrieve backward and project forward again- offering a new perception of spatial depth. As Reiser further reflects: "Everything is sheathed on both faces. We tried to keep the space really clean. So we took advantage of the idea of having a different internal form and surface than the external. It isn't just an offset, but it gets really thick." The illusion of the walls becoming thick is evident through this image where the undulating curvature of the walls provide a wider field of view, both distancing the body from the image, while immersing it - giving the interior space an impression of movement. In this sense, RUR's play on the panorama effect provides the practice with a wider visualization - allowing a collective, more engaging, 'sticky' experience within the 'expanded image space ${ }^{83}$ for the constituent parties involved in the project. In the case of such visualization, RUR's immersive image-making strategies render the image space an artificial construct that is nevertheless 'sticky'; pulling the body into (and out) the "sweet spot" where indeed, "everything converges."

\section{Repulsion through Overload of Whiteness}

Second, the effect of immersion is refracted through an uncanny sensation (or "feeling of unease $^{\text {" } 85}$ ) produced by RUR's overload of whiteness. The interior visualization is, indeed, flooded with whiteness, but deliberately so. As Reiser points out:

[There was] the idea of keeping the spaces internally relatively clean, so that there would be very directed views. I mean that was one of the things that were really important [and] I had it in the presentation. That when you enter the space, there is sort of a sweet spot when you enter that you can actually look down every single vista, and that it branches into the three spaces. So you'd be able to clearly see the programmes above as well as below, sort of panoramic idea. ${ }^{86}$

The overload of clean white space is thereby parallel to RUR's design intention, and is employed as a strategy to enhance the view of the port terminal's interior. This is further emphasized through RUR's design and image-making process of concealing luminosity (lighting).

Traditionally, in panorama works, lighting was natural, emanating from the top, but its source

\footnotetext{
83 This term is taken from Marius Nedelcu, "Expanded Image Space. From Panorama Image to Virtual Reality, through Cinema," Close Up: Film and Media Studies 1, no.1 (2013).

${ }^{84}$ Reiser, interview, (2014).

85 This illustration of the uncanny is taken from Elena del Río’s review of Anthony Vidler's The Architectural Uncanny. Elena del Río,

“The Architectural Uncanny: Essays in the Modern Unhomely by Anthony Vidler," Discourse 15, no.3 (Spring 1993 ): 178.

86 Reiser, interview, (2014).
} 
was concealed by a roof or veil that makes it impossible to see beyond the edge of the canvas. In RUR's panorama image - there is equally a form of affective tinkering through the use of intense lighting - much more than we see in reality, and is also concealed. As Reiser explains: "There are also ... articulations on the walls; there are cuts and stripes that bring light from the poche space. [The light] appears to be from the outside, but actually, it's from within the space in-between." ${ }^{, 87}$ Through this lighting, the white appears too bright, blurry, and visually disrupts the audience desensitizing them by the excess. The interior visualization, is therefore, uncannily white. This cleanliness (sterile) of the architectural surface through the overload of whiteness is able to overaffect the body - resulting in repulsion. As Mark Wigley, in conversation with Olafur Eliasson and Daniel Birnbaum on 'A Discussion on the Colour White,' remarks referring to Le Corbusier's position: for him, "the white wall exposes everything, not just a painting, but also your clothing, your body, your lifestyle .... So the white wall is a mechanism of surveillance, which purifies everything in front of it." ${ }^{\prime 88}$ But equally, and more importantly, when all surfaces of an interior space are white, Wigley claims "[the] supposedly innocent, modest, recessive white wall turns into a radical destabilizing act." ${ }^{, 89}$ In this manner, the over-load of whiteness generates an experience of over-affect where a sense of unease on the image accrues, but simultaneously, through the sheer spectacle effect, whiteness also envelopes and entraps bodies. ${ }^{90}$ The temporal entrapment creates an experience of a stilled stutter. This then, provokes a continuous oscillation between immersion and repulsion reinforcing the sticky-value of the image-surface.

Furthermore, as RUR emphasize - "We tried to keep the space really clean" - the function of whiteness (or absence of colour) in their image-making is evidently a device for the practice to explore and subsequently control, the 'ambiance' of the "sweet spot." As they assert:

The ambiance of the space... we felt, was something that an architect could control. I mean there is nothing new about that. But it was something that it wasn't going to be affected by programme - it would be about what you do to the architecture to produce the ambiance - the ambiance was totally something an architect should be handling. That's where they could actually affect something . . . . It's actually what you do to the space - and - so that's something that, in a way, has been, I don't know if it has been ignored. But it's something that I think has always been part of what an architect can do to change, to do something. ${ }^{91}$

\footnotetext{
${ }^{87}$ Reiser, interview, (2014).

${ }^{88}$ Mark Wigley, Olafur Eliasson and Daniel Birnbaum, "The Hegemony of TiO2: A Discussion on the Colour White; A Conversation between Mark Wigley, Olafur Eliasson and Daniel Birnbaum," in Olafur Eliasson: Your Engagement has Consequences; On the Relativity of Your Reality, edited by Studio Olafur Eliasson (Baden: Lars Müller Publishers, 2006).

${ }^{89}$ Wigley, Eliasson and Birnbaum, "The Hegemony of TiO2: A Discussion on the Colour White; A Conversation between Mark Wigley, Olafur Eliasson and Daniel Birnbaum."

90 As Ernest Pascucci writes, "In a psychoanalytic sense, white envelopes the most beautifully dumb substitute objects, on to which fantasies of pure form and good democracy are projected and acted out" Ernest Pascucci, cited in "Dancing in the Dark: The Construction of Blackness in Le Corbusier's Radiant City," in Architecture Theory, edited by Andrew Ballantyne, (London: Continuum, 2005), 228.

${ }^{91}$ Reiser, interview, (2014).
} 
Between the oscillating process of immersion through architectural pull/push and the unease through the overload/excess of whiteness and cleanliness, RUR create an 'affective resonant' ambiance - whereby the image becomes 'sticky.' In this sense, RUR's play off the art practice of the panorama effect not only contribute to the production of an image charged with affect, but further makes apparent RUR's design intention. In effect, image-making - particularly of this "sweet spot" - illustrates, well as partakes in- the design process of the Port Terminal. When analysed within the context of a practice (of architecture) that seeks to engage intensely with the making of visual representation - we can begin to view the panorama within a dialogue on the process of image creation and its interconnected relation to the process of design; the affective tinkering oscillating panorama effects of immersion and repulsion strengthen the connection between RUR's design-process and image-making process.

\subsubsection{Playing upon Atmospheric Means}

The second part of this section highlights further RUR's investment in the charging of their images with affect where the images act as participants in the design process, particularly of formgeneration. Specifically, the analysis focusses on two external visualizations constructed for the Kaohsiung Port Terminal - that play on atmospheric means that resonate with RUR's formmaking process. Broadly, the analysis asks - how is affect produced through different image-sites and moments of architectural design? And more specifically- what does it mean to design while considering atmosphere through image-making? In addressing these questions, this part concentrates the analysis on the expressive and immersive atmospheres that are tightly coupled to the design process involving what Reiser describes as "both the specific-tuning of the forms [of the Port Terminal] to the site and into the programming." ${ }^{93}$ Following Latham and McCormack's assertion that indeed "images are also blocks of sensation with an affective intensity" - the analysis which follows explores RUR's use of image-making that engages in the design process of "tuning of the form into the programming" that in part play upon variable active atmospheric means.

\footnotetext{
92 The reference here is to Silvan Tomkins' phrase 'affective resonance.' As developed by Tomkins, affect is a contagion, meaning that we resonate with others as we see expressions/emotions on the face. Silvan Tomkins, "What Are Affects?" in Shame and Its Sisters, edited by Eve Kosofsky Sedgwick and Adam Frank. (Durham: Duke University Press, 1995).

93 Reiser, interview, (2014).

${ }^{94}$ Reiser, interview, (2014).
} 
In particular, two positions guide the discussion and analysis on image-making attuned to atmospheres $^{95}$ and its connection to design processes. One is that of Ben Anderson who draws on Mikel Dufrenne offering insight of atmosphere as emanating from "the ensemble of elements that make up the aesthetic object."96 Importantly, Anderson extends Dufrenne's emphasis on the aesthetic object to include other atmospherics. As he claims, "[e]pochs, societies, seasons, couples, places, buildings and much more can be said to be atmospheric." ${ }^{.97}$ In this sense, atmosphere can be said to exist in all things, but also simultaneously "overflow[ing] the representational context of the aesthetic object," and thereby, can be contained and escaped. ${ }^{98}$ Such position is echoed by Philippopoulos-Mihalopoulos who describes atmosphere's overflow as an 'affective excess': "originating within the body, yet surpassing it, reaching out for other bodies and thus creating an atmosphere." ${ }^{.99}$ Indeed, such descriptions account for atmosphere's capacity to keep 'bodies together' and to generate stickiness. The second position is by Derek McCormack, who brings a notion of "affective materiality" to the term 'atmosphere. ${ }^{100}$ Drawing on Jane Bennett and her notion of "thing-power," McCormack accounts for how objects embody capacity to affect and to be affected. While McCormack's argument is articulated in the context of "aerostatic things," in the context of this analysis, it can be put to work in order to rethink how the affective materiality of cloudscapes and more specifically, activated atmospheres, can indeed hold a certain "thing-power" - an affective one. These two positions outlined above are particularly relevant in the context of RUR's image-making and its intertwined relation to their design process, as it focusses on atmosphere's "force of attraction," 101 instead of the term remaining an ambiguous concept. In thinking of atmospheres as a force, an appealing force that has potential to 'reach out,' suggests atmospheres as having a sticky quality - capable of drawing and pulling two or more bodies together. Thereby, drawing upon such works, the following analysis takes seriously the sticky and material force of activated atmospheres - and more importantly, how these atmospheric charges/forces employed by RUR in their image-making partakes in the design process of form-generation.

\footnotetext{
${ }^{95}$ Indeed, there are other prominent scholars on 'atmosphere' - see for example, Peter Sloterdijk, "Atmospheric Politics," in Making things Public: Atmospheres of Democracy, edited by Bruno Latour and Peter Weibel, 944-951 (Karlsruhe: ZKM and MIT Press, 2005). Mark Wigley, "The Architecture of Atmosphere," Daidalos 68 (1998): 18-27. Jonathan Hill, Weather Architecture (London: Routledge, 2012), 46-85. Also, Tim Ingold's concept of being immersed by the "weather-world." See for example, Tim Ingold, "The Eye of the Storm: Visual Perception and the Weather," Visual Studies 20, no.2 (2005): 98-104. The position by Gernot Böhme is also of interest - see, Gernot Böhme, "Atmosphere as the Fundamental Concept of a New Aesthetics," Thesis Eleven 36 (1993): 113-126.

${ }_{96}$ Ben Anderson, “Affective Atmospheres,” Emotion, Space and Society 2 (2009): 77-81.

${ }^{97}$ Anderson, "Affective Atmospheres," 79.

98 Anderson, "Affective Atmospheres," 79.

99 Andreas Philippopoulos-Mihalpoulos, “Atmospheres of Law: Senses, Affects, Lawscapes,” Emotion, Space and Society 7 (2012), 9.

100 Derek P. McCormack, "Aerostatic Spacing: On Things Becoming Lighter than Air," Transactions of the Institute of British

Geographers 34, no.1 (2009): 25-41.

101 Philippopoulos-Mihalpoulos, “Atmospheres of Law: Senses, Affects, Lawscapes,” 7.
} 
Specific to the Port Terminal project, the form-making design process involves a productive exchange between physical modelling and a more digitally orientating model making methods. As Reiser illustrates, "[t]here was a kind of rough diagram in CAD and then there was a wax model generated to start to work out the volume. And then ... people were modelling in the computer at the same time we were physically modelling. Both are happening in parallel." 102 It is through the simultaneous/parallel oscillating process between analogue-digital modelling that the form of Kaohsiung Port Terminal is generated, and importantly, through which visualizations/images are created. In this sense, an argument can be advanced to suggest that RUR's form-making investigation, which interplays between 2-D and 3-D mediums, is partially, if not directly, connected to the importance of image-making. Here, modelling and subsequently, image-making partakes in RUR's practices' valuation of their Port Terminal, generating images with what Mark Wigley would call "image-power." Image-making allows the practice to evaluate and compare between the changing forms developed at different stages. In the context of Kaohsiung Port Terminal, RUR uses image-making as a primary vehicle for their form-making design research - one that particularly deals with "fusing a tower building with a more laterally developing building connected to a landscape."

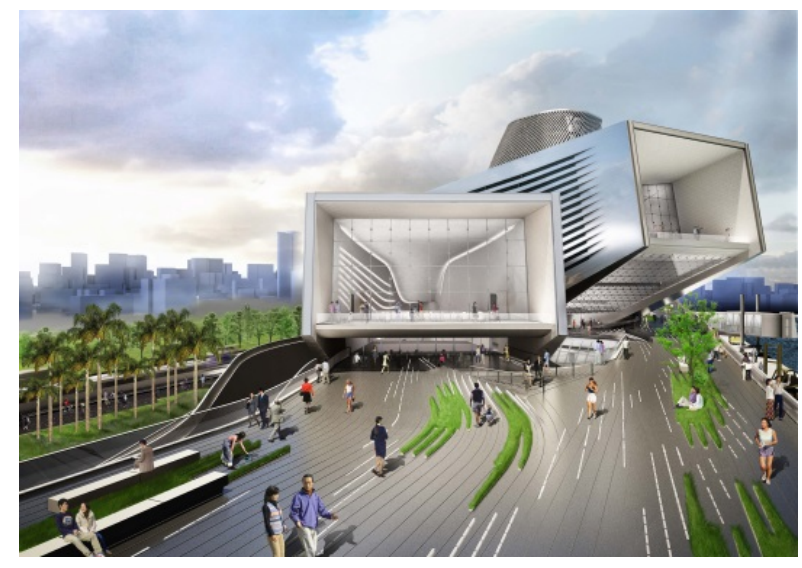

Fig. 2. RUR, Exterior Visualization, 2013, digital Render. ${ }^{104}$

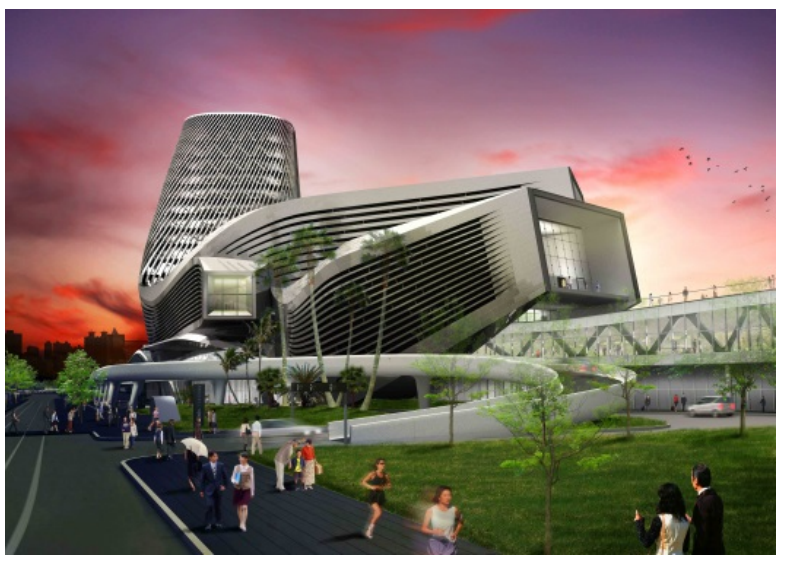

Fig. 3. RUR, Exterior Visualization, 2013, digital Render. ${ }^{105}$

\section{Tuning of the Forms into the Programming}

Of particular interest here are two exterior renders constructed for Kaohsiung Port Terminal depicting distinct perspectives of the terminal. What remains the same in both images is the play upon expressive and highly activate atmospheric scenes. What follows seeks to argue how RUR's

\footnotetext{
102 Reiser, interview, (2014).

103 Reiser, interview, (2014).

104 RUR Architecture PC, Exterior Visualization of Kaobsiung Port Terminal, 2013, digital render, image C and courtesy of RUR Architecture PC.

105 RUR Architecture PC, Exterior Visualization of Kaobsiung Port Terminal, 2013, digital render, image C and courtesy of RUR Architecture PC.
} 
image-making process partakes in RUR's design process of "specific-tuning of the form ... into the programming." In discussing the programming, RUR emphasize one particular concern raised by the clients - "there was concern about how the port-terminal will operate if there were no ships there. So, I guess that related to the kind of the mixed used ambition - that the boardwalk will keep the place active."106 As a direct response to this concern, RUR's images appear to focus-in on the boardwalk reflecting its maximum usability and performance illustrating the potential of an active public space. The focus on this boardwalk, is reflected particularly in the two visualizations constructed (Fig.2 and Fig.3), albeit in different degrees and visual angles, where RUR's image-making process lie somewhere in-between making an aesthetic/expressive and uncanny staged environment. In RUR's compositions, there is an element of tinkering play between modern architecture (Port Terminal), the elements of nature (cloudscapes) together with highly active everyday scenarios. Here, RUR populate the images with people engaged in a range of activities (talking on cell phones, jogging, sitting, gazing, and even watering plants). The foreground figures (in action) emphasize the possibility of an everyday active and affective environment - generating an active atmosphere emanating from these various ensembles of active and moving bodies. This image-making process thereby in part works with, and on - the appropriate fine-tuning of the port terminal forms with the required programming.

There is another connection worth evaluating. As Reiser comments, "They [the clients] wanted to maintain the kind of working industrial port, but they [also] wanted the kind of postindustrial public space to happen simultaneously. So we resolved it as a linear, as a kind of edge boardwalk that would be elevated."107 In order to emphasis the linearity, and equally, the horizontality of the project, RUR employ a design process of sectional stratification that both informs and is informed by the process of image construction. Reiser explains:

There was a built-in problem with two-dimensional planning. If you wanted to get a mixed-used site to work there that you couldn't do it just on the surface of the ground, you know, zoning. And so ... our solution came from the idea of bringing it up into the $3 \mathrm{D}$, and making a kind of sandwich, so that there would be a public space - the boardwalk was on the top, the terminals, in the middle, and the industrial thing at the bottom. ${ }^{108}$

The programme 'sandwich' is explored through in RUR's exterior visualizations - specifically their use of different angles, and faces of the terminal, begin to investigate the potential of this

\footnotetext{
106 Reiser, interview, (2014).

107 Reiser, interview, (2014).

108 Reiser, interview, (2014).
} 
programme stratification working from diverse orientations. Moreover, the 'activated space' also directs the viewer's gaze to the Port Terminal itself - which appears to loom out or stand boldly forth the surface of the image, and simultaneous recess backward to become part of the sublime backdrop (expressive cloudscape). These organic forms of the terminal, particularly, the various protruding ends (lobes) that project in different orientations, appear to be specifically-tuned with the active public space below (by making adjustments to the form in order to achieve the best or a desired performance). Reiser explains, "There is a port of authority tower, and then each of the lobes of that building is more or less orientated to a certain vector in the harbour and also pointing towards where ships would be docking." 109 These directional lobes highlight and direct the active public space. In order to further portray this, RUR's image-making invests in generating vector relationships between objects - generating a visual path from sky-scape, architectural object(s), to active boardwalk. In this sense, the images depict not a single 'object' or individualized components, rather, the affective and continuous flows between them -that is, their "interconnectedness... that finds expression in the continuity of temporal and spatial existence. ${ }^{" 110}$ Here, then, affect structures relationships and thereby, attachments, between people, things and ideas. This illustrates how RUR's design process of "specific-tuning of the forms ... into the programming" is, albeit in an experimental and testing form (designing through images), explored through their image-making.

The analysis of the external visualizations for Kaohsiung Port Terminal has allowed discussion of RUR's image-making as a process that slips over and into the design process itself, as an active participant in exploring form-generation. In a sense, RUR's images are not just representational - rather as affective mediator it captures the materiality of the atmospheres (through active atmospheres) - and its relation to the variant scenes, things and perspectives, including that of the port terminal - than in itself, changes throughout each image. This in turn echoes RUR's practice ambition: “There are ambitions of the office [practice] to make connections across scales that we wouldn't want to see architecture circumscribed, say by, only building design. But that it be connected to a larger scale system of infrastructure, landscape, and urban planning." ${ }^{111}$ RUR's image-making process is both an aesthetic and atmospheric process that also incorporates interconnected and diverse materialities (i.e. architectural object(s), boardwalk, and staged people).

Accordingly, RUR's image-making go beyond making photorealistic environments, and instead, do more with images. This is necessary for a practice that is based solely on competition

\footnotetext{
109 Reiser, interview, (2014).

110 Georg Simmel, “The Philosophy of Landscape,” Theory, Culture \& Society 24(7-8): 21.

111 Reiser, interview, (2013).
} 
work, where making-images that are "powerful, compelling and appealing"" is key to win over and attract certain people involved in the decision-making process of design competitions. In this regard, the making of Kaohsiung Port Terminal's external images is part of the critical process of design (rather than a by-product of the design process).

\subsubsection{Playing upon Iconography}

Lastly, this third section evaluates RUR's image-making as involving a play upon the art practice of iconography-iconology. This part examines a particular exterior visualization of Kaohsiung Port Terminal, where the image employs an iconic figure, within a highly hyper-real scene. In effect, the art practice of iconography-iconology, when played upon by the practice of RUR in their image-making process, may be taken not merely as a method of analysis but as a generative mode that produces new sensibilities, approaches and affective processes within design. Iconography, proposed through works by Aby Warburg was later developed most notably by Erwin Panofsky through his formulation of iconology. This latter method is a strategy for saying more about works of art (including images) beyond its formal analysis. According to Daniels and Cosgrove, such deep analysis involves "a kind of detective synthesis." 113 Panofsky importantly claims how the art practice of iconology might "emphatically differ from what [the artist] consciously intended to express." $" 114$ This section extends this claim to the architect - as well as extending the interpretation of symbolical values towards discovering affective values of the image. In this sense, the analysis is positioned within recent affective discourse, where there is a reaction toward the 'textual turn' (Panofsky); going from the semantic and the linguistic to the embodied, the affective and the material. Specifically, this research and analysis is positioned as part of this turn - and it does so with reference to (but not replicating) recently developed notions towards 'contemporary iconography.' Charles Jencks describes this 'new iconography' as involving cross-coding or double-coding, that is, "the mixture of an iconography based on cosmogenic themes set against another set of codes based on our contingent desires." 115 Such cross-coding's are affective in that there is a push-pull between, for instance, as Jencks puts it, "biomimesis, or morphology" and symbolism. These two set of codes act as strange and yet "richer and metaphysically more convincing" attractors. ${ }^{116}$ Applying such concept relative to architectural practices, Ben Pell describes Alejandro Zaera-Polo practice as investing in "the

\footnotetext{
112 Coleman, Transforming Images, 17.

113 Stephen Daniels and Denis Cosgrove, "Introduction: Iconography and Landscape," in The Iconography of Landscape, Denis Cosgrove and Stephen Daniels, eds. (Cambridge: Cambridge University Press, 1988), 2.

114 Panofsky, Meaning in the Visual Arts, 31. See also, http://w3.gril.univ-tlse2.fr/Proimago/LogiCoursimage/panofsky.htm

115 Charles Jencks, “Toward an Iconography of the Present," Anyone Corporation (3) (2004): 107.

116 Jencks, "Toward an Iconography of the Present," 107.
} 
convergence of material and performative logics with culturally-specific iconography is a strategy towards a kind of ulterior practice." 117 Indeed, in this sense, it could be said, 'contemporary iconography' provides for an affective image-making strategy. As it will become evident, the analysis of RUR's exterior visualization leads to a mixture of an iconographic strategy and forces of hyperreal expressions at play. The juxtaposition between a symbol of iconic figure and hyperrealism heightens the affective charge of the image - and is stickier than images based on a singular focus. Such sticky image works with and through specific design ambitions that RUR hold for Kaohsiung Port Terminal. The following seeks to establish first, the sticky character/iconic figure of Christina, and second, how this particular image construction can be seen to inform and enhance RUR's design process. It thereby highlights RUR's working method and the important exchange across their design ambitions and image creation.

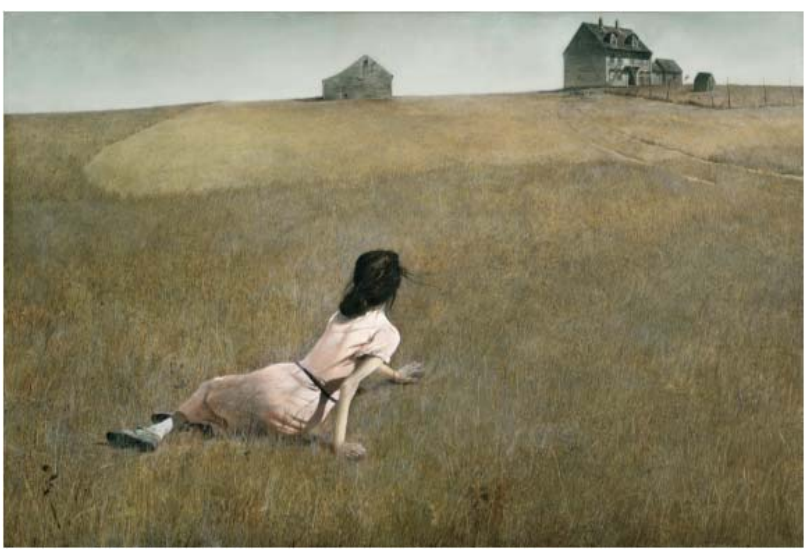

Fig.4: Andrew Wyeth, Christina's World, 1948, oil painting. ${ }^{118}$

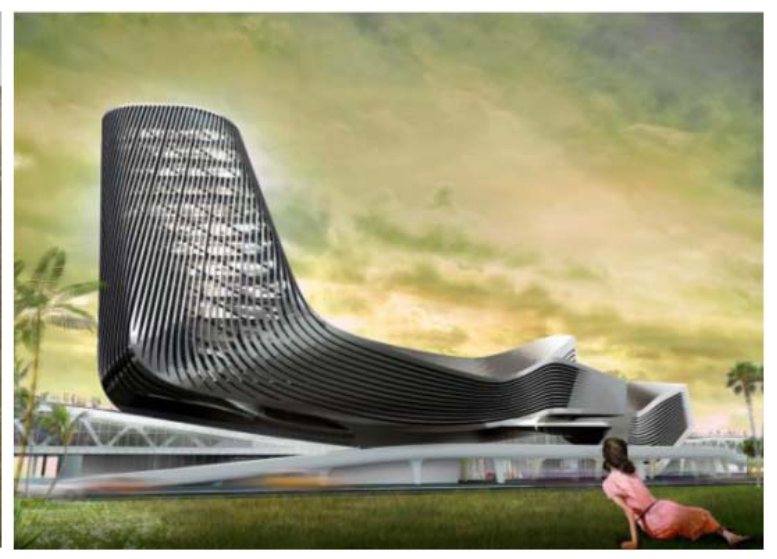

Fig. 5: RUR, Exterior Visualization, 2013, digital render. ${ }^{119}$

First, among the most obvious play upon artistic practice of iconography is RUR's inclusion of the symbolic figure of Christina Olson from Andrew Wyeth's 1948 painting of "Christina's world" (Figure 4). As art scholar Rendall C. Griffins has convincingly argued, Wyeth's painting is an "iconic image," overexposed and too familiar, making it a cliché ${ }^{120}$ and according to curator Laura J. Hoptman, extensively parodied. ${ }^{121}$ The iconic painting's diagonal composition and abrupt shift from foreground to background draws the viewer into the image space. At the foreground, is the

\footnotetext{
117 Ben Pell, “The Articulate Surface, Introduction," in The Articulate Surface: Ornament and Technology in Contemporary Architecture, Ben Pell, ed. (Basel: Birkhauser Press, 2010), 15.

118 Andrew Wyeth, Christina's World, 1948, painting, The Museum of Modern Art, New York, purchased 1949. Illustration from Thomas Hoving, Two Worlds of Andrew Wyeth: A Conversation with Andrew Wyeth (Boston: Houghton Mifflin Company, 1978), 118119.

119 RUR Architecture PC, 2013, Exterior Visualization of Kaohsiung Port Terminal, digital render, image (C) and courtesy of RUR Architecture PC.

120 Rendell C. Griffins, “Andrew Wyeth's Christina’s World: Normalizing the Abnormal Body,” American Art 24, no.2 (2010): 30 49.

${ }^{121}$ Laura J. Hoptman, Wyeth: Christina's World (One on One) (New York: The Museum of Modern Art, 2012). Hoptman notes in regards to the reproductions of "Christina's World" which was "widely parodied... the lone figure gazing longingly at a distance goal cheerfully co-opted to sell everything from pale ale to air conditioner."
} 
figure of Christina who was "in her mid-fifties, paraplegic, and weathered-looking, but Wyeth transformed her into a much younger, more winsome figure." ${ }^{122}$ To Wyeth, she is seen as a symbol of strength and perseverance; as he asserts, "Christina was not crippled at all." ${ }^{123}$ From the back, in a large field, "her silhouette is tense, almost frozen" ${ }^{124}$ but more importantly, this position of crawling toward her home "allows scope for a viewer's imagination and reinforces the timeless quality of the image." 125 In this sense, Christina's figure has been traditionally employed with affective intent.

That RUR employs the figure of Christina in their own image-making practice is both attracting and disturbing. Rather than conforming to the cliché associated to "Christina's World", Christina's figure is interpreted and transported into a different artistic space and medium (Fig.5). Reminiscent of Wyeth's comment when drawing Christina, "my cold eye took in the deformity and it shook me"126 - the viewer is equally disturbed, more so shocked, by seeing Christina decontextualized $^{127}$ - where Christina's figure pushes and pulls the scene with a kind of seductive force. RUR's play upon iconography focusses equally on details where they tinker with, manipulate and retouch surface properties, specifically the colour of Christina's dress and the texture of the grass where she lies, now taking on a hyper-saturated pink and green tone, respectively. Indeed, as Forsyth et al stress in the context of rethinking surface matters, "we must not overlook the ability of ... surfaces, textures, luminosity and colour ... to create a sense of wonder." 128 Attending to these components then, RUR's image-making plays on the iconic figure of Christina through the direct manipulation of colour, tone, and texture, as well as adjustment of scale and position, conveying a sense of uncanny suspension. In this sense, driven by the logic of Ahmed's 'sticky' (through familiarity) affects, RUR's image-making is both intentional and unanticipatory, being something we deliberately turn ourselves towards - but equally repel. Having established the sticky character of Christina, this part moves forward to evaluate how RUR's play upon Christina (as iconic figure) - acts as a vehicle (affective mediator) to both attune to-and express potential in/through the development of the Kaohsiung Port Terminal project.

\footnotetext{
122 Hoptman, Wyeth: Christina's World, 21.

123 Wyeth, "Two Worlds of Andrew Wyeth: Kuerners and Olsons," 134. Wyeth writes: "I know I was getting pretty close to putting Christina in the position I wanted, the arms and everything, you know, where it showed the tragedy as well as the joyfulness of her life." Andrew Wyeth, quoted in Thomas Hoving and Andrew Wyeth, et al. "Two Worlds of Andrew Wyeth: Kuerners and Olsons," The Metropolitan Museum of Art Bulletin, New Series 34, no.2 (1976), 133.

${ }^{124}$ Hoptman, Wyeth: Christina's World, 5.

125 Hoptman, Wyeth: Christina's World, 21.

126 Wyeth quoted in Hoptman, Wyeth: Christina's World, 22.

${ }^{127}$ Christina is decontextualized in the way she is placed in RUR's image in $20^{\text {th }}$ Century Taiwan - or this place could be in what Marc Augé calls a 'non-place.' Marc Augé, Non-Places: Introduction to an Anthropology of Supermodernity, translated by John Howe (London and New York: Verso Books, 1995).

128 Isla Forsyth, Hayden Lorimer, Peter Merriman and James Robinson, "What are surfaces?," Environment and Planning A 45, no.5 (2013): 1014.
} 
RUR's play upon iconography is not only about re-interpreting and transposing Christina's figure - rather, it is also about its association within the larger context, the visualized setting. Clearly, there is no attempt to mask the constructed nature of mixing the symbolic reference of Christina and the high modernity scene where RUR's Port Terminal building is visualized. Here, the analysis takes the eye diagonally from foreground to background -examining the tension as well as attraction between the two bodies. Importantly, Christina's calculated posturing - now reversed from Wyeth's original position - accentuates precisely the synthetic character of her reclining body, where almost intentionally, the rounded forms of her body are echoed in the curved outline of the building. This smooth surface is further enhanced through, albeit subtly, a blurring hyper-real effect where the outline of the port terminal is fuzzy, lines fade with atmospheric effects - purposefully rounding off the edges, intensifying the surface curvature of the building shape. The ironic parallelism between the port terminal and the figure highlights an important exchange across RUR's image-making play on the artistic means of iconography and a particular design ambition. Whereas Christina's symbolic figure is clothed with a single continuous surface, the Port Terminal desires this singular surface continuity. As Reiser recalls on being presented with a positive structural solution by the engineers:

[T] he things that we couldn't know, or we didn't know, was whether these [forms] would be separated structures or more continuous -because there is a whole seismic problem of Taiwan and how these things would behave structurally - with lateral forces and all that. And that's something that we were really happy about - that it could be ... it should be all tied together. It should be one continuous structure, rather than a discrete tower and lobes. But it matched the form perfectly. ${ }^{129}$

Such account attends to, first, form-generation in RUR's practice as always investigatory orientated (that is, structural specifications coming into the design somewhat at a later stage), whereby form is manipulated to conform to a particular design ambition - in this case, a desire for one continuous building, connected as one form structurally, rather than three distinct forms. Hence, in RUR's images, it is the continuous and multiple undulating contours on the terminal that captures our attention. In this regard, and second, it is significant to acknowledge RUR's image-making as a site to examine how this all-connected 'continuous structure' may be enhanced. While RUR did not speak directly regarding the iconic image of Christina (as a sticky figure in art practice), the figure nevertheless partakes of and participates in the accentuation of the terminal's form. Indeed, it could be suggested how RUR play on the figure of Christina as a way to accentuate their design ambition - creating a visual flow from foregrounded Christina's curved figure, to the "one continuous structure" of the port terminal.

\footnotetext{
${ }^{129}$ Reiser, interview, (2014).
} 
Ironically, while the structure is 'tied together' - the surface, or, more accurately, surfaces, are composed of multiple panels all varying in degrees of curvature. Some of these panels of sheetrock, according to Reiser, "would be totally flat, [others] could be torqued into space without being custom made ... [others] would be compound and complicated and expensive."130 In the design process, RUR develops smooth and rough zones on the panelling through manipulating the "speed of curves," so that the surfaces "look like they are curved but they are actually flat." 131 This is where RUR's concept of "a-perception" comes in, that is, in Reiser's words "what you unconsciously intuit from the development of the tectonic. So that you can't figure out why exactly, as a viewer, but then, nevertheless, there is quite a vivid sense." 132 This experiential 'a-perceptive' illusion is directly tied to how RUR control their 'ambiance' - as they put it: "It's a whole set of coordinated moves that creates certain [ambiance] effects. For example, in Kaohsiung ... we are playing with the modulations [of panel curvature] to change the perception." ${ }^{\prime 133}$ Here, the image surface is charged with an affective current that blurs both reality and imagination; stilling present and future temporalities. ${ }^{134}$

Therefore, in this particular exterior visualization, the above evaluation suggests how RUR projects Christina "gazing longingly at a distance goal," ${ }^{135}$ seducing the viewer to follow her contour and the contour of the smooth and almost polished-like surface of the port terminal, which in actuality, consists of multiple layered surfaces. This creates a space of stilled affective stutter in the design process. We are not just seeing a building as an object, but as 'a building being looked at,' and in this sense, although RUR's visualization is a static image, the image has duration and thereby encompasses time. This is further accentuated by the motion blur of the cars depicted through an accelerated/exaggerated speed, heightening the effects of hyperrealism (in actuality, no matter how fast the speed of a car, one sees it, yet here, we cannot or do not) further provoking disorientation in terms of the scene being unreal or real (or hyperreal), normal or distorted, static or moving.

Affirming RUR's image's seductive and affective power, the exterior visualization analysed here plays with a high degree of familiarity through the recognition of an iconic figure providing a highly sticky surface. This particular image uses the symbolic figure of Christina to allow for a slippage of high art and contemporary architecture within a hyper-real setting.

\footnotetext{
130 Reiser, interview, (2014).

131 Reiser, interview, (2014).

132 Reiser, interview, (2014).

133 Reiser, interview, (2014).

134 Ironically, the multiplicity of different panels of sheetrock and more significantly, the 'curved' look of the port terminal generates, as Reiser recalls, "a lot of tension and a lot of anxiety" in the project's tendering process. Here, "the contractors... saw all those curves - and they weren't confident that they could come in at the price that was required by the government" Reiser, interview, (2014).

135 Hoptman, Wyeth: Christina's World, 7.
} 
Referring again to Jencks' proposition on 'new iconography' as involving cross-coding, ${ }^{136}$ in effect, the analysis of this exterior visualization leads to a play (of cross-coding) between iconography and forces of experiential illusion and hyper-reality. The juxtaposition and contrast between these two themes (codes) heightens affect - and is stickier than images based on a singular focus. As in Wyeth's “Christina's World," in RUR's affectively charged image, there is a surreal combination of beauty, illusion and, (borrowing Baudrillard's words), “nondeliberate parody." ${ }^{137}$ RUR's imagemaking process is hence not to render or construct reality (and is thus opposed to the current trend in visualizations towards the 'photoreal'); rather, the analysis above argues how RUR employ the art practice of iconography in pursuit of constructing compositions that are slightly out of kilter, and as a consequence, crafting highly sticky-images. Arguably, such process of image-making involves consideration of both quickened and stilled stutters, whereby in its collapse, affect is heightened.

\section{Brief Reflection on Analysis}

The above three analysis of RUR's play on different art practices considers seriously the role and purpose of image-making in the design process of architectural projects. For by pointing to critical and intertwined aspects of image-making and design processes, we may consider how the designing through images contributes to the creation and construction of architecture.

Particularly, image-making offers RUR a tool/strategy that allow their practice to widely investigate Kaohsiung Port Terminal's surface-articulation, form-development and its tuning to the specific site and programming, as well as, and perhaps most significantly, their 'sweet spot' interior space generation. Thinking through and designing through image-making then, allows for testing, tinkering, experiencing and imagining how the terminal might be, even if only at the speculative level. Such notion alludes back to Chapter 4 where the practice of architecture was placed in the extended present (through stilled stutters), but always necessarily looking towards and anticipating the future (through quickened stutters). Each image analysed in this chapter hold a promising and appealing (and sticky) future for the waterfront dock site in Taiwan. Thinking through sticky-images this chapter concludes by considering some of the implications of extending the theory of affect to account for architectural practices invested in image-making.

\footnotetext{
136 Jencks, "Toward an Iconography of the Present," 107.

137 Jean Baudrillard, “The Hyper-realism of Simulation," in Art in Theory 1900-2000, Charles Harrison and Paul Wood eds.

(Oxford: Blackwell Publishing, 1993), 1020.
} 


\subsection{CONCLUDING DISCUSSION}

This chapter began with a review of critical discourse on architecture in images, imaging architecture and image in architecture. In this context, the analysis of the case study practice of RUR focussed precisely on their engagement with image-making processes, through the lens of affect. By considering affect, the images are seen as sites of potential - attracting and appealing to bodies that come in its proximity, thereby sticky image-sites. Where RUR's design evaluation reflectively points to - is the fact that there is some kind of parallel image-making process (involving both affective mediation and tinkering activities) operating in and through their design process - often driven by particular design motivations. Reflecting on Murray Fraser's words on the role of design research as having the potential to "influence the design process as it is happening," "138 this section has attempted to argue RUR's image making as capable of being informed by - and informing, RUR's design research and ambitions. These ambitions can trigger both stilled and quickened stutters in the design process. Particularly, RUR's image-making practice is as much about a process of the charge of the image as about a process of generating new strategies to design from- or design to- for the production of architecture. This method of investigating how images and image-making can inform and be informed by the design process, and moreover, how they can create a surplus of affect, thereby making sticky-images, can be useful for designers at large, as a tool of research in the design process.

\section{Affective Stutter of Image-making}

By way of conclusion, but also for clarification, it is necessary to comment briefly on the timing of the images analysed in this chapter. Each image is a constructed digital visualization made before construction of the Kaohsiung Port Terminal began. In this sense, throughout the chapter, it has been suggested how these images partake in the design process - and thereby are not considered 'final' images (or finished processes). Rather, they are working-images in that they are open to subtle adjustments to the proposed form, material and colour alterations, as well as acting as tools to project and communicate desired moods and feelings of the visualized spaces. Often, this openness of digital visualization can impact the design process through stilled and quickened stutters. Indeed, as in any architectural project, the design can (and in most cases, does) change even in its final stages of documentation. Therefore, in this thesis, the analysed sticky-images are seen in its active form; reflecting a point made by Coleman, where "[i]mages $d o$;

138 Murray Fraser, "Introduction," in Design Research in Architecture: An Overview, edited by Murray Fraser (London: Ashgate, 2013), 1. 
they are involved in the production of feelings and experiences" ${ }^{\prime 139}$ - and by extension, generating sticky attachments through affect. Furthermore, while the images are not 'real' in that they are computer rendered visualizations, they are potential realities. It is through this potential (vs. reality/actual), precisely in how RUR's images are painterly, surreal, exaggerated, working on spectacularity - that they open up to possibilities that is different from the present.

Finally, in returning to the larger aim of this thesis, what follows seeks to discuss some of the implications of extending affect theory to account for image-making processes in practices of architecture. Most notably, and as mentioned throughout this chapter, the recent work by Coleman on Transforming Images: Screens, Affect and Futures is helpful here. While Coleman's focus is on television and billboard images including promotional images used for campaigns such as Change4Life, her position on "image as potential" 140 points also to architectural practices' imagemaking invested in generating "affective appeal"141. In the case of architecture, this affective charm or charge reinforces a sense of an optimistic future that is yet to be realized, where the image-in-making are sites of experimentation and affective tinkering's (hence, never final), or in the case of Kaohsiung Port Terminal project, sites of playing on- and off- artistic techniques, pulling bodies towards the design through affective means. As discussed through the analysis section of this chapter (5.4), by bringing in artistic means, RUR's image-making is invested in the building for affective spectacularity through the surface of the image. Extending notions of affect (as a capacity to move/act and affect bodies, as well as be affected by them) to image-making processes in practices of architecture demonstrates ways in which affect can be experimented onand through-, as well as tinkered with- image constructions that project neither the real nor fake. Rather, and as argued in Chapter 4, RUR's images analysed in this chapter illustrate a temporality that is out of real-time: the image surface connects the present (yet-ness) and the future (not-yetness) through affective stutters. By doing so, the practice of RUR creates active image-sites of affectability/stickiness between, as Ahmed writes, the "now to the not yet"142 - the extended present to the near future.

The next chapter continues to unpack how affect partakes in everyday architectural practices, specifically design processes. Specifically, it considers the case study practice of Kerstin Thompson Associates and their Monash University Museum of Art project. The chapter analyses and aims to illustrate how affects hold together and animate/activate design processes through its stickiness, accounting for sticky processes. By investigating the sticky-interplay between two distinct design processes, the chapter argues that it is in their oscillation, continual dialogue and

\footnotetext{
139 Coleman, Transforming Images, 18.

140 Coleman, Transforming Images, 29.

141 Coleman, Transforming Images, 89.

142 Ahmed, "This Other and Other Others," 562.
} 
co-constitution that we are able to discuss critically how affect (as stickiness-in-process) may be situated in practice. 


\section{6.}

Kerstin Thompson Architects: Sticky Process

\subsection{INTRODUCTION}

The previous chapter (Chapter 5) focussed on the practice of RUR and their affective imagemaking process that partakes in informing, and in being informed by - the design process for Kaohsiung Port Terminal project. Particularly, it gave some conclusions on how image-making practice is as much about a process of the charge of the image as about a process of generating new strategies to design from- or design to- for the production of architecture. At issue here was to "make more of image," where images become sticky through affect. Chapter 6 continues to provide a more grounded attempt to think about the relationship between affect and practice. It does so by evaluating a second case study of an affective architectural practice and design project: Kerstin Thompson Architects (hereafter referred to as KTA) and the design process for their Monash University Museum of Art (hereafter referred to as MUMA).

At this point, it is necessary to clarify on two terms, 'practice' and 'process,' as used in this chapter. While these terms are used interchangeably at times, the researcher acknowledges there are fundamental differences. Unlike 'practice,' which suggests something absolute and fixed, or as Jane M. Jacobs describes it, "authoritative,"” the word 'process' always has something of the temporary about it. Referring to sets of relations, process is inherently in-motion, generating relationships through effects, experiences and interactions. In this sense, and as explored indepth in Chapter 3 of this thesis, 'process' is connected to notions of 'practicing' architectures, as proposed by Jane M. Jacobs and Peter Merriman, ${ }^{3}$ as well as explored by Peggy Deamer in her writing 'Practicing Practice.' The move from noun to verb (practice to practicing) helps to discover potentials of generative and relational design processes. Specifically, this chapter seeks to situate affect within interplay of architectural design processes. The question investigated here is twofold: first, how can practices and design processes be apprehended through the concept of affect. More specifically, and second, how do affects hold together (through stilled stutters) and animate different ways of designing (through quickened stutters) through its stickiness, accounting for sticky processes. The chapter will show how affect as stickiness-in-process, enables KTA to bring together seemingly disparate design processes: first, a hunch-driven process (quickened affective stutter) and, second, a textual-literally driven process, that share a productive relationship through the affective medium of diagramming. This interplay generates

\footnotetext{
${ }^{1}$ Latham and McCormack, "Thinking with Images," 252.

2 Jane M. Jacobs, 'A Geography of Big Things,' Cultural Geographies 13 (2006): 12.

3 Jacobs and Merriman, "Practicing Architecture," 211-222.
} 
different yet interlinked iterations of diagrammatic spatial configurations for MUMA used both as a communicative as well as generative tool producing a multitude of possible design conditions, effects, and atmospheres, as well as the final design outcome.

This chapter is divided into five sections, including this introductory section (6.1). Section 6.2 lays out the context of this chapter by reviewing architectural discussions on atmospheres. This section also provides a brief outline of the platform of this chapter's research exploring Sara Ahmed's notion of sticky affects. Ahmed argues affect has a sticky property which allows objects and ideas to generate attachments. ${ }^{4}$ While Ahmed's position has been elaborated and discussed in Chapter 2 of this thesis, this chapter seeks to extend her concept of 'stickiness' to incorporate design situations and processes as sticky. In this sense, affect is understood as a sticky connective element, providing a way to situate it in the interplays between two distinct design processes. Following from this, Section 6.3 illustrates the case study and methodology specific to this chapter, and is divided in two. First, it introduces the case study architectural practice of KTA and the analysed project of MUMA. Then, and second, it briefly illustrates the specific methodology used for the study. Briefly, the material investigated for this study includes in-depth interviews with architect Kerstin Thompson and senior curator of MUMA, Geraldine Barlow, as well as drawings and textual material, the latter specifically referring to Rémy Zaugg's literary text on museum design, 'Das Museum, das ich rmir ertaume. ${ }^{5}$

Section 6.4 then examines the different processes involved in developing the spatial formations and organizations of MUMA. Two things are interweaved and explored throughout the analysis: 1) the idea of situating affect through its stickiness-in-process (generating stilled stutters), and 2) the design process of KTA in which Thompson alternates between two seemingly contrasting design processes, an intuitive hunch-driven process and a more defined literary-driven process. The interest here is to understand how she shifts from one to the other through three themes that were identified from the interviews: the curve problem, the corner problem, and the servicing problem. Finally, Section 6.5 begins by discussing the importance of situating affect within active forces and interplays that partake in the process of making architectures. The concept of affect allows a way to apprehend practice and design processes as a situation open to change and contingency, through both stilled and quickened stutters. Reflecting on this, the chapter gives some concluding considerations in extending the theory of affect to account for affective possibilities arousing and operating through sticky design processes.

\footnotetext{
${ }^{4}$ Ahmed, 'Happy Objects,' 29.

${ }^{5}$ Rémy Zaugg, The Art Museum of My Dreams, or A Place for the Work and the Human Being, translated by Liz Libbrecht, (Berlin: Sternberg Press, 2013).
} 


\subsubsection{Intersections between Architecture, Atmosphere, Diagramming and Affect}

Architectural discussions have been increasingly attentive to atmospheres - notably, through two interrelated discourses. The first expands on Mark Wigley's claim of "architecture is defined by atmosphere" and Gernot Böhme's notion of 'architectural atmospheres. ${ }^{77}$ Together, they take seriously the connection between sensual experience and architecture's atmospheric dimensions, often conceived through the production of material effects (including immaterial materiality such as light). ${ }^{8}$ Indeed, as Böhme suggests, practices (including architectural practices) can generate or manipulate conditions of intensified atmospheres. ' Informing- and informed by- Böhme's position, (as well as influenced by theorist Maurice Merleau-Ponty), architects including Peter Zumthor and Juhani Pallasmaa are 'building atmospheres ${ }^{10}$ through architectural effects and intensities; their designs invite affection and stimulate the body's sensory-motor functions. This interest in atmospheres suggests a focus away from architecture as 'object' - towards architecture as contingent constructions of spatial experiences. The second trajectory relating architecture and atmosphere has been seen through the recent theorization of 'affective atmospheres' in human geography. Scholars such as Ben Anderson ${ }^{11}$, David Bissell ${ }^{12}$ and Derek McCormack ${ }^{13}$ offer accounts of the force of atmospheres through affect (nonrepresentational registers). In this context, affective atmospheres are seen as "a pull or a charge" 14 that have the capacity to "interrupt, perturb and haunt ... persons, places or things"15 as well as architectures, both static and mobile (i.e. spaces of public transport). Within the same field, but more directly speaking toand through- architectural practices, Jane M. Jacobs and Peter Merriman reflect on works by

\footnotetext{
6 Wigley, “The Architecture of Atmosphere," 18-27.

7 Gernot Böhme, “Atmosphere as the Subject Matter of Architecture," in Herzog \& de Meuron. Natural History, edited by P. Ursprung, (London: Lars Muller Publishers, 2006).

${ }^{8}$ In his essay "Atmosphere as the Fundamental Concept of a New Aesthetics," Gernot Böhme illustrates the term 'atmosphere' as a space of interstitial condition binding subjects and objects. As such, 'atmosphere' may be thought to confound any straightforward appeal to subjective or objective accounts. They foster in fact in-determinate affective conditions. Yet, it is incumbent on us to think the material qualities of atmospheres, their agencies and relational processes. In this way, and following Böhme, the attempt to materialize and localize atmosphere in architectural design brings about the potential for a space of affective materiality. See Böhme, "Atmosphere as the Fundamental Concept of a New Aesthetics," 113-126.

${ }_{9}^{9}$ Böhme, "Atmosphere as the Subject Matter of Architecture," 113-126. This is articulated by Ben Anderson. Referencing Böhme, Anderson writes: "[b]y creating and arranging lights, sounds, symbols, texts and much more, atmospheres are 'enhanced', 'transformed', 'intensified', 'shaped', and otherwise intervened on" Anderson, "Affective Atmospheres," 80.

10 This phase refers to the title for the recent OASE Journal of Architecture. "OASE \#91: Building Atmosphere: Material, Detail and Atmosphere in Architectural practice," edited by Klaske Havik, Hans Teerds, Gus Tielens, Peter Zumthor, Juhani Pallasmaa, OASE Journal of Architecture, (nai010 Publishers, 2013).

11 Anderson, "Affective Atmospheres," 77-81.

12 David Bissell, "Passenger Mobilities: Affective Atmospheres and the Sociality of Public Transport," Environment and planning D: Society and Space 28, no.2 (2010): 270-289. Here, Bissell attends to affects in public architectures, specifically of public transport.

13 McCormack, "Engineering Affective Atmospheres," 413-430.

14 Bissell,"Passenger Mobilities," 273.

15 Anderson, "Affective Atmospheres," 78.
} 
Peter Adey and Peter Kraftl ${ }^{16}$, who attend to the cultivation of affects in architectural designs and built works. ${ }^{17}$ They trace the co-production of affective capacities that "engender particular modes of inhabitation" $" 18$ and experience of a building. Joining these writings is a strong orientation towards understanding and analysing atmospheres within already-built architectures. This chapter both draws upon and wishes to extend these discussions to consider architectural design process as part of the elaboration of an atmospheric sensibility. In particular, it explores how processes (that occur before construction) produce and are produced by affective powers. In this sense, and in the analysis that follows, design processes are seen through their multiple situations and affective stutters, that is, sets of relations open to fluctuations and contingency.

The precise notion of an approach to the design of architecture as a situation(s) connects to the design process as spatial-temporal, experiential conditions moved by relationships, rather than being focused on problem-solving and form-creation. For contemporary design practices, to advance/progress beyond a traditional, linear trajectory requires reframing design as an intertwining, entangling, and stuttering, of the variation of conditions and situations that emerge from specific architectural projects. This chapter hence begins to reconsider and resituate the process of design, the negotiations between different parties, experiences and affects that develop through associations and tensions - as well as accounting for sticky attachments. ${ }^{19}$ Particular to the case study discussed in this chapter, the design process for MUMA is largely driven by vacillating interplay between a hunch-driven process and a more formal literary process. In regards to the former process, the hunch is here referred to also as an affective quickened stutter, where affect allows ways of conceptualizing the pre-conscious, pre-intentional, pre-verbal processes that occur in architecture's making. Allowing these quickened stutters, hunches and approximations to partake in design processes provides potential for design/creative processes to include, in Perry Kulper's view, “an expanded set of constituencies, or possible participants, real,

\footnotetext{
16 Adey, "Airports, Mobility and the Calculative Architecture of Affective Control," 438-451. See also, Peter Kraftl, "Geographies of Architecture: The Multiple Lives of Buildings," Geography Compass 4 (2010): 402-415. And, Kraftl and Adey,

"Architecture/Affect/Inhabitation," 213-231.

17 Jacobs and Merriman, "Practicing Architectures," 217-218.

${ }^{18} \mathrm{Kraftl}$ and Adey, "Architecture/Affect/Inhabitation," 215.

${ }_{19}$ Parallel to architectural discourse, the field of 'interiors' is increasingly framed in the realm of 'expanded spatial practices' to explore conditions and possibilities for cross-disciplinary as well as trans-disciplinary approaches. Gini Lee takes up a similar theme, (re)framing the making of interiors as a "collaborative ephemeral practice." Gini Lee, "Curatorial Thinking: Performance Space and Interior," in Thinking Inside the Box: A Reader in Interiors for the 21st Century, edited by John Gigli, Frazer Hay, Ed Hollis, Andrew Milligan, Alex Milton and Drew Plunkett (London: Middlesex University, 2007), 12. This connects us to a general shift in interior practice towards engaging with atmospheric interiors where affect plays an important role in shaping interior space. As noted by Julieanna Preston, interiors are "ambient environments delimited by the aura of affect and subjectivity" Julieanna Preston, "Introduction: In the Mi(d)st Of," Architectural Design 78, no.3 (2008): 8. Equally, attesting interiors relative to affect, Suzie Attiwill emphasises interior as "composed of relations, phenomenal and emotive" Suzie Attiwill, "What's in a Canon?" in Thinking Inside the Box: A Reader in Interiors for the 21st Century (London: Middlesex University Press, 2007), 63. See also, Jill M. Franz and Steffen Lehmann, "Side-By-Side: A Pedagogical Basis for (Design) Transdisciplinarity." IDEA Journal (2004): 9-30.
} 
conceptualized and as yet unimaginable." 20 This coupling (co-existence of 'fairly certain ideas and hunches'), specifically in the context of this chapter, leads to contrasting and contradictory spatial qualities of informal and formal, that is, idiosyncratic and neutral spaces.

As seen in this chapter, the iterative and reciprocal interplay of design processes are activated through operative and mediating instrument of diagramming - where diagrams become generative tools rather than a fixed and prescriptive approach. While this chapter does not attempt to engage in a substantive review of the intersections between diagramming and architecture, it seeks to present some useful (and current) orientations that draw on Deleuze's assertion of the diagram as an "abstract machine." ${ }^{21}$ Focussing on the potential generative and transformative power of diagramming, architectural scholars such as Stan Allen, ${ }^{22}$ Peter Eisenman, ${ }^{23}$ Sanford Kwinter, ${ }^{24}$ and Robert Somol, ${ }^{25}$ as well as geographers such as Mark Paterson ${ }^{26}$ and Derek McCormack, ${ }^{27}$ account for two interrelated characteristics which are particularly relevant to this chapter. First, diagramming is fundamentally an exploratory and experimental process. In this manner, diagramming takes the role of a mediating participant in the production of architectural space, or as Eisenman puts it, the diagram "acts as an intermediary in the process of generation of real space and time." ${ }^{28}$ Anthony Vidler equally insists on its mediating quality, referring to Somol's stance on the diagram as the 'matter of architecture', he writes: "Operating between form and word, space and language, the diagram is both constitutive and projective; it is performative rather than representational." 29 Diagramming thereby operates, albeit abstractly, as an instrumental and affective medium, that is, as "intervening apparatus" between "unformed matters and functions." 30

It flows from this, and second, that diagramming is an active process, whereby it partakes in what McCormack describes as the "distribution of the power to affect and the power to be

\footnotetext{
${ }^{20}$ Perry Kulper, "Drawing Architecture, Conversation with Perry Kulper," WAI Think Tank, accessed August 15, 2014, http://waithinktank.com/

21 Gilles Deleuze, A Thousand Plateaus (London: Athlon Press, 1988), 141-142; cited in Stan Allen, "Diagram Matter," in Any: Diagram Work 23 (1998), 16. The full quote reads: "The diagrammatic or the abstract machine does not function to represent, even something real, but rather constrcuts a real that is yet to come, a new type of reality."

22 Allen, "Diagram Matter," in Any: Diagram Work 23 (1998).

23 Peter Eisenman, Diagram Diaries (London: Thames \& Hudson, 1999). See also, Peter Eisenman, "Diagram: An Original Scene of Writing," in The Diagrams of Architecture: AD Reader, edited by Mark Garcia, (Chichester: Wiley, 2010).

${ }^{24}$ Sanford Kwinter, "The Hammer and the Song," in The Diagrams of Architecture: AD Reader, edited by Mark Garcia, (Chichester: Wiley, 2010).

25 Robert E. Somol, "Dummy Text, or the Diagrammatic Basis of Contemporary Architecture," in Diagram Diaries, edited by Peter Eisenman, (London: Thames \& Hudson, 1999).

${ }^{26}$ Mark Paterson, "More-Than Visual Approaches to Architecture: Visual, Touch, Technique," Social and Cultural Geography 12 , no.3 (2011): 263-281.

27 Derek McCormack, "Diagramming Practice and Performance," Environment and Planning D: Society and Space 23 (2005): $119-147$. See also Derek McCormack, "Drawing Out the Lines of the Event," Cultural Geographies 11 (2004): 211-220; and McCormack, "A Paper With an Interest in Rhythm," 469-485.

28 Eisenman, "Diagram: An Original Scene of Writing," 95.

29 Anthony Vidler, "Diagrams of Diagrams: Architectural Abstraction and Modern Representation," Representations 72 (August, 2000): 5-6.

30 Eisenman, "Diagram: An Original Scene of Writing," 97.
} 
affected." 31 This "doubly affective power" of the diagram produces a multitude of possible conditions, affects, and atmospheres - beginning to organize, explore, select, hold together/connect, albeit in a fluid manner, different bodies. Indeed, as McCormack goes on to suggest the pulling and pushing of these bodies as "set of lines ... opens onto moments of affectivity and connective potential." ${ }^{, 32}$ These potential relationships developed through diagramming, as Allen points out, includes "both formal and programmatic configurations: space and event, force and resistance, density, distribution and direction. ${ }^{33}$ In this sense, and in the context of design practices, and specifically in relation to KTA, the active quality of diagramming allows aspects of the design process to be re-situated over time and space as they move, change, generate and develop. The diagram is then, as Vidler asserts, following Deleuze, a mechanism by which the possibilities of manipulating and transforming designs are explored. ${ }^{34}$ When architectural practices engage with the indeterminate nature of a developing project through diagramming, this 'abstract machine' enables affect to be designed for through the generation of new interconnections between materiality, surfaces, events, and temporal movements. ${ }^{35}$

Connected to the contemporary architectural discourse of diagrams/diagramming discussed above, this chapter seeks to advance a related assertion in the context of an architectural design process. As an ongoing action, diagramming is iteratively developed, both intensified (and most often controlled) by the designer(s) through affective tinkering activities, and informed by external forces. Moments of attachment become interfaces between these constituent interior processes motivated by architect's desired effects (i.e. of light, occupation, and experience) coupled with requirements of the specific project and external processes "coming outside of architecture." ${ }^{36}$ The spaces between attachment points are areas where affects become maximized. In the context of the case study discussed in this chapter, a sticky/relational diagrammatic process mediates two seemingly disparate design processes, whereby the diagrams do not attempt to "bridge the gap" but rather in its interplay, "to open the gap to other unformed matters and functions" ${ }^{\prime 37}$ to partake in generating new spatial configurations. As such, the relationship between an architect's hunch, diagramming and external force/agent (such as a literary text), is crucial.

\footnotetext{
31 Gilles Deleuze, Foucault, translated by Sean Hand (Minneapolis: University of Minnesota Press, 1986), 73, cited in Derek McCormack, "Diagramming Power in Practice and Performance," Environment and Planning D: Society and Space 23 (2005), 124. 32 McCormack, "Diagramming Power in Practice and Performance," 124.

33 Stan Allen, “Diagram Matter," Any: Diagram Work 23 (1998), 16.

34 Vidler, "Diagrams of Diagrams," 5.

35 Deleuze, Foucault, 73, cited in McCormack, 'Diagramming power in practice and performance', 124.

36 Eisenman, "Diagram: An Original Scene of Writing," 103.

${ }^{37}$ Eisenman, "Diagram: An Original Scene of Writing," 97.
} 


\subsubsection{Affective Sticky Process}

As it has been discussed throughout this thesis, the theory of affect has received increased attention in recent discourse. As discussed in-depth in Chapter 2, the literature has developed a range of metaphors to illustrate the movement and channelling of affect such as 'pipes and cables, ${ }^{38}$ 'ropes and lines', 39 'transmissions', and 'contagions. ${ }^{41}$ According to Deborah Thien, such descriptions convey a kind of rapid, mechanistic and programmatic movement of affect. ${ }^{42}$ While these ways of imagining must be highlighted, Sara Ahmed's metaphor of stickiness helps us to discuss how and why certain ideas/values/ objects (and in the case of this chapter, design processes) are predisposed to orientate themselves towards or away from others. ${ }^{43}$ This section thus seeks to reiterate Ahmed's work to present the platform for the chapter.

As discussed in Chapter 2, Ahmed's exploration of affect focuses on its ability to 'accumulate' and 'stick' to particular objects. ${ }^{44}$ Importantly, affect as 'sticky' relates to an idea or object's orientation towards other objects in a given setting, including design processes.

Accordingly, the idea/object is already associated with a certain affective orientation. This influences what the 'other' idea or object entering the space (for instance, of a design process) will "receive by way of an "impression"” 45 as it will "pick up whatever comes near." ${ }^{46}$ Within such a context, things, including design processes, can become sticky through contact with other 'processes' in its proximity. Taking the affect of happiness as an example, Ahmed considers 'happy objects ${ }^{47}$ where these objects draw our body towards them, as we find them pleasing and cling to them. ${ }^{48}$ This suggests how one design process (as a particular object) can become 'means' or 'pointers' of affect ${ }^{49}$ generating attachments or repulsions with other design processes. For Ahmed the space of affect is a contact zone of impressions and orientations. ${ }^{50}$ It is a zone that while not completely localizing, as affects do not lend themselves well to being situated anywhere in particular, can nevertheless generate attachments between 'ideas, values, and objects. ${ }^{51}$ This

\footnotetext{
38 Thrift, "Intensities of Feeling: Towards A Spatial Politics of Affect," 57-78.

39 McCormack, "Engineering Affective Atmospheres," 413-430.

40 Brennan, The Transmission of Affect. (Ithaca, NY: Cornell University Press, 2004).

41 Anna Gibbs, "Contagious Feelings: Pauline Hanson and the Epidemiology of Affect," The Australian Humanities Review (2001)

http://www.lib.latrobe.edu.au/AHR/archive/Issue-September-2001/gibbs.html

42 Thien, "After or Beyond Feeling?," 452.

43 Ahmed, "Collective Feelings Or, the Impression Left by Others," 25-42. See also, Ahmed, The Promise of Happiness (Durham: Duke University Press, 2010).

44 She suggests that affect is: "...what sticks, or what sustains or preserves the connection between ideas, values, and objects" Ahmed, "Happy Objects," 29.

45 Brennan, The Transmission of Affect. 6; cited in Ahmed, "Happy Objects."

46 Ahmed, "Happy Objects," 36.

47 Ahmed, "Happy Objects," 30.

48 Ahmed, "Multiculturalism and the Promise of Happiness," 123.

49 Ahmed, "Happy Objects," 34.

50 Ahmed, “Affective Economies,”117-139. See also Sara Ahmed, The Promise of Happiness (Durham: Duke University Press, 2010).

51 Ahmed, "Happy Objects," 29.
} 
'contact zone' is where we can most clearly get a sense of the affective resonance of different bodies, objects, including design processes.

This chapter seeks to extend Ahmed's 'sticky' metaphor to bring an account of affect in the design process for an architectural project. While the previous case study of RUR attended to the initial stage of a design process, the second case study presented in this chapter discusses affect within the middle-stage of a design process. To clarify further, the process analysed covers not only the initial conceptual stage, but also extends to explore how the initial design changes through the design process up until construction begins. Specifically, the study considers how Kerstin Thompson oscillates between two conflicting design processes for MUMA's interior, connected and oriented through affective stickiness. It is this back and forth process that the "contact zone of impressions and orientation" 52 emerge, and subsequently in these attachment points, that stickiness-in-process intensifies. Accordingly, this chapter shifts from discussing sticky affects, to see stickiness-in-process. By considering affect's stickiness-in-process we are able to see affects as part of the particularities and differences intrinsic to design situations. The following presents the case study practice and project evaluated in this chapter, and then moves to a brief discussion on the methodology applied to this study.

\subsection{CASE STUDY AND METHODOLOGY}

The contemporary practice of Kerstin Thompson Architects (KTA) is selected to explore a more grounded attempt to think about the relationship between affect and practice. This is followed by an introduction of the specific design project (MUMA project) which is analysed in the rest of this chapter. The section concludes with the procedures undertaken for the critical and in-depth evaluation of the processes involved in designing for the interior of MUMA.

\subsubsection{Case Study 2: Kerstin Thompson Architects (KTA)}

The architectural practice of KTA, led by principal architect Kerstin Thompson, is based in Melbourne, Australia. According to Thompson, their practice "resists architecture just being about object-making" and instead is attuned to an understanding of practice orientated towards "an experience of space that you are orchestrating." 53 At a practical level, this is illustrated in their opposition to drawing elevations - to quote Thompson:

\footnotetext{
52 Ahmed, "Affective Economies," 117-139.

53 “And even through we've done many free-standing buildings and they are recognized as being 'beautiful' objects ... I never think about it as a making of a 'beautiful' object." Kerstin Thompson, interview, (2014).
} 
I find them [elevations] really bizarre, because I think it doesn't tell you anything - it turns it [architecture] into this object - and that is just not how I see its affect. Its affect is on the space that makes around it, the space that it makes inside itself, and the relationships it makes. So to see it [architectural building] as this 'thing' is counter to how we imagine and counter to the end effect of it. ${ }^{54}$

Reflecting the 'more than object-making' position of their architectural practice at the scale of design projects, Thompson describes certain aspirations and ambitions that drive their projects. A particular motivation is her personal interest of 'interstitial spaces' - a concept triggered through feminist criticism and post-structuralism writings that stems back to a more general interest in thinking beyond and proposing alternative relationships to "any of those polar opposites, figure-ground or inside-outside or figure, object-subject." ${ }^{55}$ Thompson claims that such attentiveness to the in-between still informs the practice's work: "The gallery [Monash University Museum of Art] is a case in point, that there is a definite continuum from inside to outside and back again, so that sort of exchange - is something that a lot of our projects pursue." ${ }^{56}$ The specific gallery referred to above is the case study project for this chapter.

Importantly, KTA embraces the reality of architectural projects as, indeed, 'messy,' where the role of the practitioner is to 'improvise' when confronted with the unexpected situations and affective stutters that arise in design processes. ${ }^{57}$ Their practice 'job,' Thompson reiterates, is "to be able to respond to the changing parameters of any project, and the shifts that happen." Accordingly it is crucial " $[\mathrm{t}]$ o take advantage of the different conditions that you're working in" where what defines a 'good project' is how the practice "tak[es] the messiness and... orchestrate[s] that stuff." 58 This process of orchestration is further articulated by Thompson, and can be specified through five design methods.

The first method is looking towards precedents. Thompson explains: "If we are doing a museum, we look at other museums, and try to understand how they did it, and what might be applicable, or different for us, in our situation, for our project." The second involves looking at typology, to "select from what is and adapt that, and maybe make a hybrid." She insists "you have all this stuff to draw from, so use it." ${ }^{, 59}$ The third method is to investigate the site. In KTA's practice, a site encompasses more than the geographical, but considers the site over time. In this

\footnotetext{
54 Thompson, interview, (2014).

55 Thompson, interview, (2014).

56 Thompson, interview, (2014).

${ }^{57}$ Indeed, the researcher is aware that the idea of architectural practice as 'messy' is not particular to KTA. However, it is important to note on, firstly, how Thompson uses this particular word -'messiness'- in the interview, and secondly, how 'messiness' is taken by KTA to be a positive force in the design process to create different and thereby unique architectural projects.

58 Thompson, interview, (2014).

59 Thompson, interview, (2014).
} 
way, Thompson claims, "we become more aware of how site, and understanding of site, is always so loaded, and not neutral. So the way we see it, can have a very direct influence on the outcome of the design .... So if we choose to think of it in cultural terms or if we choose to think of it in material terms, or morphology - that will influence what it is." ${ }^{60}$ The fourth design method is driven by a 'hunch' - that is, "this immediate intuitive response to something." views design as created through sudden 'aha' moments. This particular design process is of interest to this chapter - as it directly ties to concepts of affect. Indeed, Seigworth and Gregg describe how affect "arises in the midst of in-between-ness ... [it] is an impingement or extrusion of a momentary... state of relation as well as the passages of forces or intensities." ${ }^{\prime 62}$ Therefore, appearing abruptly and momentarily, the 'aha' quickened stuttering moments in design, experienced as a hunch or gut feeling, are characterized here as 'affective' moments. And the fifth process involves looking for the parti - or in Thompson's words “the organizing spatial diagram that is going to synthesize that thinking." Additionally, Thompson adds to these conventional practice ways the design process of "mulling over the problem through walking, reading or music" - a form of stilled stutter. ${ }^{63}$ This chapter considers Thompson's and MUMA curator Geraldine Barlow's accounts and the diagramming process of the project, to investigate how these diverse lines of design methods made their way through the MUMA design process.

\subsubsection{Monash University Museum of Art}

According to senior curator Geraldine Barlow, the MUMA project began with discussions between the museum of art (originally at the Clayton campus) and Monash University to strategically "articulate a vision around ... the museum ... joining fine arts ... at the Caulfield campus. ${ }^{" 64}$ As available space emerged at the Caulfield campus, a brief was developed by museum director, Max Delaney and Barlow. This then prompted a limited design competition involving five architectural firms to respond to the brief. Barlow reflects: "Kerstin's brief for that project, we really liked .... [T] he thing that we most liked, and still has a presence in the final result - was this kind of dialogue between what was introduced to the space, and the existing architecture - that kind of tension and movement between those elements." ${ }^{65}$ Completed in 2010, the unique architectural features of MUMA have triggered, as Thompson herself notes "a lot of feedback on it .... It does seem to be a space that people feel very strongly about when they are

\footnotetext{
60 Thompson, interview, (2014).

61 Thompson, interview, (2014).

62 Seigworth and Gregg, "An Inventory of Shimmers," 1.

63 Thompson, interview, (2014).

64 Geraldine Barlow, interview, (2014).

${ }^{65}$ Barlow, interview, (2014).
} 
in it; it does seem to affect people." ${ }^{66}$ 'This 'strong feeling' has led to MUMA receiving numerous awards, including, but not limited to, the 2011 AIA Awards: Marion Mahoney Award, and the 2011 IDEA Awards in the category of Institutional Interior Design. ${ }^{67}$

KTA's design process for the MUMA project involved, as related to the researcher by Barlow, "little conundrums," that involved extended discussions between architect Kerstin Thompson and the curatorial team. There are two issues that are worth mentioning separately here:

1. First, and as mentioned above, a prominent interest for KTA is their creation for 'interstitial spaces' in their projects. In their MUMA project, despite the competition brief only addressing the interior of the museum, KTA also proposed that "the space besides the building became a forecourt, so that it was a way to repair the whole campus, and to bring the museum program out, into the campus. ${ }^{, 68}$ This desire stems also from the practice's interest in the placement of the object within a new testing space. Spatially and diagrammatically, the MUMA building is connected to the outside through "a gradient of interiority." ${ }^{69}$ Particularly, the design process involves using the "same geometry to organize the landscape as well as the interior." ${ }^{\text {70 }}$ This is accomplished through a series of radial lines that follow the pre-existing 'beam lines.' Thompson rearticulates these 'beam' lines as "view lines from inside to outside" where the "lines move out into the courtyard.",

2. Second, a gallery or museum as a programme is, according to both Thompson and Barlow, always a highly serviced building. What is unique to the MUMA design process is Thompson's creation of a 'big canopy' where most of the servicing is fitted into.

Thompson explains the moving of the servicing outside the gallery was a way to "free up" the interior ceiling space. Moreover, aesthetically, "this...big canopy, is [a] transparent thing - you can see inside, you can see all the servicing and so it was a project that was about revealing the workings behind the scenes, but also having other spaces where it's all pristine and perfect." ${ }^{, 72}$ According to Thompson, and in terms of the design process "it's always that game of how much you show, and how much you hide."”3

\footnotetext{
66 Thompson, interview, (2014).

${ }^{67}$ Monash University of Art - Gallery, http://kerstinthompson.com/index.php?id=3

${ }^{68}$ Thompson, interview, (2014).

${ }^{69}$ Thompson, interview, (2014).

70 Thompson, interview, (2014).

${ }^{71}$ Barlow, interview, (2014).

72 Thompson, interview, (2014).

73 Thompson, interview, (2014).
} 
What connects the above design process 'conundrums' and the final design outcome is not only the emphasis on creating a dialogue between pre-existing and introduced, but moreover, as Barlow notes, there is clearly a motivation by KTA in "trying to amplify particular things" through these dialogues. ${ }^{74}$

The various stages of design and issues arising through the design process for MUMA are more extensive than can be discussed within the scope of this chapter. Here, the analysis limits the discussion to two main issues: 1) the nature of the design process as involving interplay between two seemingly contrasting processes and 2) the interplay's role in generating sticky attachments, thereby, affective stuttering processes. With respect to the first issue, the MUMA case represents a process during which conceptual elaborations and spatial explorations often progressed in unexpected directions, and at times, abrupt shifts. Particularly, the process involves an oscillating process between hunch-driven 'aha' moments - a form of quickened affective stutter, and an extended exploration of a given text, where the latter plays a playful but equally forceful role throughout the project. This latter text is described in more detail in the subsequent section (6.4). The following provides a summary of the methods employed within this chapter's study.

\subsubsection{Methodology}

Parallel to methods employed in Chapter 5 for the case study of RUR and their Kaohsiung Port Terminal project, the study in this chapter is also based on qualitative research through a case study approach. This approach is chosen since 'affect,' as a theoretical concept, has potential to be studied in-depth within a 'real-life context ${ }^{75}$ of architectural practices. Such research allows for a better account of the complexity of design processes. Specifically, the data for this study consists of qualitative fieldwork, including an in-depth semi-structured interview with principal architect Kerstin Thompson, conducted on 26 July 2013, at the School of Architecture, Victoria University of Wellington, where she currently holds a Professor of Design position. This was further complemented by an in-depth interview with MUMA senior curator, Geraldine Barlow, conducted separately at the MUMA site (Monash University Caufield Campus, Melbourne) on 4 August 2014. The responses provided by Barlow about the design process were important for understanding the collaborative work dynamics between the curatorial team and the architectural team, and the development of the different design schemes. These interviews were also

\footnotetext{
${ }^{74}$ Barlow, interview, (2014).

75 Robert K. Yin, Case Study Research: Design and Methods (Thousand Oaks, CA: Sage Publications, 2003).
} 
supplemented by visual documentation in the form of drawings, diagrams and images, of the MUMA project.

In terms of the analysis of the gathered data, this has been explained in-depth in Chapter 1- Methodology section of this thesis. However, briefly, the first stage of analysis used a combination of meaning condensation and meaning interpretation, as presented by Kvale. ${ }^{76}$ The second stage involved an analysis of the collected visual documentation through a modified form of 'compositional interpretation,' as outlined by Rose. ${ }^{77}$ Affect is the framework of analysis for the data gathered. Specific to this case study, one additional component was introduced and played an important part in the analysis - this was Rémy Zaugg's literary text on museum design. The following section analyses and discusses the research findings.

\subsection{AFFECTIVE INTERPLAY}

This section evaluates Thompson's sticky interplay between designing for 'idiosyncrasy' and 'neutrality' in the MUMA design project. More specifically, the first method is what Thompson refers to as an "immediate intuitive response" to a project that "can allow ... [one] to act on it more quickly." 78 These intuitive hunches emerge through subconscious design thinking that is always situational and open to contingency, and thereby are affective stuttering moments within the design process. The second method, happening parallel to the first, is a carefully cued spatial design framed in response to Rémy Zaugg's literary text on museum design, 'Das Museum, das ich rmir ertaume. ${ }^{79}$ According to Zaugg, the place of encounter between art and people, the museum, is "no place of illusion, it is no artificial paradise, it has, on the contrary, the function of grounding, bringing to form and enabling consciousness." ${ }^{\text {" Th }}$ Thompson tells how Zaugg's essay was given to her: “The curator, our client, gave this to me, and said to me that ... they didn't really want this, as an approach. But then, as the project went on, it became clear to me that actually, he did want this. So, it's always the running joke - that it was his subtle way of telling me what they wanted." ${ }^{81}$ Importantly, the distinction between the two approaches (hunch-driven and literary-driven processes) is debatable and therefore, this chapter does not seek to reduce the two into a binary opposition. Rather, it suggests decentring this division in terms of an active process of oscillating duality. It is the interaction and intersection of these two methods and how

\footnotetext{
76 Steiner Kvale, Interviews: An Introduction to Qualitative Research Interviewing (Thousand Oaks, CA: Sage Publications, 1996).

77 Rose, Visual Methodologies, 57.

78 Thompson, interview, (2014).

${ }^{79}$ Rémy Zaugg, The Art Museum of My Dreams, or A Place for the Work and the Human Being, trans. Liz Libbrecht, (Berlin: Sternberg Press, 2013).

80 Rémy Zaugg, cited in Stephen Bram, "The Art Museum of Rémy Zaugg," last modified 2003,

http://www.docstoc.com/docs/32296772/the-art-museum-of-r\%C3\%A9my-zaugg-Stephen-Bram-perhaps-all-visual-art.]

81 Thompson, interview, (2014).
} 
Thompson shifts from one to the other that are of prime interest, generating attachments through affective stickiness. To explore how Thompson's design process works to resolve a series of design conundrums, the section considers three elements: the 'curve' problem, the 'corner' problem, and the 'servicing' problem. ${ }^{82}$

\subsubsection{The Curve Problem}

From the outset, the MUMA project confronted the need to find a way to conceive a 'neutral' space/design in a 'slightly idiosyncratic geometry. ${ }^{83}$ As Thompson explains, "It's a really beautiful curve that is very subtle. At one stage they [the clients] wanted to get rid of that, but I'm like ... no, it's beautiful!" ${ }^{\prime 4}$ While the following analysis discusses the sticky interplay (between hunchdriven and literary-driven processes), it may also be suggested here, how the curve as a sticky architectural feature, can inform/affect and be affected by- the design process. Indeed, as Seigworth and Gregg claim, "affect need not be especially forceful. In fact ... affect more often transpires within and across the subtlest of shuffling intensities." ${ }^{\prime 85}$ This thesis considers these "shuffling intensities" as temporal stutters that can both still or quicken design processes. With curved geometry that resists design simplification to a 'perfect white space, ${ }^{, 86}$ Thompson understands that any solution to the MUMA design would have to recognize the particular nature of the given shell. ${ }^{87}$ Through this 'curve' problem, the following explores how affect as stickinessin-process "preserves the connection between" 88 two distinctive design approaches. We are able to situate affect within this sticky interplay between the orderly and the more intuitive processes for MUMA's interior.

The first interior diagrammatic scheme, prompted by a hunch, involves "a series of black and white boxes, [placing] the neutral space within the more idiosyncratic space." 89 More specifically, Thompson's initial design, sketched out through a diagram produces individual, intimate spaces for the artworks, creating autonomous, micro-white boxes or what Thompson refers to as 'crates ${ }^{90}$ within a larger container. Barlow, MUMA's senior curator, recounts: 'What I really liked about it was that there was this dynamic between some kind of rough and ready

\footnotetext{
82 Thompson, interview, (2014). The specific terms of 'idiosyncrasy' and 'neutrality' are used by Kerstin Thompson during the interview while describing the design process of MUMA. The phrase 'corner problem' is taken from the visual documentations provided by Thompson as additional material for analysis by the author. The words 'curve problem' are proposed by the author to align with this latter phrase.

83 Thompson, interview, (2014).

84 Thompson, interview, (2014).

85 Seigworth and Gregg, "An Inventory of Shimmers," 2.

86 As curator Barlow explains: "[a] curve can be a hard thing” Barlow, interview, (2014).

87 Thompson, interview, (2014).

88 Ahmed, "Happy Objects," 29.

89 Thompson, interview, (2014).

90 Thompson, interview, (2014).
} 
exterior in a kind of loose propositional sense - then also, having quite a precious interior gallery space." ${ }^{\prime 91}$ This exterior container is left purposely as a 'rough shell' - but its 'unprecious' character, in Thompson's words, “encourages a much bigger demographic and an entirely different gallery aesthetic and feel." ${ }^{\prime 2}$ These accounts illustrate a design scheme arising through an 'aha' moment (a quickened stutter), that features a spatial juxtaposition between a 'pristine white-space scenario' within a more 'behind-the-scenes' shell. Such a proposition highlights the nature of the project, which is "largely an alteration... an internal fit-out with new bits added to it." ${ }^{93}$ In this context, and particularly for Thompson, the sticky dialogue between "pre-existing and introduced" becomes crucial, and is amplified through her design proposal.

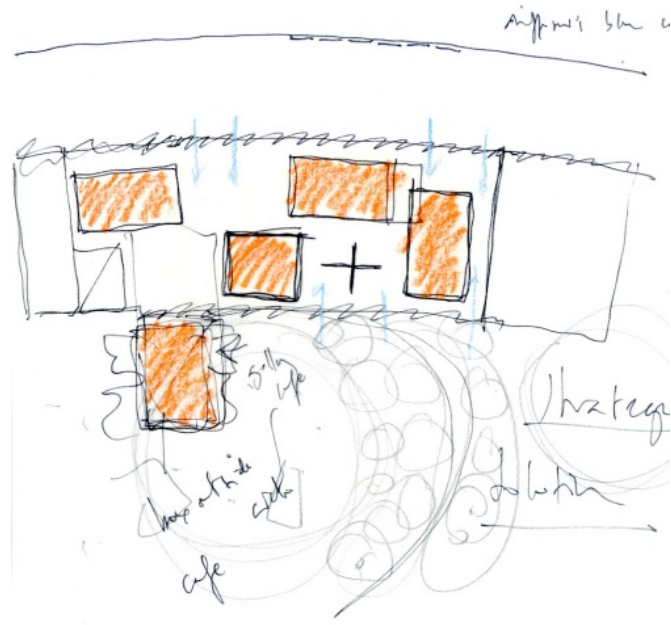

Fig. 6: Kerstin Thompson, Crates, 2013, drawing. ${ }^{94}$

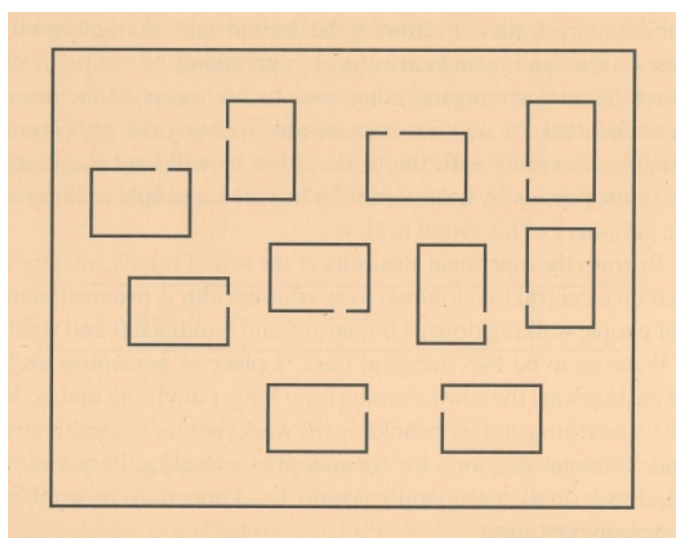

Fig. 7: Rémy Zaugg, Scattered Rooms, 1986, drawing. ${ }^{95}$

As the project progressed from competition ('ideal') to commission ('real') stage, the

'idiosyncratic' interior configuration moved towards a more structured and orderly design process, alluding to Rémy Zaugg's literary text. Thompson reflects, "I think there is always a tension between the competition winning entry and the final scheme, or, it's like there's a real brief and a competition brief, and they are often not the same." 96 The very passage from competition to commission stage is seen as a conversion point (affective stutter) containing sticky affective qualities; an accumulation of 'shuffling intensities ${ }^{97}$ of both shareable and competing forces. For MUMA, critical issues relating to curatorial restrictions and exhibitory practices came into play,

\footnotetext{
91 Barlow, interview, (2014).

92 Thompson, interview, (2014).

93 Thompson, interview, (2014).

94 Kerstin Thompson, Crates, 2013, sketch drawing, courtesy of Kerstin Thompson Architects.

95 Rémy Zaugg, Scattered Rooms, 1986, drawing, in The Art Museum of My Dreams, or A Place for the Work and the Human Being, trans. Liz Libbrecht, (Berlin: Sternberg Press, 2013): 48, courtesy of Mai 36 Galerie, Zurich. Here, it must be clarified, as Thompson explains, how Zaugg's text was introduced to KTA after the competition process. Hence, "the time of generating the first scheme - the crates (fig. 6) - there was no reference to Zaugg's scattered rooms" (Kerstin Thompson, personal communication). While acknowledging this, the thesis seeks to observe the unintended link between the two.

96 Thompson, interview, (2014).

${ }^{97}$ Seigworth and Gregg, "An Inventory of Shimmers," 2.
} 
preventing the original scheme from actualization. Barlow describes one particular stutter arising through a curatorial issue: "The [competition] proposal ... was the most exciting ... [as] I thought we would have this really beautiful, dramatic, atmospheric space ... but the problem was most of the volume of space was between the galleries... we needed to actually get more white wall gallery space." 98

Evidently, the diagrammatic exploration by KTA depicts large, almost purposeless (for gallery purposes) circulation areas between the smaller proposed gallery 'crates' (fig. 6). Additionally, Thompson recalls a second stutter arising at this stage: "When we started the real project, very quickly they said, actually, that's not going to work for us. If we want to loan works from all over the world ... in terms of climate control of things, so ... we can't have anything informal, we can't have any rough and ready, it has to be a highly serviced building." "999 From a curatorial perspective, Barlow articulates further on the difficulty of servicing the initially proposed 'crates': "It would have been a bit unclear whether those crates were each to be separated internally, temperature and humidity controlled, or whether you would've somehow delimit that to the [exterior] larger area." ${ }^{100}$ Such vagueness, associated with the mechanisms and flows for servicing the 'crates', forced, as Barlow explains, a process of "claw[ing] back a bit from the original idea."101 Clearly, there is something sticky between the desire for an 'atmospheric' space (immersive qualities) and the need for a functional and more volumetric space for the gallery. The unease produced by this tension (due to the described stutters), in part, might be about recognizing the sticky relation triggered by internal and exterior forces that have capacity to mutually affect each other.

With the principal components of the original design scheme challenged, Thompson describes the competition to commission stage as a realignment 'going back' stuttering process to reconfigure both conceptual and spatial aspects of the design: "From a project that we thought could be about looseness, informality, roughness and cheap, for the same budget, [the university] wanted something much more refined, and more highly serviced, and more neutral. So it was going back, probably, to a more classical idea of a museum ... and the perfect white space"102 Barlow and Thompson's accounts of 'claw[ing] back' and 'going back', highlight affective stuttering as not only prompting a forward movement, where indeed, "affect acts" - but also can "suspend us," 103 and in MUMA's design process, can even set processes backward. Affective stickiness can be described, then, as a flow that seeps between design processes, pulling them

\footnotetext{
98 Barlow, interview, (2014).

99 Thompson, interview, (2014).

100 Barlow, interview, (2014).

101 Barlow, interview, (2014).

102 Thompson, interview, (2014).

103 Seigworth and Gregg, "An Inventory of Shimmers," 1.
} 
together "sideways ... through 'sticky' associations"104 (as a force of attraction), as well as, holding them apart (as a force of repelling).

In search for a more 'perfect white space' and a more neutral interior, Thompson articulates the radial 'idiosyncratic' geometry by introducing a 'new geometry' (fig. 8). ${ }^{105}$ As a hunch-activated design, she explains her diagramming process: 'You've got this radial geometry here; we'll introduce a series of parallel lines. It is as if you use the straight to be a datum against which you notice the existing geometry." ${ }^{106}$ Interestingly, this intuitive approach generates a sticky connection with, and an orientation towards, the carefully cued spatial design framed by Zaugg (fig.9).

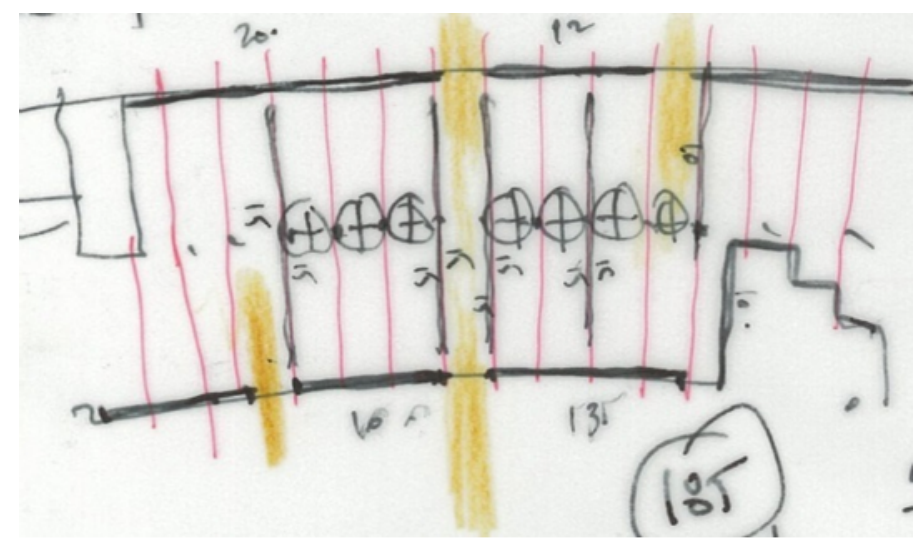

Fig. 8: Kerstin Thompson, Light and Views, 2013, drawing. ${ }^{107}$

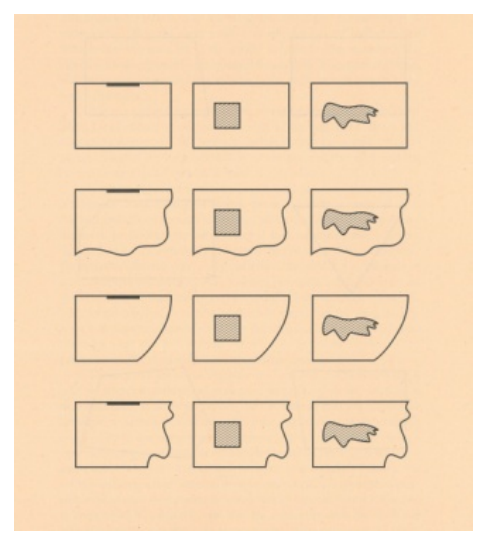

Fig. 9: Rémy Zaugg, The Walls, 1986, drawing. ${ }^{108}$

Specifically, the application of "lateral series of walls" into the interior transforms the initial design of a "loose rough space and pristine moments within [it]," 109 into transverse wall planes, thereby providing a more linear and less random interior organization. These parallel walls could be said to refer to Zaugg's strict approach to design in that they are flat and vertical, "[a] perfect limit ... impassive and mute, it is not confused with the work." ${ }^{110}$ Within this scheme, the muteness of Zaugg's walls accentuates the curved wall that is already there but would not have become visible without the intervention of the new geometry. Clearly, Thompson oscillates between designing for idiosyncrasy to neutrality and back, where affect as stickiness-in-process sustains the connection and orientation between the two distinct design methods.

\footnotetext{
104 Ahmed, The Cultural Politics of Emotion, 45.

105 Thompson, interview, (2014).

106 Thompson, interview, (2014).

107 Kerstin Thompson, Light and Views, 2013, sketch drawing, courtesy of Kerstin Thompson Architects.

108 Rémy Zaugg, The Walls, 1986, drawing, in The Art Museum of My Dreams, or A Place for the Work and the Human Being, trans. Liz Libbrecht (Berlin: Sternberg Press, 2013): 27, courtesy of Mai 36 Galerie, Zurich.

109 Thompson, interview, (2014).

110 Zaugg, The Art Museum of My Dreams, 16.
} 
The two seemingly disparate design methods further maintain a sticky attachment through affect as the design for 'new geometry' interplays with a design for 'looseness.' This is seen as Thompson playfully countered the inflexibility in Zaugg's instruction to design for a 'credible wall,"111 to design 'movable walls." ${ }^{112}$ While the credible wall "suggests its rootedness in the architecture ... [and] arouses no suspicion of being likely to disappear," 113 the 'movable' or 'added' wall suggests flexibility and temporality in the design. An 'added' wall, Zaugg contends, "would taint the work with its contingency and precariousness." 114 But from Thompson's perspective:

We showed them [clients] ... a series of diagrams .... [T] he layout [selected] was the one that gave them ... more ... flexibility for curatorial direction. And in that sense, I think it has been a museum that artists really like, and curators, because it's not prescriptive. It does allow very different approaches. Which is great. That's what we think our job is - to allow that many different ways to be possible. ${ }^{115}$

Thus, Thompson introduced a 'non prescriptive' gallery layout, which allows more flexibility for curatorial direction. ${ }^{116}$ Interestingly, however, the amount of flexibility is limited to the bounds set up by the new geometry, proposing an entanglement of contradictory processes- one driven by informal intuition, the other by a regulated and more formal spatial design. Here, designing for idiosyncrasy and neutrality activates a sticky interplay, suggesting a configuration of walls that alludes to Zaugg's 'perfect' linearity as well as Thompson's hunch-driven informality.

The design process and solution to the 'curve problem' involves two distinctive design methods that maintain their connection through affective stickiness. It is in this sticky oscillation between literary-driven and hunch-driven processes that we are able to situate affect through temporal stutters -where affect is "interested in the messy informe of the ongoing-ness of process." ${ }^{\prime 17}$ At this point in the design process, a question is posed by the client, which accurately attends to interior practice as a situation open to chance and contingency. The following section elaborates on the 'corner problem' and the eventual final interplay.

111 Zaugg, The Art Museum of My Dreams, 18.

112 Thompson, interview, (2014).

113 Zaugg, The Art Museum of My Dreams, 18.

114 Zaugg, The Art Museum of My Dreams, 18.

115 Thompson, interview, (2014).

116 Thompson, interview, (2014).

117 Seigworth and Gregg, "An Inventory of Shimmers," 14. 


\subsubsection{The Corner Problem}

Having broadly defined the interior design for MUMA, or, more specifically, as Barlow recalls, when the project was "almost ready to go on this particular iteration - the radial scheme which flowed with the beams," we got in the gallery?" 119 While this corner issue, according to Barlow, had been "weaved through at certain points" and therefore "had a presence throughout the process"120, the question became a major pivot and stuttering point in the project. The response to the corner question and the subsequent change of MUMA's interior scheme is recounted by Thompson, and is worth citing at length:

I did a count and I think we had two or three, because it was very radial, it was much more planes, rather than corners, internally. And they said, well, corners are really important to our curatorial practice and how you can arrange paintings. . . . So I could tell they weren't that happy. And it was one of those moments where you have a client brief given to you, and you've ticked everything off on that. But, in their brief there are some things they haven't written that turn out to be really important but no-one ever thinks to put in the brief. So we had this moment where I thought, well, I can try and make this existing design, muck around a bit and try and get corners. But it's never really going to be that integrated and it sounds like an important thing that should drive the project more. So, I remember at that point in time, at the risk of jeopardizing programme and everything, just going away over the weekend, and coming back with an entirely different scheme ... because it ended up with, I think 13, or 14 corners. ... So, it was just that sort of example, where your brief is not always what you think it is, or what it seems to be, and the client doesn't know that either. And the tiny little comment of theirs can change the whole design, completely. And I said to them, I think we have to go back to first principles, so it's not compromised. You'll end up with something that is much more suited to what you need this to be. And it was a real turning point in the project but it was a much better outcome - to this day I think, thank God I said, let's go back and start at square one. ${ }^{121}$

Similar to the previous scheme evaluated, the design process and solution to the 'corner problem,' moved to and fro- between a literary-driven process and a hunch-driven process, sustaining attachment through affective stickiness. It is in this connection or an attachment point that affects are maximized and generates a sticky process. To begin, the 'corner problem,' Thompson explains, "can be attributed to that essay of Rémy Zaugg's ... about corners and things. So, that was an interesting point in its development." "22 Zaugg's 'ideals,' echoing the curatorial 'ideals,' became the driving force, albeit subtly, for the design of a whole new layout, and more

\footnotetext{
118 Barlow, interview, (2014).

119 Thompson, interview, (2014).

120 Barlow, interview, (2014).

121 Thompson, interview, (2014). Thompson further clarifies that the use of the word 'programme' in this quote is in reference to 'time' programme, as opposed to functional programme.

122 Thompson, interview, (2014).
} 
specifically, towards a "fundamentally different project." ${ }^{\text {123 }}$ For curatorial purposes, and specific to MUMA, the importance of the corner can be characterized in two ways: first, it has the capacity of amplifying and intensifying the spatial experience. The need of corners "is really built in together with this question of maybe slowing down the itinerary through the space and giving a sense of surprise." 124 This experiential impact of movement and surprise is interlinked to the second aspect, that of the curatorial benefits attached to corners. As Barlow reiterates, "The corner gives you an opportunity - even if you might have quite an amount of wall space.

Inevitably that space needs some kind of end point ... you can kind of be in the corner more completely. Even if there is something quite different behind you. It kind of surrounds you, a little bit more." Interestingly, Barlow emphasises how the 'corner' issue also reflects on curators becoming "fussier" and "greedier that ever for space for artists," as artists work in an "installation sense" - and thereby, there's a "theatrical [and] total use" of the space. ${ }^{125}$

In order to satisfy the requirement for more corners then, Thompson's design orientates (through stickiness) toward Zaugg's systematic parameters: the new scheme presents enclosed gallery spaces, "made up of four walls. Its perimeter is rectangular." ${ }^{\text {"26 }}$ All walls meet "at a right angle" to allow for "direct and immediate ... orthogonal perceptive relationship," between the work [of art] and the human body. ${ }^{127}$ As evident in Thompson's diagrammatic process - the criticality of the corners is shown by the red dots (fig. 10). Adopting Zaugg's proposition and insistence for a 'right angle' connection between walls (fig. 11), Thompson was able to create multiple corners that accommodate MUMA's curatorial practice.

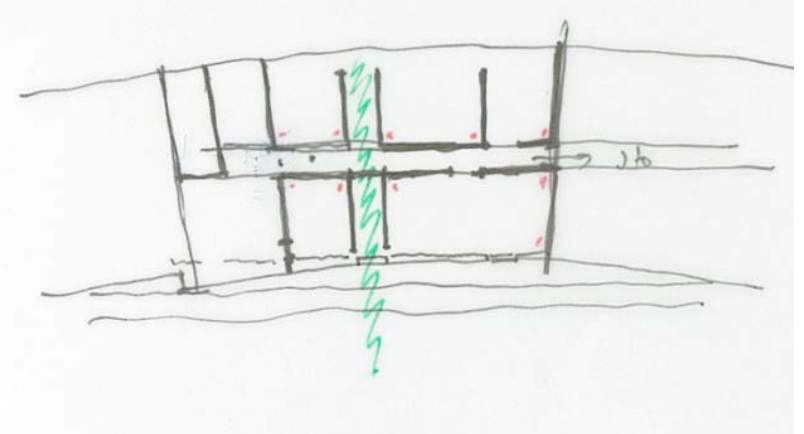

Fig. 10: Kerstin Thompson, Corners, vistas, itineraries, 2013, drawing. 128

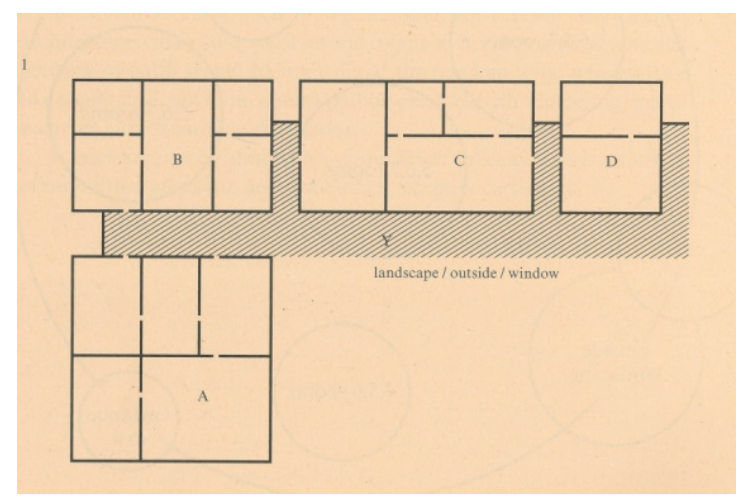

Fig. 11: Rémy Zaug, Gallery for Baron Thyssen, 1986, drawing. ${ }^{129}$

\footnotetext{
123 Thompson, interview, (2014).

124 Thompson, interview, (2014).

125 Barlow, interview, (2014). Barlow further articulates, "the space itself - this theatrical use of space - you might have a massive big picture on one wall, another wall - empty, and then, the opposite two walls might be empty but just a tiny little thing down below. So you might have this tension between the massive thing and the tiny little thing- but you might want the empty space to almost accentuate the drama around the small thing."

126 Zaugg, The Art Museum of My Dreams, 29.

127 Zaugg, The Art Museum of My Dreams, 30.

128 Kerstin Thompson, Corners, vistas, itineraries, 2013, sketch drawing, courtesy of Kerstin Thompson Architects.
} 


\subsubsection{The Servicing Problem: the Blue Spine and Two Big Doors}

The literary-driven design process continued in a sticky interplay that drew Thompson to engage in a more intuitive-driven process. The first of these offsets the white cube with an idiosyncratic blue spine.' While physically positioned as an in-between space with the formal, neutral galleries at either side, the spine is 'like a little orientation space. ${ }^{130}$ However, in contrast to Zaugg's pristine spaces, the spine physically exposes 'looseness, informality, [and] roughness. ${ }^{, 131}$ As Thompson describes, "We've left uncovered a lot of the existing ... [so] you can see the timber walls, as if the plasterboard have been taken off ... and you see all the servicing. And then when you get into the galleries, they [are] very neutral and clean and white boxes. So it's this play between revealing and concealing the machinations of the gallery." ${ }^{\prime 32}$ The uncovering of the existing and "exposed services" is not only an aesthetic design move, but is also connected to a strategic method of lowering the ceiling height in the spine to allow for "delivering the mechanical services" needed in the galleries. ${ }^{133}$ What is more, the low ceiling helps to accentuate and has an "effect of dramatizing"134 the white galleries' relatively higher ceiling, which is critical to the curatorial practice. Barlow articulates, "We didn't want the gallery to look too domestic. We didn't mind that it was not one of those really vast institutional spaces that are hugely intimidating and grand - but we wanted to be elegant and to feel that it was kind of airy." ${ }^{135}$

Another prominent feature of this 'orientation' space is the pre-existing exposed concrete columns where "the curve of the columns ... is accentuated by the straightness of the corridor." ${ }^{136}$ This curved alignment of the columns, echoing the curvature of the north wall, intensifies an awareness of the "very subtle shifts in geometry, how your body is apprehending those and reacting to it." ${ }^{137}$ Ironically, however, Barlow notes how "some people don't notice it at all - that movement of the curve. Different people have different sensibility to the space." Thompson's initial 'idiosyncratic' design prompted through a quickened affective stutter or 'aha' moment proved helpful to distinguish the 'behind-the-scenes quality of space' by the use of fluorescent lighting, which is tinkered with to accentuate the difference with gallery space. ${ }^{138}$

\footnotetext{
129 Rémy Zaugg, Gallery for Baron Thyssen, 1986, drawing, in The Art Museum of My Dreams, or A Place for the Work and the Human Being, trans. Liz Libbrecht, (Berlin: Sternberg Press, 2013): 58, courtesy of Mai 36 Galerie, Zurich.

130 Thompson, interview, (2014).

131 Thompson, interview, (2014).

132 Thompson, interview, (2014).

133 Barlow, interview, (2014).

134 Barlow, interview, (2014).

135 Barlow, interview, (2014).

136 Barlow, interview, (2014).

137 Thompson, interview, (2014). Once again, this highlights the subtleness of affect - as indicated with the curved wall, the curve of the columns is apprehended whereby affect need not be "forceful" but rather can be triggered "across the subtlest of shuffling intensities." Seigworth and Gregg, "An Inventory of Shimmers," 2.

138 As Thompson explains, 'it was really about having a more expressive space, but also a more behind-the-scenes quality of space, that is so different to the formality of the galleries on either side.'
} 
Thompson explains, "it was really about having a more expressive space, but also a more behindthe-scenes quality of space, that is so different to the formality of the galleries on either side."139

Fluorescent lighting is undesirable for Zaugg's model interiors: "Fluorescent light, the impact of which would accompany the subject throughout his encounter with the work, [is] absurd." ${ }^{140}$ Supporting this view, albeit more subtly, Barlow points out how the "strength of the glow" can, depending on the intensity, "spill from the corridor into the galleries."141 Interestingly, it is this 'absurdity' and 'spilling' that gives the client an identity of the museum, "where the architecture can be more present, because it's not disrupting what happens in those more neutral spaces ... which I think they are delighted by." 142 This feeling of delight is further echoed in how the blue spine "led to the profile of the campus" where "they could have the branding and that excitement, without disrupting the more curatorial needs that they had."143

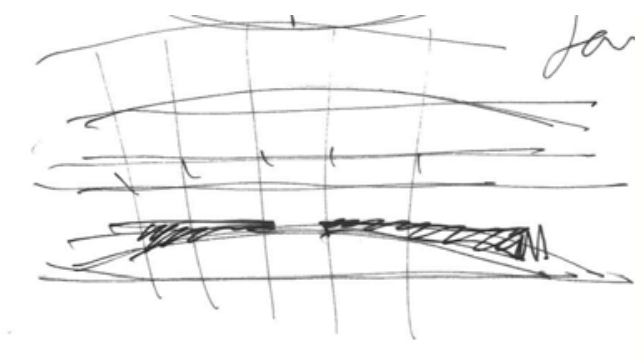

Fig. 12: Kerstin Thompson, Parallels, 2013, drawing. ${ }^{144}$

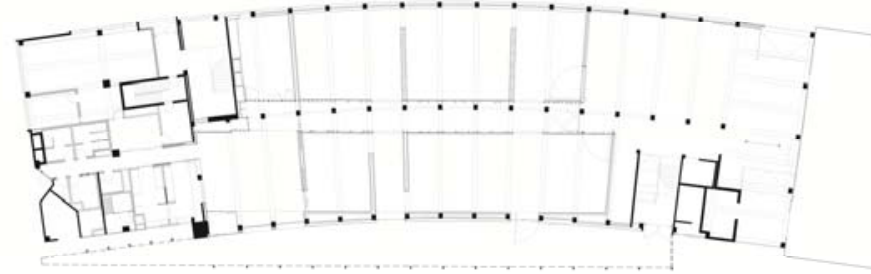

Fig. 13: Kerstin Thompson, Final Plan of MUMA, 2013, drawing. ${ }^{145}$

Thompson's second intuitive-driven process is expressed in a rather subtle and quiet manner - a form of stilled stutter. Perhaps as a play on Zaugg's and the curatorial team's 'ideals,' Thompson adds an idiosyncratic architectural feature to the new scheme. Now with "13 or 14 corners," the new layout is characterized by a sequence of white-wall gallery spaces (fig. 13). However, it also has a peculiar set of walls that are in actuality, albeit subtly, "two big doors - that give access to the store area." 146 Barlow explains, "Even though they are subtly built, they look like part of the wall. But they always kind of do something to the overall space that makes it less gracious. It

\footnotetext{
139 Thompson, interview, (2014).

140 Zaugg, The Art Museum of My Dreams, 59.

141 Barlow, interview, (2014).

142 Thompson, interview, (2014).

143 Thompson, interview, (2014).

144 Kerstin Thompson, Parallels, 2013, drawing, courtesy of Kerstin Thompson Architects.

145 Kerstin Thompson, Final Plan of MUMA, 2013, drawing, courtesy of Kerstin Thompson Architects.

146 Barlow, interview, (2014).
} 
somehow cuts into the way that it operates." 147 So in the process of designing for more corners, Thompson brings into the white-walled precious-pristine gallery, a playful and affective, 'ungracious' architectural element. Inadvertently, in defending her vernacular 'rough and ready' idea through affective hunch-driven processes, but motivated by Zaugg's literary formality, Thompson oscillated to and fro-, so the processes attained attachment through affective stickiness.

The final scheme reveals an interior that reflects the sticky interplay between neutral and idiosyncratic, the anonymous and identifiable (fig. 14) - or more specifically, as Barlow describes, "a repetition of white [the variation of white-gallery volumes] into contrasting space [central spine]." "148 Thompson's and Barlow's account of reified repetition, where, borrowing Ahmed's words, "signs (and equally spaces) become sticky through repetition,"149 reemphasizes the nature of MUMA's interior configuration as also, physically sticky (fig. 15). Here, neutrality and whiteness, as well as the idiosyncratic spine, attach themselves, albeit in different degrees, to moving bodies.

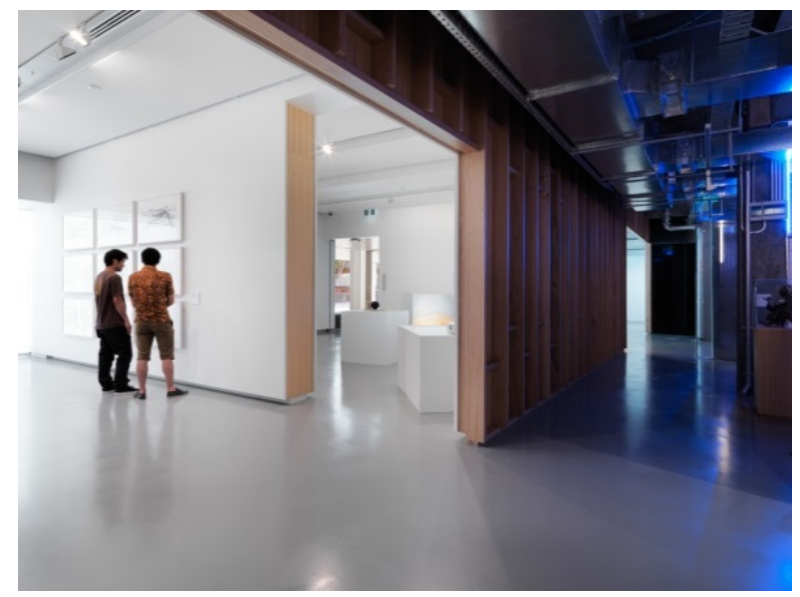

Fig. 14: KTA, Interior of MUMA, 2013, photograph. ${ }^{150}$

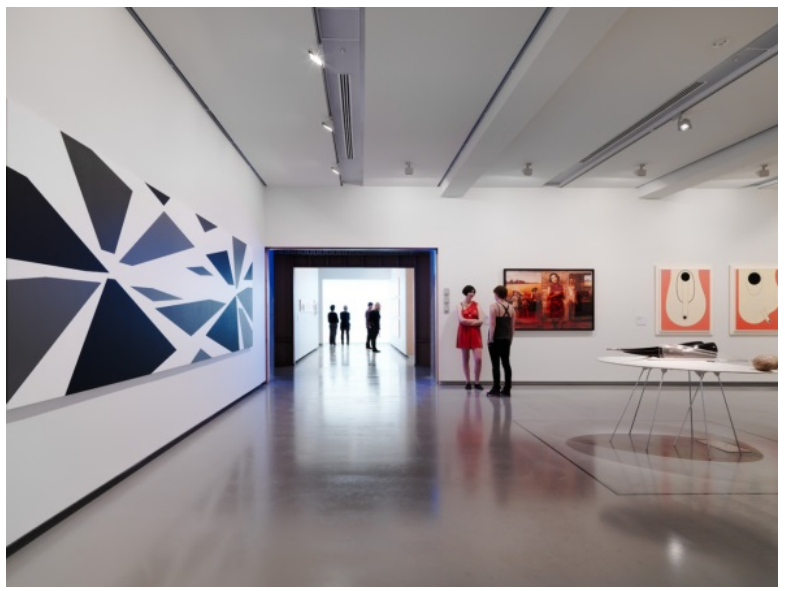

Fig. 15: KTA, Interior of MUMA, 2013, photograph. ${ }^{151}$

The MUMA project by Thompson precisely presents an architectural design process where affect as stickiness-in-process "sustains [and] preserves the connection between" 152 a literary-driven design process and a more intuitively-driven one. Importantly, it is in this 'contact zone" ${ }^{153}$ of distinctive 'impressions and orientations' that we are able to see affects maximized. Thompson's thinking through and between the two design methods illustrates how this particular process of design operates in-between designing for 'idiosyncrasy' and 'neutrality.' The design for MUMA

\footnotetext{
147 Barlow, interview, (2014).

148 Barlow, interview, (2014).

149 Ahmed, The Cultural Politics of Emotion, 90.

${ }^{150}$ KTA, Interior view of Monash University Museum of Art, 2013, photograph, C image and courtesy of KTA.

${ }^{151}$ KTA, Interior view of Monash University Museum of Art, 2013, photograph, C image and courtesy of KTA.

152 Ahmed, 'Happy Objects,' 29.

153 Ahmed, “Affective Economies,” 117-139. See also Ahmed, The Promise of Happiness (Durham: Duke University Press, 2010).
} 
involves a sticky interplay between the known and unknown aspects of design thinking triggered by affective stutters, both stilled and quickened ones. Affect acts as a sticky connective element, providing a way to situate affect within the interplay between the systematic and the more momentary practices of design. Thinking through affect as a stuttering process helps us understand how these two seemingly disparate design processes become sticky relations. The effect of bringing these two approaches together is to help us understand the process of designing as a situation open to fluctuations and affective stutters.

\subsection{CONCLUDING DISCUSSION}

This chapter began with a reflection on the way in which architectural (as well as geographical) discourse is re-orientating towards an interest in the atmospheric/affective spatial experiences of the built environment. This chapter contributes to these bodies of work by attending to the design processes that occur before inhabitation takes place, and more specifically, to consider the sticky relationship between the different processes that a particular architectural project may encounter. Importantly, the concept of affect provides here modes of exploring what kinds of new thinking/design configurations might emerge in that sticky intersection. The chapter has argued how affect's sticky quality can both inform and be amplified within explorations of architectural design processes: from the informal, affective stuttering moments of design (including guesswork, contingency and unknowns) to the more formal processes. Specific to this case study, it is through Thompson's continuous and iterative diagrammatic process where the reciprocal interplay of two seemingly different design processes is activated and mediated through. To reiterate a point made by Eisenman, the diagram "as a generator is a mediation between a palpable object, a real building, and what can be called architecture's interiority." 154 The active and affective quality of diagramming allows KTA to discover spatial organizations that indeed are open to change, but also flexible to take on affective stutter - abrupt shifts in programmatic requirements arising in the design process, such as the corner problem discussed above.

Of course, it is acknowledged that research conducted on other projects and practices would generate a series of alternate stickiness-in-process. Also, while this chapter has explored indepth the main sticky interplay between a hunch-driven process and a literary-driven process of the MUMA project, these are certainly not the only interplays articulated by Thompson and Barlow. But what makes this specific interplay a creative site for an exploration of affect is that it

154 Eisenman, "Diagram: An Original Scene of Writing," 94. 
allows (and affords) a direct response to Kraftl and Adey's call for works that "explore the nittygritty, material, localized details of architectural design and form making, be it the curvature of a window seat or the diffuseness of a light." ${ }^{155}$ In this particular case, the study has explored the curvature of the north wall and the number of corners for MUMA's interior. Indeed, these 'localized details' that are shaped by- and through - design processes, are "what sticks, or what sustains or preserves the connection between ideas, values and objects"156 and by extension, two seemingly disparate processes. In turn, the stickiness leads to generating stuttering processes that also (equally) "become sticky, saturated with affects, as sites of personal and social tension.",157

As suggested above, the 'sticky interplay' of the two design processes, extends further to include several other key oscillations between different bodies (human and non-human). Before concluding this chapter, a particular interplay is worth exploring here. Through the MUMA project, there is a coupling (what could be termed as affective mediation), or what Thompson refers to as synergy, that occurs "between art practice and the architectural motivations."158 For instance, the synergy between artist Callum Morton's façade design 'Silverscreen' and Thompson's interior configuration; and, the synergy between MUMA's curatorial principles and architect's design philosophy. Specifically, the latter coupling influences the art exhibitions happening post-occupancy, where sticky affects become attached to the architectural features of both the curved wall and blue spine (with curve of columns). As Ahmed would argue, the wall and columns become bearers of affective value. Barlow notes on the interplay between architecture and art: "I invited an artist, Kerrie Poliness, to basically work along this northern curved wall. And just make this big long wall drawing that was in blue textile; and setting up these series of, almost like diamonds, as the base pattern, and then skewing the points and then everything unfolds from there." 159 This installation triggers a "beautiful rhythm and flow through the space." In another instance, an artist's creative intervention accentuates - and is accentuated by- the affective materiality of the blue spine. Barlow articulates:

[A] further wall was built down the centre (of the spine), confining the space. And then we had this little entry area, to what the artist Stuart Ringholt called 'Club Purple' .... [A] little awning was put up and a neon sign. And there was a club manager - [because] the project was a nude disco - a nude day-time disco .... And this area [at the end of the spine] became a disrobing room - and people [were] dancing naked. ${ }^{160}$

\footnotetext{
155 Kraftl and Adey, "Architecture/Affect/Inhabitation," 228.

156 Ahmed, Happy Objects, 29.

157 Ahmed, The Cultural Politics of Emotion, 11.

158 Thompson, interview, (2014).

159 Barlow, interview, (2014).

160 Barlow, interview, (2014)
} 
Such curatorial orientations that intimately engage with the designed architecture prove how in the shifting/circulation of different exhibitions within MUMA, affects loosens or hardens, or does both. The curved wall and the blue spine, both already saturated with affect, co-participate (through oscillation) with art practice in intensifying, erotizing, and fetishizing, the architectural features and spaces. ${ }^{161}$

Lastly, this chapter concludes by outlining two key reasons for the importance of situating affect within the practice of architectural design. First, one of the key points this chapter has sought to develop is that affective moments, that is, quickened stutters, and the more formally-driven design processes are never fully separable. Rather, it is in their oscillation, continual dialogue and co-constitution that we are able to discuss critically how affect (as stickiness-in-process) are creative of- and co-created by relational processes. Therefore, situating 'sticky' affects in practice attends to and attunes to the event of unpredictable interplays, affective stutters, and hybrids of different bodies, including design processes. Connected to this, and second, analysis of KTA's design process for their MUMA project and articulations by both Thompson and Barlow has provided architectural and curatorial perspective into how architectural design is a practice that works through sticky and affective interplays; practice is open to the contingencies that 'sticky' affects bring. Both of these reasons connect to a final assertion: by looking at the practice of architecture and design process, specifically through affect as stickiness-in-process, we are better able to understand practice as a situation open to chance, contingency and affective stutters. More importantly, efforts to apprehend and become more attentive to the potential of affectivity-in-process might begin to open the field of affect into further discourse that valorises fluid (and sticky) interplays.

This chapter has offered insight into expanding Ahmed's notion of sticky affects in relation to- and in the context of- architecture and its practice. By doing so, it allows us to stretch affect's stickiness not only as a quality of transference/circulation and a theoretical lens through which to make sense of current architectural practice. Rather, also, to extend an understanding of 'sticky affect' to incorporate what the kinds of attachments it produces, that is, intractably stuck situations. For it is only once we acknowledge these potential 'stuck' sites or interplays that, as Clare Colebrook explains, "bring us to an experience of 'affectuality' - or of the fact that there is

\footnotetext{
161 While the above interplay between art and architecture, or the sticky-process (sticky-interplay) discussed in Section 6.4 - does not refer to specific kinds of sticky affects - throughout the interviews, there are some identifiable affects that are articulated. One particular affect is that of "fondness" or as Barlow further articulates, "Having been through the process with Kerstin, I feel a great fondness for the architecture and also her approach to space and materiality. So having the work with the column in the corridor ... I was really pleased about. Because I felt like it left the corridor some space to do its own thing - but it also spoke to the corridor in its essential terms" Barlow, interview (2014). In this sense, the design process itself provides grounds for an emergence of fondness - that is, an affect of positive inclination towards the architectural design, final spatial and material outcome, and design principles of KTA. Particularly in this case, the design process for MUMA, generating a feeling of fondness, acts as affect "means ... or pointers" Ahmed, Happy Object, 34 - for body(-ies) to further 'become fond' (in sticky association) and care for -the interior immersive qualities.
} 
affect."162 Things and processes are sticky through stutters - because of ways in which they are caught up in highly affectively charged scenarios.

162 Claire Colebrook, "Specificity of Affect," in Deleuze and Space, edited by Ian Buchanan and Gregg Lambert (Edinburgh: Edinburgh University Press, 2005), 199. 


\subsection{INTRODUCTION}

The previous chapter (Chapter 6) discussed the practice of KTA and their design process for MUMA. Particularly, it examined the sticky interplay between two seemingly disparate processes: a hunch-driven affective process and a more formal and literary driven process. The analysis provided an account of how affect's stickiness-in-process within a design practice situation can begin to extend the theory of affect towards affective possibilities arousing through stickyprocesses. This chapter continues to extend an investigation of affective practices through a third case study architectural practice and design project: Shigeru Ban Architects (hereafter referred to as SBA) and the design process for their Christchurch Transitional Cardboard Cathedral (hereafter referred to as Transitional Cathedral). This exploration aims to offer another possibility of seeing affect more grounded in practice. Here, the analysis moves to discuss the latter part of design process, whereby the project discussed is in its construction.

Recent debates have grown beyond the perception of 'architecture' simply as an object and have, instead, began to define it as a process and practice. ${ }^{1}$ This allows us to regard architecture as involving "different kinds of embodied engagements with and sensory apprehensions of buildings, as well as different modes of dwelling and inhabiting, and different perspectives on architectural spaces." In this sense, architecture is both the material matter of buildings and the experiences connected with those particular circumstances related to the design process and the eventual occupation, ${ }^{3}$ which, in turn, generates varying atmospheres and affects. ${ }^{4}$ Accounting for such registers allows us to go beyond the realms of an architect's design aspirations and touch upon affective and embodied aspects of the design process and practicing. Aligning with this recent attention to the affective operations within 'practicing architectures, ${ }^{5}$ this chapter focuses on the affects that arise through the evaluation of things. By extension to this approach, and crucially, this chapter argues how the work of affect needs to take the force of materials seriously. Specifically, the analysis which follows asks: How do the negative affects of

\footnotetext{
1 As discussed in Chapter 4 of this thesis. See also, Jane M. Jacobs and Peter Merriman, "Practicing Architectures," Social and Cultural Geography 12, no.3 (2011): 222-236.

2 Jacobs and Merriman, "Practicing Architectures," 213-214.

3 Ignaz Strebel, "The Living Building," 243-262.

${ }_{4}$ See for example, Kenneth Olwig, "Performance, Ethereal Space and the Practice of Landscape/Architecture: The Case of the Missing Mask," Social and Cultural geography 12, no.3 (2011): 305-318; Vasudevan, "Dramaturgies of Dissent," 283-303; Jacobs and Merriman, "Practicing architectures."

5 Jacobs and Merriman, "Practicing Architectures."
} 
restlessness, which stick to objects, arouse interest and positively impact the evaluative processes of design? This question is explored through an examination of the design, production and assembly of the cardboard paper tubes recently designed by SBA for their Transitional Cathedral project. The analysis argues that the design actions are not independent and, in fact, embody affects. In particular, those of restlessness that arise through processes of evaluation between bodies, including designed objects. Accordingly, affects of restlessness transmit and 'stick' on the paper tubes, thus intensifying the object's 'stickiness, ${ }^{6}$ thereby both arousing interest and positively impacting the design process.

This chapter is divided into five sections, including this introductory section (7.1). Section 7.2 explores the perspective towards matter's agency, followed by a brief reflection on the work of Sara Ahmed., as discussed in the previous chapters (Chapters 5 and 6). However, more specific to this chapter, this section addresses Ahmed's use of affect that involve the stickiness experienced in the encountering and evaluation of the process. This view is particularly useful for the case study of this chapter, as the matter, that is, the designed object, arouses specific kinds of affects, as it circulates around bodies. Section 7.3 will then provide a description of the case study practice and the project analysed. It will also give a brief account of the methodology used for this specific chapter. Thereafter, in Section 7.4, referencing interviews with architect Shigeru Ban and other key actors involved in the Transitional Cathedral project, it discusses the affects of restlessness through stutters that arise in the designing, production and assembling process of the paper tubes. This case study analysis will make it evident that 'restlessness,' as an affective condition, is not simply a negative reaction in the design process. Instead, it is a method of actively orienting oneself, albeit temporally, towards different objects. Lastly, section 7.5 will conclude by discussing how body's desire to implement certain objects in a design and evaluation because of their ability to arouse interest. Affects of restlessness are helpful in a design context because they help recognize design problems for future resolution.

\subsection{TOWARDS STICKY OBJECTS}

As already explored in-depth in Chapter 2 of this thesis, scholars of the 'affective turn,' such as Brian Massumi, follow the Spinozian-Deleuzian-Guattarian lineage and define affect as "intensity embodied in autonomic reactions." ${ }^{, 7}$ This perspective provides venues of conceptualizing the preconscious processes that occur between bodies. This chapter acknowledges this position, but aligns more with Patricia Clough's line of thought, regarding the Massumian position as "linking

\footnotetext{
${ }^{6}$ Ahmed, The Cultural Politics of Emotion (New York: Routledge, 2004).

${ }^{7}$ Massumi, Parables of the Virtual, 25.
} 
affect to current mainstream psychological and neuro-scientific explanations of the individual bodies, rather than bodies in affective transmission." " The notion of 'affective transmission' is important in architectural practice because the design process is built upon the relations between both human and non-human bodies and the acts of orientation and evaluation between them (including designed environments and objects). Therefore, to emphasize this affective transmission, this section begins by considering two movements/streams of work that are focusing on the correlation between affect and material matters.

\subsubsection{Intersections between Affect and Matter ${ }^{9}$}

The first stream looks at the recent work on new materialism. Against the commonly assumed notions of matter that is passive and inactive, new materialism attends to matter as, "indeterminate, constantly forming and reforming in unexpected ways" ${ }^{10}$; it explores materialityin-change, in-activity. In this context, and for the purpose of this chapter, it is critical to address how we can think of affect as explored through the recent turn to new materialism. This exploration of the affect of matter (material affect) and matter of affect (affective materiality) is possible only because of major shifts in how matter is being reconfigured, especially in the light of contemporary feminist and cultural theory discourse on 'materiality in-process. ${ }^{, 11}$ In this sense, new materialism looks at affect also, but matter is given, more, of its due. The call for the rethinking of matter has been taken up by diverse fields of discipline, ${ }^{12}$ where matter is, according to Diana Coole and Samantha Frost, (re)engaged as "forces, energies and intensities (rather than

\footnotetext{
8 Patricia Clough, "Afterword: The Future of Affect Studies," Body and Society 16, no.1 (2010): 225.

${ }^{9}$ The work of Pia Ednie-Brown must be acknowledged here as she contributes to discourse on affect, process of design and matter. In her work "The Will to Animation," she draws attention to what she calls the "materiality of affect" through the recent advancement of architectural animation. Important to this thesis, Ednie-Brown's work expands our understanding of materials, as she writes, "materiality is never simply located in the static life of materials as it operates more powerfully in the relations between them (and other forces)." Pia Ednie-Brown, "The Will to Animation," in Animation and Arcbitecture, edited by Bob Fear, Architectural Design Academy Editions 72, no. 2 (2001): 64-73.

${ }^{10}$ Coole and Frost, "Introducing the New Materialism," 10.

${ }^{11}$ See, for example, Manuel DeLanda, "Material Complexity," in Digital Tectonics, edited by Neil Leach, David Turnbull and Chris Williams, 14-21 (London: Wiley-Academy, 2004); Karen Barad, "Re(con)figuring Space, Time and Matter, in Feminist Locations: Global and Local, Theory and Practice, edited by Marianne DeKoven (New Brunswick: Rutgers University Press, 2001); Karen Barad, "Posthumanist Performativity: Toward an Understanding of How Matter Comes to Matter," Signs: Journal of Women in Culture and Society 28, no.3 (2003): 801-831; Coole and Frost, "Introducing the New Materialism," 1-43; Rick Dolphijn and Iris van der Tuin, New Materialism: Interviews \& Cartographies (Michigan: Open Humanities Press, 2012).

${ }^{12}$ For other works on 'New Materiality,' see for example, Rosi Braidotti, Metamorphoses: Towards a Materialist Theory of Becoming (Cambridge: Polity Press, 2002); Mariam Fraser, "What is the Matter of Feminist Criticism," Economy and Society 31, no.4 (2002): 606-625; Susan Sheridan, "Words and Things: Some Feminist Debates On Culture And Materialism," Australian Feminist Studies 17, no.37 (2002): 23-30; Momin Rahman and Anne Witz, "What Really Matters? The Elusive Quality of the Material in Feminist Thought," Feminist Theory 4, no.3 (2003): 243-261; Stacy Alaimo and Susan Hekman (eds), Material Feminism (Bloomington and Indianapolis: Indiana University Press, 2008); Claire Colebrook, "On Not Becoming Man: The Materialist Politics of Unactualized Potential," in Material Feminisms, edited by Stacy Alaimo and Susan Hekman (Bloomington and Indianapolis: Indiana University Press, 2008): 52-84; Susan Hekman, The Material of Knowledge: Feminist Disclosures (Bloomington and Indianapolis: Indiana University Press, 2010).
} 
substances) and complex, even random processes (rather than simple, predictable states). ${ }^{, 13}$ In this sense, this chapter seeks to look at matter - and more particularly, a designed matter (designed object), as a form of affective mediator, that is, as having the capacity to affect and be affected, and in the process, generating sticky-objects. This chapter wishes to use these affective objects - to open up current thinking about the relationship between practice and affect.

At this point, it is necessary to clarify on a key concept that is expanded on through the subsequent sections. Crucially, the term 'materiality' is interchanged with 'matter' where materiality consists of both the matter of material matter (i.e. walls and surfaces) and atmospheric matter (i.e. felt and ambient). This chapter expands on the former "material matter" to include 'things,' particularly, architectural materials, such as designed objects. Thus, for the purpose of this chapter, the terms materiality/matter is also interchanged with material/architectural 'object.' More recently, the discussion has shifted in favour of new materiality to redirect "our attention from the materiality of objects to the properties of materials." ${ }^{14}$ This latter perspective looks at the expressive properties of materials - matter's relational capacities and interactive effects ${ }^{15}$ generating what Latham and McCormack call "affective materialities."16

While there are a number of attributes given to the renewal of materialism, this thesis limits its scope to focus on the work of DeLanda and Barad. Specifically, it looks first at matter as being characterized by "intra-activity," "intensive processes." ${ }^{18}$ For Barad, intra-activity is a different proposition to exploring "interactions" between components, as this would imply that they are independent entities from the outset. Rather the body and the building, for example, are in lively and varied intra-actions prior to engagement. The innovation here is shifting from thinking of matter (and in this chapter, objects) as passive or separate to us from the outset. Delanda looks at how matter is not an object to be measured, but rather, has a capacity to act, to engage and to be transformed; matter is immanent and intensive. The following expands on these perspectives.

Asking, how can matter be understood to be affectively intra-active? Barad, in an interview, states that " $[\mathrm{m}]$ ateriality itself is always already a desiring dynamism ... energized and

\footnotetext{
13 Diana Coole and Samantha Frost, "Introducing the New Materialism," in New Materialisms: Ontology, Agency and Politics, edited by Diana Coole and Samantha Frost (Durham and London: Duke University Press, 2010), 13. Coole and Frost also explain the turn to new materialism as a movement that rethinks materiality from the perspective of matter as "always something more than 'mere' matter: an excess, force, vitality, relationality, or difference that renders matter active, self-creative, productive, unpredictable" Coole and Frost, "Introducing the New Materialism,", 9.

14 Tim Ingold, “Materials Against Materiality,” Archaeological Dialogues 14, no.1 (2007): 12.

15 Karen Barad, "Posthumanist Performativity: Toward an Understanding of How Matter Comes to Matter," Signs: Journal of Women in Culture and Society 28, no.3 (2003): 822.

16 Alan Latham and Derek McCormack, "Moving Cities: Rethinking the Materialities of Human Geographies," Progress in Human Geography 28, no.6 (2004): 706.

17 Barad, "Posthumanist Performativity," 817.

18 Manuel DeLanda, Intensive Science and Virtual Philosophy (London: Bloomsbury Academic, 2002$), 67$.
} 
energizing, enlivened and enlivening. ${ }^{\text {19 }}$ Critically for Barad matter is not mute, or held at a distance, rather matter is dynamic and alive. It yearns as well as struggles as it is acted upon and acts on 'other' matter, through the "stabilizing and destabilizing process of iterative intra-activity" ${ }^{20}$. This means that matter has an agency. An example of this, from experience, is living in a concrete block house where the coolness radiates and has an impact on how we engage with the space. The concrete blocks, in this case, are another component, like our own bodies, that engages in the world. Intra-activity suggests that matter is necessarily composed of 'other' matter through "reconfigurings/entanglements/relationalities/(re)articulations." "21 Matter in Barad's work is active and has a force. Her work allows us to focus on the assemblage between the body and the built as a process that affect each other. This moves us away from a literary or discursive understanding of matter.

Similarly, DeLanda connects an understanding of matter as active to notions of affect, within an architectural context. To explore this DeLanda uses the example of the formation and behaviour of metal, which continuously changes "from ductile and tough to rigid and brittle" via heating and cooling processes. ${ }^{22}$ Matter such as this is not merely self-enclosed, but assumes its characteristic states through intensive processes and activities. To demonstrate this further, DeLanda examples soap bubbles which form spherical shapes in an attempt to minimize surface tension. The point is that we might look at the soap bubble as one complete thing, but in looking closer, it is made up of different tensions between individual molecules that make up the bubble. In this way DeLanda stresses that matter sustains its own intensive thresholds, the bubble, for example, does not exist without tension. Here, DeLanda explicitly calls us to take matter as "active and affective ... energetic materialit[ies] in movement" ${ }^{23}$ linking notions of new materialism and affect.

In considering these positions of new materialism, this chapter seeks to consider matter through its transformative intra-activity, always in-processes of being acted upon and acting on 'other' matters. That is, and following Bennett, it attends to processes where "human beings and thinghood overlap." ${ }^{24}$ Drawing on this current thinking about matter-in-process, the analysis of this chapter aims also to extend these discussions to incorporate architectural 'things' and materials, in the form of designed objects. Partaking inside the "sticky web of connections" 25 between bodies (human and non-human), these objects have capacity to affect and be affected in

\footnotetext{
${ }^{19}$ Karen Barad interviewed in Rick Dolphijn and Iris van der Tuin, New Materialism: Interviews \& Cartographies (Michigan: Open Humanities Press, 2012), 59

${ }^{20}$ Barad, "Posthumanist Performativity,"822. Emphasis in the original.

21 Barad, "Posthumanist Performativity," 818.

22 DeLanda, "Material Complexity," 17.

23 DeLanda, "Material Complexity," 19.

24 Bennett, "The Force of Things," 349.

25 Bennett, "The Force of Things," 365.
} 
the process of design. Such perspective allows us to open up current thinking about the relationship between matter and affect - to include, albeit, to use DeLanda's word, the "humblest" 26 of forms, such as cardboard tubes.

This leads to the second consideration which draws on recent feminist works with a focus on affect as a material encounter between animate and inanimate objects. Despite other contributions to this area-notably Teresa Brennan, who sees affect as a judgmental "evaluative (positive or negative) orientation towards an object," ${ }^{, 27}$ this chapter's study focusses on works by Ahmed and her insistence of affect's relation to various objects. She asserts that, "[t]o be affected by something is to evaluate that thing. Evaluations are expressed in how bodies turn toward things." 28 Therefore, affective transmission is experienced through evaluation-where bodies are turning toward each other-in 'sticky' compositions and connections. This leads to a brief discussion about the evaluative process to determine affect and involve both the object's approach and how we approach the object (our 'angle of arrival'). The two views are coconstituted in the evaluation practice and cooperate in the creation and participation of "materializing the surfaces and boundaries" of bodies. ${ }^{29}$

\subsubsection{Sticky Affects and the Affect Evaluative Process}

Ahmed's exploration of affect exposes the character of its transmission and evaluation as being cross-temporal and cross-spatial, where affects are attributed to circulating objects that become 'sticky' and accumulate affective value. Stickiness suggests a touch where 'negative' affects are associated with an object that distances itself from the body, whereas a 'positive' object arouses a desire for a closer proximity —as if to touch it. ${ }^{30}$ In this sense, a 'sticky' affect relates to an object's orientation, or its embedded approach in a given setting or environment.

Ahmed emphasizes the affective processes of evaluation as "the arrival of an object ... [and] also how we turn toward the object." 31 The affect embodied in objects does not merely 'stick' to other bodies approaching it. Rather, Ahmed describes how our body's approach to a work is never neutral: 'We may walk into a room and 'feel the atmosphere', but what we may feel depends on the angle of our arrival" 32 and clarifies how affect is "always felt from a specific

\footnotetext{
${ }^{26}$ Manuel DeLanda, A Thousand Years of Nonlinear History (New York: Swerve Edition, 2000), 16. Cited in Bennett, "The Force of Things," 351.

${ }^{27}$ Brennan, The Transmission of Affect, 5 .

28 Ahmed, "Happy Objects," 31.

29 Ahmed, "Affective Economies," 191.

30 Ahmed, "Happy Objects," 32.

31 Ahmed, Queer Phenomenology: Orientations, Objects, Others, 2.

32 Ahmed, "Happy Objects," 37.
} 
point." 33 This suggests that the approach or position depends on "the arrival of the body that perceives" ${ }^{\prime 4}$ it together with the already angled object; affect arises from the two-way encounter between objects and bodies. Thus, affects are not necessarily our own or the object's because they may have been transmitted by someone else, or by an entirely different object or environment.

By illustrating affect's evaluative process as a material and sticky encounter, Ahmed shows how affect-objects are interactively co-constituted through the evaluation of things. This evaluative process, in turn, influences the bodies' "awayness and towardness" 35 in regard to the affect-object. As she notes in relation to Husserl: "Within the joy we are 'intentionally' (with feeling intensions) turned toward the joy-object as such in the mode of affective 'interest."”36 Indeed, as a mode, 'affective interest' is continually "mode-ify[ing] and ... [is] modified ... always subject to the contingency of aleatory encounters with other modes. ${ }^{37}$ Ahmed posits how the joy-object incites a need for/arouses us to - come in proximity, where the positive material “provide[s] a 'means' for making us happy ... directing ourselves towards this or that object."

Ahmed's position forms a strong platform for this chapter, but she is not writing about a design situation. The exploration which follows, then, will extend and depart from Ahmed's opinion to propose how negative affects of restlessness within certain objects are able to arouse affection and interest, an important element of any design process. Accordingly, it will transition from discussing sticky affects to affects of restlessness (restless-objects), with the latter attaching to objects and subsequently increasing their stickiness. What follows explains why this thesis departs from stickiness to restlessness - addressing the relationship between these two terms, particularly as it occurs in design situations.

\subsubsection{Affects of Restlessness and the Practice of Architecture}

The practice of architecture involves any number of bodies, objects, and elements with complex interactions. As a result, there is a restlessness that surrounds architectural projects; an inherent uncertainty that forces shifts in orientation and direction through affective stutters. For the purposes of this chapter's analysis, restlessness is an on-going affective condition, or stutter, that helps form evaluations and orientations toward the constructed environment and its designed

\footnotetext{
33 Ahmed, "Happy Objects," 37.

34 Ahmed, Queer Phenomenology: Orientations, Objects, Others, 38.

35 Ahmed, "Happy Objects," 32.

${ }^{36}$ Edmund Husserl, Ideas Pertaining to a Pure Phenomenology and to a Phenomenological Philosophy - Second Book: Studies in the Phenomenology of Constitution, translated by Richard Rojcewicz and André Schuwer (Doredrecht: Kluwer, 1989), 14; cited in Ahmed, "Happy Objects," 31.

37 Bennett, "The Force of Things," 353.

38 Ahmed, "Multiculturalism and the Promise of Happiness," 125.
} 
objects. Restlessness also allows for the possibility of intensifying 'stickiness' or 'towardness' between bodies and objects. ${ }^{39}$ While considerable work has been done emphasizing particular types of affect, for instance, works positing importance of positive affects (such as joy and hope) against negative affects (such as anxiety and fear), ${ }^{40}$ this chapter interrogates this division between affects by proposing to look at affects of restlessness as moving between negative and positive capacities to affect and be affected.

Ahmed defines 'happiness levels' as ranging from higher levels of happiness to "much weaker, much thinner happiness" ${ }^{41}$ forms to an ultimate level of unhappiness. ${ }^{42}$ In a similar manner, while this chapter does not make subtle distinctions of these levels of restlessness, it is worth noting how restlessness may involve a gradual increase of affect, beginning with slight discontentment, unease, ending with anxious worrying. While affects of restlessness may halt activity (have a negative impact) through stilled stutters, they have an equal capacity to keep bodies in the present; restlessness can be a positive energy that sustains an object's 'stickiness'. In this sense, and following Sianne Ngai, restlessness or as Ngai describes, the "state of feeling vaguely "unsettled",43 is, in contrast to more powerful and sudden affects such as hate, fear, or anger, equated as "unprestigious affects" disordered stutters. These 'non-cathartic' affects, as Ngai calls them, are characterized through their 'flatness' and 'on-goingness' and have an extensive capability for duration. ${ }^{45}$ This latter evaluation of restlessness is of interest to this chapter, given how the persistent character of restless affects can extend to counter the shifting and often contingent architectural design process. By bringing together Ngai and Ahmed's perspectives, the chapter considers restless affects as less forceful and less dramatic, but having the capacity for persisting and lingering between bodies, both human and non-human, as well as sustaining itself - 'sticking' on objects themselves. In the analysis section of this chapter, the term 'restless-objects' is used to describe objects that embody restlessness. In this manner, restlessness can arouse interest; intensifying desirability and 'towardness' - a sense of strong attachment and stickiness between things. ${ }^{46}$

\footnotetext{
39 Ahmed, "Multiculturalism and the Promise of Happiness," 123.

40 See for examples, Silvan S. Tomkins, Affect, Imagery, Consciousness: Volume II. The Negative Affects (New York: Springer Publishing, 1963); Massumi, Parables of the Virtual, 2002; Brennan, The Transmission of Affect, 2004; Sianne Ngai, Ugly Feelings (Cambridge and London: Harvard University Press, 2005); Ahmed, "Affective Economies," 117-139; Ahmed, The Cultural Politics of Emotion, 2004; Ahmed, "Happy Objects," 29-51.

41 Richard Schoch, The Secret of Happiness (New York: Scribner, 2006), 1; cited in Sara Ahmed, The Promise of Happiness (Durham: Duke University Press, 2010), 12.

42 Sara Ahmed, "The Politics of Good Feeling," ACRAWS A e-journal 4, no.1 (2008): 2.

43 Ngai, Ugly Feelings, 14.

44 Ngai, Ugly Feelings, 6.

45 Ngai, Ugly Feelings, 7.

46 Ahmed, "Multiculturalism and the Promise of Happiness," 123.
} 
Here, the chapter moves forward to consider restlessness as an affect (in its optimistic and affirmative evaluation) that generates interest towards things. These affects help us form evaluations of, and orientations toward the built environment, specifically designed objects.

Specifically, this chapter considers how the designed object of cardboard paper tubes begins to acquire and accumulate restless affects. The analysis illustrates how restlessness transmit through and stick on the tubes, at times enhancing and intensifying its stickiness by drawing bodies toward it through its capacity of 'duration', while at other times, weakening its stickiness. Here, the tubes become active agents in the circulation of restless affects, as it passes around between different bodies. The following section (7.3) provides an illustration of this chapter's case study architectural practice, and the design project that is analysed. This is followed by a brief outline of methodology specific to this chapter's analysis.

\subsection{CASE STUDY AND METHODOLOGY}

This section introduces the third case study architectural practice of this thesis. This is followed by an illustration of the architectural project analysed in section 7.4, specifically attending to the architectural object of the cardboard paper tubes. Lastly, a research methodology specific to this chapter is outlined, and which asks: How do we capture, document and analyse, instances where affect attaches to objects by way of an evaluative process?

\subsubsection{Case Study 3: SBA}

Shigeru Ban Architect's (SBA) is led by principle Shigeru Ban, and the practice's offices span between Tokyo-New York and Paris. The amount of projects currently being taken up by SBA is 'uncountable' - or more specifically, as Ban himself noted, "I have never counted them," attesting to the multiple processes of design occurring at the same time. Despite the many architectural projects happening parallel and in different countries, SBA's practice is primarily led by Shigeru Ban and his strict design principles. Here, there are two points worth considering. The first involves Ban's position, albeit a seemingly strict one, to "design it all" - as Ban himself elaborates: "I do all the design. From coming up with the concept - to thinking through the structure and the details." ${ }^{47}$ This is reemphasized by Yoshie Narimatsu, project architect for the Christchurch Transitional Cathedral: "I believe what is unique (or particular) to the practice is that Mr. Ban always, without exception, decides on the concept design. Whether it is for a very

\footnotetext{
${ }^{47}$ Shigeru Ban, interview by author, Christchurch, NZ, February 23, 2013.
} 
small project - he always designs the concept. "48 SBA's projects are then, firmly designed by Ban, and there is "no wavering" on Ban's side - where "what Mr. Ban cannot agree on, he will never agree on .... What is most important - when working in SBA, is to understand Mr. Ban's design principles and priorities, what he can defer/concede- give-up on -, what he can't, what he can yield a little, what he can't at all -those kind of priorities.”49 The practicality of this all-seeing, all-designing approach to design is described by Narimatsu: "Mr. Ban would draw a quick sketchand this could be a very simple sketch ... and sometimes, through rarely, he communicates [his design concept] through words - if you are a long-time staff, you get told the concept, and there are those that get it." 50

This unique design method is, to some degree, counter to other characteristic Japanese architectural firms where principal architects "do competitions within the firm, and choose the best design concept, which is then implemented to present to clients or for entries to competitions." 51 In other words, architects rely on their staff's creative abilities to "design" so that, their practices expand. Interestingly, Ban reflects on how there is "no meaning in making yourself famous," and as such, SBA's architectural portfolio attests to a practice drawn to projects of various scales. Ban articulates:

Indeed, I want to continue doing small projects. Houses are among the least profitable projects, and they are the most difficult to work with, because you have to give uniqueness to each different project. In comparison to say, spaces such as an office or firms, these can be more universal. And so, [with houses] you don't get any profit, and it takes a long time. Each client is also always different. But for me, architecture is like a training ground. Also, it is an experimental site/ground, to try and test out new ideas. That is why, even Corbusier, Wright, Kahn, and Mies, they continued designing houses. ${ }^{52}$

This comparison by Ban, and equally Narimatsu, of SBA's practice and 'others' - particularly Japanese firms - is in no way addressed as demeaning the other practices. Rather, as Ban asserts,

It is not a matter of what is good or bad [practice] ... there is nothing bad with knowing your own capacity, what you are good at, what you aren't .... And what's more, it is not only my kind of architecture that is desired. There are different architects, and because of this diversity, there are different values, which make different architectures. And that's a good thing. ${ }^{53}$

The second point that is worth noting as particularly unique to SBA's practice is their concern for 'materiality.' Although Ban himself does not refer to this term exactly, he is nevertheless

\footnotetext{
48 Yoshie Narimatsu, interview by author, Christchurch, NZ, February 20, 2013.

49 Narimatsu, interview, (2013).

50 Narimatsu, interview, (2013).

51 Narimatsu, interview, (2013).

52 Ban, interview, (2013).

53 Ban, interview, (2013).
} 
concerned with "things" - as he says, "It's just that I think anything around us is thas the potential to be] an architectural material, it's not that I am absorbed in it - ('kotteiru wake jyanakute'), but I am almost surprised that most people don't think that way. Because, anything, everything, can become a material [for architecture] ... even plastic [drinking] bottles." 54 One particular object, that of cardboard paper tubes, is used extensively as an architectural material by SBA. As Murray Fraser most recently characterizes SBA's practice through “Ban's long-standing design research into the responsive yet aesthetic use of cheap ordinary materials." ${ }^{.55}$ In this regard, the practice of SBA places critical importance on both the process of shaping the paper tubes and facilitating their seamless and smooth connection with other materials. The recently completed Christchurch Transitional Cathedral grappled with various contingencies associated with the cardboard paper tube production. The following part briefly describes this project, and the importance of the paper tube as a sticky object in the design process.

\subsubsection{Project and Object}

As a disaster-relief "emergency project" (as Ban puts it), the Transitional Cathedral project began as a 'site-less' project which envisioned a 'transitional' cathedral for the now-demolished Christchurch Cathedral. According to project architect Narimatsu, the conversation between the Cathedral representatives and SBA began approximately a month before the 13 June, 2011

Christchurch earthquake. Ban and Narimatsu's first visit, already planned beforehand, occurred exactly a week after the June earthquake, where SBA offered their design service free of charge. As project architect Narimatsu elaborates, this pro-bono stance extends beyond their own practice: "Not only on our part, but also from other companies and parties involved, there is a little bit of a collaborative volunteering attitude. Unlike other profit-based work, this project is not at all a 'money-orientated' one. That is one reason that there isn't that kind of awkward and uneasy tension that emerges [between parties]. ${ }^{, 56}$ Despite the lack of site, the Transitional Cathedral project initiates as a 'temporary' structure, but quickly shifts to become a 'permanent' building. The client explains -“you can't really put up any old building in Christchurch now, because of the earthquake ... you have to put a strong building .... But even though it changed to a permanent structure, it is still, what they call it a 'transitional' - when the building in the square, the Cathedral, is fixed, this [one] will become a parish church." ${ }^{, 57}$

\footnotetext{
54 Ban, interview, (2013).

55 Murray Fraser, “'A Two-Fold Movement': Design Research as Dialectical Critical Practice,” in Design Research in Architecture: An Overview, edited by Murray Fraser (Burlington: Ashgate, 2013), 224.

56 Narimatsu, interview, (2013).

${ }^{57}$ Cathedral Development Manager, interview by author, Christchurch, NZ, August 15, 2013.
} 
The conceptual design is sketched by Ban on his initial trip: "He went into the building in the square, and he just sketched. He looked at the old building and he came up with this design. Very very quickly." 58 This swiftness of design continues throughout the project, and even in the construction process - where, as the client side asserts, "We really designed as we went ... in order to get it done quickly, we started constructing before the full design was done, and we designed on the move. So there were things that needed to be designed - and it's not the best way to work, because it was frustrating for the builders. They weren't exactly sure what it was going to [be] ... what was involved." 59 Throughout the quickness (quickened stutters), as well as delays and frustrations (stilled stutters) of the Transitional Cathedral design process; this chapter aims to trace the process(es)of making the architectural object of the paper tubes. The particular architectural material of the cardboard paper tubes confronts multiple forms of resistance in the form of affective stutters; by the public who raised doubts of the strength of this material; by financial struggles; by the manufacturing company's limited capabilities, among others. Nevertheless, the cardboard tubes capture attention, generating sticky affects. This stickiness induces bodies in their proximity to orientate toward them (interest), prompting assessment and evaluation. The following outlines the research methodology utilized for the analysis.

\subsubsection{Methodology}

Data collection in the Transitional Cathedral design process study aimed at closing the gap between design architects, producers of designed materiality/objects, assemblers and artefacts (objects). In this sense, it attends to, borrowing the words of Jacob and Merriman (referring to Bohme), the "co-production" $" 60$ of affects, asking how do we capture, document and analyse, instances where affect attaches to objects by way of an evaluative process?

Specifically, in-depth interviews were conducted with people who had been involved in the design of the cardboard paper tubes. This includes design architect Shigeru Ban, project architect Yoshie Narimatsu, the paper tube manufacturer and a client representing Christchurch Cathedral. Interviewees were contacted by email in the first instance, and were interviewed at various locations, including the Christchurch Airport, outside the construction site of the Transitional Cathedral, the paper tube manufacturing factory, and inside the finished Transitional Cathedral, respectively. Each of the articulations by the different bodies regarding the design,

\footnotetext{
58 Cathedral Development Manager, interview, (2013).

59 Cathedral Development Manager, interview, (2013).

60 Jacobs and Merriman, "Practicing Architectures," 218.
} 
production and assemblage of the paper tubes - were essential in understanding the design process as relational, and generative of a co-production of affects.

Particular to this case study, the researcher conducted the interviews with both architect Shigeru Ban and project architect Yoshie Narimatsu, in Japanese, as this was both the researcher and interviewees' native language. The researcher acknowledges that there are potentials as well as disadvantages associated with this interviewing method. The potential lies in providing an environment where the interviewee's are able to discuss issues and articulate points of views without the need to translate their thoughts to English. In this respect, this chapter's analysis acknowledges and agrees with Rubin and Rubin's position whereby using the interviewee's native language can be "an indicator of one's "willingness to enter into the world of the interviewees." In reflection - using both the researcher and interviewees' first language (Japanese) provided a "neutral platform" for the exchange of ideas and allowed "more authentic answers that exhibit 'more subtle nuances."'62

There are, however, challenges associated within the analysis stage, specifically; the inaccuracies that may arise when translating interview transcripts. In regards to this point, and particularly for this case study, the data analysis involved a two-stage process. First, the researcher transcribed the interviews entirely in the native Japanese language. Second, the analysis of the transcripts occurred in both Japanese and English simultaneously. The main challenge for the researcher was the step in translation as to the accuracy of choosing the right English words to represent interviewees' meaning. The researcher acknowledges these possible inaccuracies; however, the researcher has attempted to ensure accuracy by attending design meetings held in English, with both Ban and Narimatsu attending. In this way, key words and phrases used in the design discussions in English have provided a useful guidance in the translation of the interview transcript conducted by the researcher.

The following section analysis the design, manufacture and assembling process of the cardboard paper tubes used in the construction of the Transitional Cathedral. By tracing these three different (yet interlinked) stages - the study explores how the tubes begin to acquire and accumulate affects of restlessness through acts of orientation and evaluation prompted by stutters in the design process. Interwoven with this exposure is an exploration as to how these affects are transmitted to the designed object in order to intensify its 'stickiness.'

\footnotetext{
${ }^{61}$ Herbert J. Rubin and Irene S. Rubin, Qualitative Interviewing: The Art of Hearing Data (Thousand Oaks: Sage, 1995), 173. Cited in Catherine Welch and Rebecca Piekkari, "Crossing Language Boundaries: Qualitative Interviewing in International Business," Management International Review 46 (2006): 420.

62 Welch and Piekkari, "Crossing Language Boundaries," 428.
} 


\subsection{AFFECTIVE RESTLESSNESS OF STICKY OBJECTS}

Compiling the gathered evidence provided insight into the different forms of the affects of restlessness that arose and lingered through the shaping process of the architectural material of the cardboard paper tubes. This process led from the initial design to the production-site assembly where, albeit temporally, the level of restlessness intensified through the different stages. The following is divided into three interlinked component/stages of design: designing, producing, and assembling. Again, it should be reiterated that affects of restlessness do not necessarily express a negative evaluation. It will become evident that restlessness can positively intensify interest toward an object on which such affects further build the 'stickiness' between bodies.

\subsubsection{Designing}

The Transitional Cathedral project presented a significant challenge to implement the original design of the tubes. Though we may analyse this as a conflict between intent and reality, it can also be considered as a conflict of productive differences. The provided accounts show that the first tube design was abandoned due to the lack of production capacity within the factories and resulted in a sense of restlessness amongst the involved bodies. As this restlessness stuck to the tubes, the stutter in the design process simultaneously prompted a shift in both the approach and evaluation. The overall process intensified the 'affective interest,' ultimately increasing the desire to further explore the objects of interest: the tubes. 


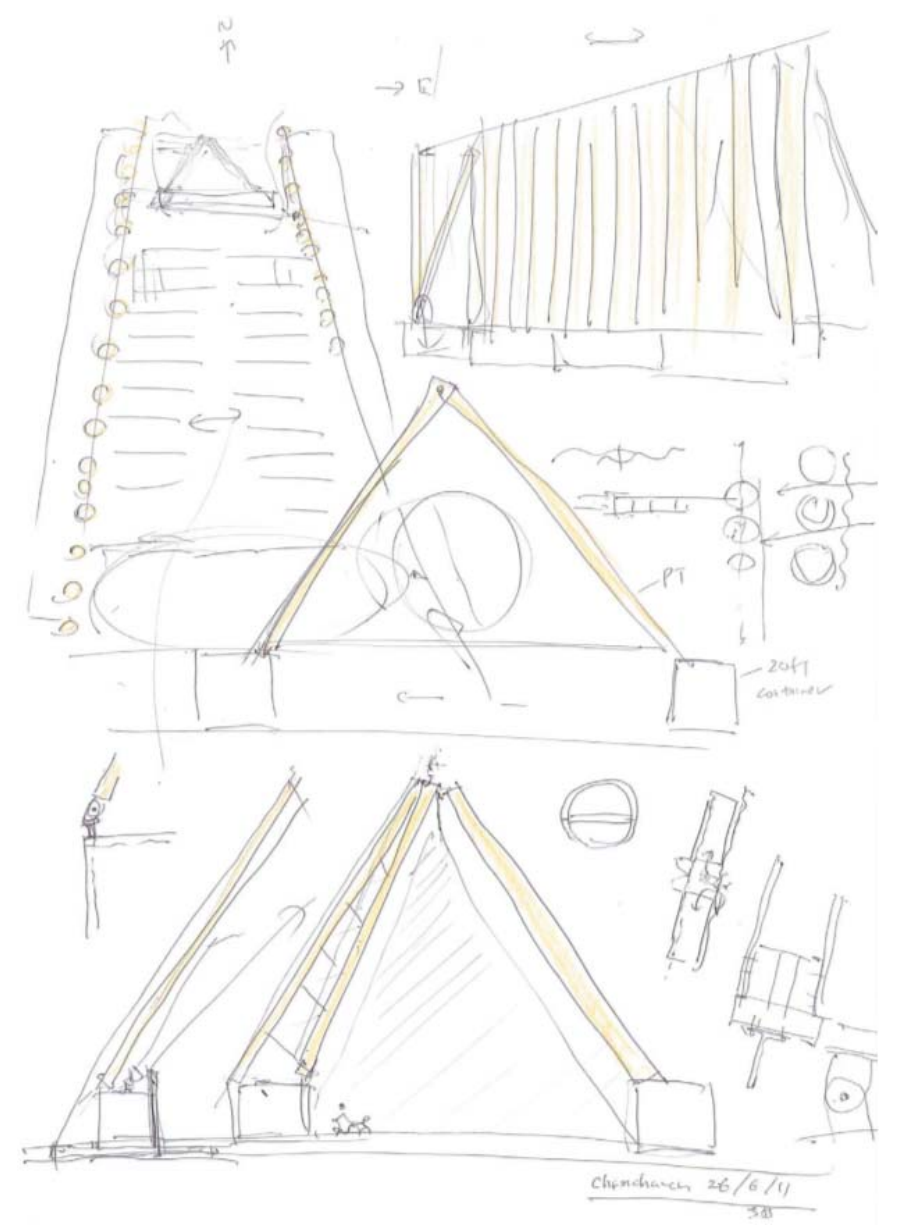

Fig. 16: Shigeru Ban, Christchurch Transitional Cathedral Concept Drawing, 2011, sketch drawing. 63

The initial accounts by the design and project architects suggest the paper tubes arriving to the design process already angled to a particular position, with Shigeru Ban determining their value as "one that could be used structurally" (fig. 16). ${ }^{64}$ Project architect Yoshie Narimatsu agreed: "At the beginning stage, the paper tubes were $880 \mathrm{~mm}$ in diameter and $15 \mathrm{~mm}$ in thickness. And so, the tubes were the structure." ${ }^{95}$ As evidenced in the first stages, evaluation of the tubes was based strictly upon their capabilities as structural objects, with calculations being utilized to evaluate their potential strength to support the weight of the whole building.

This orientation was forced to shift as the limited capability of the manufacturing factories within New Zealand became apparent. As a stutter in the design process and with the set back of their idea, Narimatsu recalled, "we found out that it was impossible to build such thing ... [the Christchurch factory] didn't have the capacity needed." ${ }^{, 66}$ This sentiment was shared by the client: "[We hoped them] to be structural, but we couldn't do it. It was just too big ... we couldn't manufacture cardboard tube here that was long enough in one length, so we had to do

\footnotetext{
63 Shigeru Ban, Christchurch Transitional Cathedral Concept Drawing, 2011, sketch drawing, courtesy of Shigeru Ban Architects.

65 Narimatsu, interview, (2013).

66 Narimatsu, interview, (2013).
} 
three lengths. We couldn't manufacture it thick enough to hold the building up, so we had to put beams through the centre of them." ${ }^{97}$ With the intended structural design of the tubes no longer able to be realized, restless feelings began to form.

Responding to the factories' inability to produce the 'big' tubes, Ban regretfully expresses: “[The Christchurch factory] didn't have the capacity needed ... they had never manufactured [a tube] of that (big) size." 68 The client equally notes disappointedly: "We couldn't manufacture cardboard tube here that was long enough, in one length, so we had to do three lengths. We couldn't manufacture it thick enough to hold the building up, so we had to put beams through the centre of them. ${ }^{\prime 69}$ Both Ban and the client express restlessness as they are affected by the factory's lack of capacity to produce the required tubes. The temporal stutter causes restlessness to become associated with the tubes, momentarily making them 'restless-objects.' The shared feeling towards the object echoed their shared evaluation of the object: a negative evaluation based on their 'non-structural' condition. This affective state of restlessness lingered as the involved parties modified the design to account for the loss of structural value; the tubes, as restless-objects, then became objects of concern, and aroused heightened levels of interest.

Though subtle, the affects of restlessness were transmitted through the different parties and stuck on the cardboard tube design before it materialized beyond the blueprints. This frame of thought illustrates the evaluative shift toward the tube-from its capacity to be ideally structural to then becoming realistically non-structural—and allows the object to become 'sticky' with affective interest.

\footnotetext{
${ }^{67}$ Cathedral Development Manager, interview, (2013).

${ }^{68} \mathrm{Ban}$, interview, (2013).

${ }^{69}$ Cathedral Manager, interview, (2013).
} 


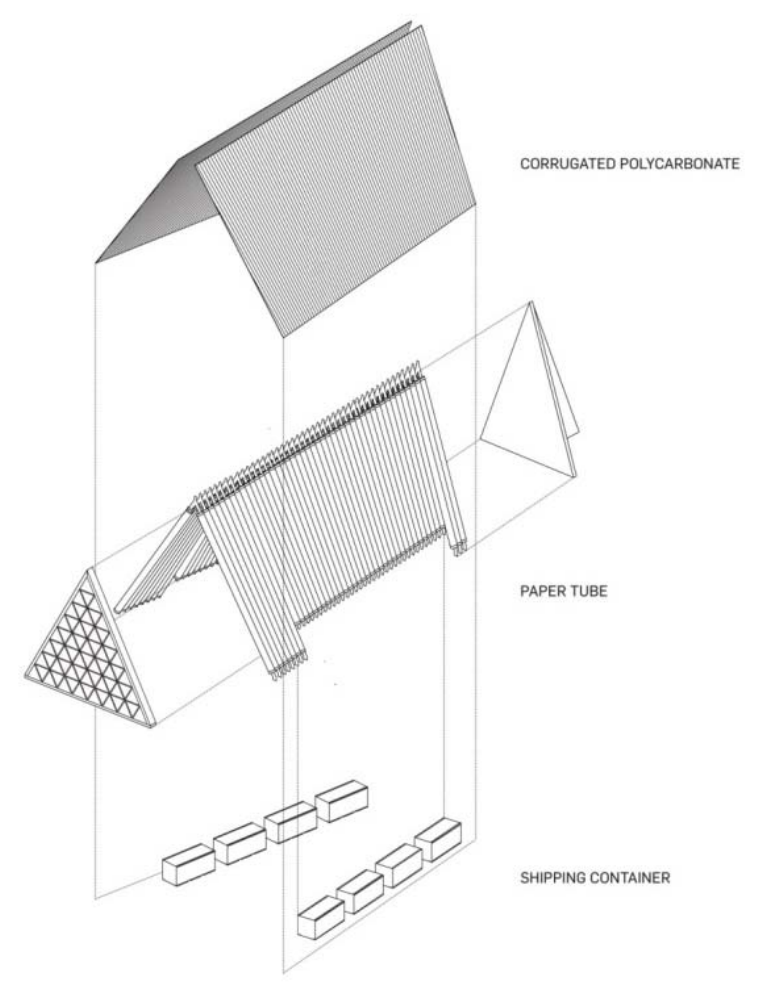

Fig. 17: Shigeru Ban, Christchurch Transitional Cathedral-Local Materials, 2011, drawing. ${ }^{70}$

The on-going evaluative process modified the tubes' affective value. As he realigned the design approach, Ban recounted, "There is an option to get them [paper tubes] imported, but for me, what matters most is not to use the paper structurally. Rather, it is to try as best as possible to use locally made paper tubes. So, even if it's a compromise to our [original] design, the priority is to use local material" ${ }^{71}$ (fig. 17). The affective stutter in the design process shifts the design focus from structural concerns to those prioritizing the use of local materials and production sites. Here, a change is evident within the evaluation of the tubes: a desire to have a closer proximity within the production process, thus developing a 'sticky' connection between Ban and the object. The re-orientation of approach elicits a positive affect (and interest) between the different parties, bringing a heavier amount of goal-oriented teamwork. The cardboard tube manufacturer described the collaboration:

So that's where we came up with the idea that we join them together on an LVL truss, which is the structural element of the tube. So, really, the tube is ... just an aesthetic show piece at the end of the day ... which I was quite happy about, actually. Because when you turn something, you know, it's all good having it standing up like that, with all the forces going down. But when you build it angled ... it has a tendency to buckle and you lose all that capability. ${ }^{72}$

\footnotetext{
${ }^{70}$ Drawing illustrating materials used in the design with locally available materials, Shigeru Ban, Christchurch Transitional Cathedral Local Materials, 2011, drawing, courtesy of Shigeru Ban Architects.

${ }^{71} \mathrm{Ban}$, interview, (2013).

72 Paper Tube Manufacturer manager, interview by author, Christchurch, NZ, February 22, 2013.
} 
The reorganization that modified the tube's function from being a structural component to being an aesthetic contribution also reveals an increase in their affective interest. Here, we see how the initial evaluation of the tubes, through the designing process (through drawings and discussions), even before being manufactured, has aroused restlessness between the bodies (both human and non-human, including objects). Additionally, through the shift in approach towards the object, there is an increased desire to interact/connect with the tubes; a stickiness in the form of affective interest. To expand further on this last point, the affective value of the paper tubes accumulates through tense, restless and stuttering moments. As seen above, Ban's swift change (a quickened stutter) in prioritizing local manufacturing, which to some extent is a sacrifice to his original intent of the tubes being structural, allows for bodies to come together to do their best in now making the product as 'aesthetically' beautiful. Here, the tubes as restless-objects equally become attractors of a shared sense of interest. We can see how a community of shared tendency and happy-orientation towards the tubes arise, where the restless-object (still in its design stage) is affective in the way it draws bodies around it - as if to indeed, albeit metaphorically, care for it. $^{73}$

The initial design of the tube, now re-evaluated and re-designed to accommodate the limited capacity of the Christchurch manufacturing company is then transferred into the process of production. The next section analyses the making of a paper tube, highlighting how the process requires multiple forms of contact between objects. In turn, the production triggers higher levels of restlessness surfacing between the parties and objects involved.

\subsubsection{Producing}

The evaluation of the tubes extended into the second phase, composed of creating and transporting the designed objects. The beginning production process is the combination of varied elements and contacts of specific objects to form the physical tube. Knowing the background of the manufacturing steps is critical to understanding how the restless affect can surface and intensify as the tubes circulate between different bodies throughout the design process.

The investment of time and effort in production process creates an undeniable sense of attachment toward the object. As revealed by the manufacturer: "[Making] one tube will take us 3 minutes ... the drying would take at least 24 hours. [And] there's a lot of set-up in the process. It

\footnotetext{
73 This analysis echoes recent works on materiality, notably by Christopher Tiley. Tiley suggests the importance of the concept of materiality, as it begins to address why some objects/materials "become important to people." The analysis in this chapter seeks to align with Tiley's position - to go "beyond ... [the paper tube] itself and situating it in relation to other ... landscapes, persons, and their doings" Christopher Tiley, "Materiality in Materials," Archaeological Dialogues 14, no.1 (2007): 16-20. Specifically, the chapter seeks to illustrate the complex and lively relation between the paper tubes design process and the bodies (i.e. different people and environments) it comes in contact with.
} 
takes us at least a day and a half just to set up and get ready for it." ${ }^{, 74}$ The preparation of the machine extends the time required for the tube's production and accentuates the overall accumulating affective quality. This reflects back to Chapter 4 , whereby design processes do require times of waiting, or more specifically, stilled stutters, but also mundane processes as 'setting up' machines. To reiterate, these moments of stilled affective stutters, where indeed the act of designing has taken a pause, are crucial to highlight the sense of attachment to the process of preparation itself. Producing each cardboard tube requires an intense process of pulling, pushing, and pressuring and involves a highly complex set of components that make impressions and marks on the recycled paper.

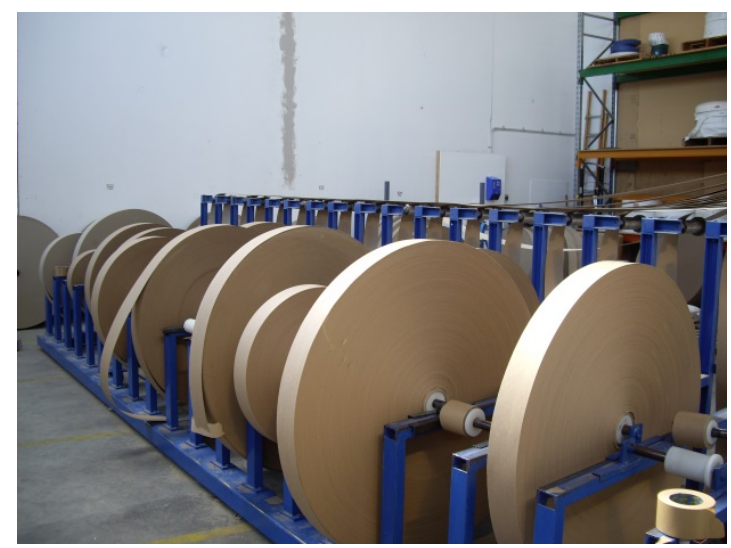

Fig. 18. Cardboard Paper Tube Manufacturing Company, Recycled Paper Strips, 2013, photograph. ${ }^{75}$

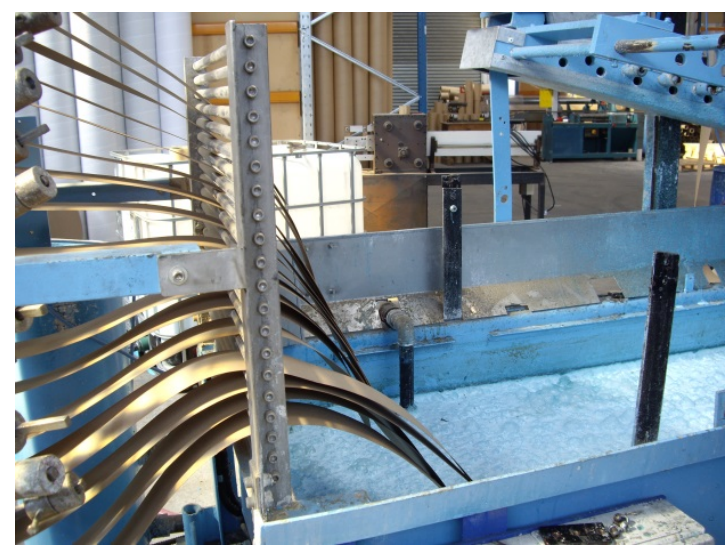

Fig. 20: Cardboard Paper Tube Manufacturing Company, Glue Bath, 2013, photograph. ${ }^{77}$

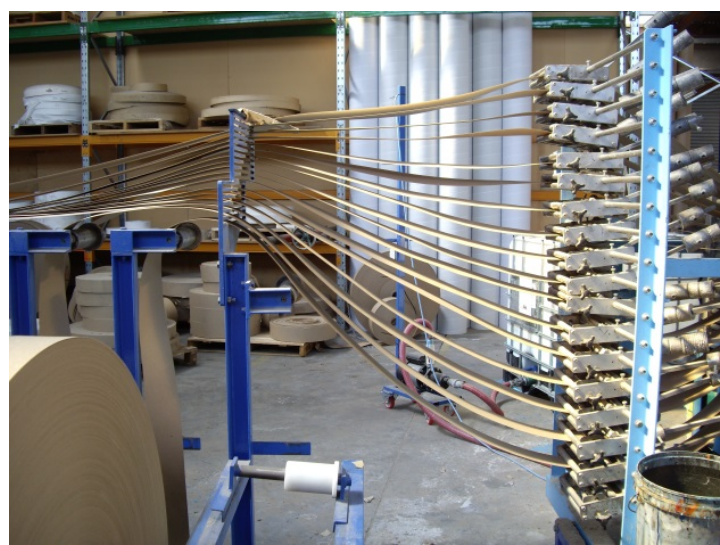

Fig. 19: Cardboard Paper Tube Manufacturing Company, Quail Stand, 2013, photograph. ${ }^{76}$

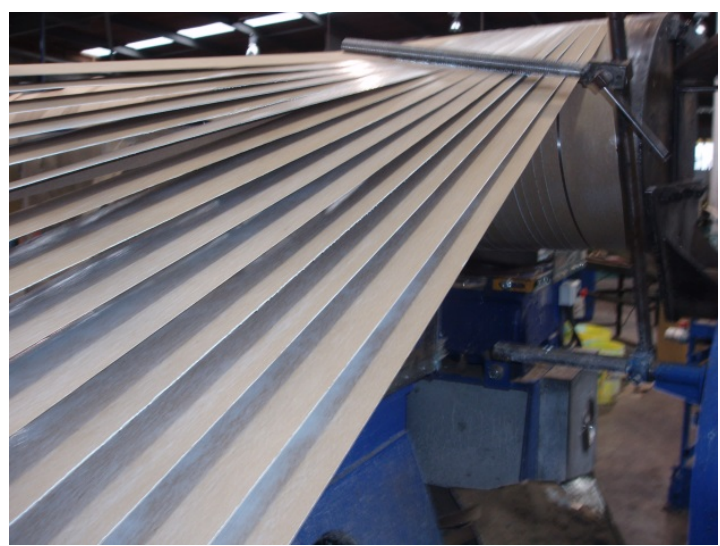

Fig. 21: Cardboard Paper Tube Manufacturing Company, Core Winding Macbine, 2013, photograph. ${ }^{78}$

\footnotetext{
74 Paper Tube Manufacturer manager, interview, (2013).

75 Recycled Paper Strips, 2013, photograph, taken by author.

${ }^{76}$ Quail Stand, 2013, photograph, taken by author

77 Glue Bath, 2013, photograph, taken by author

${ }^{78}$ Core Winding Macbine, 2013, photograph, taken by author
} 
According to the same manufacturer: the ribbons of recycled paper acquire their shape as "a quail stand ... the glue bath ... the core winding machine ... [and] the belt" ${ }^{\text {"79 }}$ all work together toward a final product (fig.18 to fig.21). Interestingly, the manufacturer's account gives value to each of these separate objects, the quail stand in equal importance to the process as the glue bath, and so on. It is indeed through the assemblage of these different parts and bodies that come together in sticky connections (one following the other) that a cardboard tube is formed. Through the whole system, it can be argued that the production is a 'sticky' process making 'sticky objects, ${ }^{80}$ wherein the finished object's surface will reflect the stages of the total process and its various contacts.

As the designed object is transformed from strips of recycled paper to a functional cardboard tube, it simultaneously accrues affective interest and generates both a strong orientation and a desire for further interaction and engagement by the bodies involved, including Ban and the client, but also the manufacturer. This is strengthened by the transportation of the cardboard paper tubes by the construction company, where there emerges an undeniable sense of attachment. The impact of this attachment transmits uneasiness to the manufacturer body: "I think they chopped some .... It's just like us buying a lump of timber, you know. Only for us ... we saw our tubes, we lost our tube ... as soon as it leaves here, we've got no control." ${ }^{\prime 1}$ Underlying the sentiment is an inherent restlessness of not knowing what may have happened to their cardboard tubes; this is directly tied to a loss of control. The restlessness is again evidenced by the physical shift of the location of materials from the factory to the warehouse where the construction company took control. The evaluative process is based on the manufacturer's disagreement with what has happened to his tubes—specifically that he is restless at the thought of the tubes being 'chopped.' The tubes continue to accumulate restlessness as they circulate between bodies and retain their association as 'restless-objects.'

With the product on-site, another affective stutter arises in the design process as the facilitators face the challenge of creating continuous lengths of tubing. Under the control of the construction team, the issue was resolved by sleeving the tubes over the LVL trusses and joining them with laminated, timber joints. With a viable solution in place, the manufacturer's opinion became more positive: "[The construction team] have made a nice beautiful cut around, and then have joined the tubes together .... They've got a special adhesive, which they have developed ... and they have formulated the glue and adhesive in the middle, to be the same colour as the paper. So you see very little difference." ${ }^{\prime 2}$ The evaluation of the tubes displays a shift in orientation

\footnotetext{
79 Paper Tube Manufacturer manager, interview, (2013).

80 Ahmed, Queer Phenomenology: Orientations, Objects, Others, 40.

81 Paper Tube Manufacturer manager, interview, (2013).

82 Paper Tube Manufacturer manager, interview, (2013).
} 
toward the construction body, whose insightful skills and adept craftsmanship produced a positive affect (of feeling at ease) concerning the reconnection of the 'chopped' pieces.

There was a series of evaluative processes in the production and transportation phases of the required paper tubes. These steps created a 'stickiness' between the bodies and the objects and generated a stronger sense of restlessness as they were circulated. Such affective modifications illustrate the range of methods of creating stickiness by "materiali[zing] the surfaces and boundaries" of bodies, including various designed objects and environments. ${ }^{83}$

\subsubsection{Assembling}

The affective process of evaluation continues as the paper tubes are assembled on-site, where the architect's original assembly intentions are challenged. Concerning this stage, Ban notes that he designed with an A-frame because it "requires the most limited construction and it is the easiest shape to achieve a good balance." ${ }^{84} \mathrm{He}$ further describes how the people have suggested how "the design is taken (takes a hint from) the Maori house structures," but, he clarifies, "that is not the case. All indigenous people, from any country, are the same in that an A-frame is the simplest structure for anyone, for any country." ${ }^{85}$ Interestingly, the Cathedral client also suggests that the A-shape design by Ban and its connection to the Maori culture was, "pure accident: a nice accident." $" 86$

This positive evaluation of designing for a simple assemblage is re-emphasized, as Ban expresses: "my architecture is easily understandable because even the assembling can be done like assembling a car." ${ }^{\text {87 }}$ He further articulates, "When talking about how to make an affordable easily-assemblable design, it always goes back to the triangle. But more importantly, and specific to this project, we analysed the plan and elevations of the original cathedral and used that geometry [which happened to be a triangle]." ${ }^{88}$ Tracing back to the first conceptual design, albeit a very quick sketch drawn by Ban, the concept already holds much of this design principle of placing importance in the geometry of the original cathedral (see Fig.16 above). As Narimatsu recalls:

\footnotetext{
83 Ahmed, The Cultural Politics of Emotion, 191.

${ }^{84}$ Ban, interview, (2013).

85 Ban, interview, (2013).

86 Cathedral Manager, interview, (2013).

87 Ban, interview, (2013).

88 Ban, interview, (2013).
} 
The most significant aspect of this project is that, indeed, there was an original cathedral that was standing. And so, when thinking of how to create a connection between [original and transitional], it was seen best to take upon the geometry - to inherit the dimensions and geometry of the original Cathedral. So, even at the conceptual stage, when we did not know the scale [of this project], Mr. Ban's very first sketch, albeit a very conceptual one, had the containers, and above them an A-frame - [aligned by] paper tubes - these tubes were all the same length, but changed in angle, [from an equilateral triangle], gradually rising towards the end [getting steeper]. ${ }^{89}$

The original focus aimed for a comprehensive, easy-to-assemble construction. In reality, this 'easily understandable' design required a subtle-, yet challenging- assembly that soon revealed extensive difficulties (stuttering the project temporality) within the actual construction. This hurdle was not lost on Ban, but was necessary for his ultimate ambition: stemming directly from the geometrical analysis of the original cathedral, "[w]e wanted to create a space that did not have the continuation of the same cross-section ... instead, to have the space above the altar as the highest." ${ }^{\prime 90}$ Specifically, this creates an emphasis on the procession (processional space), common to church design, as Ban elaborates on the spatial experience: "As you walk towards the altar, the height of the ceiling rises as if it is drawing closer to heaven .... And so, as a spiritual/sentimental space ... when there is a flowing movement, certainly, as a space, it becomes a good space." 91

While consideration is given in regards to keeping all the paper tubes the same length and by doing so "reduce the cost and the time of manufacturing," because of the modifications in the angle of the tubes, each cross-section of the A-frame building differs from the others. As the client noted, assembly problems became obvious after the tubes arrived at the build site "because the building flares, then all the connection points, change by about three degrees down the building. So that was a challenge to get all the steel work done." 92 The manufacturer agreed: "It actually became quite technical . . it got quite complicated and a stretch on the construction team." ${ }^{93}$ This disconnect, a form of stilled stutter, creates higher levels of restlessness, which attaches to the tubes and has a further effect on the construction team as it is being 'stretched' in the process.

\footnotetext{
${ }^{89}$ Narimatsu, interview, (2013).

${ }^{90}$ Ban, interview, (2013).

${ }^{91}$ Ban, interview, (2013).

${ }^{92}$ Cathedral Manager, interview, (2013).

${ }^{93}$ Paper Tube Manufacturer manager, interview, (2013).
} 


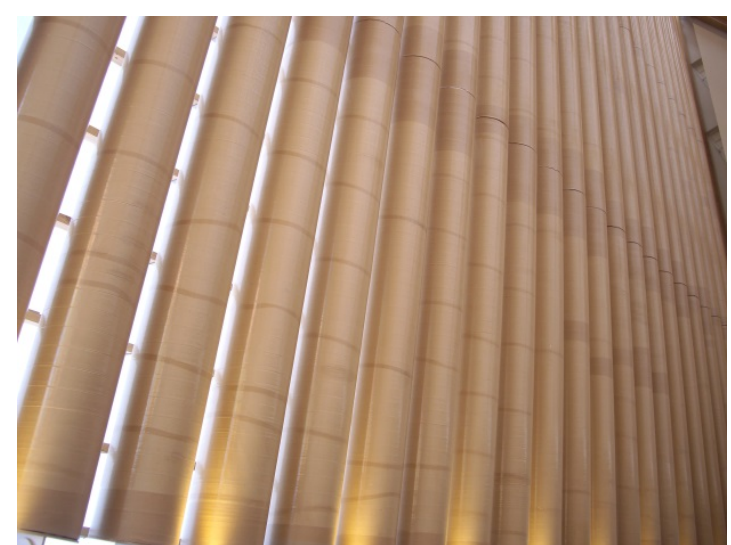

Fig. 22: Damage to Cardboard Paper Tubes, 2014, photograph. ${ }^{94}$

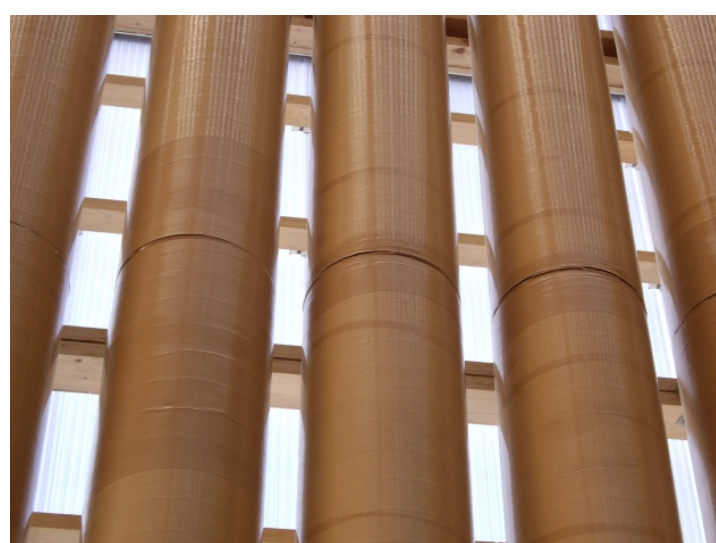

Fig. 23: Detail of Damage to Cardboard Paper Tubes, 2014, photograph. 95

Moreover, weather-related conditions intensified the restlessness, with the potential of physical damage to the tubes (fig.22 and fig.23). The client comments, "It was the damage to the tubes that was most stressful, the water going through. So, repairing that cost quite a lot of money and took a lot of time. As you can see, we had the joints covered up. But, as the building has warmed up, the tubes have shrunk. So that's why you see the split, so that would have to be done again."96 The unexpected weather raised concerns about the damaged materials and enhanced the restless affects impacting the bodies' orientation towards the assembled objects. They then acquired both a monetary and temporal value because the now-needed repairs became a necessary segment of the assembly process; using the words of the manufacturer, the tube is no longer "just an aesthetic show piece." ${ }^{\text {97 }}$ Rather, through 'sticky attachments,' it has accumulated an affective capacity to provide a significant impact on the design project.

The involved bodies (the architect, design architect, manufacturer, and client) feel a desire to turn toward the 'restless-objects' (the tubes), where the restlessness then leads to a heightened interest. At this point, any affective interest is characterized as a continual process of 'needing to know' the situation of the paper tubes and the affect-object relationship (the restlessness associated with the pieces) remains temporally inseparable. Finally, after the materials are assembled on-site, the paper tubes continue to be affectively charged through temporal stutters: the repairs and on-going maintenance are therefore able to sustain their value as 'affective transmitters.'

\footnotetext{
94 Damage to Cardboard Paper Tubes, 2014, photograph, taken by author.

95 Detail of Damage to Cardboard Paper Tubes, 2014, photograph, taken by author.

${ }^{96}$ Cathedral Manager, interview, (2013).

${ }^{97}$ Paper Tube Manufacturer manager, interview, (2013).
} 


\section{Towards Sticky-Objects of Politics and Finance}

Before concluding this section, it is worth noting, albeit briefly, on the following: the restlessobject of the paper tubes, analysed so far, intensifies in stickiness as it ties directly to the restlessobject of politics involved in financing the Transitional Cathedral project. Again, emphasizing on the co-production and co-habitation of affects - restlessness permeates through different bodies/objects - and particularly in this case, interweaves through the design object of paper tubes, and the finances (as object). As Ban asserts, "designing public buildings is always a political act. Even if the church is not 'public,' it still is significantly 'public' in terms of its meaning." 98 The object of politics accompanied by an intensified restlessness as the project progresses is directly reflected on issues with finance. As the client representing the Cathedral clarifies in regards to the public's acceptance of the design: "Yes, people were amused by it, some people. Some people thought it wouldn't look good. Most people thought, great. But it all got caught up with the debate over the building in the square. So the controversy has never been over the design. It's been over the taking money from the insurance for this building. That's where people got caught up." ${ }^{\text {99 }}$ Interestingly, this financial debate involves a tension between rebuilding the original cathedral (with the insurance money), or build a 'transitional' cathedral. To this, Ban provides a clear position:

There are still many people wanting to rebuild the original cathedral. And there is an ongoing court case ... appealing against the use of the insurance money for the Cardboard Cathedral. This is the biggest surprise for me. That there are people who go to court about these issues ... because, you cannot build the same original [Cathedral]. If you do, it's all going to be fake. There's no meaning in making architecture that is 'fake.' And, what's more, you would be using more unnecessary money to make the 'fake.' You cannot rebuild the same original Cathedral. ... This was the most unexpected thing [of this project]..$^{100}$

As a result of this object of politics and finance that sticks through the design process, four fullsize paper tubes were especially manufactured, to help in fundraising for the project (see fig. 24 below). As a sticky-symbol of the Transitional Cathedral, each tube, in the most direct sense, holds capacity to affect and be affected.

\footnotetext{
98 Ban, interview, (2013).

${ }^{99}$ Cathedral Manager, interview, (2013).

${ }^{100}$ Ban, interview, (2013).
} 

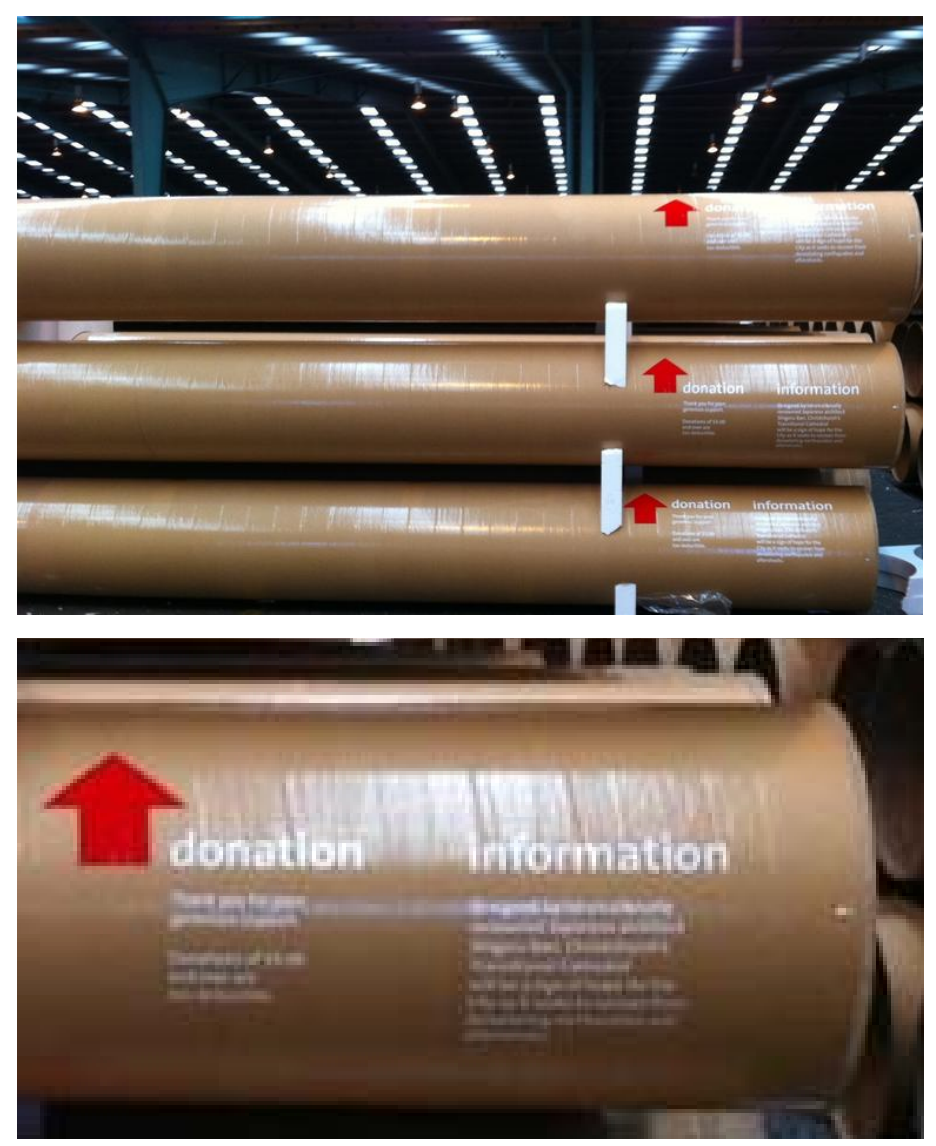

Fig. 24: Shigeru Ban Architects, Cardboard Paper Tubes for Fundraising, 2014, photograph. ${ }^{101}$

The restlessness attached to the cardboard tubes thereby extends beyond the assembling stage on-site. Rather, it continues to intensify through the sticky-object of finance and politics; drawing more bodies toward it, capturing attention and generating interest. As the client puts it: "It wasn't too difficult to get contributions and discounts. It's harder to get the money to pay for it. Because ... that is many millions of dollars. I'm still working with Shigeru to try and do that. So the main fundraising still really has to happen, but... the building is up, it's being used, people are happy." "102 As the Transitional Cathedral is now seen as a 'happy-object,' there is "hope," as the client puts it - to provoke enough stickiness on bodies to respond with financial support. As such, paper-tubes and finance - two sticky-objects of the design process, are intimately tied together. In conclusion, the final section of this chapter offers a few concluding remarks, particularly, it raises a number of implications that sticky affects have for 'practicing architectures.' 103

\footnotetext{
${ }^{101}$ Four cardboard paper tubes were made, identical to the ones used for the Transitional Cathedral and placed outside the cathedrals in Auckland, Napier, Wellington and Dunedin for fundraising purposes. Shigeru Ban Architects, Cardboard Tubes for Fundraising, 2014, photograph, courtesy of Anglican Taonga News, http://www.anglicantaonga.org.nz/News/CommonLife/Cardboard-tubes-in-funding-drive, accessed 12 Aug. 2013.

102 Cathedral Manager, interview, (2013).

103 Jacobs and Merriman, "Practicing architectures," 222-236.
} 


\subsection{CONCLUDING DISCUSSION}

Recent concerns, presented in the collections of essays edited by Jacobs and Merriman, for instance, turn towards investigating architecture as practice, questioning the static descriptions of buildings. ${ }^{104}$ This tract of thought explores the varying interactions between the bodies, objects and elements, the varying forms of occupation, and design processes that could involve any number of unexpected affective stutters. Extending the theory of affect to intersect with the practice of architecture, this chapter argued that the practice of architecture directly concerns the interrelations between bodies (both human and non-human), and more importantly, addresses the acts of orientation and evaluation between one body and another (including designed environments and objects) that occur through stutter in the design process. The chapter also is a response to a recent call, particularly by Tim Ingold, to "engage... directly with the stuff we want to understand...." 105 The analysis conducted here has intentionally slowed down and taken a 'step back' from the finished object to engage with the very process of an architectural material's ongoing formation and generation of affect. This conclusion seeks to consider some implications for thinking through, and with, restless affects in practices of architecture.

Following Sara Ahmed, thinking of affect as possessing stickiness also requires a consideration of the material encounter between objects and bodies as being co-constituted in the practice and stuttering process of architecture. This framework was applied in the examination of SBA's Transitional Cathedral cardboard paper tube design, production and assembly. Two issues were revealed in the analysis of how the designed objects gained their 'stickiness' through the affects of restlessness:

1. The affects of restlessness are embodied in the design process through the bodies' varying acts of orientation and evaluation of the material objects. The affective capacity of the designed object emerges as it interacts with 'other' bodies and is brought forth and intensified through the sticky connections between them. In this sense, bodiesincluding designed objects - do not stand alone but are, instead, part of a conjunctive and co-occurring affective stuttering process.

\footnotetext{
104 Jacobs and Merriman, "Practicing architectures," 222-236.

105 Ingold, "Materials Against Materiality," 3.
} 
2. As affects of restlessness transmit and 'stick' on the object, they increase a body's desire to further engage and interact with the object, thereby intensifying the 'affective interest.' Restlessness, as an affective condition, is not just a negative evaluation or reaction, but a way of orientating oneself (albeit temporally) towards the object. Restlessness is a form of lingering stutter that leads to a heightened interest and is an on-going process of staying informed about the condition of the objects. Such an affect acts as a means of orientation and evaluation: the desire to turn towards objects when we design and evaluate a product because of the inherent interest; creating an evaluation is vital to capturing the encounters between the involved bodies.

Both extending and growing from Ahmed's work, this chapter suggests that it is not only affects of 'happiness' or 'joy' that can turn bodies toward particular objects. As "[happy] objects provide a 'means' for making us happy ... directing ourselves towards this or that object"106 then the affects of restlessness sticking to objects (making restless-objects) also provides a 'means' for arousing interest and thereby bring problems to our attention in the design process, so they can be resolved. Considering affect's relation to the pieces is to accept the movement of the affect across temporalities, stutters, and bodies. This helps to understand, recognize, and respond to the diversity of transmitted and sticky affects that arise in the evaluation and production of buildings and designed objects.

\section{Of Other Sticky-Objects}

This chapter has examined the affect-object interaction that arises through the evaluative process of a single designed object. The specificity of one object allows exploring and analysing questions in a concentrated manner. There are, of course, other architectural objects/materials that arise through the design process, and which hold the capacity to affect and be affected - impacting bodies - and 'stickiness' between them. There are two particular concerns, or design issues (restless-objects, both material and immaterial) to be considered here.

The first involves the "sophisticated bracing system" - which seemingly becomes an object that both activates worry and inhibits progress of the project. Ban recounts, "the engineers are specifying a very sophisticated bracing from England - this delivery is delaying [the project] over... two weeks. I cannot understand why we need such a sophisticated bracing... when it's

106 Ahmed, "Multiculturalism and the Promise of Happiness," 125. 
hidden!"107 Contradicting SBA's design concept to use local material, Ban characterizes how engineers can "sometimes become structurally- innovative oriented, instead of being logical and practical."108 He emphasizes, “[temporary] things should be dealt with a 'matter-of-fact' attitude"109 - in Japanese, it is the understanding of this 'warikiri,' between temporary and permanent that can avoid over-specification (and thereby, delays). Ban states, "There is no difference between permanent and temporary architecture in terms of architectural meaning or quality of space." 110 However, he clarifies, for things like "structure and use, in temporary projects, one must drop/reduce the budget on these things. Because you have to construct things faster, one needs to hold that attitude of compromising structure,"111 to achieve fast delivery and within low cost.

The second concern is an issue arising with lighting design, or more specifically, the lighting of the paper tubes. Narimatsu explains, "The lighting of the tubes - is not going as we were hoping... there is something of a conflict in opinion occurring ('kuichigai')." ${ }^{\text {112 }}$ One major 'object' of concern is the type of lighting that has been selected. Narimatsu evaluates: "These are the big ones used in factories and sport stadiums - big round ones. It has to be that big in size, as the ridge beam is too high - and it won't shine/illuminate the tubes as desired. So, that's okay, but in terms of the position - these round ones will come out (protrude) from the tubes - and that is, first of all - not acceptable for Mr. Ban." ${ }^{, 13}$ Such conflict with the object of lighting goes beyond the tube's lighting issue and involves also the illumination of the Rose Window:

We (SBA) did not know they (the lighting consultants) had put it in. While Mr. Ban has said firmly, that there is no point in lighting just the bottom of the rose window (as suggested), because it will only light the bottom part. There's no point of lighting the Rose Window at all, if the lighting does not shine the entire window. And so, he says, we don't need it. ${ }^{114}$

As such, both the bracing system and the lighting elements, far from being simply inanimate 'things' - are also, borrowing Tim Ingold's words, "active constituents" 115 of the design formation. Beyond being passive and stable matters, these objects hold power and capacity to modify and be modified - influencing the design process and the final design outcome. In this sense, the analysis in this chapter of the affect-object of the paper tube, is but one, albeit important,

\footnotetext{
107 Ban, interview, (2013).

108 Ban, interview, (2013).

109 Ban, interview, (2013).

110 Ban, interview, (2013).

111 Ban, interview, (2013).

112 Narimatsu, interview, (2013).

113 Narimatsu, interview, (2013).

114 Narimatsu, interview, (2013).

115 Ingold, "Materials Against Materiality," 11.
} 
object of affect produced by the stuttering temporalities of the design process. Indeed, design process is a co-orchestration of evaluations of diverse material designs/objects and the affects it produces.

Any evaluations allow for co-creation and co-participation in "materiali[zing] the surfaces and boundaries" of bodies. ${ }^{116}$ This position suggests ambivalent and ambiguous stuttering steps rather than a static, linear and predictable process of architectural production. This chapter extended the understanding of architectural practices as processes that embody and transmit affect between bodies, stick on objects and inevitably impress upon and impact the parts of the design process and its outcomes. Indeed, 'sticky' affects propose alternative ways for comprehending the multiple forces involved in architecture.

116 Ahmed, The Cultural Politics of Emotion, 191. 


\section{8. \\ Final Considerations}

\subsection{INTRODUCTION}

The preceding three chapters explored the architectural practices of RUR Architecture PC, Kerstin Thompson Architects, and Shigeru Ban Architects, respectively, to further explore the affective possibilities and different temporalities through an empirical study of actual design projects and their particular design processes. The analysis suggested three ways affect theory can be extended; through sticky images, sticky design processes and lastly, sticky design objects. These propositions focus on how each of these case study provide insight into design process as both an embodied activity, but also, and importantly, an affective process. The empirical engagement as a whole attempted to address areas that have received less attention in architectural discourse to date and engages with investigating the sticky relationships between bodies (both human and nonhuman). Of course, as noted throughout this thesis, architectural geographers such as Peter Kraft and Peter Adey and their text 'Affect/Architecture/Inhabitation: Geographies of Being-In Buildings, ${ }^{1}$ address these links between architecture and affect, but it is noteworthy that at the moment the link is being drawn to occupation of space rather than the design of space. In this sense, there is less attention to affects that arise in the process of design. This gap needs to be noted, as the possibility to explore architectural practice and its design process through the lens of affect offers a way to take affect into real-world and everyday situations. As an effect, this offers ways to further extend the current discourse of affect as well as illustrating potential for future directions in qualitative architectural geography, focused on design processes. Importantly, this thesis has argued that affect is present not only in architecture as a material static object (what is produced), but also in the designing of architecture (how it is produced), considered as an active and affective process. Rather than seeing affect as an aftereffect of given spaces, it considers affect as a found (and an always re-founding) force which cannot be easily put into words, yet always pervasive agent in the designing of spaces.

The theoretical and empirical focus on affect and architectural practice that this thesis has undertaken provides a contribution to both discourses of affect and architectural practice, exploring architectural and theoretical relations which can be drawn out when architectural practices are viewed through the lens of affect. Such investigation is critical to allow practices of architecture to be seen not through defined patterns or contained agenda's but rather through intensities and forces between bodies (both human and non-human); it is to discover practice as

\footnotetext{
${ }^{1} \mathrm{Kraftl}$ and Adey, “Affect/Architecture/Inhabitation,” 213-231.
} 
sites of potential - and in doing so to address the potential of affect to be applied to more grounded practice fields.

In concluding this thesis, this final chapter is divided into three sections. Firstly, it returns to summarize each of the chapters in turn, recounting the research question and how the chapters responded to it. From this, and secondly, it will outline specific contributions and implications of this thesis to current discourse on practices of architecture and theories of affect. Thirdly, it discusses the specific limitations of the research presented here, and how it could be augmented, both by research relating to architectural practices, but also by research within affect. Finally, and as a conclusion, a brief summary is provided pointing to opportunities for interventions at the intersection of affect and architectural practice.

\subsection{OVERVIEW OF THESIS}

Before discussing the specific chapters involved in this thesis, this section begins by briefly recounting the research question below, as originally set out in Chapter 1. The research question responded to a lack of engagement with theories of affect and architectural practices, specifically its design process as both a dynamic and affective activity. Further, it also aimed to open a discussion between architectural theories and architectural geographies, links between theory and real practice. The specific research question was also followed by three sub-questions as part of the case studies, focussed around three interrelated themes: architecture, affect, and architectural practice. The main research question, albeit broadly put, asked about the relationship between affect and practice: What architectural and theoretical relations can be drawn out when architectural practices are viewed through the lens of affect? In concluding this thesis, the final chapter returns to this question and summarizes how this thesis has engaged with it throughout the chapters.

In relation to the research question, albeit in a general sense, the thesis has shown that there are many architectural and theoretical relations that can be drawn out when architectural practices are viewed through the lens of affect. More specifically, in reviewing how the current affect literature answers that question (see Chapter 2), the thesis identified how, in order to understand affect, it is necessary to consider bodies (in plural and both human and non-human ways) and spaces as relational, displacing either human and our built environment from the centre of analysis to reinforcing its relations. Specifically, Chapter 2 offered a critical survey of the major academic contributions to the study of affect. While attending to the history and broader approaches to affect, it focussed on current discussions in geography and cultural theory that engage the affect-body-space relation. Particularly, reviewing works by Massumi, McCormack 
and Thrift, affect precedes emotion and therefore has a degree of autonomy from the human subject. Each of their engagements with affect links it with practical experiments and everyday situations, but more importantly, they propose affect as a medium through which the body relates to the materiality of its environment, including our home-space, event-space and cityspace. As the chapter proceeded to highlight, some feminist voices see these latter contributions as over-generalizing our bodies: as Thien puts it, the acceptance of the autonomy and multiplicity of relations that affect brings, "discourages an engagement with everyday emotional subjectivities...." This chapter proposed that we must look at affect as indeed something fleeting but equally able to be located and specified in terms of context. Furthermore, one of the issues that this chapter begins to unpack is, moving on from distinction between emotions and affect, the potential of affect theory for architectural discourse are the ways in which affect can move. Ahmed's 'sticky' movement of affect is but one of these characteristics of affect's motion, but is useful for the analysis of design processes that involve different bodies drawing towards each other or repelling away.

After the literature review chapter, two theory-orientated chapters followed that sought to draw the link stronger between architecture, affect and architectural practice. Specifically, Chapter 3 and Chapter 4 investigated the way in which practices of architecture are practicing affects, and in parallel, how affects are affecting these practices. It reflected once more the research question- where the theoretical concept of 'affect' explored in Chapter 2 was extended to analyse theories of architectural practice. Particularly, Chapter 3 attempted to draw stronger links in the works by architectural scholars and geographers - between architecture, affect and architectural practices. Although most of the authors discussed in this chapter did not explicitly use the language of affect, it is arguably attractive to both architectural and geographical discourses on practice, precisely because it delivers currents of openness and fluidity into practice. Drawing from recent works by geographers, Chapter 4 engaged the practice of architecture through time. Specifically, it addressed the time of practice through two forms of stuttering's (still and quickened stutters) that addressed temporal relations between what Ahmed describes as the "now to the not yet." It is through the affective oscillation of these stutters, that affects may indeed arise, intensify and thereby be noted, albeit in most cases, in movement. This is especially evident through the practice of Shigeru Ban, and the process involved in designing, producing and assembling the paper cardboard tube. This process, as analysed in Chapter 7, involved moments of pause, but also sudden shifts, whereby affects of restlessness followed by happiness and joy, and back to unease were noted. It is also evident how the object of the paper tube began

2 Thien, "After or Beyond Feeling?" 450.

3 Ahmed, "This Other and Other Others," 562. 
to act as an agent in quickening the process of drawing people to contribute money to the project. The paper tube object in this case acts as a stimulant to attract bodies, but it equally provokes a sense of unease and restlessness which circulate around different bodies. The relation between architecture and affect is in this sense held tightly together through stuttering temporalities, oscillating as the process of design develops, but also stopping abruptly.

Based on the theory chapters, the thesis turned to the analysis of three empirical case studies. Chapters 5, 6 and 7 examined three key contemporary architects, Jesse Reiser, Kerstin Thompson and Shigeru Ban, their design practices, RUR Architecture PC, KTA and SBA, and specific design projects, through an appropriate qualitative research with a case study strategy. The analysis of these case studies drew attention to Ahmed's affective metaphor of stickiness. ${ }^{4}$ Literature of affect has developed a range of illustrations of the movement and channelling of affect: for instance, Thrift's engineering metaphor of affect moving through 'pipes and cables, McCormack's similar suggestion of affect travelling like 'guide ropes and drag lines, ${ }^{6}$ Brennan's affect 'transmissions' like radio waves, ${ }^{7}$ and Gibbs' position of affect as a virus that is 'contagious'. ${ }^{8}$ Such descriptions convey a kind of rapid, mechanistic and programmatic movement of affect. While these conceptualizations are acknowledged (specifically in Chapter 2), the case studies in this thesis looked at Ahmed's metaphor of stickiness as the theoretical platform for the analysis.

Chapter 5 presented the first of three empirical investigations conducted for the analysis of architectural practices through the framework of affect. Specifically, this chapter discussed RUR Architecture PC and their Kaohsiung Port Terminal project, evaluating how affect operates within practices of- and processes of- affective image-making. Looking at extending the interrelation between architecture and its image by considering affect, particularly through an affective image-making process, the question posed here was: What is involved in the practice invested in affective image-making? In these series of images analysed, we find processes of affective charge particularly through plays on artistic techniques: the use of panorama effects in investigating the 'sweet spot'; employing painterly means to fine-tune the port terminal's form to the site and programme; placing iconic figures (iconography) to draw bodies into the image-site. In discussing these image-making practices the chapter argued RUR's image-making as invested in affective charge where the charge intensifies the surface of the images, thereby creating sticky images. RUR's image-making practice is as much about a process of the charge of the image as about a

\footnotetext{
4 Ahmed, "Happy Objects," 29-30.

5 Thrift, "Intensities of Feeling," 58.

${ }^{6}$ McCormack, "Engineering Affective Atmospheres," 426.

${ }^{7}$ Brennan, The Transmission of Affect (New York: Cornell University Press, 2004).

8 Gibbs, "Contagious Feelings," 2001.
} 
process of generating strategies to design from- or design to- for the production of architecture. At issue here is not a matter of image as representation that sticks to reality. Rather, as Latham and McCormack put it, the endeavour is "to make more of the participation of images"' in the design process of architectural spaces, where images (can) become sticky through affect.

Chapter 6 continued to provide a more grounded attempt to think about the relationship between affect and practice. It did so by evaluating a second case study of an architectural practice and their design project: Kerstin Thompson Architects and the design process for their Monash University Museum of Art. In seeking to situate affect within interplay of architectural design processes, it asked: How do affects hold together and animate different ways of designing through its stickiness, accounting for sticky processes? This chapter showed how affect as stickiness-in-process, enables KTA to bring together seemingly disparate design processes: first, a hunch-driven process and, second, a textual-literally driven process. Reflecting on this, the chapter gave some concluding considerations in extending the theory of affect to account for affective possibilities arousing and operating through sticky design processes.

Chapter 7 explored the design, production and assembly of the cardboard paper tubes recently designed by Shigeru Ban Architects for their Transitional Cathedral project in Christchurch. In aiming to open up current thinking about the relationship between practice and affective objects, the chapter asked: How do the negative affects of restlessness, which stick to objects, arouse interest and positively impact the evaluative processes of design? The analysis enquired on how matterand more particularly, a designed matter such as the designed paper tubes, has the capacity to affect and be affected, and in the process, generating sticky-objects. Importantly, affects of restlessness transmit and 'stick' on the paper tubes, as the tubes circulate around different bodies, thus intensifying the object's 'stickiness, ${ }^{, 10}$ thereby both arousing interest and positively impacting the design process.

There is much to be taken from these case studies including how the various design actions are not independent of -, but in fact, embody affects. The research has focussed on how each of these case studies provides insight into design process as both an embodied activity, but also, and importantly, an affective process. Of course each of the three sub-questions are specifically designed and orientated to address each case study. However, of interest to the discussion of this thesis is how questions like these provide the context for extending our understanding of affect into practice of architecture. Indeed, they also highlight aspects of practice that may often go unnoticed and considered mundane. But in exposing these practices and processes, we are able to grasp the complexity that architectural projects involve - in terms of

9 Latham and McCormack, "Thinking with Images in Non-Representational Cities: Vignettes from Berlin,” 252.

10 Ahmed, The Cultural Politics of Emotion, 2004. 
the assemblage of different bodies (including images, processes and images). Far from being just taken for granted activities in practices of architecture, they are set to engage and play an integral role in creating architectures. Perhaps in some cases, the images, objects and different processes need to be brought into light through an analytical engagement, as this thesis has considered.

The empirical discussions summarized above, were carried out in three separate chapters (chapter 5, 6, and 7), where each chapter built up to offer specific considerations in the final section about the link between affect and practice of architecture, suggesting how affect theory may offer an extended theoretical model for understanding architectural practices. The discussion below pulls the different strands of the thesis together to consider how they contribute to extending our understandings of, firstly, architectural practices, and secondly, theories of affect.

\subsection{THE THESIS IN CONTEXT: MAKING A CONTRIBUTION}

The research in this thesis is situated within the current discourse of affect, concerned with the exploration of intensities, forces and relations between bodies (both human and non-human) across diverse disciplines. Although the theory of affect in cultural as well as feminist studies, but also human geography has been extensively studied in the past few decades, the affect of practice, specifically, the practice of architecture has remained relatively unexplored. This thesis has set out to examine the link between architecture, affect and architectural practice, particularly the ways in which affect is embedded in design processes, and therefore shaped by, but also always shaping different forms of affect. What follows provides insight into how the research conducted for this thesis makes contribution in particularly two areas; first, in the discourse of architectural practice, and second, in the theory of affect.

\subsubsection{Implications for Architectural Practice}

As reviewed in Chapter 4, architectural scholars such as Stan Allen and Jeremy Till, explore the varying interactions and interrelations between bodies/objects/elements, the varying ways of occupation, as well as design processes that involve any number of unexpected disruptions. ${ }^{11}$ Extending the theory of affect to intersect with the practice of architecture, this thesis has argued that the practice of architecture is indeed about the interrelations between bodies, both human and non-human, but it is also about the acts of orientation and evaluation between one body and another, including designed environments and designed objects. It must be noted here, before

\footnotetext{
${ }^{11}$ See Allen, Practice Architecture, Technique and Representation (London: Routledge, 2000). See also Till, Architecture Depends (Cambridge: MIT Press, 2009).
} 
proceeding further, that the arguments made are additional to those that already exist in architectural geography and architectural practice literature, not set against them (see Chapter 3 and 4). ${ }^{12}$ In outlining the role of affect in architectural practice, the aim has been to account for the usefulness of affect as being able to be incorporated in the design process and experience of making architectures that such literatures have yet to address in substantial detail.

Chapter 3 and 4 looked at several authors, both from geography and architectural backgrounds that extend the practice of architecture to consider aspects that often occur backstage, and are considered mundane. These chapters linked these explorations with the theory of affect, which albeit indirectly, these work were already doing, without using the language of affect. Chapter 4 specifically hoped to contribute to recent discussions of architectural practice to input notions of affective stuttering, that is, the temporal stillness and quickness that occur in design processes. The oscillation between these two temporal stutters suggests practice as a site in-between an extended present and promising future, projecting forward, but with the possibility of remaining still. It is in between these stutters that affects emerge, but also intensify. Design practice is ridden with such temporalities, and it is important to acknowledge the often mundane and boring times of waiting that often occur in designing a building - can indeed arouse affects that can linger on throughout the entire process, draw bodies together and hold them together. In this sense, the role of affect indeed has potential to impact the design process 'as it is bappening, ${ }^{13}$ drawing bodies together, repelling others, generating affective relations. These considerations were brought forward into the case studies where each architectural practice and project reflected stuttering instances that may rise in different stages of the design process. Specifically, Chapter 5 attended to the more initial stages of design, where the discussion engaged in the images produced at the competition and exploratory stage of form and project generation. Chapter 6 evaluated the middle stage of the design process, where the project, already commissioned, undergoes abrupt stutters that changed the design entirely. Finally, Chapter 7 traced the stutters that occur even after construction is in process.

The three case studies provided specific but also more practical and grounded ways to extend our understanding of architectural practice when looked through the lens of affect. More specifically, in Chapter 5 it was showed how in the architectural practice of RUR and their Kaohsiung Port Terminal, the images produced as part of the project allowed analysis of the strategies and processes employed by RUR to affectively charge their images to become sticky -

\footnotetext{
12 See, for example, essays in the edited work by Jane M. Jacobs and Peter Merriman. Jane M. Jacobs and Peter Merriman, "Practising Architectures," Social and Cultural Geography 12, no.3 (2011): 211-222.

13 The phase "as it is happening” is used also by Ghassan Hage, in his close review of Spinoza's work. Ghassan Hage, “'On the Side of Life" - Joy and the Capacity of Being - with Ghassan Hage," in Hope: New Philosophies for Change, edited by Mari Zourzani, 150171 (London: Lawrence \& Wishart, 2002): 152, emphasis original. Cited by Rebecca Coleman and Mónica Moreno Figueroa, "Past and Future Perfect? Beauty, Affect and Hope," Journal for Cultural Research 14, no. 4 (October 2010$): 372$.
} 
and thereby act as active participants in the design process. In this context, the images contributed to drawing bodies towards the design before it was constructed. Further, in Chapter 6, KTA and their MUMA project exhibited how the concept of affect allows a way to apprehend practice and design processes as a situation open to change and contingency. Particularly, it is a situation that involves an affective interplay between formal and more informal processes of design, such as a sudden hunch for a specific project. To key into these moments of back-andforth between processes is important in seeing how some aspects of a process begin to attach (in its stickiness), while others are left aside. In this way, architectural practices operate through various trajectories - but always looking at ways of bringing these trajectories together. And finally, in Chapter 7, the analysis of paper tubes accumulating affects of restlessness highlighted how being restless, as an affective condition, is not simply a negative reaction in the design process. Instead, it is a method of actively orienting oneself, albeit temporally, towards different objects. In this sense, the chapter discussed how bodies' desire to implement certain objects in a design and evaluation because of their ability to arouse interest. Affects of restlessness, particularly, are helpful in expanding our understanding of design contexts, because they help recognize design problems for future resolution.

Importantly, these explorations affirm ambivalence and indeterminacy (in the form of affective stutters), rather than architectural production as a static, predictable, linear process. The thesis has sought to extend the understanding of practices of architecture as a process that embodies and transmits affect between bodies, sticking on images, processes, and objects, impressing upon and impacting the design process including design outcomes. Indeed, 'sticky' affects point to a way to apprehend the multiple forces involved in making architecture. Furthermore, the idea that an architect has given thought to the affective experience through designing 'sweet spots' (RUR), idiosyncratic and neutral spaces (KTA), and even as small as restless-objects, is evidence of affects that indeed are embedded in the process of design. Thinking through affect - that is, applying affect as a theoretical framework in analysing these case studies proved vital in understanding the practice of architecture not as a contained, agendaand money driven business, but rather composed of intensities and forces that generated affective attachments between bodies.

In the broadest possible terms, the discussion so far represents the findings of this thesis, specifically, its contribution of an extended perspective to the field of architectural practice and its understanding of the design process through affect. However, there is one more matter to be noted. This thesis and the research conducted herein are also reflections of the current rise in discourse of design-as-research - whereby the focus lies in investigating and experimenting with a 
practice's research focus through the act of designing, more so than the final outcome.

Interestingly, all three case studies could be said to partake in this form of practicing. For instance, RUR Architecture PC takes image-making as a way to test out how a space may look like and 'feel' but also how affect may indeed come about and be appealing to bodies that come in its proximity. The practice of KTA is perhaps more direct, in terms of looking at precedents, researching the ways that programmes and functions, but also spatial layouts, has successfully worked for other projects and adapting them in their own projects. Lastly, SBA is known, as appropriately pointed out by Murray Fraser in his book Design Research in Architecture: An Overview, to be driven by research into new innovative ways of using the cardboard paper tube. ${ }^{14}$ Albeit in different ways, the case studies presented here highlight the recent rise of research-orientated practices and it could be of interest to attend to the ways of the role of affect (in terms of drawing bodies together or apart) in these forms of practices. The following part discusses specific implications and contributions that this research has brought to the current affective discourse.

\subsubsection{Implications for Affect Theory}

The emphasis on affect in this thesis responds to the recent attention of conceptualizing the dynamic relations between bodies in geography, cultural studies, and beyond. In the first instance, the following reiterates several points from each of the chapters in this thesis, pertaining to affect theory. As outlined in Chapter 2 of this thesis, following the philosophies of Spinoza and D\&G, scholars of the 'affective turn' define affect as intensity. ${ }^{15}$ This main thread of research on affect draws a distinction between affect and emotion where emotion is something that can be put into words, such as 'I feel happy', while affect is described as autonomous because it occurs before we are able to name how we feel; it precedes emotion. This emphasis on the autonomy of affect provides a variety of ways of conceptualizing the pre-conscious, pre-intentional, pre-verbal processes that occur between bodies. In architecture, affect, for the most part, continues this lineage of defining affect as autonomous, but critically also as an instrument of analysis. For instance Hélène Frichot's analysis of Olafur Eliasson's interior installations underscores the highly seductive and affective nature of his work where "affects are the transformative shifts in register that allow the subject to recognise his or her subjectivity in transformation." ${ }^{16}$ While this thesis acknowledges the strength of the autonomy of affect which allows for the analysis of pre-

\footnotetext{
14 Murray Fraser, Design Research in Architecture: An Overview (London: Ashgate, 2013).

15 Massumi, Parables for the Virtual: Movement, Affect, Sensation, 27. See also, Gregg and Seigworth, The Affect Theory Reader, 2.

${ }^{16}$ Hélène Frichot, "Olafur Eliasson and the Circulation of Affects and Precepts: In Conversation," Architectural Design 78 (May/June 2008): 34.
} 
conscious experiences of the body (human and non-human), it equally questions an overemphasis of this autonomy, particularly where "affective atmospheres" are presumed to be immaterial and unlocalizable. ${ }^{17}$ Instead of using affect to analyse our environment (already built spaces), this thesis follows in the line of Philippe Rahm's Honorarium, which designs for affect by looking for what moves us in materialized and localizable condition. Crucially, this thesis has extended such orientation of affect to bring an awareness of affect within the design process of architectural practices.

While in architecture affect is largely associated with place and context, this thesis has taken up the language of affect to explore and observe affect in architectural practice's designing process through affect that roams between context/place-specific and the more abstract nature of it (independent of context). The interest lies in the in-between gap of intentional and unintentional acts, specifically in the case of this thesis, within the process of design, rather than the final outcome. Particularly, the research has considered seriously through affect, the design intuitions and hunches that drive the process of producing architectural spaces, but also designed objects and images. As such, the in-depth analysis of architectural practices provides insight into how affect can be extended to practical fields of architectural practice and acts of designing.

\section{From Ahmed and Beyond}

The case study chapters of this thesis - Chapter 5, 6, and 7- sought to address the links between architecture, affect and architectural practices in a more empirical grounded study, by drawing particularly from Ahmed's proposition of 'sticky affects.' It is around these three key case studies of affective architectural practices, looking at - sticky images, sticky processes, and sticky objects - that this thesis moves beyond the expected reading of Ahmed's notions of affect's 'stickiness.'

First, it must be acknowledged here that there are, inevitably, many definitions of affect. The thesis has attempted to give a review of the relevant literature in Chapter 2, particularly focussed on aspects of affect as redefining our understanding of bodies, movement and space. From this review, the thesis has focussed on the work by Ahmed, as her concept of 'stickiness' provided a way to address how bodies (both human and non-human) come together and engage, often sticking to each other (but of course, not always). To reiterate, Ahmed posits how affects are "about attachments or about what connects us to this or that." ${ }^{\text {" } 18}$ In this sense, Ahmed is focussed on the "stickiness" between bodies highlighted through acts of orientations toward or

\footnotetext{
17 Anderson, "Affective Atmospheres," 77.

18 Ahmed, The Cultural Politics of Emotion, 11
} 
away certain objects. ${ }^{19}$ Thereby, Ahmed offers a way of approaching affect, not as entirely abstract and autonomous and leaning towards a universalized theoretical concept (thereby, inapplicable to practical fields). Rather, she proposes affect as indeed graspable, despite us not always being aware that we are surrounded by it - and exhibiting affects ourselves. Similarly, this thesis proposes that affect - both happy (positive) and unhappy (negative) ones, can indeed penetrate and hold together or break the continuity of design processes. Hence, Ahmed's sticky affects are transferable to other empirical enquiries of everyday practices. This thesis has proposed extending it into explorations of architectural practices.

In focussing on affective practices (that engage in sticky images, sticky processes, and sticky objects) - a particular strength of the thesis lies in its ability to create a dialogue between architectural design process, architectural geography and affect theory. This thesis has also sought to show how affect is location-specific and context-specific. Through Ahmed's concept of sticky affects, the following provides some feedback that is given to sticky affects, specifically in the way it has changed and has expanded, in its relationship with architecture and its practice.

Chapter 5 showed how Ahmed's notions of sticky affects can extend to incorporate such things as sticky images- where the stickiness surfaces through the process of affective imagemaking. Importantly, this chapter suggested that Ahmed's concepts, while not discussed in the context of a design situation, may be applied to the practice of architecture - where affective sticking and surfacing processes are an important part of design practices. It positioned affect as a way of approaching images as more than just representational. Instead, it looked at images in terms of its surface intensity and stickiness- its affective charge and as Rebecca Coleman puts it, the image's "appeal to the future." 20 Thinking through sticky-images, images become a more complex site of exploration, and image-making, a more activating process. Further, Chapter 6 offered insight into stretching affect's stickiness not only as a quality of transference/circulation, rather also, to incorporate what the kinds of attachments affect produces, that is, sticky situations and in the case of this chapter, design processes. For it is only once we acknowledge these potential sticky sites or interplays that 'bring us to an experience of 'affectuality' - or of the fact that there is affect." ${ }^{21}$ Things and processes are sticky - because of ways in which they are caught up in highly affectively charged scenarios. Finally, Chapter 7 extended and departed from Ahmed's work, by suggesting that it is not only affects of 'happiness' or 'joy' that turns us toward particular objects. Rather, as “'happy] objects provide a 'means' for making us happy ... directing

\footnotetext{
19 Ahmed, The Cultural Politics of Emotion, 18.

${ }^{20}$ Coleman, Transforming Images: Screens, Affect, Futures, 2.

${ }^{21}$ Claire Colebrook, "Specificity of Affect," in Deleuze and Space, edited by Ian Buchanan and Gregg Lambert (Edinburgh:

Edinburgh University Press, 2005), 199.
} 
ourselves towards this or that object" 22 , then also, restless affects sticking on objects (making restless-objects) provide a 'means' for making us interested and engaged. Thinking through affect's relation to objects is to consider the movement of affect, across temporalities, across bodies, which help us to understand, recognize, and respond to, the diversity of transmitted and sticky affects that arises in the evaluation and production of built 'things.' The practice of evaluation in architectural process, when viewed through affect, allows for processes of cocreation/-participation in "materiali[zing] the surfaces and boundaries" of bodies. ${ }^{23}$

Another aspect worth noting, and which has been elaborated specifically through Chapter 7 and the SBA case study is amplifying affect through matter - particularly through the recent discourse of 'New Materialism.' The turn towards affect and new materialism, taken together allows for the exploration of the affect of matter (material affect) and effect of affect (affective materiality). In this thesis, the term 'materiality' has been taken to include both solid matter (for example walls and surfaces) and atmospheric or ephemeral matter (i.e.. the felt and the ambient). More recently, new materiality has, according to Tim Ingold, aimed to redirect "our attention from the materiality of objects to the properties of materials" ${ }^{24}$ Critical in this perspective are the expressive properties of materials - matter's relational, interactive and affective capacities. ${ }^{25}$ This is particularly useful for the practice of architecture as it addresses architectural practice and its many operations - in its potentiality as "materiality in-process." But also, offers ways to expand affect theory to consider affective matter as actively engendering new affects.

The thesis contributes to the growing concern with the complexity and interconnectivity of bodies that affect theory is proposing, extending these investigations to address architectural practices. At a broad level, the thesis engages and makes a tentative return to the often mundane but highly creative aspect of design processes, not so much in terms of the results, or impact, of affect in the final architectural space (occupation/inhabitation of space), but in terms of how design processes consist of stuttering's where affect can bring bodies together through affective stickiness. This section, in reflection of the thesis research, has highlighted some original contributions to the field of architectural study but also theories of affect in which the analytical capacity of architectural design process is underrepresented. The following moves to discuss limitations of the study and recommendations for further research.

\footnotetext{
22 Ahmed, "Multiculturalism and the Promise of Happiness," 125.

23 Ahmed, The Cultural Politics of Emotion, 191.

24 Ingold, "Materials Against Materiality," 12.

25 Barad, "Posthumanist Performativity," 822. See also, Latham and McCormack, "Moving Cities," 706.
} 


\subsection{CRITICAL REFLECTIONS AND RECOMMENDATIONS FOR FUTURE RESEARCH}

On the basis of what has been analysed and discussed in this thesis, there are a number of areas in which this research could be pursued further. These areas are divided, albeit broadly, into three key observations, relating to: first, limitations arising from the time-frame set up by the research; second, methodological considerations of this present research and possible ways to engage further with affect; and third, observation of the lack of diversity of kinds of affect, but also scale of projects, both of which could be extended into further research.

\subsubsection{Time}

First, given the time constraint of the study, the period of gathering data and analysis was confined to certain times and locations. The present research primarily focussed on the design process of an architectural project - and by taking three case studies, the time given was divided into three. Therefore, research that goes in-depth (more integrated) through one case study, may have provided further engagements of affects through the bodies that are involved in the design process. Particularly, this advantage has been presented in the research conducted by Albena Yaneva who studied the practice of OMA in a detailed and comprehensive manner. ${ }^{26}$ However, it could also be noted how this thesis, in comparison to Yaneva's research, was able to explore affect closely in three practices, rather than drawing conclusions from only one practice. Furthermore, as acknowledged in Chapter 3, there has been a relatively small concern but also input to the affective interplays, attachments and relations that occur after the construction of buildings - specifically from the view of carer, maintenance workers, and simply matter - like the cardboard tubes. Affect could be further examined within the everyday use of these spaces (and thereby highlighting the wear and tear of the tubes). Indeed, a longer duration of data collections may have facilitated these processes.

\subsubsection{Method}

Second, this thesis has argued for the value of engaging theoretical discourse of affect with more practical and grounded aspects of architectural practices. Emphasizing the relationship between affect and practice, aspects of architectural practices was a guiding principle in selecting the methodological approach for the research (see Chapter 1, Methodology Section). It was

${ }^{26}$ Albena Yaneva, Made by the Office of Metropolitan Architecture: An Ethnography of Design (Rotterdam: 010 Publishers, 2009). 
important that both the affective nature of practices and affect's impact on its processes was allowed to come to the fore to address what this thesis considered the lack of explicit engagement with architectural practice research around the concept of affect, and vice versa. The approach that was adopted was an in-depth analysis involving both interviewing and gathering visual material. The method of interviewing architects in a semi-structured format, as well as other bodies of the architectural design process proved to be beneficial for a number of reasons.

Firstly, an investigation of the design process requires at times 'looking back' but also 'looking ahead' - particularly in the case of SBA, where the interview took place while the project was 'happening.' This was also reflected in RUR's case, where the ground-breaking for the Kaohsiung Project was, at the time of interview, about to happen. The open-ended nature of the interview offered not only an opportunity to observe the architects' concerns, worries, joys and excitement, in their 'natural' setting - but also offered an opportunity to observe relations between the different bodies (including objects and images) that arise through the design process. For example, while interviewing architect Reiser from RUR, the discussion content suddenly prompted Reiser to walk through his office, talking about the different stages of the Kaohsiung project in its development through models and images - exhibiting a mixture of hesitation, excitement, group bonding - as the design team joined in. Alongside these aspects, the semistructured interviewing technique also allowed the researcher to query further certain points that the architect and other bodies involved in the design had discussed, prompting them to think, but also to voice in their own words their concerns, worries, and aspirations/hope of what the future may hold for the project.

A further pursuit of an understanding of the architectural design process and its practice could be undertaken more thoroughly by means of video recording events between the different bodies involved in the making of architecture. These video recordings will complement the audio recorded interviews, but also offer other expressions (facial, bodily) that may be analysed in terms of how affect emerges in the process; it may aid to be a more fruitful approach to uncover different expressions of affects. The researcher expects that using video as a tool will "provide a useful supplement for field observation and help generate a rich data set for subsequent analysis."27 As an example, geographer Jamie Lorimer makes use of moving images to analyse intensities of affect between human and non-human relations. Taking elephants (non-human bodies) as his case study, Lorimer stresses the usefulness of moving images (film) to document "communicative performance" between human and elephant interactions which "evoke affect". ${ }^{28}$

\footnotetext{
${ }^{27}$ Jamie Lorimer, “Moving Image Methodologies for More-Than-Human Geographies,” Cultural Geographies 17, no.2 (2010): 242.

${ }^{28}$ Lorimer, "Moving Image Methodologies for More-Than-Human Geographies, 242-243.
} 
This method certainly merits further investigation when applying affect as a theoretical framework on real-world practices, such as practices of architecture.

\subsubsection{Scale of Project and Variance of Affects}

In addition, and third, this thesis concurs with many authors, where affect cannot be quantifiable, and thus it is not easy to document these affects in precision. Following from this, some of the forms of affects addressed in the case study chapters are of course, partly subjective, and comes directly from the researcher's point of view. For example, the affect of restlessness that attaches to the cardboard paper tubes discussed in Chapter 7, could have also accumulated affects of joy in the passing and circulating around of this object. It is indeed difficult to enrol and address all forms of affect, as affect is indeed momentarily present. The researcher is only able to tease out particular affects while perhaps neglecting others.

Importantly, moving the discussion beyond a specific interest in architectural practice, while Chapter 7 (SBA) discussed the undertaking of designed object and the affect it gathered and repelled, more can be said about the ways in which the other objects, including the design at the scale of furniture's or even fittings can acquire affects also. This is something architectural scholars and possibly architectural geography has not attended to in-depth. Studying the small scale design processes may prove to be useful in providing an intense engagement of how bodies come together to form a small object, such as a doorknob, rather than large scale public architectural buildings. Of course, from a geographical angle, Nigel Thrift, as explored in the literature review in Chapter 3 has attended to what he calls "light-touch, partially-engaged, partially disengaged" 29 small-gatherings that occur in urban cities, and how bodies partaking in these intimate meetings increasingly bond together through affect, the latter acting as a kind of glue between them. ${ }^{30}$ It may be of interest to look at how this concept of small-gatherings can extend to account for small-scale design processes.

Finally, and as a conclusion, the next section points to opportunities for interventions at the intersection of affect and architectural practice. Particularly, two considerations are given: first, towards linking geographical studies and architectural practice discourse through affect, and second, towards linking ethics and architectural practice, through the affirmative use of affect in the designing of spaces.

\footnotetext{
29 Thrift, "But Malice Aforethought,"138.

30 Thrift, "But Malice Aforethought," 146.
} 


\subsection{DRAWING AFFECTIVE CONCLUSIONS}

\section{Towards linking Geography and Architectural Practice}

Broadly put, and perhaps pertaining to an academic concern, architectural scholars (architects and theorists) and architectural geographers, as well as cultural and human geographers would do well to engage in further discourse. Recent debates in geography focus on a shift away from perceiving architecture purely as an object towards architecture as process and practice. ${ }^{31}$ This concern allows us to regard architecture as contingent, involving "different kinds of embodied engagements with and sensory apprehensions of buildings, as well as different modes of dwelling and inhabiting, and different perspectives on architectural spaces" ${ }^{\prime 32}$. In this sense architecture is, on the one hand, the material matter of buildings, but, at the same time, it is also the experiences connected with particular contingencies in relation to a building's design process and occupation which in turn generate varying atmospheres and affects. ${ }^{33}$ Accounting for such affective registers allows us to go beyond the realms of architect's design aspirations, and touch upon affective and embodied aspects of the architectural design process and practice. The research found, although by no means through an exhausted inquiry, that the cross-over between these disciplines was rather light, or at times, even non-existent. ${ }^{34}$ In this context, or lack thereof-, this thesis opens up for a much needed discussion of the role of architectural geography in architectural practice scholarship and further research would do well to elaborate on the links between affective experience as attended to by geographers within the design process and affective experience of the final space. This also points to opportunities for pragmatic interventions at the intersection of affect, architectural practice, and geography.

\section{Towards linking Affect, Ethics and Architectural Practice}

The exploration of this thesis did not attend to questions of how ethics come to play within affects arising from architectural practices. This is an aspect that could have been developed further in the thesis, but doing so would have required more time, but also a different angle to the analysis of the case studies. Indeed, the engagement of affect and ethics is already being undertaken by scholars such as Ahmed. For example in her text, 'This Other and Other Others,'

\footnotetext{
31 Jacobs and Merriman, "Practicing Architecture," 211-222.

32 Jacobs and Merriman, "Practicing Architecture," 213-214.

33 Strebel, "The Living Building," 243-262; Kenneth Olwig, "Performance, Ethereal Space and the Practice of

Landscape/Architecture: The Case of the Missing Mask," Social and Cultural geography 12, no.3 (2011): 305-318; Vasudevan,

"Dramaturgies of Dissent," 283-303.

${ }^{34}$ Here, one scholarly intersection between architecture and geography must be noted through the works by Stephen Cairns and Jane M. Jacobs. See for example, Jacobs, Jane M. and Stephen Cairns, "Ecologies of Dwelling: Maintaining High-Rise Housing in Singapore," in The New Companion to the City, edited by Gary Bridge and Sophie Watson, 79-95 (Oxford: Blackwell, 2011).
} 
Ahmed (following Emmanuel Levinas) claims how "the concern with 'the other' [i]s the promise

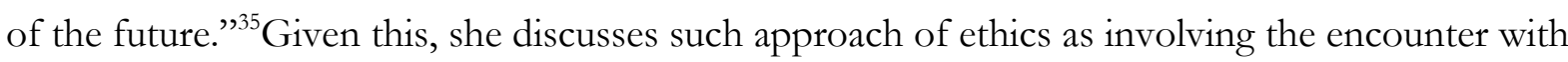
'the other' through affective touch and communication. An ethics of touch, Ahmed writes, can come through the "violence of the grasp, the shake or the beating" but also, can communicate such things as love. ${ }^{36}$ While Ahmed's position is grounded on feminist perspective, it is of interest to this thesis as her model of ethics places importance on collective encounters. Ethics should indeed be a concern for design practices as it deals with people, intimately. What is the good (or bad) that affect does through architecture and its practice? Of course, the sticky metaphor of affect alludes to an understanding - a possibility of ethical understanding of affect. If affect can draw bodies together and equally repel them apart - drawing communities/collectives together for the common good of, for instance, building a community hall, this would touch on aspects of ethical affect. What forms of affects would this be? It is the position of the researcher that indeed, it is in forms of joy, ethical joy, and hope, but also bitterness and even withdrawal from the process of design. In this sense, the engagement with others, and with others' desires - is a collective struggle. But, and following Ahmed, it is through the "willingness to struggle with and for others" ${ }^{\prime 37}$ that we can embrace a 'we'. The ethical act of affect, and to extend this, the ethical act of affective practices is crucial in bringing bodies together to form attachments - precisely ones which are worked for.

There is certainly a great amount of discussion still to be had in regards to how the ethics of affect should be understood, especially in relation to the design process. An engagement between ethics and affect has been taken up most recently by Ben Anderson in his work Encountering Affect ${ }^{38}$ - specifically his first chapter, "Affective Life" - and thereby is of interest to architectural scholars to engage in these works by geographers. Indeed, it may bring more promising futures, tied both ethically and affectively, to architectural practices. Perhaps this is an agenda for further research.

While the study of affect is broad, as this thesis has shown, the recent 'affective turn' looks to go beyond the privileging of affect's autonomy, fostering instead attendance on affect's materiality and generative valance. This thesis is placed as one such contribution to this call, arguing that a concept of affect should crucially be assessed on its ability to establish how affects are indeed localizable, material and effecting. This argument has been developed by presenting the means through which affect and architecture may be connected within theoretical discourse and within design processes. This thesis has explored architectural practices which focus

\footnotetext{
35 Ahmed, "This Other and Other Others," 560.

36 Ahmed, "This Other and Other Others," 564.

37 Ahmed, "This Other and Other Others," 571.

38 Ben Anderson, Encountering Affect: Capacities, Apparatuses, Conditions (Aldershot: Ashgate, 2014).
} 
primarily on the sticky particularities of affective interplays - including images, processes and objects. In summary, the way that the thesis conceptualises the architectural design process and its practice through affect, highlights the dynamic nature of relationships between different human bodies partaking in the design process, but also objects, and images. This offers an alternative model for the study of how affect plays itself out in different happenings and relations, and more specifically, affective mediations, tinkering's and stuttering's that occur in current practices of architecture, a model which holds much promise for future investigations. 
vi.

\section{Bibliography:}

Adey, Peter. "Architectural Geographies of the Airport Balcony: Mobility, Sensation and the Theatre of Flight." Geografiska Annler: Series B, Human Geography 90, no.1 (2008): 29-47. “Airports, Mobility and the Calculative Architecture of Affective Control." Geoforum 39 (2008): 438-451.

. "Holding Still: The Private Life of an Air-Raid." M/C Journal: A Journal of Media and Culture 12, no.1 (2009). Accessed September 10, 2014, http://journal.media-culture.org.au/index.php/mcjournal/article/viewArticle/112.

Adkins, Lisa. "Practice as Temporalization: Bourdieu and Economic Crisis." In The Legacy of Pierre Bourdieu: Critical Essays, edited by Simon Susen and Bryan S. Turner, 347-366. London: Anthem Press, 2011.

Ahmed, Sara. “Affective Economies.” Social Text 22, no.2 (Summer 2004): 117-139.

—. "Collective Feelings or: The impressions left by others." Theory, Culture \& Society 2, no. 2 (2004): 25-42.

- The Cultural Politics of Emotion. Edinburgh: Edinburgh University Press, 2004. . "The Politics of Good Feeling." ACRAWSA e-journal 4 4, no.1 (2008): 1-18.

-The Promise of Happiness. Durham and London: Duke University Press, 2010. . "Happy Objects." In The Affect Theory Reader, edited by Melissa Gregg and Gregory J.

Seigworth, 29-51. Durham \& London: Duke University Press, 2010.

. "Multiculturalism and the Promise of Happiness." New Formations 63 (2008): 121-137.

. "Orientations Matter." In New Materialisms: Ontology, Agency, Politics, edited by Diana

Coole and Samantha Frost, 234-257. Durham \& London: Duke University Press, 2010.

- Queer Phenomenology: Orientations, Objects, Others. Durham: Duke University Press, 2006.

—. "This Other and Other Others." Economy and Society 31, no.4 (2002): 558-72.

Alaimo, Stacey and Susan Hekman. "Introduction: Emerging Models of Materiality in Feminist Theory." In Material Feminisms, edited by Stacey Alaimo and Susan Hekman, 119. Bloomington: Indiana University Press, 2008.

Albrecht-Crane, Christa, and Jennifer Daryl Slack. "Toward a Pedagogy of Affect." In Deleurian Encounters: Studies in Contemporary Social Issues, edited by Anna Hickey-Moody and Peta Malins, 99-110. Houndmills, Hampshire and New York: Palgrave Macmillan, 2007.

Allen, Stan. "Dazed and Confused." Assemblage 27 (August 1995): 47-54.

. "Diagram Matter." Any: Diagram Work 23 (1998).

Practice Architecture, Technique and Representation. London: Routledge, 2000. 
Anderson, Ben. "Affect and Biopower: Towards a Politics of Life." Transactions of the Institute of British Geographers 37, no. 1 (2012): 28-43.

. “Affective Atmospheres.” Emotion, Space and Society 2 (2009): 77-81.

. "Becoming and Being Hopeful: Towards a Theory of Affect." Environment and Planning

D: Society and Space 24, no.5 (2006): 733-752.

—. Encountering Affect: Capacities, Apparatuses, Conditions. Aldershot: Ashgate, 2014.

. "Practices of Judgement and Domestic Geographies of Affect." Social \& Cultural

Geography 6, no.5 (2005): 645-659.

-. "Time-Stilled Space-Slowed: How Boredom Matters." Geoforum 35 (2004): 739-754.

Anderson, Ben and John Wylie. "On Geography and Materiality." Environment and Planning A 41, no.2 (2009): $318-335$.

Anderson, Ben, Mattew Kearnes, Colin McFarlane, and Dan Swanton. "On Assemblages and Geography." Dialogues in Human Geography 2, no.2 (2012): 171-189.

Anderson, Ben and Paul Harrison. Taking-Place: Non-Representational Theories and Geography.

Ashgate: Aldershot, 2010.

. "Questioning Affect and Emotion.” Area 38, no.3 (2006): 333-335.

Artieri, Charles. “Affect, Intentionality, and Cognition: A Response to Ruth Leys.” Critical Inquiry 38 (Summer 2012): 878-881.

Ash, James. "Architectures of Affect: Anticipating and Manipulating the Event in Processes of Videogame Design and Testing." Environment and Planning D: Society and Space 28, no.4 (2010): 653-671.

Attiwill, Suzie. "What's in a Canon?" In Thinking Inside the Box: A Reader in Interiors for the $21^{\text {st }}$ Century, edited by John Gigli, Frazer Hay, Ed Hollis, Andrew Milligan, Alex Milton and Drew Plunkett, 57-66. London: Middlesex University Press, 2007.

Augé, Marc. Non-Places: Introduction to an Anthropology of Supermodernity, translated by John Howe. London and New York: Verso Books, 1995.

Ballantyne, Andrew. Deleuze and Guattari for Architects. London and New York: Routledge, 2007.

Banham, Reyner. “The New Brutalism.” Architectural Review 118 (December 1955): 354-61.

Barad, Karen. "Posthumanist Performativity: Toward an Understanding of How Matter Comes to Matter." Signs: Journal of Women in Culture and Society 28, no.3 (2003): 801-831.

. "Re(con) figuring Space, Time and Matter." In Feminist Locations: Global and Local, Theory and Practice, edited by Marianne DeKoven. New Brunswick: Rutgers University Press, 2001. 
Barnes, Barry. "Practice as Collective Action." In The Practice Turn in Contemporary Theory, edited by Theodore R. Schatzki, Karin Knorr Cetina and Eike von Savigny, 17-28. London: Routledge, 2001.

Baudrillard, Jean. “The Ecstasy of Communication.” In The Anti-Aesthetic, edited by Hal Foster, translated by John Johston, 126-134. Washington: Bay Press, 1983.

."The Hyper-Realism of Simulation.” In Art in Theory 1900-2000, edited by Charles Harrison and Paul Wood, 1018-1020. Oxford: Blackwell Publishing, 1993.

Bell, Jeffrey A. Deleure's Hume: Philosophy, Culture and the Scottish Enlightenment. Edinburgh: Edinburgh University Press, 2009.

Bennett, Jane. "The Force of Things: Steps Toward an Ecology of Matter." Political Theory 32 (2004): 347-372.

- Vibrant Matter: A Political Ecology of Things. Durham and London: Duke University Press, 2010.

Benjamin, Andrew. “Jesse Reiser and Nanako Umemoto.” BOMB 84 (2003): 64-69. . "Passing through Deconstruction: Architecture and the Project of Autonomy." In Critical Architecture, edited by Jane Rendell, Jonathan Hill, Murray Fraser and Mark Dorrian, 40-47. Oxon: Routledge, 2007.

Benjamin, Walter. The Work of Art in the Age of Its Technological Reproducibility and Other Writings on Media, edited by Michael W. Jennings, Brigid Doherty, and Thomas Y. Levin. London: Harvard University Press, 2008.

Bergson, Henri. Matter and Memory. New York: Zone Books, 1991.

Bissell, David. “Animating Suspension: Waiting for Mobilities.” Mobilities 2, no.2 (2007): 277298.

. "Comfortable Bodies: Sedentary Affects." Environment and Planning A 40, no.7 (2008): 1697-1712.

_. "Passenger Mobilities: Affective Atmospheres and the Sociality of Public Transport." Environment and Planning D: Society and Space 28, no.2 (2010): 270-289.

Blackman, Lisa. "Embodying Affect: Voice-hearing, Telepathy, Suggestion and Modelling the Non-conscious.” Body \& Society 16, no. 1 (2010): 163-192.

. "Habit and Affect: Revitalizing a Forgotten History." Body and Society 19, no.2/3 (2013): $186-216$.

Blau, Judith R. Architects and Firms. Cambridge and London: MIT Press, 1984.

Bloch, Ernst. The Principle of Hope (vols. 2-3). Translated by Neville Plaice, Stephen Plaice and Paul Knight. Blackwell: Oxford, 1986. 
Blondel, Eric. Nietzsche: The Body and Culture. Translated by Séan Hand. Stanford: Stanford University Press, 1991.

Bogdan, Robert and Sari Knopp Biklen. Qualitative Research for Education: An Introduction to Theory and Methods, 3rd Edition. Boston: Allyn and Bacon, 1998.

Böhme, Gernot. "Atmosphere as the Fundamental Concept of a New Aesthetics." Thesis Eleven 36 (1993): 113-126.

. "Atmosphere as the Subject Matter of Architecture." In Herzog \& de Meuron.

Natural History, edited by Phillip Ursprung, London: Lars Muller Publishers, 2006.

Bondi, Liz. "Making Connections and Thinking through Emotions: Between Geography and Psychotherapy." Transactions of the Institute of British Geographers 30, no.4 (2005): 433-448.

Booth, Wayne C., Gregory G. Colomb and Joseph M. Williams. The Craft of Research. Chicago: The University of Chicago Press, 1995.

Borden, Iain. "Imaging Architecture: The Uses of Photography in the Practice of Architectural History." Journal of Architecture 12, no.1 (2007): 55-77.

- "Material Sounds: Jacques Tati and Modern Architecture." In Architecture + Film II Architectural Design 70: 1, 26-31.New York: Wiley, 2000.

. Skateboarding, Space and the City: Architecture and the Body. Oxford: Berg, 2001.

Braun, Bruce. "Environmental Issues: Writing a More-Than-Human Urban Geography." Progress in Human Geography 29, no.5 (2006): 635-650.

Bruno, Giuliana. Atlas of Emotion: Journeys in Art, Architecture, and Film. New York: Verso, 2002.

Bondi, Liz. "Making Connections and Thinking through Emotions: Between Geography and Psychotherapy." Transactions of the Institute of British Geographers 30, no.4 (2005): 433-448.

Bourdieu, Pierre. Distinction: A Social Critique of the Judgement of Taste. Translated by Richard Nice. London, Routledge, 1984 [1979].

. "Habitus." In Habitus: A Sense of Place, edited by Jean Hillier and Emma Rooksby, 27-

34. Aldershot: Ashgate, 2002.

- The Logic of Practice. Translated by Richard Nice. Stanford, Stanford University Press, 1990 [1980].

. Outline of a Theory of Practice. Translated by Richard Nice. Cambridge: Cambridge

University Press, 1977.

—. Pascalian Meditation. Translated by Richard Nice. Cambridge: Polity Press, 2000 [1997].

Bourdieu, Pierre and Löic Wacquant, An Invitation to Reflexive Sociology. Cambridge: Polity Press, 2004. 
Braidotti, Rosi. Metamorphoses: Towards a Materialist Theory of Becoming. Cambridge: Polity Press, 2002.

Bram, Stephen. "The Art Museum of Rémy Zaugg." Accessed January 15. 2014, http://www.docstoc.com/docs/32296772/the-art-museum-of-r\%C3\%A9my-zauggStephen-Bram-perhaps-all-visual-art.

Brennan, Teresa. The Transmission of Affect. New York: Cornell University Press, 2004.

Brody, Alyson. “The Cleaners You Aren't Meant to See: Order, Hygiene and Everyday Politics in a Bangkok Shopping Mall." Antipode 38, no.3 (2006): 534-56.

Brown, Andrew D., Martin Kornberger, Stewart Clegg and Chris Carter. "Invisible Walls' and 'Silent Hierarchies': A Case Study of Power Relations in an Architecture Firm.” Human Relations 63, no.4 (2010): 525-549.

Brown, Stephen, A. Communication in the Design Process. London and New York: Spon Press, 2001.

Buchanan, Ian. "Deleuze and Pop Music." American Humanities Review (August 1997). Accessed March 30, 2012, http://www.australianhumanitiesreview.org/archive/Issue-August1997/buchanan.html.

. "The Problem of the Body in Deleuze and Guattari, or, What Can a Body Do?" Body and Society 3, no.3 (1997): 73-91.

Burke, Anthony and Therese Tierney, eds. Network Practices: New Strategies in Architecture and Design. New York: Princeton Architectural Press, 2007.

Burke, Anthony. "Redefining Network Practices." In Network Practices: New Strategies in Architecture and Design, edited by Anthony Burke and Therese Tierney, 54-77. New York: Princeton Architectural Press, 2007.

Buser, Michael. "Thinking through Non-representation and Affective Atmospheres in Planning Theory and Practice.” Planning Theory 13, no.3 (2014): 227-243.

Calvino, Italo. Invisible Cities, translated by William Weaver. New York and London: Harcourt Brace Jovanovich, 1974.

Cairns, Stephen. “Agency.” Architectural Research Quarterly 13, no. 2 (June 2009): 105-108 . "Flows." In The SAGE Handbook of Architectural Theory, edited by C. Greig Crysler, Stephen Cairns and Hilde Heynen, 451-465. London: SAGE, 2012.

Casey, Edward S. Representing Place: Landscape Painting and Maps. Minneapolis: University of Minnesota Press, 2002.

Certeau, Michel de. The Practice of Everyday Life. University of California Press: Berkeley, 1984. 
Clough, Patricia. “Afterword: the Future of Affect Studies.” Body and Society 16, no.1 (2010): 222-30.

"Introduction." In The Affective Turn: Theorizing the Social, edited by Patricia Clough, 1-33.

Durham: Duke University Press, 2007.

Clough, Patricia Ticineto and Jean Halley. The Affective Turn: Theorizing the Social. Durham:

Duke University Press, 2007.

Cohen, Robert, Mark Standeven, Bill Bordass and Adrian Leaman. "Assessing Building Performance in Use 1: The Probe Process.” Building Research and Information 29, no.2 (2001): 85-102.

Colebrook, Claire. “On Not Becoming Man: The Materialist Politics of Unactualized Potential. In Material Feminisms, edited by Stacy Alaimo and Susan Hekman, 52-84. Bloomington and Indianapolis: Indiana University Press, 2008.

. "The Space of Man: On the Specificity of Affect in Deleuze and Guattari." In Deleuze and Space, edited by Ian Buchanan and Gregg Lambert, 189-206. Edinburgh: Edinburgh University Press, 2005.

. "Time and Autopoesis: The Organism Has No Future." In Deleuze and the Body, edited by Laura Guillaume and Joe Hughes, 9-28. Edinburgh: Edinburgh University Press, 2011.

Coleman, Rebecca. "Be(come) Yourself Only Better': Self-transformation and the Materialisation of Images." In Deleure and the Body, edited by Laura Guillaume and Joe Hughes, 144-164. Edinburgh: Edinburgh University Press, 2011.

. "Things that Stay." Time and Society 17, no.1 (2008): 85-102.

.Transforming Images: Screens, Affect, Futures (London and New York: Routledge, 2013).

Coleman, Rebecca and Mónica Moreno Figueroa. "Past and Future Perfect? Beauty, Affect and Hope." Journal for Cultural Research 14, no. 4 (October 2010): 357-373.

Colomina, Beatriz. “Architectureproduction.” In This Is Not Architecture: Media Constructions, edited by Kester Rattenbury, 207-221. New York: Routledge, 2002.

. "Media as Modern Architectures." In Thomas Demand, Serpentine Gallery. London:

Serpentine Gallery; Munich: Mosel, 2006.

- Privacy and Publicity: Modern Arcbitecture as Mass Media. Cambridge: MIT Press, 1994.

Colman, Felicity. "Affective Terrorism." In Deleuzian Encounters: Studies in Contemporary

Social Issues, edited by Anna Hickey-Moody and Peta Malins, 122-134. Houndmills:

Palgrave Macmillan, 2007.

Comment, Bernard. The Panorama. London: Reaktion Books, 1999. 
Conradson, David and Alan Latham. "The Affective Possibilities of London: Antipodean Transnationals and the Overseas Experience." Mobilities 2, no.2 (2007): 231-254.

Conradson, David and Deirdre Mckay. "Translocal Subjectivities: Mobility, Connection, Emotion.” Mobilities 2, no.2 (2007): 167-174.

Coole, Diana and Samantha Frost. "Introducing the New Materialism." In New Materialisms: Ontology, Agency and Politics, edited by Diana Coole and Samantha Frost, 1-43. Durham and London: Duke University Press, 2010

Cox, Christoph. Nietssche: Naturalism and Interpretation. Berkeley: University of California Press, 1999.

. "The 'Subject' of Nietzsche's Perspectivism." Journal of the History of Philosophy 35, no.2 (1997): 269-291.

Creswell, John W. Research Design: Qualitative, Quantitative, and Mixed Methods Approach. Thousand Oaks, CA: Sage Publications, 2003.

Cresswell, Tim. "Landscape and the Obliteration of Practice." In Handbook of Cultural Geography, edited by Kay Anderson, Mona Domosh, Steve Pile, and Nigel Thrift, 269-281. London: SAGE, 2003.

“Mobilities II: Still.” Progress in Human Geography 36, no.5 (2012): 645-653.

“You Cannot Shake the Shimmie Here': Producing Mobility on the Dancefloor." Cultural Geography 13, no.1 (2006): 55-77.

Cross, Nigel. Design Thinking. Oxford and New York: Berg, 2011.

Crysler, Greig, Stephen Cairns and Hilde Heynen, eds. The SAGE Handbook of Architectural Theory. London: SAGE Publications, 2012.

Cuff, Dana. Architecture: The Story of Practice. Cambridge, MA: MIT Press, 1991.

"Divisive Tactics: Design-Production Practices in Architecture." Journal of Architectural Education 45 (July 1992): 204-212.

. "Introduction: Architecture's Double-Bind." In The SAGE Handbook of Architectural Theory, edited by C. Greig Crysler, Stephen Cairns and Hilde Heynen, 385-393. London: SAGE, 2012.

Curley, Edwin. Bebind the Geometrical Method: A Reading of Spinoza's Ethics. Princeton: Princeton University Press, 1988.

D’Alleva, Anne. Methods and Theories of Art History. London: Laurence King, 2012.

Datta, Ayona. “Architecture of Low-Income Widow Housing: 'Spatial Opportunities' in Madipur, West Delhi.” Cultural Geographies 15, no.2 (2008): 231-253. 
Davies, Gail and Claire Dwyer. "Qualitative Methods: Are You Enchanted Or Are You Alienated?” Progress in Human Geography 31, no.2 (2007): 257-266.

. "Qualitative Methods II: Minding the Gap." Progress in Human Geography 32, no.3 (2008): 399-406.

Dawney, Leila. “The Motor of Being: a Response to Steve Pile's 'Emotions and Affect in Recent Human Geography." Transactions of the Institute of British Geographers 36, no.4 (2011): 599-602.

Deamer, Peggy. "Practicing Practice.” Accessed June 15, 2013, www.peggydeamer.com/images/practicing_practice.

Deamer, Peggy and Phillip G. Bernstein, eds. Building (in) the Future: Recasting Labor in Architecture. Princeton: Princeton Architectural Press, 2010.

Debord, Guy. Society of the Spectacle. Detroit: Black and Red, [1967].

Degen, Monica, Gillian Rose and Begum Basdas. "Bodies and Everyday Practices in Designed Urban Environments." Science Studies: An Interdisciplinary Journal for Science and Technology Studies 23, no.2 (2010): 60-76.

DeLanda, Manuel. Intensive Science and Virtual Philosophy. London: Bloomsbury Academic, 2002. . "Material Complexity." In Digital Tectonics, edited by Neil Leach, David Turnbull and Chris Williams, 14-21. London: Wiley-Academy, 2004.

. "Material Evolvability and Variability." In Research \& Design: The Architecture of V ariation, edited by Lars Spuybroek. London: Thames and Hudson, 2009.

. "Space: Extensive and Intensive, Actual and Virtual." In Deleuze and Space, edited by Ian Buchanan and Gregg Lambert, 80-88. Toronto: University of Toronto Press, 2005.

Deleuze, Gilles. Expressionism in Philosophy: Spinoza. Translated by Martin Joughin. New York: Zone Books, 1990.

—. Difference \& Repetition. Translated by Paul Patton. London: Athlone Press, 1994. . "He Stuttered." In Gilles Deleure and the Theater of Philosophy, edited by Constantin V.

Boundas and Dorothea Olkowski, 23-29. New York and London: Routledge, 1994.

- Nietzsche and Philosophy. Translated by Hugh Tomlinson. London: Atholone Press, 1983.

- Spinoza: Practical Philosophy. Translated by Robert Hurley. San Francisco: City Lights Books, 1988.

Deleuze, Gilles and Félix Guattari. A Thousand Plateaus: Capitalism and Schirophrenia. Translated by Brian Massumi. Minneapolis: University of Minnesota Press, 1987. . A Thousand Plateaus: Capitalism and Schizophrenia. Translated by Brian Massumi. London and New York: Continuum, 2004. 
- What is Philosophy? Translated by Hugh Tomlinson and Graham Burchill. London: Verso, 1994.

Denzin, Norman K. and Yvonna S. Lincoln. Strategies for Qualitative Inquiry. Thousand Oaks: Sage Publications, 1998.

de Solà-Morales, Ignasi. “Weak Architecture.” In Architecture Theory Since 1968, edited by Michael K. Hays, 616-623. Cambridge: MIT Press, 2002.

del Rio, Elena. "Review: The Architectural Uncanny: Essays in the Modern Unhomely by Anthony Vidler.” Discourse 15, no.3 (Spring 1993): 177-181.

Diprose, Rosalyn. The Bodies of Women: Ethics, Embodiment and Sexual Differences. New York: Routledge, 1994.

Dolphijn, Rick and Iris van der Tuin. New Materialism: Interviews \& Cartographies. Michigan: Open Humanities Press, 2012.

Dovey, Kim. Framing Places: Mediating Power in Built Form. London: Routledge, 1999. . "The Silent Complicity of Architecture.” In Habitus: A Sense of Place, edited by Jean Hillier and Emma Rooksby, 283-296. London: Ashgate, $2^{\text {nd }}$ Edition 2005.

Dovey, Kim, Ian Woodcock and Stephen Wood. "A Test of Character: Regulating Placeidentity in Inner-city Melbourne.” Urban Studies 46, no.12 (2009): 2595-2615.

Doucet, Isabelle and Kenny Cupers. "Agency in Architecture: Reframing Criticality in Theory and Practice." Footprint 4 (Spring 2009): 1-6.

Duncan, Nancy and James Duncan. "Doing Landscape Interpretation." In The SAGE Handbook of Qualitative Geography, edited by Dydia DeLyser, Steve Herbert, Stuart Aitken, Mike Crang and Linda McDowell, 225-248. London: SAGE Publications, 2010

Edensor, Tim. "Entangled Agencies, Material Networks and Repair in a Building Assemblage: The Mutable Stone of St Ann's Church, Manchester." Transactions of the Institute of British Geographers 36, no.2 (2011): 242-243

Ednie-Brown, Pia. "Falling into the Surface (toward a materiality of affect)." International Journal of Screendance 2 (2012): 99-106.

—. "The Will to Animation." In Animation and Architecture, edited by Bob Fear, Architectural Design Academy Editions 72, no. 2 (2001): 64-73.

Edwards, Brian W. and Emanuele Naboli. Green Buildings Pay: Design, Productivity and Ecology. Third Edition. Abingdon: Routledge, 2013.

Eisenman, Peter. Diagram Diaries. London: Thames \& Hudson, 1999. . "The Diagram.” In Eisenman: Feints. Milan, London: Thames \& Hudson, 2006.

Eisenstein, Sergei M. “Montage and Architecture.” Assemblage 10 (1989): 110-131. 
Featherstone, Mike. "Body, Image and Affect in Consumer Culture." Body \& Society 16, no.1 (2010): 193-221.

Fisher, Thomas. Architectural Design and Ethics - Tools for Survival. Oxford: Architectural Press, 2008.

. In the Scheme of Things: Alternative Thinking on the Practice of Architecture. Minneapolis:

University of Minnesota Press, 2000.

Fontana, Andrea and James Fray. "Interviewing: The Art of Science." In Handbook of Qualitative Research, edited by Norman K. Denzin and Yvonna S. Lincoln, 361-376. Thousand Oaks, CA: Sage Publications, 1994.

Forsyth, Isla, Hayden Lorimer, Peter Merriman and James Robinson. "What are Surfaces?" Environment and Planning A 45, no.5 (2013): 1013-1020.

Foster, Hal. Design and Crime, and Other Diatribes. New York: Verso books, 2002. "Image Building." In Arcbitecture Between Spectacle and Use, edited by Anthony Vidler. New Haven: Yale University Press, 2008.

Frampton, Kenneth. "A Note on Photography and its Influence on Architecture.” Perspecta 22 (1986): 38-41.

- Commodification and Spectacle in Architecture: A Harvard Design Magazine Reader, edited by William S. Saunders. Minneapolis: University of Minnesota Press, 2005.

Franck, Karen A. and Teresa von Sommaruga Howard. Design Through Dialogue: A Guide for Architects and Clients. West Sussex: John Wiley \& Sons, 2010.

Frank, Adam and Elizabeth A. Wilson. "Critical Response I: Like Minded." Critical Inquiry 38 (Summer 2012): 870-877.

Franz, Jill M. and Steffen Lehmann. "Side-By-Side: A Pedagogical Basis for (Design) Transdisciplinarity." IDEA Journal (2004): 9-30.

Frascari, Marco, Jonathan Hale, and Bradley Starkey (Eds.) From Models to Drawings: Imagination and Representation in Architecture. London and New York: Routledge, 2007.

Fraser, Mariam. "What is the Matter of Feminist Criticism." Economy and Society 31, no.4 (2002): 606-625.

Fraser, Murray. "Introduction." In Design Research in Architecture: An Overview, edited by Murray Fraser, 1-14. London: Ashgate, 2013.

Frichot, Hélène. "Olafur Eliasson and the Circulation of Affects and Precepts: In Conversation." Architectural Design 78 (May/June 2008): 30-35.

Gatens, Moira. "Feminism as 'Password': Re-Thinking the 'Possible' with Spinoza and Deleuze." Hypatia 15, no.2 (2000): 59-75. 
Gatens, Moira and Genevieve Lloyd. Collective Imaginings: Spinoza, Past and Present. New York: Routledge, 1999.

Gibbs, Anna. “After Affect: Sympathy, Synchrony, and Mimetic Communication.” In The Affect Theory Reader, edited by Gregory J. Seigworth and Melissa Gregg, 186-205. Durham: Duke University Press, 2010.

."Contagious Feelings: Pauline Hanson and the Epidemiology of Affect." Australian Humanities Review 24 (2001). Accessed July 15, 2011, http://www.australianhumanitiesreview.org/archive/Issue-December-2001/gibbs.html.

Giddens, Anthony. The Constitution of Society. Cambridge: Polity Press, 1984.

Giedion, Sigfried. Space, Time and Architecture: The Growth of a New Tradition. Cambridge: Harvard University Press, 1952.

Gillham, Bill. Case Study Research Method. London: Bloomsbury Academic, 2000.

Graham, Stephen and Nigel Thrift. "Out of Order: Understanding Repair and Maintenance." Theory, Culture \& Society 24, no.3 (2007): 1-25.

Grau, Oliver. "Immersion and Interaction: From Circular Frescoes to Interactive Image Spaces." In Media Art Net1 / A Survey of Media Art, edited by Rudolf Frieling and Dieter Daniels, 292-313. Vienna: Springer, 2004.

—. Virtual Art: From Illusion to Immersion. Cambridge/Mass.: MIT Press, 2013.

Gregg, Melissa and Gregory J. Seigworth. The Affect Theory Reader. Durham, North Carolina: Duke University Press, 2010.

Groat, Linda and David Wang. Architectural Research Methods. New York: John Wiley and Sons, 2002.

Grossberg, Lawrence. We Gotta Get Out of This Place: Popular Conservatism and Postmodern Cultures. London: Routledge, 1992.

Grosz, Elizabeth. Architecture from the Outside: Essays on Virtual and Real Space. Cambridge: The MIT Press, 2001. ."Habit Today: Ravaisson, Bergson, Deleuze and Us." Body and Society 19, no.2-3 (2013): 217-239.

Guattari, Félix. "Space and Corporeity." Columbia Documents of Architecture and Theory 2 (1993): 139-148.

Guba, Egon G. and Yvonna S. Lincoln. Fourth Generation Evaluation. Newbury Park: Sage, 1989.

Gutman, Robert. Architectural Practice: A Critical View. New York: Princeton Architectural Press, 1988. 
—. "Emerging Problems of Practice." Journal of Architectural Education 45 (July 1992): 198202.

Hage, Ghassan. "“On the Side of Life" - Joy and the Capacity of Being - with Ghassan Hage.” in Hope: New Philosophies for Change, edited by Mari Zourzani, 150-171. London: Lawrence \& Wishart, 2002.

Hansen, Mark B.N. “Affect as Medium, or the 'Digital-Facial-Image.”' Journal of Visual Culture 2, no.2 (2003): 205-208.

\footnotetext{
- Bodies in Code: Interfaces with Digital Media. New York and London: Routledge, 2006.

—. New Philosophy for New Media. Cambridge and London: MIT, 2004.

—. "The Time of Affect, or Bearing Witness to Life." Critical Inquiry 20, no.3 (2004): 584626.
}

Harrison, Paul. "Corporeal Remains: Vulnerability, Proximity, and Living on After the End of the World." Environment and Planning A 40, no.2 (2008): 423-445.

- “'How shall I say it...?' Relating the non-relational." Environment and Planning A 38, no.3 (2006): 590-608.

—. "In the Absence of Practice." Environment and Planning D: Society and Space 27, no.6 (2009): 987-1009.
—. "Making Sense: Embodiment and the Sensibilities of the Everyday." Environment and Planning D: Society and Space 18, no. 4(2000): 497-517.
- "The Space Between Us: Opening Remarks on the Concept of Dwelling." Environment and Planning D: Society and Space 25, no. 4 (2007): 625-47.

Hartoonian, Gevork. Architecture and Spectacle: A Critique. London: Ashgate, 2012.

Hauptmann, Deborah. The Body in Architecture. Rotterdam: 010 Publishers, 2006.

Havik, Klaske, Hans Teerds, Gus Tielens, Peter Zumthor, and Juhani Pallasmaa (Eds).

"OASE \#91: Building Atmosphere: Material, Detail and Atmosphere in Architectural practice," OASE Journal of Architecture, nai010 Publishers, (2013).

Heidegger, Martin. Nietæsche. Translated by David Farrell Krell. San Francisco: Harper \& Row, 1979.

Hekman, Susan. The Material of Knowledge: Feminist Disclosures. Bloomington and Indianapolis: Indiana University Press, 2010.

Hemmings, Clare. "Invoking Affect: Cultural Theory and the Ontological Turn." Cultural Studies 19, no.5 (2005): 548-567.

Henke, Christopher R. “The Mechanics of Workplace Order: Toward a Sociology of Repair.” Berkeley Journal of Sociology 43 (2000): 55-81. 
_ . "Situation Normal? Repairing a Risky Ecology." Social Studies of Science 37, no.1 (2007): 135-142.

Hickey-Moody, Anna. "Intellectual Disability, Sensation and Thinking Through Affect." In Deleurian Encounters: Studies in Contemporary Social Issues, edited by Anna Hickey-Moody and Peta Malins, 79-98. Houndmills: Palgrave Macmillan, 2007.

Hickey-Moody, Anna and Peta Malins. "Introduction: Gilles Deleuze and Four Movements in Social Thought.” In Deleuzian Encounters: Studies in Contemporary Social Issues, edited by Anna Hickey-Moody and Peta Malins, 1-26. Houndmills: Palgrave Macmillan, 2007.

Hill, Jonathan. Architecture: the Subject is Matter. London: Routledge, 2001.

-. Immaterial Achitecture. Abingdon: Routledge, 2006.

—. "Lawless institutions: Architecture and its practice." Journal of Architecture 4, no. 1 (1999): 89-93.

- Weather Architecture. London: Routledge, 2012.

Hubbarb, Bill. A Theory for Practice: Architecture in Three Discourses. Cambridge and London: MIT Press, 1995.

Husserl, Edmund. Ideas pertaining to a pure phenomenology and to a phenomenological philosophy - Second book: Studies in the phenomenology of constitution. Translated by Richard Rojcewicz and André Schuwer. Doredrecht: Kluwer, 1989.

Imrie, Rob and Emma Street. Architectural Design and Regulation. Chichester, West Sussex: WileyBlackwell, 2011.

—. "Regulating Design: The Practices of Architecture, Governance and Control." Urban Studies 46, no.12 (2009): 2507-2518.

—. "Risk, Regulation and the Practices of Architects." Urban Studies 46, no. 12 (2009): 25552576.

Ingels, Bjarke. Yes Is More: An Archicomic on Architectural Evolution. Koln: Taschen, 2009.

Ingold, Tim. "Materials Against Materiality." Archaeological Dialogues 14, no.1 (2007): 1-16.

Jacobs, Jane M. “A Geography of Big Things.” Cultural Geographies 13, no.1 (2006): 1-27.

Jacobs, Jane M. and Peter Merriman. "Practising Architectures." Social and Cultural Geography 12, no.3 (2011): 211-222.

Jacobs, Jane M. and Stephen Cairns. "Ecologies of Dwelling: Maintaining High-Rise Housing in Singapore." In The New Companion to the City, edited by Gary Bridge and Sophie Watson, 79-95. Oxford: Blackwell, 2011.

Jencks, Charles. The Language of Post-Modern Architecture. London: Academy Editions, 1977. 
Jenkins, Lloyd. "Geography and Architecture: 11, Rue du Conservatoire and the Permeability of Buildings." Space and Culture 5, no.3 (2002): 222-236.

Johnson, Paul-Alan. The Theory of Architecture: Concepts, Themes, \& Practices. New York: Van Nostrand Reinhold, 1994.

Jones, John Chris. Design Methods, $2^{\text {nd }}$ Edition. New York: Van Nostrand Reinhold, 1992.

Kellner, Douglas. "Virilio, War and Technology: Some Critical Reflections." In Paul Virilio, from Modernism to Hypermodernism and Beyond, edited by John Armitage, 103-126. London: Sage, 2000.

Keiller, Patrick. "Architectural Cinematography." In This Is Not Architecture: Media Constructions, edited by Kester Rattenbury, 37-44. NewYork: Routledge, 2002.

King, Nigel and Christina Horrocks. Interviews in Qualitative Research. Thousand Oaks, CA: Sage Publications, 2010.

Kirby, Kathleen M. Indifferent Boundaries: Spatial Concepts of Human Subjectivity. New York: The Guilford Press, 1996.

- "Thinking Through the Boundary: The Politics of Location, Subjects and Space." Boundary 2 20, no.2 (1993): 173-189.

Kipnis, Jeffrey. "Re- originating Diagrams." In Eisenman: Feint, edited by Silvio Cassarà, 193-201. Milan: Skira, 2006.

Kostof, Spiro, ed. The Architect: Chapters in the History of the Profession. New York: Oxford University Press, 1977.

Kraftl, Peter. "Ecological Architecture as Performed Art: Nant-y-Cwm Steiner school, Pembrokeshire." Social and Cultural Geography 7, no.6 (2006): 927-48.

—_. "Geographies of Architecture: The Multiple Lives of Buildings." Geography Compass 4, no.5 (2010): 402-415.

—. "Utopia, Performativity, and the Unhomely." Environment and Planning D: Society and Space 25, no.1 (2007): 120-43.

Kraftl, Peter and Peter Adey. "Architecture/Affect/Inhabitation: Geographies of Being-in Buildings." Annals of the Association of American Geographers 98, no.1 (2008): 213-231.

Krippendorff, Klaus. The Semantic Turn: A New Foundation for Design. Boca Raton, London and New York: Taylor and Francis, 2006.

Kulper, Perry. "Drawing Architecture, Conversation with Perry Kulper." WAI Think Tank, accessed August 15, 2014, http://waithinktank.com/

Kvale, Steinar. Interviews: An Introduction to Qualitative Research Interviewing. Thousand Oaks: Sage Publications, 1996. 
Kwinter, Sanford. “The Judo of Cold Combustion." In Atlas of Novel Tectonics, edited by Reiser + Umemoto, 12-15. New York: Princeton Architectural Press, 2006.

Franck, Karen A., and Teresa von Sommaruga Howard. Design Through Dialogue: A Guide for Architects and Clients. West Sussex: John Wiley \& Sons, 2010.

Lasanksy, D. Medina. "Sensationalizing OMA's Milstein Hall at Cornell University." The Senses \& Society 9, no.1 (2014): 99-107.

Latham, Alan. "Research, Performance, and Doing Human Geography: Some Reflections on the Diary-Photograph, Diary-Interview Method. Environment and Planning A 35 (2003): 1993-2017.

Latham, Alan and Derek McCormack. "Globalizations Big and Small: Notes on Urban Studies, Actor Network Theory, and Geographical Scale.” In Urban Assemblages: How Actor-Network Theory Changes Urban Studies, edited by Ignacio Farías and Thomas Bender, 53-72. Routledge: New York, 2010.

_. "Thinking with Images in Non-Representational Cities: Vignettes from Berlin." Area 41, no.2 (2009): 252-262.

. "Moving Cities: Rethinking The Materialities of Urban Geographies." Progress in Human Geography 28, no.6 (2004): 701-724.

Latour, Bruno. "How to Talk About the Body? The Normative Dimension of Science Studies." Body \& Society 10, no.2-3 (2004): 205-229.

Laurier, Eric and Barry Brown. "Rotating Maps and Readers: Praxiological Aspects of Alignment and Orientation." Transactions of the Institute of British Geographers 33 (2008): 201221.

Lawson, Bryan. (2006). How Designers Think: The Design Process Demystified. Oxford; Burlington, MA: Elsevier/Architectural, 2006.

Leach, Neal. "Saturation of the Image." In The Anaesthetics of Architecture, edited by Neal Leach, 1-16. Cambridge: The MIT Press, 1999.

Lee, Gini. "Curatorial Thinking: Performance Space and the Interior.” In Thinking Inside the Box: A Reader in Interiors for the $21^{\text {st }}$ Century, edited by John Gigli, Frazer Hay, Ed Hollis, Andrew Milligan, Alex Milton and Drew Plunkett, 133-143. London: Middlesex University Press, 2007.

Lees, Loretta. "Towards a Critical Geography of Architecture: The Case of an Ersatz Colosseum.” Cultural Geographies 8, no.1 (2001): 52-86.

_. "Rematerializing Geography: The 'New' Urban Geography." Progress in Human Geography 26, no.1 (2002): 101-112. 
Leigh-Star, Susan. "The Ethnography of Infrastructure." American Behavioural Scientist 43, no.3 (1999): 377-391.

Leys, Ruth. "Facts and Moods: Reply to My Critics." Critical Inquiry 38 (Summer 2012): 882-891. . "The Turn to Affect: A Critique." Critical Inquiry 37, no. 3 (Spring 2011): 434-472.

Lincoln, Yvonna S. and Egon G. Guba. Naturalistic Inquiry. Beverly Hills: Sage, 1985.

Lipstadt, Helene. "Can 'Art Professions' be Bourdieuean Fields of Cultural Production? The Case of the Architecture Competition." Cultural Studies 17, no. 3/4 (2003): 390-419.

Llewellyn, Mark. "Polyvocalism and the Public: 'Doing' a Critical Historical Geography of Architecture." Area 35, no.3 (2003): 264-270.

. “'Urban Village' or 'White House': Envisioned Spaces, Experienced Places, and

Everyday Life at Kensal House, London in the 1930s." Environment and Planning D: Society and Space 22, no.2 (2004): 229-249.

Lorimer, Hayden. "Cultural Geography: Non-Representational Conditions and Concerns." Progress in Human Geography 32, no. 4 (August 2008): 551-559.

_ . "Cultural Geography: The Busyness of Being 'More-Than-Representational.” Progress in Human Geography 29, no. 1 (2005): 83-94.

. "Cultural Geography: Worldly Shapes, Differently Arranged." Progress in Human Geograpby 31, no.1 (2007): 89-100.

. "Herding Memories of Humans and Animals." Environment and Planning D: Society and Space 24, no.4 (2005): 497-518.

Lorimer, Jamie. "Moving Image Methodologies for More-Than-Human Geographies." Cultural Geographies 17, no.2 (2010): 237-258.

Lorraine Tamsin. "Ahab and Becoming-Whale: The Nomadic Subject in Smooth Space.” In Deleuze and Space, edited by Ian Buchanan and Gregg Lambert, 156-175. Edinburgh: Edinburgh University Press, 2005.

MacCormack, Patricia. "Multi-Dimensional Modifications." In Deleuze and the Body, edited by Laura Guillaume and Joe Hughes, 188-202. Edinburgh: Edinburgh University Press, 2011. . "Parabolic Philosophies: Analogue and Affect." Theory, Culture \& Society 21, no.6 (2004): 179-187.

Macpherson, Hannah. "Non-Representational Approaches to Body-Landscape Relations." Geography Compass 4, no.1 (2010): 1-13.

Malnar, Joy Monice and Frank Vodvarka. Sensory Design. Minneapolis: Minnesota University Press, 2004. 
Manning, Erin. “Always More than One: The Collectivity of a Life.” Body \& Society 16, no.1 (2010): 117-128.

. Politics of Touch, Sense, Movement, Sovereignty. Minneapolis: University of Minnesota Press, 2006.

. "Sensing Beyond Security.” In Deleurian Encounters: Studies in Contemporary Social

Issues, edited by Anna Hickey-Moody and Peta Malins, 111-121. Houndmills: Palgrave

Macmillan, 2007.

Marble, Scott. "Imagining Risk.” In Building (in) The Future: Recasting Labor in Arcbitecture, edited by Phillip G. Bernstein and Peggy Deamer. New Haven and New York: Princeton Architectural Press, 2010.

Marshall, Catherine and Gretchen B. Rossman. Designing Qualitative Research (4 $4^{\text {th }} \mathrm{ed}$.). Thousand Oaks: Sage Publications, 2006.

Massumi, Brian. “The Autonomy of Affect.” In Deleuze: a Critical Reader, edited by Paul Patton, 217-239. Blackwell, Oxford, 1996.

. “Navigating Movements (interview)." In Hope: New Philosophies for Change, edited by Mary Zourzani, 210-242. New York: Routledge, 2002.

. "Notes on the Translation and Acknowledgements." In A Thousand Plateaus:

Capitalism and Schizophrenia, by Gilles Deleuze and Félix Guattari, xvii-xx. London:

Athlone Press, 2004.

- Parables for the Virtual: Movement, Affect, Sensation. Durham: Duke University Press, 2002. ."The Political Economy of Belonging and the Logic of Relation.” In Anybody, edited by Cynthia Davidson, 175-188. Cambridge: MIT Press, 1997.

—. "Sensing the Virtual, Building the Insensible." In Hypersurface Architecture, edited by Stephen Perella, Architectural Design (Profile no. 133) 68, no. 5/6 (May-June 1998): 16-24.

McCormack, Derek. "Aerostatic Spacing: On Things Becoming Lighter than Air." Transactions of the Institute of British Geographers 34, no.1 (2009): 25-41.

. "Diagramming Performance and Practice." Environment and Planning D: Society and Space 23, no.1 (2005): 119-147.

- "Engineering Affective Atmospheres on the Moving Geographies of the 1897 Andrée Expedition.” Cultural Geographies 15 (2008): 413-430.

. "An Event of Geographical Ethics in Spaces of Affect." Transactions of the Institute of

British Geographers 28, no. 4 (2003): 488-507.

. "Fieldworking with Atmospheric Bodies." Performance Research 15, no.4 (2010): 40-48. 
—. "For the Love of Pipes and Cables: A Response to Deborah Thien." Area 38, no.3 (2006): 330-332.

—. "Geographies for Moving Bodies: Thinking, Dancing, Space." Geography Compass 2, no.6 (2008): 1822-1836.

_. "Molecular Affects in Human Geographies." Environment and Planning A 39, no.2 (2007): 359-377.

—. "A Paper with an Interest in Rhythm.” Geoforum 33 (2002): 469-485.

_. "Politics and Moving Bodies, Review Essay." Political Theory 35, no.6 (2007): 816-824.

_. "Remotely sensing affective afterlives: the spectral geographies of material remains." Annals of the Association of American Geographers 100, no.3 (2010): 640-654.

- "Thinking-spaces for research creation." Inflexions 1, no.1 (2008). Accessed February 15, 2014, http://www.senselab.ca/inflexions/htm/node/McCormack.html

McLuhan, Marshall. The Medium is the Massage: An Inventory of Effects. London: Penguin Books, 1967.

Merriam, Sharan B. Qualitative Research and Case Study Applications in Education. San Francisco: Jossey-Bass, 1998.

Merriman, Peter, George Revill, Tim Cresswell, Hayden Lorimer, David Matless, Gillian

Rose and John Wylie. “Landscape, Mobility, Practice." Social and Cultural Geography 9, no.2 (2008): 191-212.

Message, Kylie. "Body Without Organs" in The Deleuze Dictionary, edited by Adrian Parr, 32-34. New York: Columbia University Press 2005.

Miles, Matthew B. and Michael Huberman. Qualitative Data Analysis: A Sourcebook of New Methods. Thousand Oaks: Sage Publications, 1994.

Miller, Angela. “The Panorama, the Cinema, and the Emergence of the Spectacular.” Wide Angle 18, no.2 (1996): 34-69.

Munt, Sally. Queer Attachments: The Cultural Politics of Shame. Hampshire and Burlington: Ashgate Publishing, 2008.

Murray, Fraser. “"A Two-Fold Movement': Design Research as Dialectical Critical Practice.” In Design Research in Architecture, edited by Murray Fraser, 217-248. Burlington: Ashgate, 2013.

Nash, Catherine. "Performativity in Practice: Some Recent Work in Cultural Geography." Progress in Human Geography 24, no.4 (2000): 653-644.

Nedelcu, Marius. "Expanded Image Space. From Panorama Image to Virtual Reality, through Cinema." Close Up: Film and Media Studies 1, no.1 (2013).

Ngai, Sianne. Ugly Feelings. Cambridge and London: Harvard University Press, 2005. 
Nietzsche, Friedrich. Beyond Good and Evil: Prelude to a Philosophy of the Future. Translated by Reginald J. Hollingdale. Harmondsworth: Penguin Books, 1973.

- Beyond Good and Evil: Prelude to a Philosophy of the Future. Translated by Judith Norman. Cambridge: Cambridge University Press, 2002.

- On the Genealogy of Morals. Translated by Walter Kaufman. New York: Vintage, 1989.

. Thus Spoke Zarathustra: A Book for Everyone and No One. Translated by Graham Parkes.

New York: Oxford University Press, 2005 [1885].

- The Will to Power: A New Translation. Translated by Walter Kaufmann and Reginald J.

Hollingdale. New York: Vintage, 1968.

Oettermann, Stephan. The Panorama: History of a Mass Medium. New York: Urzone, 1997.

Oliver, Giles. “Responsive Practice.” In Architecture and its Ethical Dilemmas, edited by Nicholas Ray, 55-68. London: Taylor and Francis, 2005.

Oliver, Paul. "Purposive Sampling." In The SAGE Dictionary of Social Research Methods, edited by Victor Jupp, 245-46. London, England: SAGE Publications, Ltd., 2006. Also available from http://srmo.sagepub.com/view/the-sage-dictionary-of-social-researchmethods/SAGE.xml.

Olwig, Kenneth. "Performance, Ethereal Space and the Practice of Landscape/Architecture: The Case of the Missing Mask." Social and Cultural geography 12, no.3 (2011): 305-318.

Pallasmaa, Juhani. The Embodied Image - Imagination and Imagery in Architecture. Chichester: John Wiley \& Sons, 2011.

Pantzar, Mika and Elizabeth Shove. "Understanding Innovation in Practice: A Discussion of the Production and Re-Production of Nordic Walking." Technology Analysis and Strategic Management 22, no.4 (2010): 447-461.

Paterson, Mark. “More-Than-Visual Approaches to Architecture. Vision, Touch, Technique." Social \& Cultural Geography 12, no.3 (2011): 263-281.

Patton, Michael Quinn. Qualitative Evaluation and Research Methods, $2^{\text {nd }}$ Edition. Thousand Oaks: Sage Publications, 1990.

- Qualitative Evaluation and Research Methods, 3rd Edition. Thousand Oaks: Sage Publications, 2001.

Pelizzari, Maria A. and Paulo Scrivano. "Intersection of Photography and ArchitectureIntroduction." Visual Resources 27, no.2 (2011): 107-112.

Pell, Ben. The Articulate Surface: Ornament and Technology in Contemporary Architecture. Basel: Birkhauser Press, 2010. 
Petrescu, Doina. “Losing Control, Keeping Desire.” In Architecture and Participation, edited by Jones Blundell, Doins Petrescu and Jeremy Till, 43-64. London and New York: Spon Press, 2005.

Petrescu, Doina and Prue Chiles. "Agency: Alternative Practices and Alternative Worlds." Architectural Research Quarterly 13 (2009): 109-111.

Petroski, Henry. Success Through Failure: The Paradox of Design. Princeton: Princeton University Press, 2006.

Philippopoulos-Mihalpoulos, Andreas. "Atmospheres of Law: Senses, Affects, Lawscapes." Emotion, Space and Society 7 (2013): 35-44.

Pile, Steve. "Emotions and Affect in Recent Human Geography." Transactions of the Institute of British Geographers 35, no.1 (2010): 5-20.

Press, Mike and Rachel Cooper. The Design Experience: The Role of Design and Designers in the Twenty-First Century. Aldershot, Hands, England; Burlington, VT: Ashgate, 2003.

Preston, Julieanna. "Introduction: In the Mid(s)t Of.” Architectural Design 78, no.3 (2008): 611.

. “A Fossick for Interior Design Pedagogies.” In After Taste, edited by Kent Kleinman, Joanna Merwood-Salisbury and Lois Weinthal, 92-109. New York: Princeton Architectural Press, 2012.

Probyn, Elspeth. Blush: Faces of Shame. Minneapolis: University of Minnesota Press, 2005.

Protevi, John. "'Larval Subjects, Autonous Systems and E. Coli Chemotaxis."In Deleuze and the Body, edited by Laura Guillaume and Joe Hughes, 29-52. Edinburgh: Edinburgh University Press, 2011.

- Political Affect: Connecting the Social and the Somatic. Minneapolis: University of Minnesota Press, 2009.

Rahim, Ali. "Uniformity and Variability in Architectural Practice.” In Research \& Design: The Architecture of Variation, edited by Lars Spuybroek. London: Thames and Hudson, 2009.

Rahman, Momin and Anne Witz. "What Really Matters? The Elusive Quality of the Material in Feminist Thought." Feminist Theory 4, no.3 (2003): 243-261.

Rancière, Jacques. The Future of the Image, translated by G. Elliott. London and New York: Verso, 2007.

Rattenbury, Kester. "Introduction." In This Is Not Architecture: Media Constructions, edited by Kester Rattenbury, xxi-xxiv. NewYork: Routledge, 2002.

Ray, Nicholas, ed. Architecture and its Ethical Dilemmas. London and New York: Taylor and Francis, 2005. 
Ravaisson, Félix. Of Habit. Translated by Clare Carlisle and Mark Sinclair. London: Continuum, 2008.

Reckwitz, Andreas. "Toward a Theory of Social Practices." European Journal of Social Theory 5, no.2 (2002): 243-263.

Rieger, John H. "Photographing Social Change." Visual Sociology 11 (1996): 5-49.

Ritchie, Jane and Jane Lewis. Qualitative Research Practice: A Guide for Social Science Students and Researchers. London: Sage Publications, 2003.

Rose, Gillian. Visual Methodologies. London and Thousand Oaks: Sage Publications, 2007.

Rose, Gillian, Monica Degen and Begum Basdas. "More on 'Big Things': Building Events and Feelings." Transactions of the Institute of British Geographers 35, no. 3 (July 2010): 334-349.

Rose, Mitch and John Wylie. “Animating Landscape.” Environment and Planning D: Society and Space 24, no.4 (2006): 475-479.

Rouse, Joseph. "Practice Theory." In Handbook of Philosophy of Science, Vol. 15: Philosophy of Anthropology and Sociology, edited by Stephen Turner and Mark Risjord, 500-540. Amsterdam: Elsevier, 2006.

. "Two Concepts of Practice." In The Practice Turn in Contemporary Theory, edited by Theodore R. Schatzki, Karin Knorr Cetina and Eike von Savigny, 189-198. London: Routledge, 2001.

Rowe, Peter. Design Thinking. Cambridge, Mass.: MIT Press, 1987.

Salomon, David. "Plural Profession, Discrepant Practices." In The SAGE Handbook of Architectural Theory, edited by C. Greig Crysler, Stephen Cairns and Hilde Heynen, 430-451. London: SAGE, 2012.

Rubin, Herbert J. and Irene S Rubin. Qualitative Interviewing: The Art of Hearing Data. Thousand Oaks: Sage, 1995

Schatzki, Theodore R. "Introduction: Practice Theory." In The Practice Turn in Contemporary Theory, edited by Theodore R. Schatzki, Karin Knorr Cetina and Eike von Savigny, 1-13. London: Routledge, 2001.

- Social Practices: A Wittgensteinian Approach to Human Activity and the Social. Cambridge: Cambridge University Press, 1996.

_. "Spatial Ontology and Explanation." Annals of the Association of American Geographers 81, no.4 (1991): 650-670.

Schatzki, Theodore R., Karin Knorr Cetina and Eike von Savigny, eds. The Practice Turn in Contemporary Theory. London: Routledge, 2001. 
Schillmeier, Michael. “Assembling Money and the Senses.” In Urban Assemblages: How ActorNetwork. Theory Changes Urban Studies, edited by Ignacio Farías and Thomas Bender. London and New York: Routledge, 2010.

Schoch, Richard. The Secret of Happiness. New York: Scribner, 2006.

Schön, Donald. The Reflective Practitioner: How Professionals Think in Action. New York: Basic Books, 1983.

Schumacher, Patrik. The Autopoiesis of Architecture: The New Agenda for Architecture. West Sussex: John Wiley and Sons, 2012.

Schwarzer, Mitchell. “'Television' and 'Film." In Zoomscape: Architecture in Motion and Media, 206-305. New York: Princeton Architectural Press, 2004.

Schweizer, Harold. “On Waiting.” University of Toronto Quarterly 74, no.3 (Summer 2005): 777-792.

Seale, Clive. "Quality in Qualitative Research.” Qualitative Inquiry 5, no.4 (1999): 465-478.

Sedgwick, Eve. Touching Feeling: Affect, Pedagogy, Performativity. London: Duke University Press, 2003.

Semetsky, Inna. "The Complexity of Individuation." International Journal of Applied Psychoanalytic Studies 1, no.4 (2004): 324-346.

Serraino, Pierluigi. "Framing Icons: Two Girls, Two Audiences / The Photographing of Case Study House \#22.” In This Is Not Architecture: Media Constructions, edited by Kester Rattenbury, 127-135. NewYork: Routledge, 2002.

Serres, Michel. The Five Senses: A Philosophy of Mingled Bodies. Translated by Margaret Sauke and Peter Crowley. London: Athlone, 2008.

Sharp, Hasana. "The Force of Ideas in Spinoza.” Political Theory 35, no.6 (2007): 732-755.

Sheridan, Susan. "Words and Things: Some Feminist Debates on Culture and Materialism." Australian Feminist Studies 1, no.37 (2002): 23-30.

Shotter, John. The Cultural Politics of Everyday Life: Social Constructionism, Rhetoric and Knowing of the Third Kind. Buckingham: Open University Press, 1993.

Shouse, Eric. "Feeling, Emotion, Affect.” M/C Journal 8, no.6 (2005). Accessed May 15, 2011, http://journal.media-culture.org.au/0512/03-shouse.php

Shove, Elizabeth and Mika Pantzar. "Consumers, Producers and Practices: Understanding the Invention and Reinvention of Nordic Walking." Journal of Consumer Culture 5, no.1 (2005): 43-64. 
Shukin, Nicole. "Deleuze and Feminism: Involuntary Regulators and Affective Inhibitors." In Deleuze and Feminism, edited by Ian Buchanan and Claire Colebrook, 144-155. Edinburgh: Edinburgh University Press, 2000.

Simmel, Georg. “The Philosophy of Landscape.” Theory, Culture \& Society 24, no.7-8 (2007): 20-29.

Simonsen, Kerstin. "Practice, Spatiality and Embodied Emotions: An Outline of a Geography of Practice." Human Affairs 17 (2007): 168-181.

Sloterdijk, Peter. “Atmospheric Politics.” In Making things Public: Atmospheres of Democracy, edited by Bruno Latour and Peter Weibel, 944-951. Karlsruhe: ZKM and MIT Press, 2005.

Solá-Morales, Ignasi de. “Absent Bodies.” In Anybody, edited by Cynthia Davidson, 16-24. Cambridge: MIT Press, 1997.

Somol, Robert E. "Dummy Text, or the Diagrammatic Basis of Contemporary Architecture." In Diagram Diaries, edited by Peter Eisenman, 6-25. London: Thames \& Hudson, 1999.

Sorkin, Michael. Local Code: The Constitution of a City at 42 N Latitude. New York: Princeton Architectural Press, 1993.

Speaks, Michael. "Design Intelligence and the New Economy." Architectural Record 190, no. 1 (Jan 2002): 72-76.

—. "Intelligence After Theory." Perspecta 38 (2006):103-106.

Spector, Tom. The Ethical Architect: The Dilemma of Contemporary Practice. New York: Princeton Architectural Press, 2001.

Spencer, Stephen. Visual Research Methods in Social Sciences: Awakening Visions. New York: Routledge, 2010.

Spinoza, Baruch. The Ethics and Selected Letters. Translated by Samuel Shirley. Indianapolis: Hackett, 1982.

- The Collected Works of Spinoza. Volume 1. Edited and translated by Edwin Curley. Princeton: Princeton University Press, 1985.

—. Spinoza: Complete Works. Edited by Michael L. Morgan, translated by Samuel Shirley. Indianapolis: Hackett, 2002.

Spuybroek, Lars. “Foreword: Research \& Design.” In The Architecture of V ariation, edited by Lars Spuybroek, 7. London: Thames and Hudson, 2009.

Stake, Robert E. The Art of Case Study Research. Thousand Oaks: Sage, 1995. . "Case studies." In Handbook of Qualitative Research, $2^{\text {nd }}$ edition, edited by Norman K. Denzin \& Yvonna S. Lincoln, 236-247. Thousand Oaks, CA: Sage Publications, 2000. 
—. "Qualitative Case studies." In Handbook of Qualitative Research, $3{ }^{\text {rd }}$ edition, edited by

Norman K. Denzin \& Yvonna S. Lincoln, 443-466. Thousand Oaks, CA: Sage

Publications, 2008.

Stengers, Isabelle. "Introductory Notes on an Ecology of Practices." Cultural Studies Review 11, no.1 (2005): 183-196.

Stewart, Kathleen. “Afterword: Wording Refrains.” In The Affect Theory Reader, edited by

Melissa Gregg and Gregory J. Seigworth, 339-354. Durham \& London: Duke University Press, 2010.

- Ordinary Affects. Durham, NC and London: Duke University Press, 2007

Strebel, Ignaz. "The Living Building: Towards a Geography of Maintenance Work." Social and Cultural Geography 12, no.3 (2011): 243-262.

Stevens, Garry. The Favored Circle: The Social Foundations of Architectural Distinction. Cambridge: MIT Press, 2002.

Swartz, David. Culture and Power: The Sociology of Pierre Bourdieu. Chicago: University of Chicago Press, 1998.

Swidler Ann. "What Anchors Cultural Practices." In The Practice Turn in Contemporary Theory, edited by Theodore R. Schatzki, Karin Knorr Cetina and Eike von Savigny, 74-92. London: Routledge, 2001.

Sweetman, Paul. "Revealing Habitus, Illuminating Practice: Bourdieu, Photography and Visual Methods." The Sociological Review 57, no.3 (2009): 491-511.

Tait, Malcolm and Aidan While. "Ontology and the Conservation of Built Heritage." Environment and Planning D: Society and Space 27, no.4 (2009): 721 - 737.

Taylor, Charles. Modern Social Imaginaries. Durham: Duke University Press, 2004.

Tellis, Winston. “Application of a Case Study Methodology.” The Qualitative Report 3, no.3 (September 1997). Accessed July 15, 2012, http://www.nova.edu/ssss/QR/QR3-3/tellis2.html.

Thévenot, Laurent. "Pragmatic Regimes Governing the Engagement with the World." In The Practice Turn in Contemporary Theory, edited by Theodore R. Schatzki, Karin Knorr Cetina and Eike von Savigny, 74-92. London: Routledge, 2001.

Thien, Deborah. "After or Beyond Feeling? A Consideration of Affect and Emotion in Geography." Area 37, no. 4 (2005): 450-454.

Thrift, Nigel. "But Malice Aforethought: Cities and the Natural History of Hatred." Transactions of the Institute of British Geographers 30, no.2 (2005): 133-150. 
—. "Intensities of Feeling: Towards a Spatial Politics of Affect." Geografiska Annaler B 86, no.1 (2004): 57-78.

\section{- Knowing Capitalism. London: Sage, 2005.}

- "Movement-Space: The Changing Domain of Thinking Resulting from the

Development of New Kinds of Spatial Awareness.” Economy and Society 33, no. 4(2004): 582-604.

- Non-representational Theory: Space, Politics, Affect. Milton Park, Abingdon, Oxon: Routledge, 2007.

- Non-representational Theory: Space, Politics, Affect. London and New York: Routledge, 2008.

—. "The Still Point: Expressive Embodiment and Dance. In Geographies of Resistance, edited by Steve Pile, and Michael Keith, 124-151. London: Routledge, 1997.

_. "Understanding the Material Practices of Glamour." In The Affect Theory Reader, edited by Melissa Gregg and Gregory J. Seigworth, 289-308. Durham \& London: Duke University Press, 2010.

Thrift, Nigel and John-David Dewsbury. "Dead Geographies - And How to Make Them Live Again.” Environment and Planning D: Society and Space 18, no.4 (2000): 411-432.

Tiley, Christopher. "Materiality in Materials.” Archaeological Dialogues 14, no.1 (2007): 16-20.

Tomkins, Silvan S. Affect, Imagery, Consciousness 4 vols. New York: Springer, 1962-92.

—. Affect, Imagery, Consciousness: Volume II. The Negative Affects. New York: Springer Publishing, 1963.

- Exploring Affect: The Selected Writings of Silvan S. Tomkins. Cambridge and New York: Cambridge University Press, 1995.

Till, Jeremy. Architecture Depends. Cambridge, MA: MIT Press, 2009.

Urry, John. Mobilities. Cambridge: Polity Press, 2007.

Urwin, Simon. Analysing Arcbitecture. London and New York: Routledge, 2003.

Valentine, Gill. “Tell Me About...: Using Interviews as a Research Methodology.” In Methods in Human Geography: A Guide for Students Doing a Research Project ( $2^{\text {nd }}$ ed.), edited by Robin Flowerdew and David M. Martin, 110-127. Edinburgh Gate: Addison Wesley Longman, 2005.

Vasudevan, Alex. "Dramaturgies of Dissent: the Spatial Politics of Squatting in Berlin, 1968-." Social \& Cultural Geography 1, no.3 (2011): 283-303.

Vidler, Anthony. The Architectural Uncanny: Essays in the Modern Unhomely. Cambridge and London: MIT Press, 1992.

—. Architecture between Spectacle and Use. New Haven: Yale University Press, 2008. 
—. "Diagrams of Diagrams: Architectural Abstraction and Modern Representation." Representations 72 (2000): 1-20.

—. "Towards a Theory of the Architectural Program.” October 106 (Fall 2003): 59-70.

- "What is a Diagram Anyway?” In Peter Eisenman: Feints, edited by Silvio Cassarà. Milan, London: Thames \& Hudson,2006.

Virilio, Paul. The Lost Dimension, translated by Daniel Moshenberg. New York: Semiotext, 1991.

- The Original Accident. Cambridge: Polity Press, 2007.

. "The Overexposed City." In Architecture Theory Since 1968, edited by K. Michael Hays.

Cambridge, MA: The MIT Press, 1998.

- "The Third Interval," in Open Sky, 9-21. New York: Verso, 1997.

Visser, Willemiem. “Schön: Design as Reflective Practice.” Collection 2 (2010): 21-25.

Wacquant, Loic. "Pierre Bourdieu." In Key Sociological Thinkers, edited by Rob Stones. London: Palgrave Macmillan, 2006.

Warde, Alan. "Consumption and the Theory of Practice." Journal of Consumer Culture 5, no.2 (2005): 131-54.

Welch, Catherine and Rebecca Piekkari. "Crossing Language Boundaries: Qualitative Interviewing in International Business." Management International Review 46 (2006): 417-437.

Wetherell, Margaret. "Affect and Discourse - What's the Problem? From Affect as Excess to Affective/Discursive Practice." Subjectivity 6, no.4 (2013): 349-368.

Whatmore, Sarah. "Hybrid Geographies: Rethinking the 'Human' in Human Geography.” In Human Geograpby Today, edited by Doreen Massey, John Allen and Phil Sarre, 22-40. Cambridge: Wiley, 1999.

. "Materialist Returns: Practising Cultural Geography in and for a More-than-Human World', Cultural Geographies 13, no.4 (2006): 600-609.

Widder, Nathan. "What's Lacking in the Lack: A Comment on the Virtual." Angelaki: Journal of the Theoretical Humanities 5, no. 3 (2000): 117-138.

Wigley, Mark. “The Architecture of Atmosphere.” Daidalos 68 (1998): 18-27.

—. "Towards a History of Quantity." In Architecture Between Spectacle and Use, edited by Anthony Vidler, 155-163. New Haven: Yale University Press, 2008.

Wigley, Mark, Olafur Eliasson and Daniel Birnbaum. "The hegemony of TiO2: A

Discussion on the Colour White: A Conversation between Mark Wigley, Olafur Eliasson and Daniel Birnbaum." In Olafur Eliasson: Your Engagement has Consequences; On the Relativity of Your Reality, edited by Studio Olafur Eliasson, 241-251. Baden: Lars Müller Publishers, 2006. 
Williams, Caroline. "Affective Processes without a Subject: Rethinking the Relation between Subjectivity and Affect with Spinoza." Subjectivity 3, no.3 (2010): 245-262.

- "Thinking the Political in the Wake Of Spinoza: Power, Affect and Imagination in The Ethics." Contemporary Political Theory 6 (2007): 349-369.

Williams, James. Gilles Deleure's Difference and Repetition: A Critical Introduction and Guide. Edinburgh: Edinburgh University Press, 2004.

Willis, Jerry W. Foundations of Qualitative Research. Thousand Oaks, CA: Sage Publications, 2007.

Wilson, Mabel. "Dancing in the Dark: The Construction of Blackness in Le Corbusier's Radiant City." In Architecture Theory, edited by Andrew Ballantyne. London: Continuum, 2005.

Woodward, Keith and Jennifer Lea. "Geographies of Affect." In The Sage Handbook of Social Geographies, edited by Susan J. Smith, Rachel Pain, Susan Smith Livingston Smith, JohnPaul Jones, and Sallie A. Marston, 154-175. London: Sage, 2010.

Wylie, John. "Landscape, Absence and the Geographies of Love." Transactions of the Institute of British Geographers 34, no.3 (2009): 275-289.

- “A Single Day's Walking: Narrating Self and Landscape on the South West Coast Path." Transactions of the Institute of British Geographers 30, no.2 (2005): 234-247.

Yaneva, Albena. Made by the Office of Metropolitan Architecture: An Ethnography of Design. Rotterdam: 010 Publishers, 2009.

Yin, Robert K. Case Study Research: Design and Methods, Second Edition. Thousand Oaks, CA: Sage Publications, 1994.

- Case Study Research: Design and Methods. Thousand Oaks, CA: Sage Publications, 2003.

—. Case Study Research: Design and Methods, Fourth Edition. Thousand Oaks, CA: Sage Publications, 2009.

-Qualitative Research from Start to Finish. New York: Guilford Press, 2011.

Young, Iris M. On Female Body Experience: "Throwing Like a Girl” and Other Essays. New York: Oxford University Press, 2005.

Yovel, Yirmiyahu. Spinoza and Other Heretics: Vol. 2. The Adventures of Immanence. Princeton, NJ: Princeton University Press, 1989.

Zaugg, Rémy. The Art Museum of My Dreams, or A Place for the Work and the Human Being, translated by Liz Libbrecht. Berlin: Sternberg Press, 2013.

Zellner, Peter. Hybrid Space: New Forms in Digital Architecture. London: Thames \& Hudson, 1999. 